\title{
Techno-economic Analysis for the Thermochemical Conversion of Biomass to Liquid Fuels
}

\author{
Y Zhu \\ SA Tjokro Rahardjo \\ C Valkenburg \\ LJ Snowden-Swan \\ SB Jones \\ MA Machinal
}

June 2011

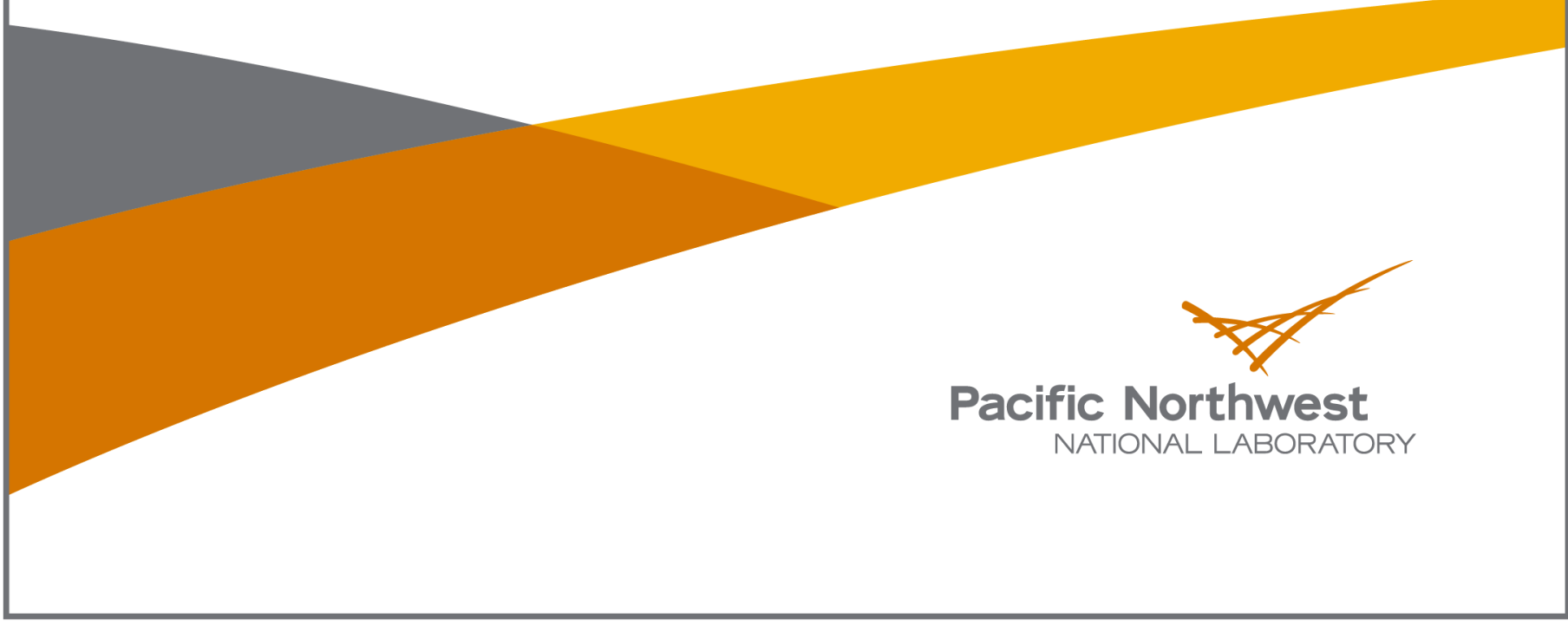




\title{
DISCLAIMER
}

This report was prepared as an account of work sponsored by an agency of the United States Government. Neither the United States Government nor any agency thereof, nor Battelle Memorial Institute, nor any of their employees, makes any warranty, express or implied, or assumes any legal liability or responsibility for the accuracy, completeness, or usefulness of any information, apparatus, product, or process disclosed, or represents that its use would not infringe privately owned rights. Reference herein to any specific commercial product, process, or service by trade name, trademark, manufacturer, or otherwise does not necessarily constitute or imply its endorsement, recommendation, or favoring by the United States Government or any agency thereof, or Battelle Memorial Institute. The views and opinions of authors expressed herein do not necessarily state or reflect those of the United States Government or any agency thereof.

\author{
PACIFIC NORTHWEST NATIONAL LABORATORY \\ operated by \\ BATTELLE \\ for the \\ UNITED STATES DEPARTMENT OF ENERGY \\ under Contract DE-AC05-76RL01830
}

Printed in the United States of America
Available to DOE and DOE contractors from the Office of Scientific and Technical Information,
P.O. Box 62, Oak Ridge, TN 37831-0062;
ph: (865) 576-8401
fax: (865) 576-5728
email: reports@adonis.osti.gov

\author{
Available to the public from the National Technical Information Service, \\ U.S. Department of Commerce, 5285 Port Royal Rd., Springfield, VA 22161 \\ ph: (800) 553-6847 \\ fax: (703) 605-6900 \\ email: orders $a$ ntis.fedworld.gov \\ online ordering: http://www.ntis.gov/ordering.htm
}

This document was printed on recycled paper.

(9/2003) 


\title{
Techno-economic Analysis for the Thermochemical Conversion of Biomass to Liquid Fuels
}

\author{
Y Zhu \\ S Tjokro Rahardjo \\ C Valkenburg \\ L Snowden-Swan \\ S Jones \\ M Machinal
}

June 2011

Prepared for

U.S. Department of Energy

under Contract DE-AC05-76RL01830

Pacific Northwest National Laboratory

Richland, Washington 99352 


\section{Executive Summary}

Biomass has the potential to make a significant impact on domestic fuel supplies and thus help meet the Energy Independence and Security Act (EISA) renewable fuels goals (CRS 2007). This study is part of an ongoing effort within the Department of Energy to meet the renewable energy goals for liquid transportation fuels. The objective of this report is to present a techno-economic evaluation of the performance and cost of various biomass based thermochemical fuel production processes. This report also documents the economics that were originally developed for the report entitled "Biofuels in Oregon and Washington: A Business Case Analysis of Opportunities and Challenges" (Stiles et al. 2008). Although the resource assessments were specific to the Pacific Northwest, the production economics presented in this report are not regionally limited. This study uses a consistent technical and economic analysis approach and uniform assumptions to evaluate different biomass based fuel production technologies.

Figure ES-1 shows the five fuel products studied. The gasification-based fuels are mixed alcohols, methanol, Fischer-Tropsch (FT), dimethyl ether (DME), ethanol via acetic acid synthesis and hydrogenation, and gasoline via methanol-to-gasoline (MTG). The liquefaction-based technologies are fast pyrolysis oil and hydrothermal liquefaction (HTL) oil and subsequent upgrading to gasoline and diesel. Some fuel products are fully compatible with the current fuel infrastructure, such as renewable gasoline and renewable diesel; some are not, such as DME and methanol.

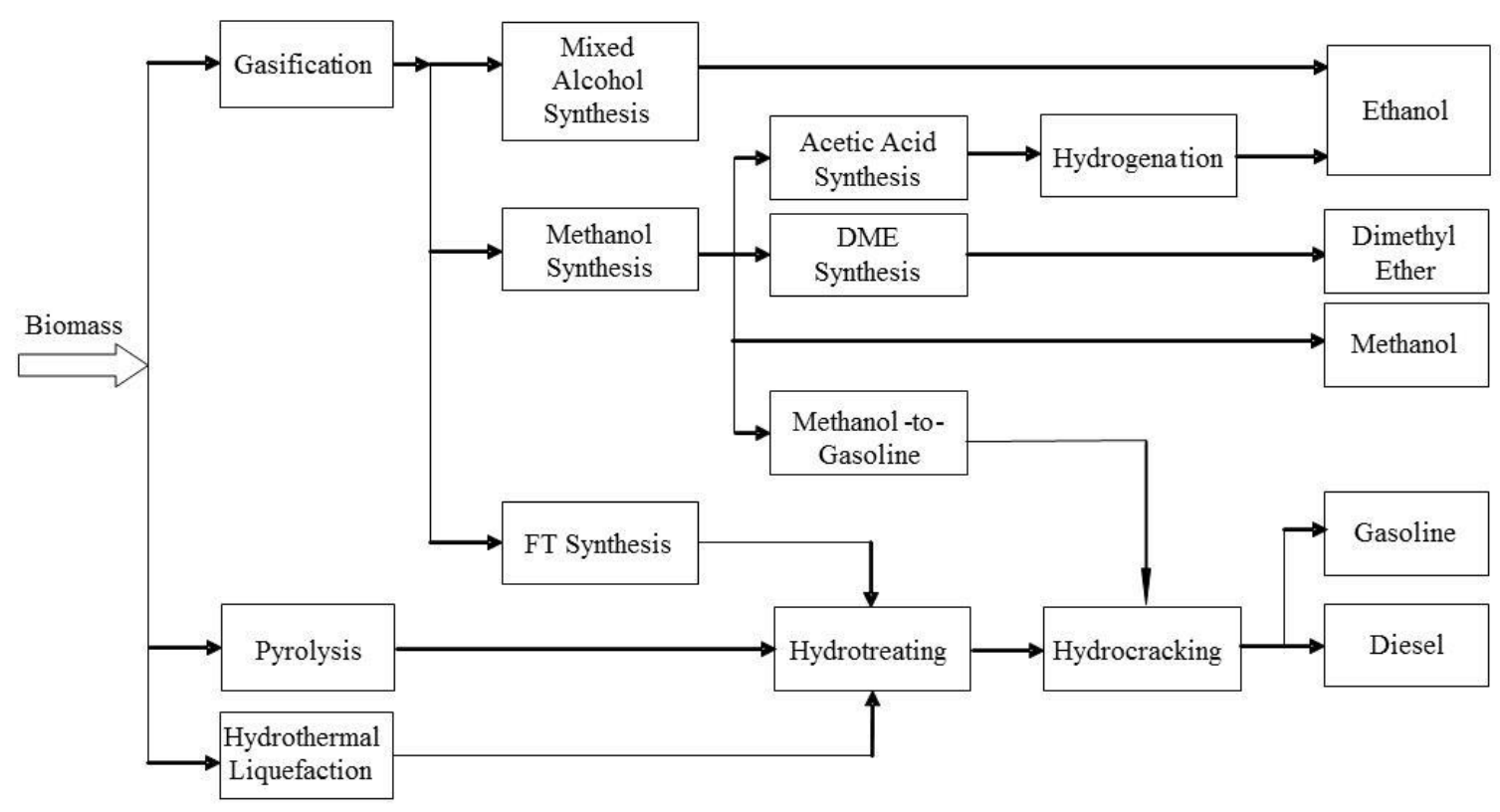

Figure ES-1 Biomass-to-Fuels Pathways

The gasification based processes were evaluated using currently existing technology. Sensitivity analysis was conducted to determine opportunities for cost reduction through process improvements. No 
commercial systems yet exist for liquefaction based technologies which produce infrastructure compatible fuels. Thus, the liquefaction based systems were analyzed on a future potential basis.

The major performance and cost analysis results are summarized in the following tables. All values assume $\$ 60 /$ dry short ton wood (delivered to the plant) and are presented in year 2008 dollars. The gasification-based conversions to currently used liquid fuels (ethanol via mixed alcohols, ethanol via acetic acid, FT diesel, and, gasoline via methanol) are shown in Table ES-1. The production costs for these fuels using existing gasification and fuel synthesis technologies exceed current market prices. However, opportunities exist to reduce these costs as shown in the potential improvements. For example, reducing syngas cleanup costs by combining tar cracking and methane reforming applies to all gasification cases. Both mixed alcohol catalysts and MTG catalysts have room for improvement. However, FT and the methanol portion of MTG and acetic acid catalysts are mature technologies and have limited opportunity for improvements. Co-production of by-products can improve economics if the co-product is more valuable than the fuel, such as acetic acid in the ethanol route.

Table ES-1 Summary of Biomass Gasification to Mixed Alcohols, MTG, FT Diesel, and Ethanol

\begin{tabular}{|c|c|c|c|c|c|c|c|c|}
\hline \multirow{2}{*}{$\begin{array}{r}\text { Case } \\
\text { Performance }\end{array}$} & \multicolumn{2}{|c|}{$\begin{array}{c}\text { Ethanol via } \\
\text { Mixed Alcohols }\end{array}$} & \multicolumn{2}{|c|}{$\begin{array}{c}\text { Methanol to } \\
\text { Gasoline (MTG) }\end{array}$} & \multicolumn{2}{|c|}{ FT Diesel } & \multicolumn{2}{|c|}{$\begin{array}{l}\text { Ethanol via } \\
\text { Acetic Acid }\end{array}$} \\
\hline & & & & & & & & \\
\hline Gasifier type & Indirec & Direct & Indirec & Direct & Indirec & Direct & Indirect & Direct \\
\hline Product & \multicolumn{2}{|c|}{ Ethanol } & \multicolumn{2}{|c|}{ Gasoline } & \multicolumn{2}{|c|}{ Diesel } & \multicolumn{2}{|c|}{ Ethanol } \\
\hline Yield, million gal/y & 43 & 45 & 40 & 40 & 24 & 28 & 130 & 260 \\
\hline Byproducts & \multicolumn{2}{|c|}{$\begin{array}{l}\text { Propanol+ at } \\
\text { chemical value }\end{array}$} & \multicolumn{2}{|c|}{ LPG } & \multicolumn{2}{|c|}{ Naphtha } & & \\
\hline Yield, million gal/y & 14 & 15 & 7 & 0 & 8 & 9 & -- & -- \\
\hline $\begin{array}{l}\text { LHV Thermal } \\
\text { Efficiency, } \%\end{array}$ & 42 & 45 & 46 & 44 & 40 & 46 & 55 & 58 \\
\hline \multicolumn{9}{|l|}{ Current technology } \\
\hline MFSP, \$/gal & 2.70 & 3.10 & 3.10 & 3.90 & 4.30 & 4.90 & 3.40 & 3.50 \\
\hline $\begin{array}{l}\text { MESP ethanol LHV } \\
\text { equiv, \$/gal }\end{array}$ & 2.70 & 3.10 & 2.10 & 2.70 & 2.80 & 3.20 & 3.40 & 3.50 \\
\hline \multicolumn{9}{|l|}{$\begin{array}{l}\text { Potential } \\
\text { improvements }\end{array}$} \\
\hline MFSP, \$/gal & 1.20 & 1.90 & 2.30 & 2.90 & 3.40 & 4.50 & 2.40 & 2.50 \\
\hline $\begin{array}{l}\text { MESP LHV ethanol } \\
\text { equiv., \$/gal }\end{array}$ & 1.20 & 1.90 & 1.60 & 2.00 & 2.20 & 2.90 & 2.40 & 2.50 \\
\hline $\begin{array}{l}\text { Research areas to } \\
\text { achieve } \\
\text { improvements }\end{array}$ & $\begin{array}{l}\text { Improv } \\
\text { cleanup } \\
\text { alcohol } \\
\text { catalyst }\end{array}$ & $\begin{array}{l}\text { syngas } \\
\text { mixed } \\
\text { nthesis }\end{array}$ & $\begin{array}{l}\text { Improv } \\
\text { cleanup } \\
\text { synthes }\end{array}$ & $\begin{array}{l}\text { nngas } \\
\text { TG } \\
\text { talyst }\end{array}$ & $\begin{array}{l}\text { Improv } \\
\text { cleanup }\end{array}$ & yngas & $\begin{array}{l}\text { Improve } \\
\text { cleanup } \\
\text { acetic ac } \\
\text { producti }\end{array}$ & $\begin{array}{l}\text { syngas } \\
\text { hd } 20 \% \\
\text { co- }\end{array}$ \\
\hline
\end{tabular}

Note: Biomass at $\$ 60 /$ dry ton, 2200 tpd dry. All values in 2008 USD, rounded to two significant figures.

The thermal efficiency for ethanol from acetic acid is somewhat inflated by the use of externally purchased $\mathrm{CO}$ for the methanol to acetic acid step and purchased $\mathrm{H}_{2}$ for acetic acid hydrogenation to ethanol. This value would likely be lower if $\mathrm{CO}$ and $\mathrm{H}_{2}$ were obtained directly from the syngas. 
The results for non-standard liquid fuels (methanol and DME) based on biomass gasification are listed in Table ES-2. Here too, gasification to these fuels using current technology results in high production costs. Potential areas of improvement include: reduction in syngas cleanup costs by combining tar cracking and methane reforming. Methanol catalyst is a mature technology with little room for major improvements. Improved one-step syngas to DME catalyst may reduce costs.

Table ES-2 Summary of Biomass Gasification to Methanol and DME

\begin{tabular}{|c|c|c|c|c|}
\hline Case & \multicolumn{2}{|c|}{ Methanol } & \multicolumn{2}{|c|}{ DME } \\
\hline \multicolumn{5}{|l|}{ Performance } \\
\hline Gasifier type & Indirect & Direct & Indirect & Direct \\
\hline Product & \multicolumn{2}{|c|}{ Methanol } & \multicolumn{2}{|c|}{ DME } \\
\hline Yield, million gal/y & 95 & 100 & 81 & 76 \\
\hline LHV Thermal Efficiency, \% & 48 & 50 & 51 & 52 \\
\hline \multicolumn{5}{|l|}{ Current technology } \\
\hline MFSP, \$/gal & 1.30 & 1.60 & 1.50 & 1.90 \\
\hline $\begin{array}{l}\text { MESP ethanol equivalent } \\
\text { LHV basis, \$/gal }\end{array}$ & 1.70 & 2.10 & 1.60 & 2.10 \\
\hline \multicolumn{5}{|l|}{ Potential improvements } \\
\hline MFSP, \$/gal & 1.20 & 1.50 & 1.40 & 1.80 \\
\hline $\begin{array}{l}\text { MESP ethanol LHV equiv, } \\
\text { \$/gal }\end{array}$ & 1.50 & 2.00 & 1.50 & 2.00 \\
\hline $\begin{array}{l}\text { Research areas to achieve } \\
\text { improvements }\end{array}$ & $\begin{array}{l}\text { Improved } \\
\text { cleanup }\end{array}$ & gas & $\begin{array}{l}\text { Improved } \\
\text { cleanup, } \\
\text { methanol } \\
\text { synthesis }\end{array}$ & $\begin{array}{l}\text { ngas } \\
\text { ME } \\
\text { alyst }\end{array}$ \\
\hline
\end{tabular}

The results for the liquefaction systems assuming potential improvements are listed in Table ES-3. Fast pyrolysis systems are commercially available, however, upgrading the oil to finished gasoline and diesel has only been proven at the research level. HTL oil systems have been demonstrated on the pilot scale, but are not yet commercially available. Also, upgrading HTL oil has not yet been demonstrated. 
Table ES-3 Summary Biomass Liquefaction to Fuel Systems Assuming Potential Improvements

\begin{tabular}{l|cc|c}
\hline Case & \multicolumn{2}{|c|}{ Hydrothermal Liquefaction HTL } & Fast Pyrolysis \\
\hline Products & Upgraded HTL oil & $\begin{array}{c}\text { Gasoline } \\
\text { and Diesel }\end{array}$ & $\begin{array}{c}\text { Gasoline and Diesel } \\
\text { Yield, million gal/y }\end{array}$ \\
LHV Thermal Efficiency, \% & 76 & 78 & 76 \\
MFSP, \$/gal & 2.30 & 63 & 64 \\
MESP ethanol LHV equiv, \$/gal & 1.60 & 2.40 & 2.40 \\
Research areas to achieve & \multicolumn{2}{|c|}{$\begin{array}{l}\text { Demonstrate HTL upgrading, catalyst } \\
\text { improvements }\end{array}$} & $\begin{array}{l}\text { Demonstrate catalyst life } \\
\text { and product quality }\end{array}$ \\
\hline
\end{tabular}

Note: Biomass at $\$ 60 /$ dry ton, 2200 tpd dry. All values in 2008 USD, rounded to two significant figures.

In general:

- High overall conversion synthesis steps, such as in methanol and DME, have better thermal efficiency than lower conversion synthesis cases, such as FT diesel or ethanol,

- No gasification systems using currently available technology are economic. For the current technology gasification cases, the total project investment ranges from $\$ 260$ to $\$ 810$ million. For the gasification based liquid fuels, the indirectly-heated gasifier based methanol system has the lowest capital cost resulting from the simple direct low cost synthesis step and high selectivity,

- The directly heated gasifier systems require more capital than the indirectly heated systems,

- Chemical by-products improve process economics,

- Both liquefaction and gasification based systems need further reductions in cost to make them economically attractive.

The analysis suggests further work in the following areas:

For the gasification based systems:

- Improve gas cleanup technologies to achieve high methane and tar removal efficiencies,

- Develop gasification technologies with syngas compositions that meet the synthesis requirements, i.e. syngas with low methane content for FT and mixed alcohol synthesis,

- Develop fuel synthesis catalysts and processing with improved conversions and selectivities to the desired end product(s),

- Reduce the number of synthesis steps (such as single step syngas to gasoline).

For the liquefaction based systems:

- Improve raw bio-oil properties from the fast pyrolysis and HTL steps,

- Improve upgrading catalyst life,

- Determine acceptable final product qualities. 


\title{
Acronyms and Abbreviations
}

\author{
$\$ \mathrm{~mm} / \mathrm{yr} \quad$ million dollars per year \\ ASU air separation unit \\ AR as received \\ atm atmospheres \\ BTU British Thermal Units \\ CARB California Air Resources Board \\ CEPCI Chemical Engineering Plant Cost Index \\ DOE U.S. Department of Energy \\ DME dimethyl Ether \\ EIA Energy Information Administration \\ EISA Energy Independence and Security Act \\ EtOH ethanol \\ FT Fischer-Tropsch \\ G\&A general and administrative (costs) \\ gal gallon(s) \\ HDS hydrodesulfurized or hydrodesulfurization \\ HHV higher heating value \\ HP high pressure \\ HTL hydrothermal liquefaction \\ HTS high temperature shift \\ kscf $\quad 1000$ standard cubic feet $(60 \mathrm{~F}, 1 \mathrm{~atm})$ \\ lb pound(s) \\ LHV lower heating value \\ LP low pressure \\ LPG liquefied petroleum gas
}




$\begin{array}{ll}\begin{array}{l}\text { MFSP } \\ \text { MESP }\end{array} & \begin{array}{l}\text { minimum fuel product selling price } \\ \text { minimum ethanol selling price }\end{array} \\ \text { mtpd } & \begin{array}{l}\text { motor gasoline } \\ \text { metric tonnes per day }\end{array} \\ \text { PSA } & \text { pressure swing adsorption } \\ \text { psia } & \text { pounds per square inch absolute } \\ \text { psig } & \text { pounds per square inch gauge } \\ \text { IRR } & \text { internal rate of return } \\ \text { scf } & \text { standard cubic feet (60 F, } 1 \text { atm) } \\ \text { syngas } & \text { synthesis gas } \\ \text { tpd } & \text { short tons per day } \\ \text { ton } & \text { short ton } \\ \text { TPEC } & \text { total purchased equipment cost } \\ \text { WGS } & \text { water-gas shift } \\ \text { yr } & \text { year(s) }\end{array}$




\section{Contents}

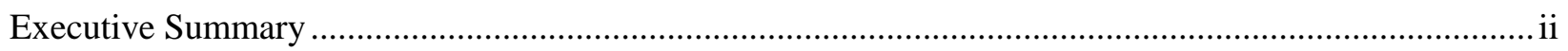

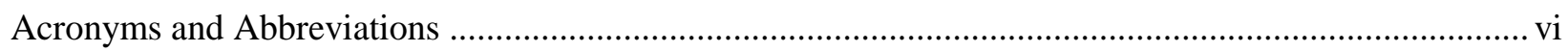

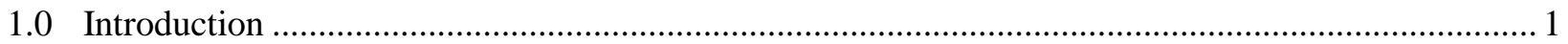

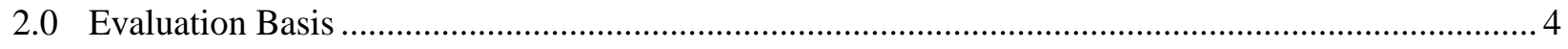

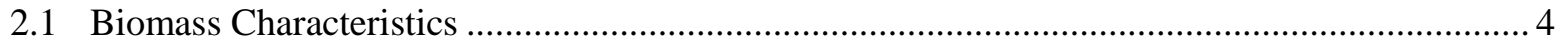

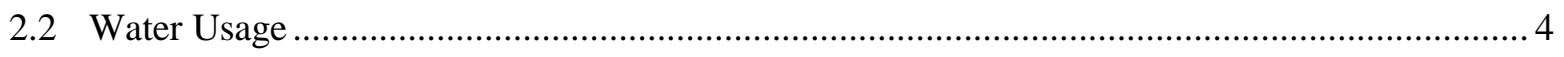

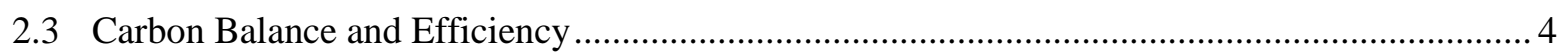

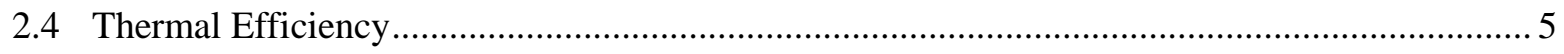

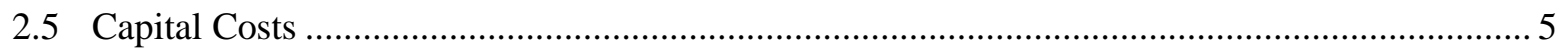

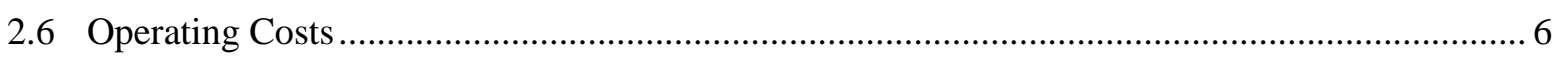

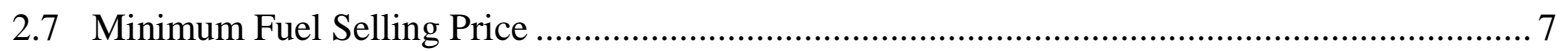

3.0 Design Description for Gasification Based Systems …............................................................ 9

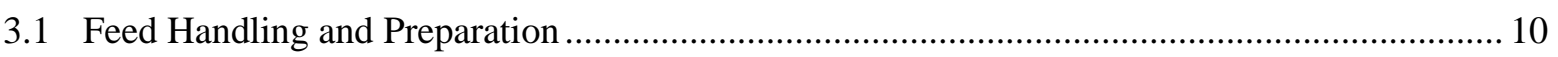

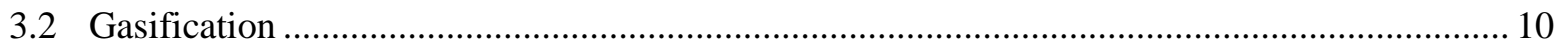

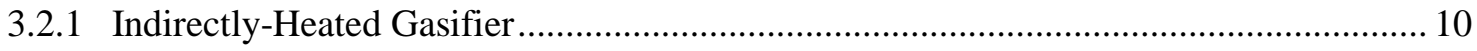

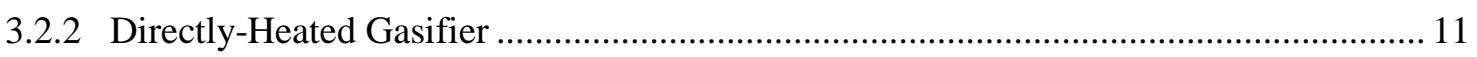

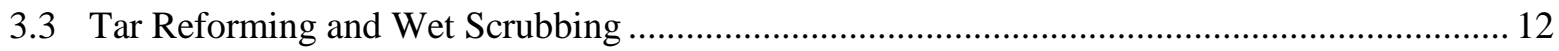

3.4 Syngas Compression and Gas Cleanup ........................................................................... 13



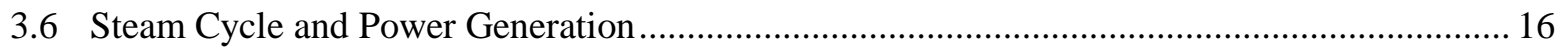

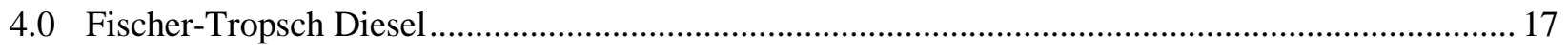

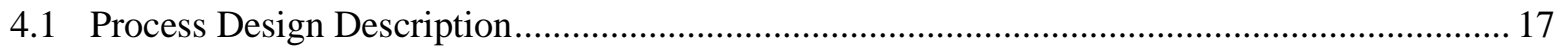

4.1.1 Steam Reforming and Hydrogen Membrane.......................................................... 19

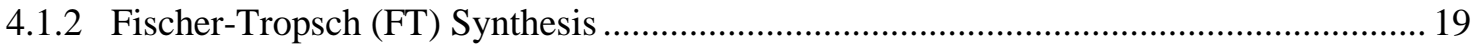

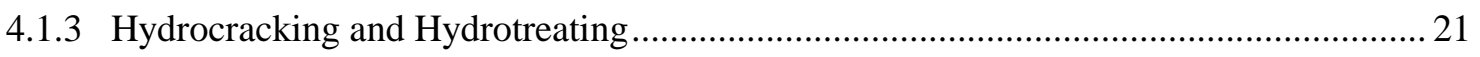

4.1.4 Product Separation and Purification....................................................................... 21

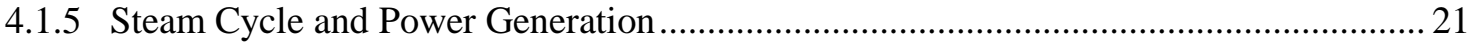

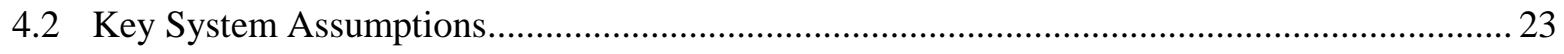

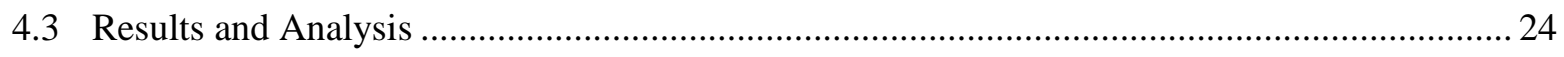

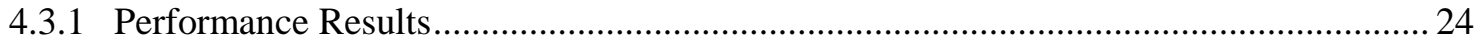

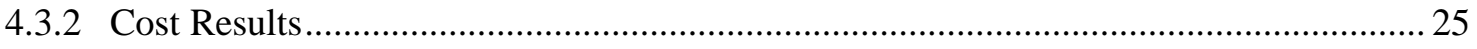

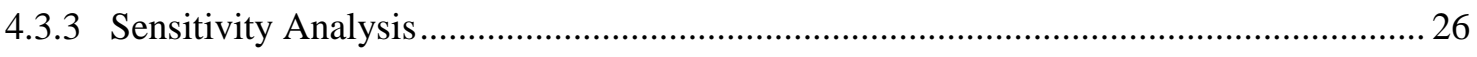

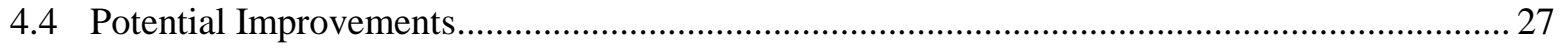

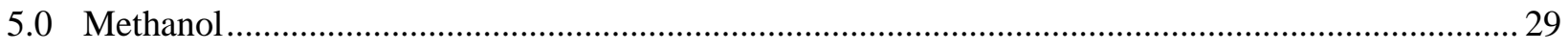

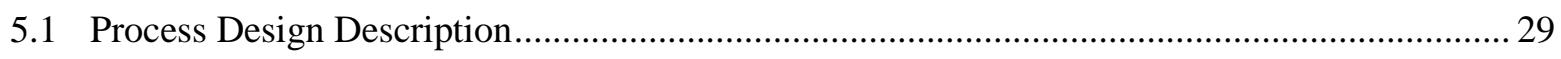




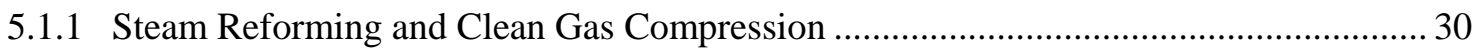

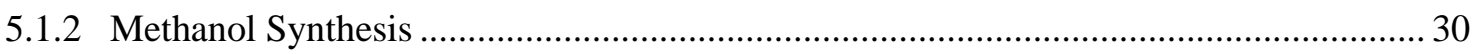

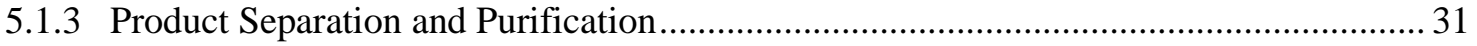

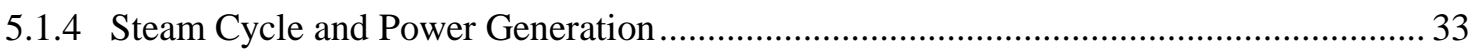

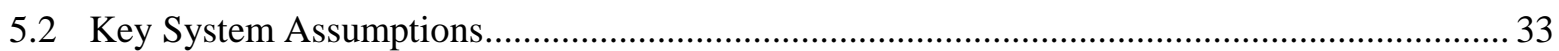

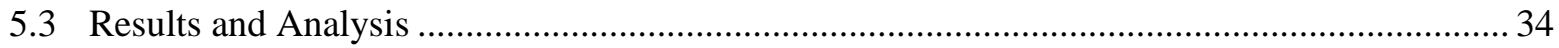

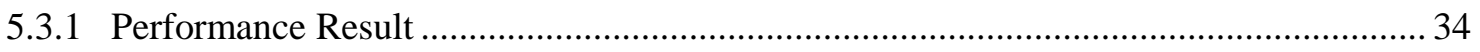

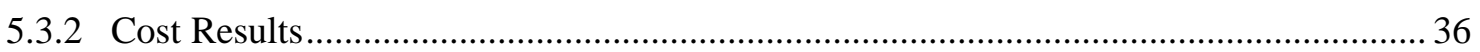

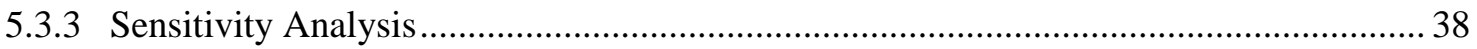

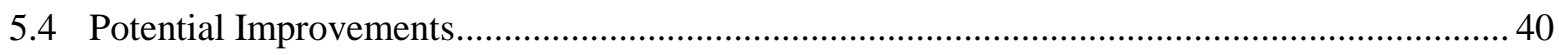

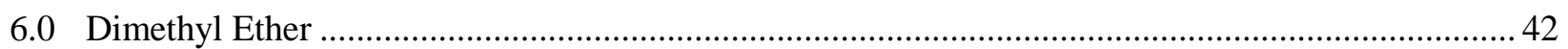

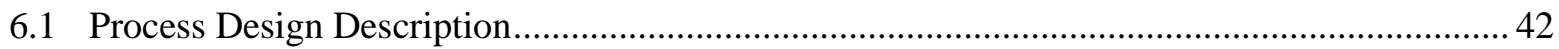

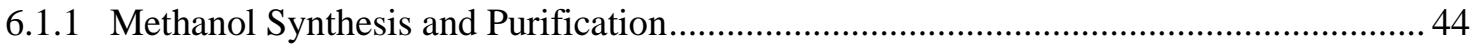

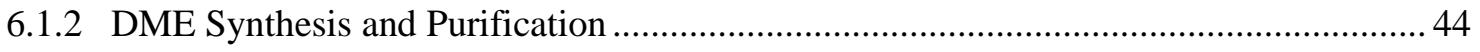

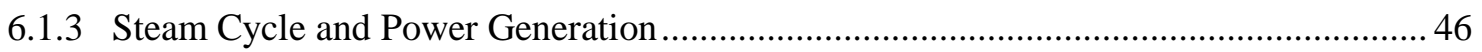

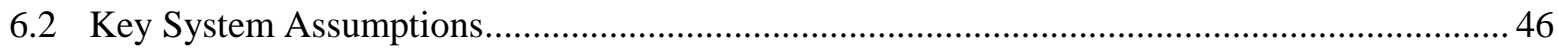

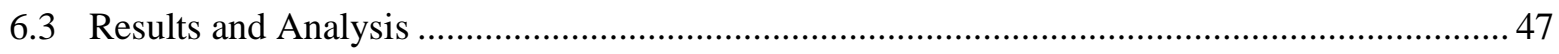

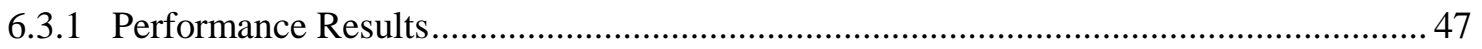

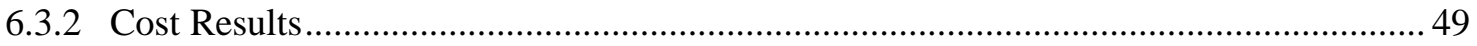

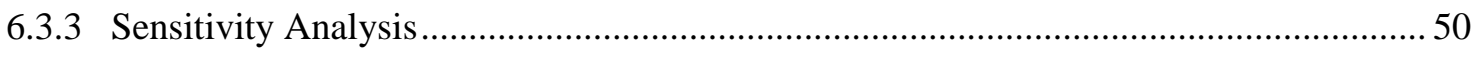

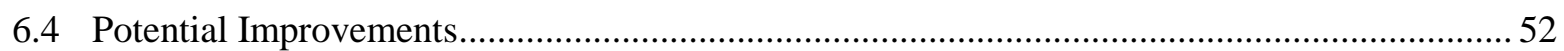

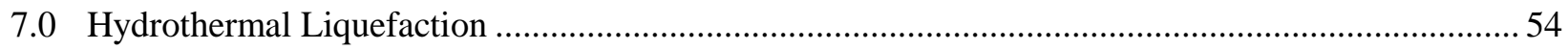

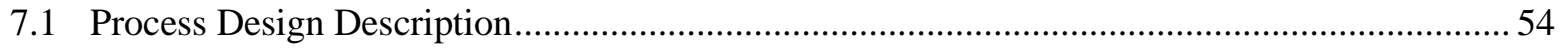

7.1.1 Feed Pretreatment and Hydrothermal Liquefaction ................................................ 55

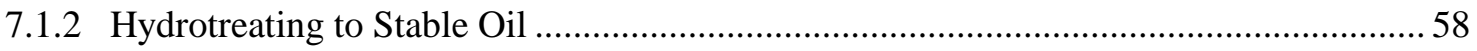

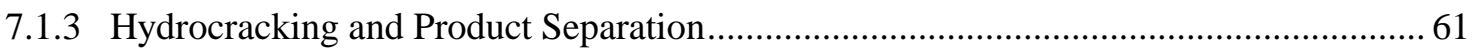

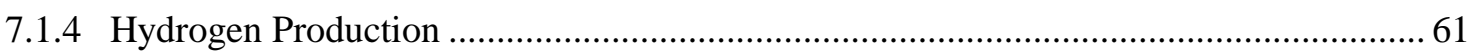

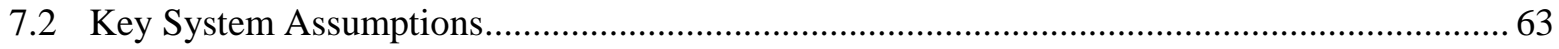



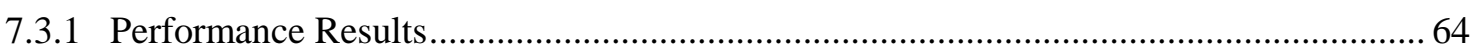

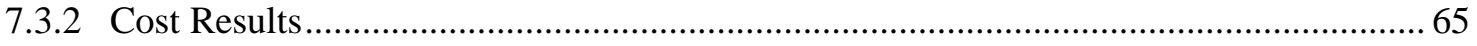

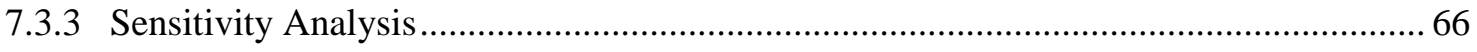

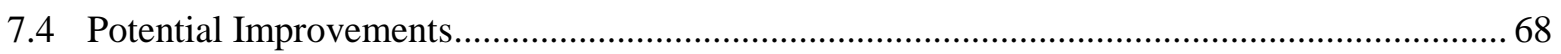

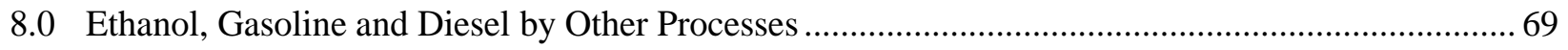

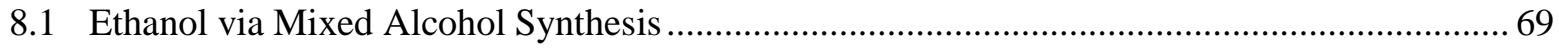

8.1.1 Process Description .........................................................Error! Bookmark not defined.

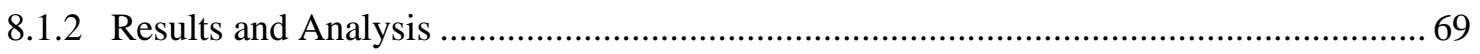

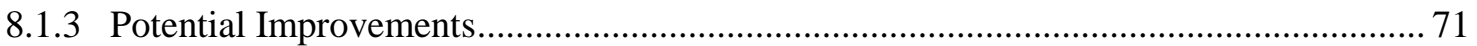


8.2 Ethanol via Acetic Acid Synthesis.

8.2.1 Process Description

.Error! Bookmark not defined.

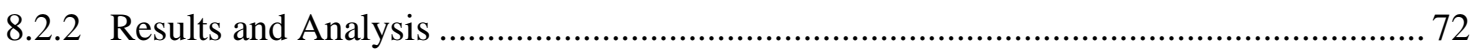

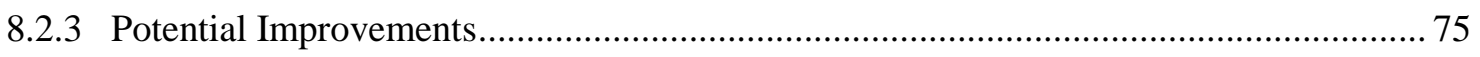

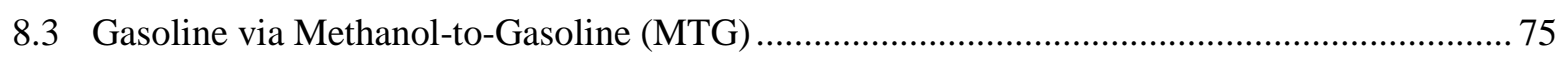

8.3.1 Process Description ......................................................Error! Bookmark not defined.

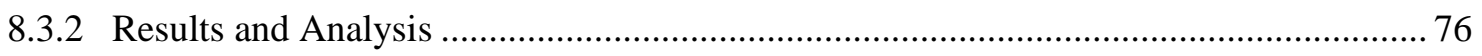

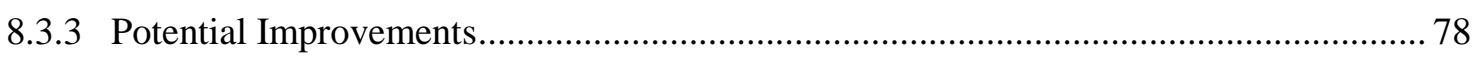

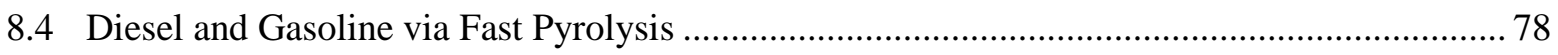

8.4.1 Process Description .......................................................Error! Bookmark not defined.

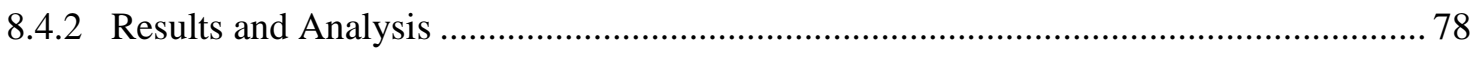



9.0 Summary and Conclusions ....................................................................ror! Bookmark not defined.

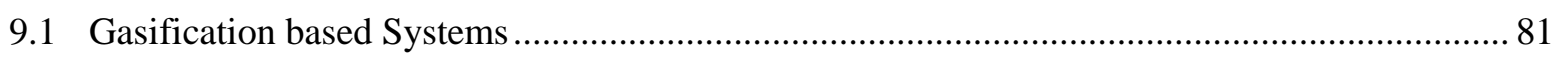

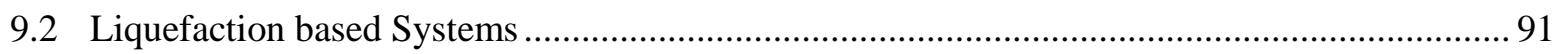

9.3 Comparison with Current Fuel Market Prices ................................................................... 92

9.4 Overall Conclusions and Recommendations

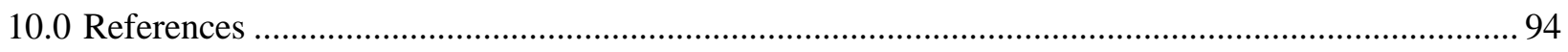

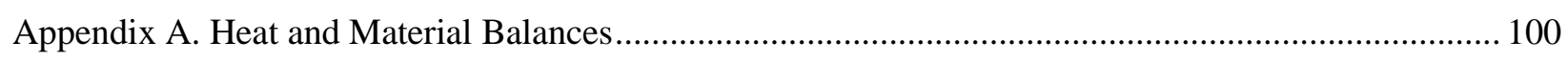

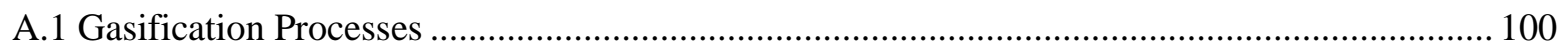

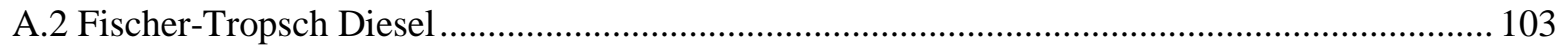

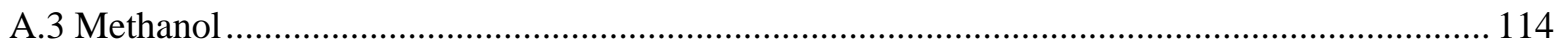

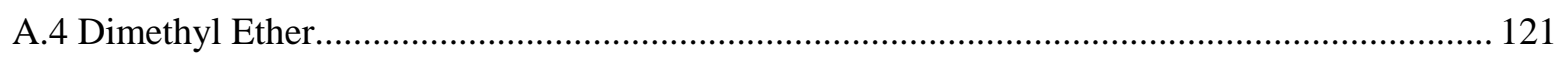

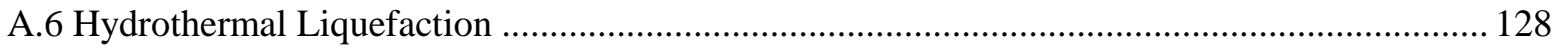

\section{Figures}

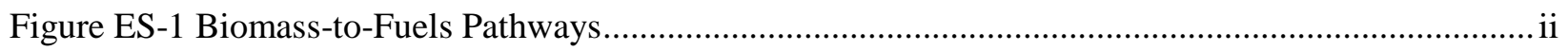

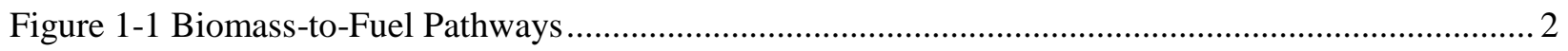

Figure 3-1 Conceptual Flow Diagram of Gasification based Biomass-to-Fuel System ........................... 9

Figure 3-2 Simplified Flow Diagram of Indirectly-Heated Gasifier and Feed Preparation........................ 11

Figure 3-3 Simplified Flow Diagram of Directly-heated Gasifier and Feed Preparation .......................... 12

Figure 3-4 Simplified Flow Diagram of Tar Reforming and Gas Cleanup ............................................ 13

Figure 3-5 Simplified Flow Diagram of Steam Reforming and $\mathrm{CO}_{2}$ Removal ..................................... 15

Figure 3-6 Simplified Flow Diagram of Steam Cycle and Power Generation.......................................... 16

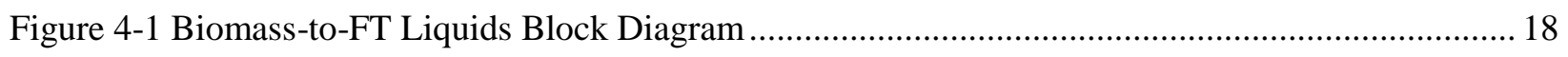

Figure 4-2 Process Flow Diagram for FT synthesis..................................................................... 20

Figure 4-3 Process Flow Diagram for Hydrocracking, Hydrotreating, and Product Separation ................ 22

Figure 4-4 Effects of Feedstock Cost and IRR on FT Diesel MFSP (Indirectly-Heated Gasifier)............. 26 
Figure 4-5 Effects of Feedstock Cost and IRR on FT Diesel MFSP (Directly-Heated Gasifier) .............. 27

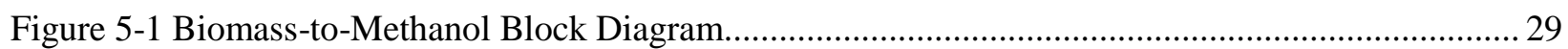

Figure 5-2 Process Flow Diagram for Methanol Synthesis and Purification Process .............................. 32

Figure 5-3 Effects of Feedstock Cost and IRR on Methanol MFSP (Indirectly-heated Gasifier) .............. 38

Figure 5-4 Effects of Feedstock Cost and IRR on Methanol MFSP (Directly-heated Gasifier)................. 39

Figure 6-1 Biomass-to-Dimethyl Ether (DME) Block Diagram........................................................ 43

Figure 6-2 Process Flow Diagram for Dimethyl Ether (DME) Synthesis and Purification....................... 45

Figure 6-3 Effects of Feedstock Cost and IRR on DME MFSP (Indirectly-Heated Gasifier).................... 51

Figure 6-4 Effects of Feedstock Cost and IRR on DME MFSP (Directly-Heated Gasifier) ..................... 52

Figure 7-1 Block Diagram for Production of Stable Oil or Gasoline/Diesel from Biomass via HTL ........ 55

Figure 7-2 Process Flow Diagram for Feed Pretreatment and Hydrothermal Liquefaction ...................... 56

Figure 7-3 Process Flow Diagram for HTL Oil Hydrotreating............................................................ 60

Figure 7-4 Process Flow Diagram for Hydrocracking and Product Separation......................................... 62

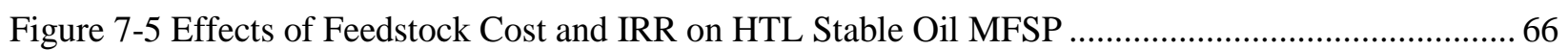

Figure 7-6 Effects of Feedstock Cost and IRR on HTL Gasoline and Diesel MFSP .............................. 67

Figure 7-7 Effect of Hydrogen Price on HTL Stable Oil and Fuel MFSP.............................................. 68

Figure 9-1 Fuel Yields of Gasification Based Biomass-to-Liquid Fuels Systems.................................... 88

Figure 9-2 Carbon and Thermal Efficiencies of Gasification Based Fuels Systems ............................... 89

Figure 9-3 Cost Comparison of Gasification Based Biomass-to-Liquid Fuels Systems .......................... 90

Figure A-1 Indirectly-heated Gasification Process .................................................................... 101

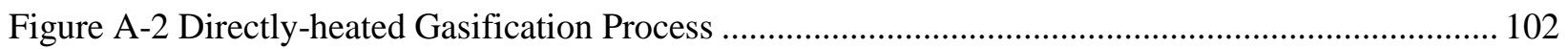

Figure A-3 FT Steam Reforming Process - Indirectly-heated Gasifier................................................. 104

Figure A-4 Fischer-Tropsch Process - Indirectly-heated Gasifier ........................................................ 105

Figure A-5 FT Hydrocracking and Hydrotreating - Indirectly-heated Gasifier .................................... 106

Figure A-6 FT Steam Cycle - Indirectly-heated Gasifier ................................................................ 108

Figure A-7 FT Steam Reforming Process - Directly-heated Gasifier ..................................................... 109

Figure A-8 Fischer-Tropsch Process - Directly-heated Gasifier ......................................................... 110

Figure A-9 FT Hydrocracking and Hydrotreating - Directly-heated Gasifier....................................... 111

Figure A-10 FT Steam Cycle - Directly-heated Gasifier ............................................................. 113

Figure A-11 Methanol Steam Reforming - Indirectly-heated Gasifier ............................................... 115

Figure A-12 Methanol Synthesis Process - Indirectly-heated Gasifier ................................................ 116

Figure A-13 Methanol Steam Cycle - Indirectly-heated Gasifier ...................................................... 117

Figure A-14 Methanol Steam Reforming Process - Directly-heated Gasifier....................................... 118

Figure A-15 Methanol Synthesis Process - Directly-heated Gasifier................................................... 119

Figure A-16 Methanol Steam Cycle - Directly-heated Gasifier.......................................................... 120

Figure A-17 DME Steam Reforming Process - Indirectly-heated Gasifier......................................... 122

Figure A-18 DME Synthesis Process - Indirectly-heated Gasifier .................................................... 123

Figure A-19 DME Steam Cycle - Indirectly-heated Gasifier........................................................... 124

Figure A-20 DME Steam Reforming Process - Directly-heated Gasifier ............................................ 125 
Figure A-21 DME Synthesis Process - Directly-heated Gasifier ...................................................... 126

Figure A-22 DME Steam Cycle - Directly-heated Gasifier ............................................................. 127

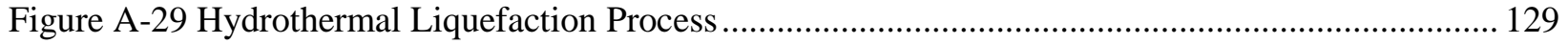

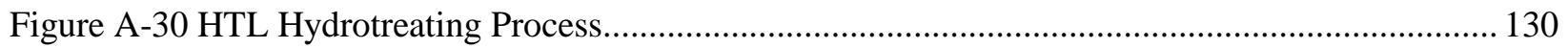

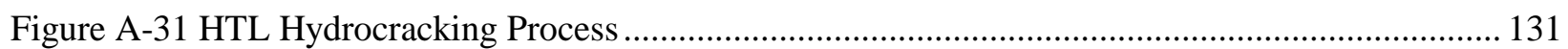

Figure A-32 HTL Hydrogen Plant -Diesel and Gasoline System ....................................................... 134 


\section{Tables}

Table ES-1 Summary of Biomass Gasification to Mixed Alcohols, MTG, FT Diesel, and Ethanol...........iii

Table ES-2 Summary of Biomass Gasification to Methanol and DME .................................................. iv

Table ES-3 Summary Biomass Liquefaction to Fuel Systems Assuming Potential Improvements ............. v

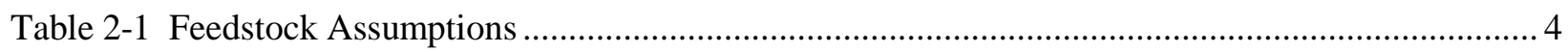

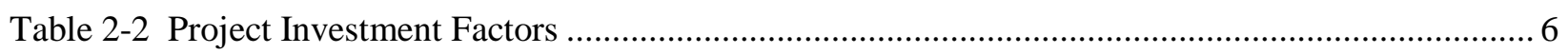

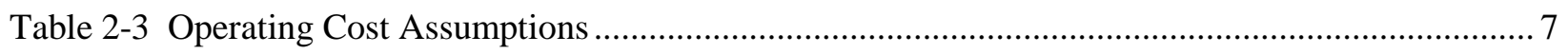

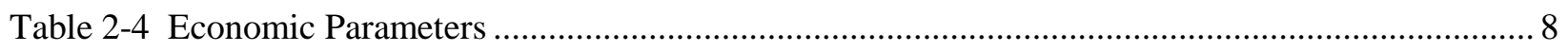

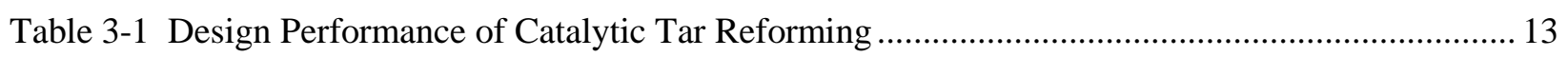

Table 4-1 Major System Assumptions for Biomass-to-Diesel via Fischer-Tropsch .............................. 23

Table 4-2 Performance Results for Biomass-to-FT Diesel System ........................................................ 24

Table 4-3 Cost Results for Biomass-to-FT Diesel System ..................................................................25

Table 4-4 Tar Reformer Design Performance for the Current and Target Cases.................................... 28

Table 5-1 U.S. Federal Grade AA Methanol Specifications................................................................. 31

Table 5-2 Major System Assumptions for Biomass-to-Methanol ........................................................... 34

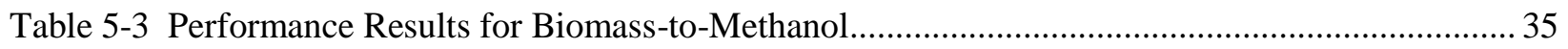

Table 5-4 Cost Results for Biomass-to-Methanol........................................................................... 37

Table 5-5 Comparison of Directly-Heated Gasifier Cases with and without Natural Gas ........................ 40

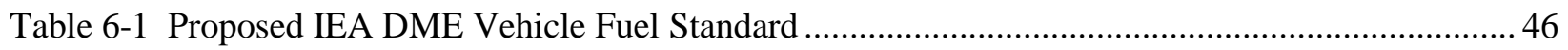

Table 6-2 Major System Assumptions for Biomass-to-DME Models ..................................................... 47

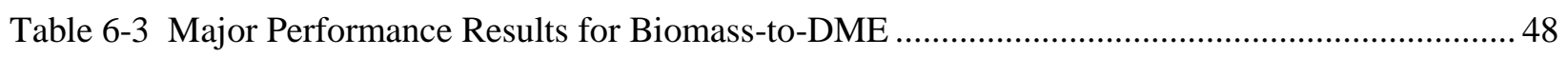

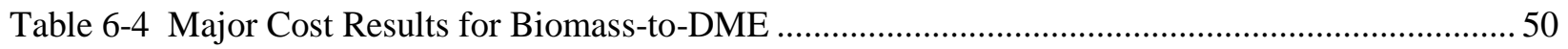

Table 7-1 HTL Process Conditions and Products Characterization......................................................... 58

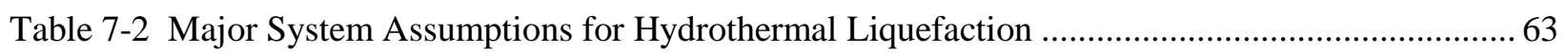

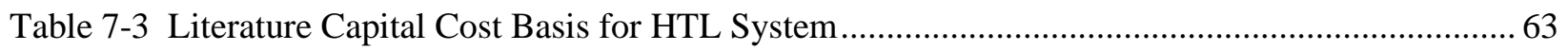

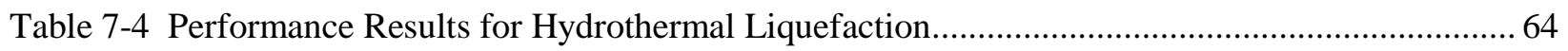

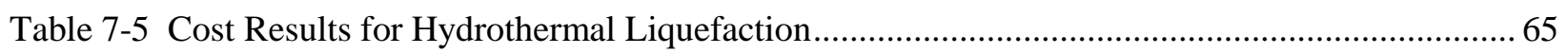

Table 8-1 Performance Results for Biomass-to-Ethanol via Mixed Alcohol Synthesis ........................... 69

Table 8-2 Cost Results for Ethanol via Mixed Alcohol Synthesis......................................................... 70

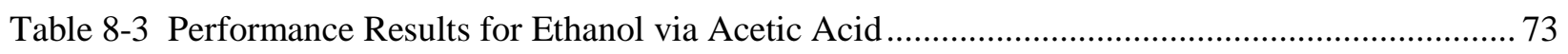

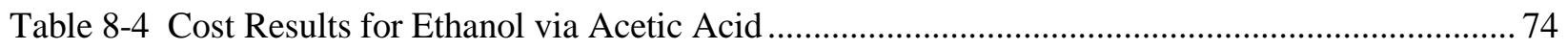

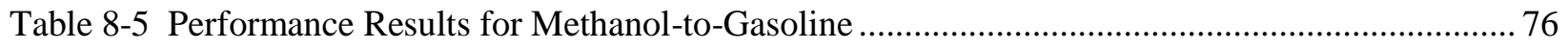

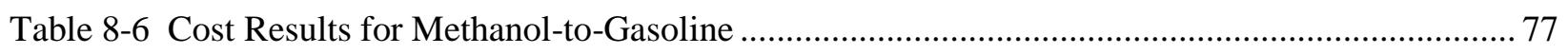

Table 8-7 Performance Results for Gasoline and Diesel via Fast Pyrolysis and Upgrading .................... 79

Table 8-8 Cost Results for Biomass-to-Gasoline and Diesel via Fast Pyrolysis .................................... 80

Table 9-1 Summary of Performance and Cost Results for Gasification to Ethanol, Gasoline and

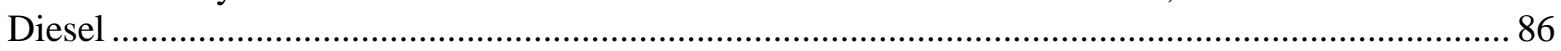

Table 9-2 Summary of Performance and Cost Results for Methanol and DME.................................... 87 
Table 9-3 Summary of Performance and Cost Results for Liquefaction Based Fuels............................. 91 


\subsection{Introduction}

Biomass is an important domestic resource that has the potential to make a significant impact on domestic fuel supplies. The renewable fuels standard of Energy Independence and Security Act of 2007 sets the supply of renewable and alternative fuels at 36 billion gallons per year by 2022 (CRS 2007). This goal is addressed in part by the U.S. Department of Energy (DOE) Biomass Program's thermochemical platform in the multiyear program plan to "convert biomass to fuels, chemicals and power via thermal and chemical processes such as gasification, pyrolysis and other non-biochemical processes" (U.S. Department of Energy 2009). This study is part of an ongoing effort within the Department of Energy to meet the renewable energy goals for liquid transportation fuels.

Biomass can be converted to liquid fuels and chemicals via a number of thermochemical approaches, such as gasification and liquefaction. Biomass gasification produces syngas which can then be converted to multiple fuel products, for example, Fischer-Tropsch (FT) gasoline or diesel blending stock, methanol, ethanol and hydrogen (Tijmensen et al. 2002, Hamelinck and Faaij 2002, and Phillips et al. 2007). From the direct synthesis products, several derivative products can be produced with additional treatment steps. Fischer-Tropsch crude oil can be converted to light diesel oil via hydrotreating and hydrocracking. FT diesel is fully compatible with conventional diesel fuels without modification to engines or significant changes in performance and has low emissions (Bergin et al. 2007). Methanol has been widely used as the raw material for chemicals and liquid fuels. Methanol can be dehydrated to produce dimethyl ether (DME), which has been demonstrated as a transportation fuel (Landälv 2006). Methanol can also be converted to acetic acid, which is well established and has high yields (Cheng and Kung 1994, Jones 2000). Acetic acid can be further converted to ethanol via hydrogenation. Methanol can also be converted to gasoline via the methanol-to-gasoline (MTG) process (Cheng and Kung 1994).

Compared with gasification, direct liquefaction features a simple and direct conversion of biomass to liquid fuel and relatively high liquid fuel yields compared to indirect conversion methods (Elliott 2007, $\mathrm{Xu}$ and Lad 2008). Typical direct liquefaction processes include fast pyrolysis and high-pressure hydrothermal liquefaction (HTL) (Elliott 2007, Oasmaa and Kuoppala 2003). Fast pyrolysis is a low pressure process while HTL is a high pressure process. Compared to pyrolysis oil, HTL bio-oil has lower oxygen/water content and thus much higher caloric values (Goudriaan et al. 2001, Elliott 2007). The pyrolysis oil or HTL oil can be converted to gasoline and diesel via hydrotreating and hydrocracking.

Of these conversion technologies, biomass gasification and fast pyrolysis systems are commercially available, while HTL has only been demonstrated at the pilot scale. For the fuel synthesis technologies, FT synthesis, methanol synthesis, acetic acid synthesis, and MTG processes are commercially available. Upgrading of fast pyrolysis oil to hydrocarbon fuels has been successfully demonstrated at the lab scale, however upgrading of HTL oil has not yet been shown. Although natural gas and coal derived syngas has been commercially used in the fuel synthesis processes, the application of biomass derived syngas to these processes is still very limited. The combination of large-scale biomass gasification and these fuel synthesis processes have yet to be demonstrated. For other synthesis processes, technical barriers still exists. For example, mixed alcohol catalysts have not reached the same level of development as FT or methanol catalysts. Currently available mixed alcohol catalysts tend to produce a variety of co-products and have relatively low activities (Nexant 2006). 
A number of techno-economic assessments have been conducted for biofuel production (Aden et al. 2002, Goudriaan et al. 2001, Hamelinck and Faaij 2002, Hamelinck et al. 2003, Spath et al. 2005, Phillips et al. 2007, Jones et al., 2009, Xu and Lad 2008). However, these analyses generally evaluate only a single biofuel. The studies also use various assumptions and cost bases, which makes the comparisons of different biofuel products difficult. In addition, the analysis of the state of technology and technical barriers in current processes are limited. In this study, three major thermochemical biomass conversion technologies and nine biomass-to-fuel systems are studied. The investigated biofuel products shown in Figure 1-1 are diesel, gasoline, methanol, DME, and ethanol. FT fuels, methanol, DME, and HTL systems are reviewed in detail. The other four biomass-to-fuel systems, mixed alcohol synthesis, ethanol via acetic acid synthesis, MTG, and fast pyrolysis, have been reported in detail in other reports and are summarized by providing results and cost analysis results. Some fuels are infrastructure compatible, such as bio-based diesel and gasoline, and ethanol, while others are not, such as DME or methanol (as a fuel).

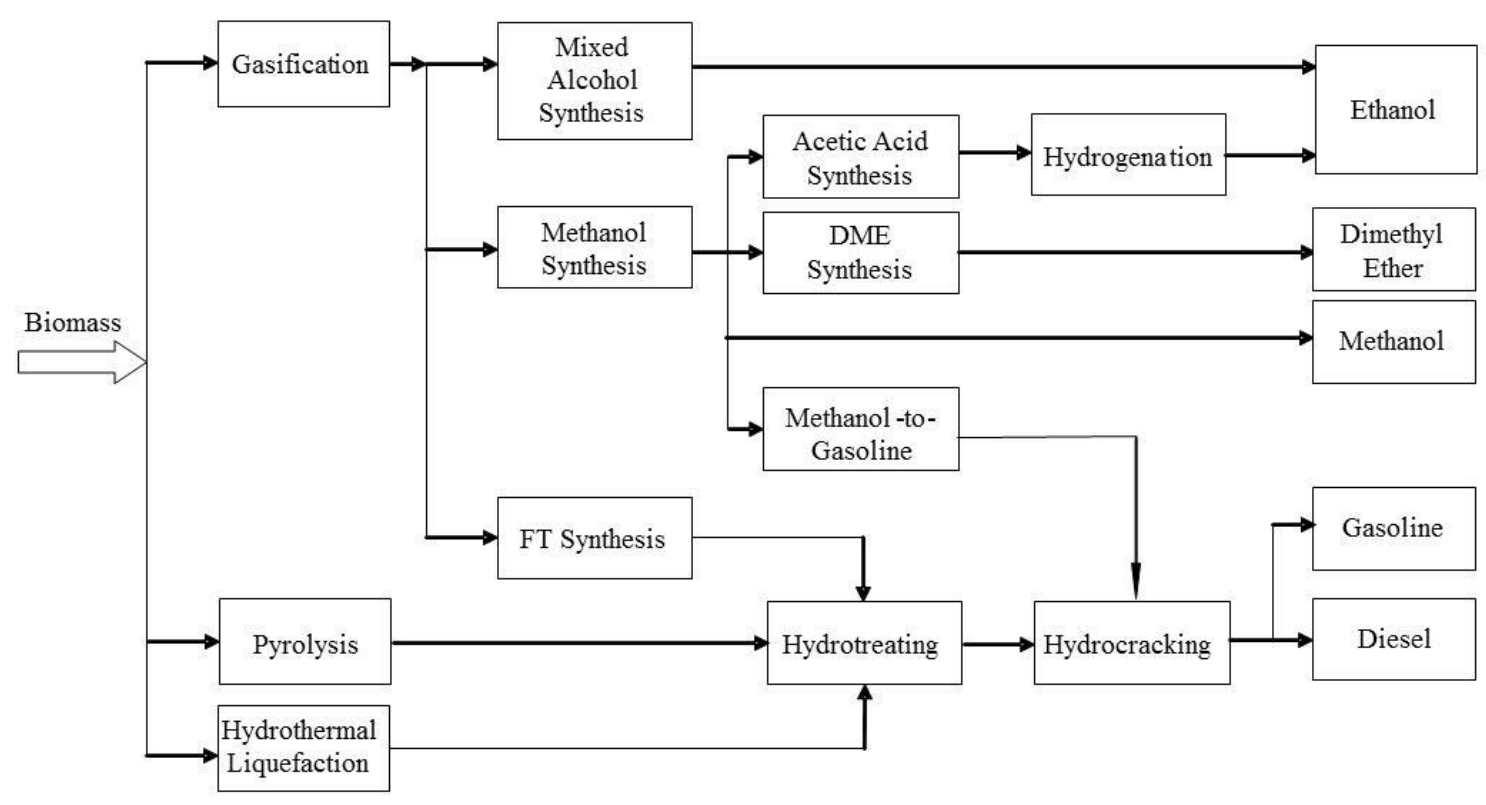

Figure 1-1 Biomass-to-Fuel Pathways

This report also serves to document the economics originally developed for the report entitled "Biofuels in Oregon and Washington: A Business Case Analysis of Opportunities and Challenges" (Stiles et al. 2008). Although the resource assessments were specific to the Pacific Northwest, the production economics presented in this report are not regionally limited. The purpose of this study is to use a consistent process design and cost analysis basis to evaluate multiple biomass conversion and fuel synthesis pathways on a relative basis. The design and simulation for gasification based systems are based on the current state of technologies, while the liquefaction cases are based on goal designs since the upgrading of pyrolysis oil is in the research phase and the upgrading of HTL oil has not yet been demonstrated. 
Sensitivity analysis is implemented to identify key process factors affecting the system cost. Based on the analysis results, the research priorities for research and development in biofuel production will be identified and the biofuel infrastructure compatibility will be discussed. Specifically, the discussion for gasification based cases will provide information about the current status of the related technologies and the potential improvements. The liquefaction cases will assess the performance and cost targets for the technologies and discuss the development goals for fuel upgrading.

This report is organized as follows:

- Section 2 introduces the process design and cost estimation assumptions for all the biomass conversion technologies,

- Section 3 describes the design details of processes common to the gasification based systems: indirectly-heated and directly-heated gasifiers, tar reforming and gas scrubbing, sulfur removal, and steam reforming,

- Sections 4 to 7 describe in detail, the simulation and analysis of four biomass conversion systems for fuel production: FT, methanol, DME, and HTL systems,

- Section 8 summarizes the major performance and cost results of the four fuel production systems that have been detailed in separate publications: ethanol via mixed alcohol synthesis, ethanol via acetic acid synthesis, MTG, and fast pyrolysis, and

- Section 9 summarizes and compares the different fuel production systems, and discusses overall conclusions from this work. 


\subsection{Evaluation Basis}

All processes are based on 2200 dry tpd (2000 dry mtpd) of biomass. The common performance and economic assumptions used to evaluate the biomass-to-fuel systems are introduced in this section.

\subsection{Biomass Characteristics}

The feedstock is assumed to be hybrid poplar wood chips with $50 \mathrm{wt} \%$ moisture. The composition of the wood chips is listed in Table 2-1.

Table 2-1 Feedstock Assumptions

\begin{tabular}{lc}
\hline Feed stock & Hybrid Poplar Wood Chips \\
Main compositions, dry basis, wt $\%$ & 50.60 \\
Carbon & 6.08 \\
Hydrogen & 40.75 \\
Oxygen & 0.61 \\
Nitrogen & 0.02 \\
Sulfur & 0.01 \\
Chlorine & 1.93 \\
Ash & 50 \\
Moisture, wt\% as received & 8,178 \\
Higher heating value (HHV), Btu/lb, dry basis & \\
\hline Source: Phyllis Database for Biomass and Waste & \\
\hline
\end{tabular}

\subsection{Water Usage}

Cooling water usage is minimized through the use of air fin coolers where applicable. The minimum stream cooling temperature by air is assumed to be $150^{\circ} \mathrm{F}\left(66^{\circ} \mathrm{C}\right)$ and the minimum cooling temperature by cooling water is assumed to be $110^{\circ} \mathrm{F}\left(43^{\circ} \mathrm{C}\right)$. The steam turbine condenser is assumed to be an air cooled condenser to minimize the water demand. Wastewater is treated in an on-site facility before discharge.

\subsection{Carbon Balance and Efficiency}

The carbon balance is represented by the carbon fractions of each major inlet and outlet streams. The carbon containing inlet streams are biomass and in some cases, natural gas and carbon monoxide. The outlet streams include fuel products, dryer exhaust, flue gas, and $\mathrm{CO}_{2}$ scrubber effluent. For each stream, the carbon molar flow rates are calculated as the sum of the carbon molar flow rates for each carboncontaining component in the stream. The carbon fraction of each outlet stream is calculated by dividing the carbon molar flow rate of the outlet stream by the total inlet carbon molar flow rates. The carbon efficiency is defined as the sum of carbon fractions of fuel and byproducts divided by the sum of the carbon fractions of the biomass plus the carbon fractions of other input fuels: 


$$
\text { Carbon Efficiency }(\%)=\frac{C_{\text {fuelprodues }}+C_{\text {byproducts }}}{C_{\text {Biomass }}+C_{\text {otherinpuffuels }}}
$$

\subsection{Thermal Efficiency}

The thermal efficiency (on a lower heating value (LHV) basis) is calculated as an important performance output, which is used to evaluate the effectiveness of different biomass conversion technologies. It is defined as the total energy output divided by the total energy input of biomass. The energy output includes the LHV of fuels, byproducts, and net power output if it is positive. The energy input includes the LHV of biomass and natural gas or other input fuels if any. If the net power output is negative, which means the power generation is less than the power consumption and the difference is assumed to be made up by the power purchased from the grid, the purchased power needs to be included in energy input. The thermal efficiency is calculated as:

When $\mathrm{W}_{\text {generation }}-\mathrm{W}_{\text {consumption }}>=0$ :

$$
\text { Thermal Efficiency }{ }_{\text {LHV }}(\%)=\frac{\mathrm{E}_{\text {fuel,LHV }}+\mathrm{E}_{\text {byproductLHV }}+\left(\mathrm{W}_{\text {generation }}-\mathrm{W}_{\text {consumption }}\right)}{\mathrm{E}_{\text {Biomass,LHV }}+\mathrm{E}_{\text {otherinpufuels,LHV }}}
$$

When $\mathrm{W}_{\text {generation }}-\mathrm{W}_{\text {consumption }}<0$ :

$$
\text { Thermal Efficiency } \text { LHV }(\%)=\frac{\mathrm{E}_{\text {fuel,LHV }}+\mathrm{E}_{\text {byproductLHV }}}{\mathrm{E}_{\text {Biomass,LHV }}+\mathrm{E}_{\text {otherinpufuels,LHV }}+\left(\mathrm{W}_{\text {consumptio }}-\mathrm{W}_{\text {generation }}\right)}
$$

\subsection{Capital Costs}

The performance model provides key operating conditions and inlet and outlet streams flow rates for each unit operation, as well as any energy consumed or produced by the process where applicable. This information was used to size standard equipment by using CHEMCAD sizing routines or standard literature sources (Perry et al. 1984, Couper et al. 2005). ASPEN Icarus was used to obtain bare equipment costs for sized equipment. Non-standard equipment costs, such as the gasifier, are from literature sources. The equipment costs assume that this is the " $\mathrm{n}$ "th" plant; that is, all research and development required to commercialize the process at the given scale is complete, and the manufacturing processes are mature and the equipment readily available. The equipment costs were estimated by scaling the base equipment costs by the appropriate metric (e.g., flow, duty, etc.) and applying an appropriate scaling factor. The equipment costs were estimated by scaling the base case equipment costs by the appropriate metric (e.g., flow, duty, etc.) and applying an appropriate scaling factor:

$$
(\text { Cost } \$)=(\text { Base Cost } \$) *[(\text { Capacity }) /(\text { Base Capacity })]^{(\text {scaling factor })}
$$


All capital costs are reported in 2008 dollars. Equipment cost escalation is calculated by using the Chemical Engineering Plant Cost Index (CEPCI). The total capital investment is factored from installed equipment costs as shown in Table 2-2.

Table 2-2 Project Investment Factors

\begin{tabular}{lc}
\hline & $\%$ of TPEC \\
\hline Total Purchased Equipment Cost (TPEC) & $100 \%$ \\
Purchased Equipment Installation & $39 \%$ \\
Instrumentation and Controls & $26 \%$ \\
Piping & $31 \%$ \\
Electrical Systems & $10 \%$ \\
Buildings (including services) & $29 \%$ \\
Yard Improvements & $12 \%$ \\
Total Installed Cost (TIC) & $247 \%$ \\
& \\
Indirect Costs & \\
Engineering & $32 \%$ \\
Construction & $34 \%$ \\
Legal and Contractors Fees & $23 \%$ \\
Project Contingency & $37 \%$ \\
Total Indirect & $126 \%$ \\
& \\
Total Project Investment & $373 \%$
\end{tabular}

Source: Peters and Timmerhaus 2003

\subsection{Operating Costs}

Table 2-3 lists the assumptions used to estimate the production costs. The catalysts and chemical prices were escalated with the annual average 2008 Producer Price Index. 
Table 2-3 Operating Cost Assumptions

\begin{tabular}{|c|c|}
\hline & Values (escalated to 2008 dollars) \\
\hline \multicolumn{2}{|l|}{ Raw Materials and Chemicals } \\
\hline Hybrid poplar chips, \$/dry ton & $60.0^{(\mathrm{a})}$ \\
\hline Natural gas, $\$ / 1000 \mathrm{scf}$ & $9.61^{\text {(b) }}$ \\
\hline Olivine makeup, \$/ton & $270^{(\mathrm{c})}$ \\
\hline Ash disposal, \$/ton & $45.8^{(\mathrm{c})}$ \\
\hline Tar cracker catalyst, $\$ / \mathrm{lb}$ & $8.46^{(\mathrm{c})}$ \\
\hline Reformer catalyst, $\$ / \mathrm{lb}$ & $26.6^{(\mathrm{d})}$ \\
\hline Water-gas shift catalyst, $\$ / \mathrm{lb}$ & $11.5^{(\mathrm{e})}$ \\
\hline Fischer-Tropsch (FT) catalyst, $\$ / \mathrm{lb}$ & $6.38^{(\mathrm{c})}$ \\
\hline Methanol synthesis catalyst, $\$ / \mathrm{lb}$ & $10.2^{(\mathrm{d})}$ \\
\hline Dimethyl Ether (DME) catalyst, $\$ / 1 b$ & $9.37^{(\mathrm{d})}$ \\
\hline Hydrotreating catalyst, $\$ / \mathrm{lb}$ & $18.8^{(\mathrm{d})}$ \\
\hline Hydrocracking catalyst, $\$ / \mathrm{lb}$ & $18.8^{(\mathrm{d})}$ \\
\hline Hydrogen plant catalysts, $\$ / 1000 \mathrm{scf} \mathrm{H}_{2}$ & $0.044^{(\mathrm{d})}$ \\
\hline Mixed alcohol synthesis catalyst, $\$ / \mathrm{lb}$ & $6.38^{(\mathrm{c})}$ \\
\hline Acetic Acid synthesis catalyst, $\$ / \mathrm{lb}$ (estimated) & $0.012^{(\mathrm{d})}$ \\
\hline Methanol-to-Gasoline (MTG) zeolite catalyst, \$/lb & $62.9^{(\mathrm{d})}$ \\
\hline \multicolumn{2}{|l|}{ Utilities } \\
\hline Waste water treatment, $\$ / 100 \mathrm{ft}^{3}$ & $2.51^{(\mathrm{c})}$ \\
\hline Cooling tower makeup, $\$ / 1000$ gal & $2.57^{\text {(c) }}$ \\
\hline Electricity, $\phi / \mathrm{kWh}$ & $7.72^{(\mathrm{b})}$ \\
\hline \multicolumn{2}{|l|}{ Labor } \\
\hline Maintenance and overhead & $95 \%$ of labor \& supervision ${ }^{(c)}$ \\
\hline \multicolumn{2}{|l|}{ Materials } \\
\hline Maintenance & $2 \%$ of total project investment ${ }^{(\mathrm{c})}$ \\
\hline Local taxes \& insurance & $2 \%$ of total project investment ${ }^{(\mathrm{c})}$ \\
\hline $\begin{array}{l}\text { Source: }{ }^{(\mathrm{a})} \text { Aden } 2008 ;{ }^{(\mathrm{b})} \text { Energy Information Administra } \\
2007 ;{ }^{(\mathrm{e})} \text { Spath } \text { et al. } 2005\end{array}$ & hillips et al. 2007; ${ }^{(\mathrm{d})}$ SRI International \\
\hline
\end{tabular}

\subsection{Minimum Fuel Selling Price}

The minimum fuel selling price (MFSP) is determined using a discounted cash flow rate of return analysis. The methodology is identical to that used in Phillips et al. (2007). The MFSP is the selling price of the fuel that makes the net present value of the process equal to zero with a $10 \%$ discounted cash flow rate of return over a 20 year plant life. The stream factor (90\%) is assumed for all the cases as a reasonable assumption for " $\mathrm{n}$ " " plant. Table 2-3 gives the economic parameters used to calculate the MFSP. 
Table 2-4 Economic Parameters

\begin{tabular}{lc}
\hline & Value \\
\hline Stream Factor & $90 \%$ \\
MACRS Depreciation, yrs & 7 \\
Internal Rate of Return, $\%$ & $10 \%$ \\
Plant life, yrs & 20 \\
Construction Period & 2.5 years \\
$1^{\text {st }}$ 6 months expenditure & $8 \%$ \\
Next 12 months expenditure & $60 \%$ \\
Last 12 months expenditure & $32 \%$ \\
Start-up time & 6 months \\
Revenues & $50 \%$ \\
Variable Costs & $75 \%$ \\
Fixed Costs & $100 \%$ \\
Working Capital & $5 \%$ of Total Capital Investment \\
Land & construction expense) \\
\hline Source: Phillips et al. 2007 & \\
\hline
\end{tabular}

Since each fuel products has a different heating value, the MFSP is also compared on an equivalent ethanol LHV basis defined as:

MFSP equivalent ethanol LHV $=\frac{\text { MFSP of Fuel }(\$ / \text { gallon }) \times \text { Ethanol LHV (Btu/gallon })}{\text { Fuel LHV }(\text { Btu/gallon })}(2-5)$ 


\subsection{Design Description for Gasification Based Systems}

The gasification based biomass conversion systems are based on both an indirectly heated gasifier and a directly heated (oxygen-blown) pressurized gasifier. Both gasifier models used similar processing assumptions and unit operation configurations as those in Aden et al. (2005) and Spath et al. (2005).

Figure 3-1 shows the simplified process flow for a gasification based biomass-to-fuel system. The main components are gasification, gas purification and conditioning (tar cracking, acid gas removal, reforming, and compression, and $\mathrm{CO}_{2}$ removal), fuel synthesis and purification, and steam cycle/power generation.

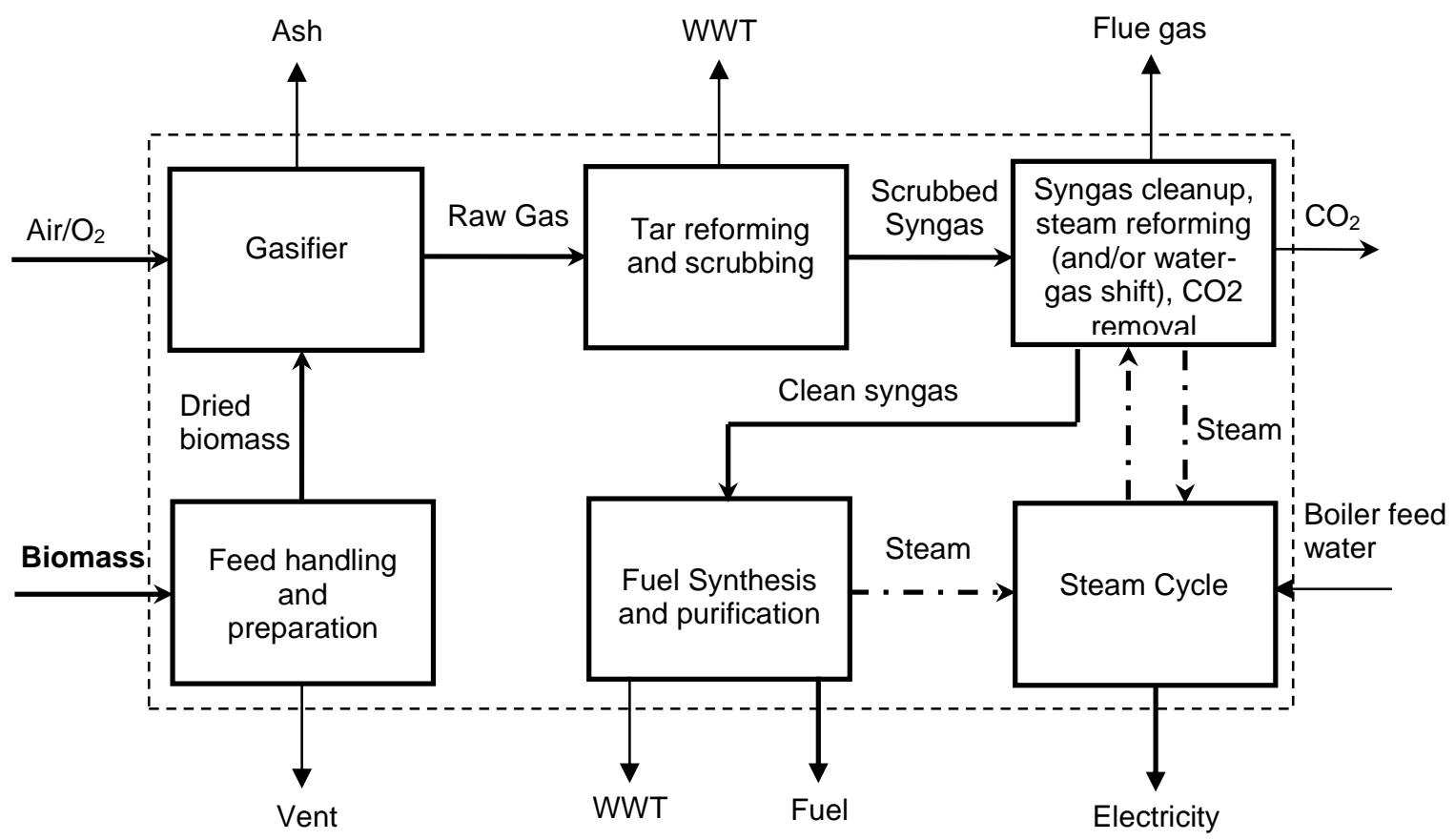

Figure 3-1 Conceptual Flow Diagram of Gasification based Biomass-to-Fuel System

In this system, wood chips are converted to raw gas in a gasifier. The raw syngas then is sent to a tar reformer and scrubber. A large portion of the tar, methane, and other light hydrocarbons in the raw gas react with steam and are converted to $\mathrm{CO}$ and $\mathrm{H}_{2}$. The syngas is then sent to a wet scrubbing unit to remove particulates in syngas. The scrubbed syngas is compressed and sulfur in the syngas is removed. The clean syngas is sent to a steam reformer where methane and other higher hydrocarbon gases are reformed to $\mathrm{CO}$ and $\mathrm{H}_{2}$ in a desired ratio. The reformed syngas is cooled by heat recovery to generate steam and then cooled by air and cooling water. An amine-based chemical absorption system is used to remove $\mathrm{CO}_{2}$ from the reformed syngas. This $\mathrm{CO}_{2}$ is currently assumed to be vented to the atmosphere, however, could be available for carbon capture and sequestration. The purified synthesis gas is compressed to the desired pressure for the synthesis process for each product. The syngas is then sent to the product synthesis process to product the target product. Byproducts and unconverted synthesis gas that are unsuitable for recovery, reuse, or sale are used as fuel to produce electricity. 


\subsection{Feed Handling and Preparation}

Biomass is assumed to be received in the form of wood chips with a moisture content of $50 \mathrm{wt} \%$. The wood feed rate to the feed preparation system is 2,200 dry tons per day (2,000 dry metric tons per day). The wood chips are dried in directly heated rotary driers. Pre-drying the feedstock before feeding it to the gasifier is necessary to minimize the heat load in the gasifier, thereby reducing char combustion requirements in the indirectly heated gasifier and oxygen requirements in the directly heated gasifier. However, drying wood chips to a moisture content of less than 10 to $15 \%$ is more energy intensive and requires significantly larger dryers (Hamelinck et al. 2003). In this study, a moisture content of $12 \%$ is assumed based on a previous study that used wood as the feedstock (Spath et al. 2005).

For the indirectly heated gasifier, the heat from the char combustor hot flue gas is used to produce steam and dry the biomass. The flue gas stack exit temperature is controlled to approximately $300^{\circ} \mathrm{F}\left(149^{\circ} \mathrm{C}\right)$ to be greater than the gas dew point. For the oxygen-blown pressurized gasifier, the heat of the flue gas from the char combustor is insufficient to completely dry the wood chips. Therefore, off-gas from the synthesis process is burned to generate additional heat for biomass drying.

\subsection{Gasification}

The indirectly heated gasifier is modeled using the correlation model developed by Spath et al. (2005) based on data from a gasifier developed at the Battelle-Columbus Laboratory. A 200 dry tpd (182 dry mtpd) demonstration-scale gasifier design was later built by Future Energy Resources Company (FERCO), Atlanta, Georgia, at a Burlington Electric Department wood powered plant in Burlington, Vermont. The syngas from the directly heated (oxygen-blown) pressurized gasifier is predicted using correlations based on the experimental data from an Institute of Gas Technology gasifier (Evans 1988). A 90-tonne/day demonstration plant based on this design was built at the Hawaiian Commercial \& Sugar Company's Paia sugar factory in Maui, Hawaii, and operated using bagasse (i.e., the biomass remaining after sugarcane stalks are crushed to extract their juice) as the feedstock. Both types of gasifiers were modeled using the stoichiometric reactor model in CHEMCAD.

\subsubsection{Indirectly-Heated Gasifier}

Figure 3-2 shows the process flow diagram of an indirectly-heated gasifier and feed preparation process. The indirectly heated gasifier contains both a gasifier and a separate combustor. Dried wood is fed into a low-pressure indirectly heated gasifier. Steam extracted from the steam cycle is sent to the gasifier at a flow rate of $0.4 \mathrm{lb}$ of steam/lb of bone-dry wood to fluidize the bed and to supply a portion of the heat required for the gasifier. The indirectly-heated gasification reactor is operated at $1598^{\circ} \mathrm{F}\left(870^{\circ} \mathrm{C}\right)$ and 23 psia. Heat is supplied by circulating hot olivine particles between the gasifier and the separate combustor (Spath et al. 2005).

A series of cyclone separators are used to remove particulates and char from the raw gas leaving the gasifier. The majority of the olivine, char, and ash is separated in the cyclone separator and then sent to the char combustor. The gas from the primary gasifier cyclone is sent to the tar reformer. The char is burned in the char combustor to reheat the olivine. The flue gas from the char combustor is sent to the primary combustor cyclone separator, which separates $99.9 \%$ of the olivine which then is returned to the gasifier. Then, the flue gas containing residual fines and ash is sent to a secondary combustor cyclone 
separator to remove these solids. The residual fines and ash are cooled to $300^{\circ} \mathrm{F}\left(145^{\circ} \mathrm{C}\right)$ using cooling water and quenched by water to control dust. The wet solids ultimately are transported to a landfill for disposal. The hot gas from the cyclone is then cooled by boiler feed water to generate saturated steam. The flue gas is then used for biomass drying.

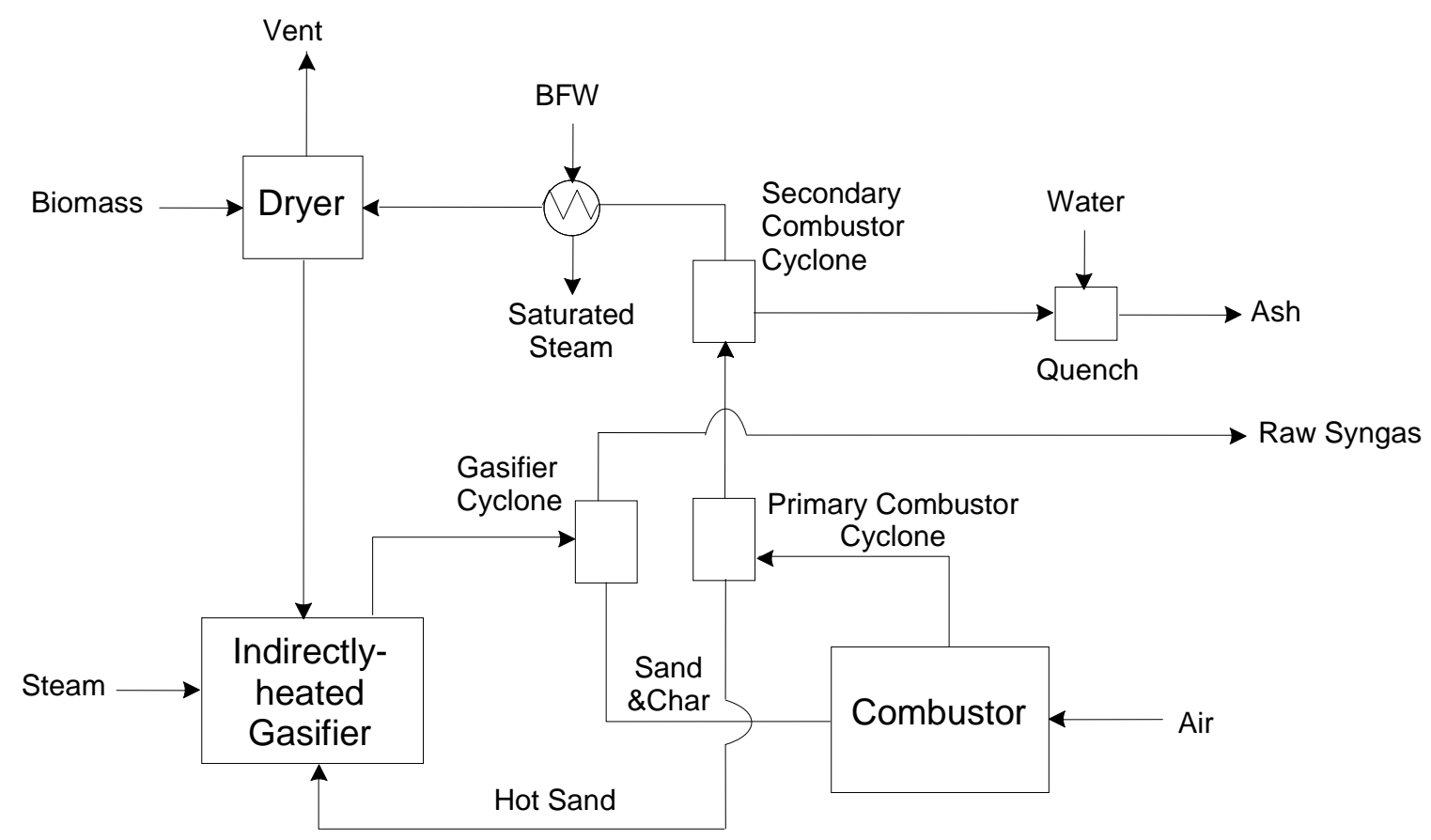

Figure 3-2 Simplified Flow Diagram of Indirectly-Heated Gasifier and Feed Preparation

\subsubsection{Directly-Heated Gasifier}

The process flow diagram for the directly-heated gasifier is shown in Figure 3-3. The directly-heated gasifier is an oxygen-fired pressurized fluidized bed reactor. In this reactor, the heat required by endothermic gasification reactions is directly supplied by burning a portion of biomass with a substoichiometric flow of oxygen in the reactor. A pressurized cryogenic air separation unit provides purified oxygen at $99.5 \%$ for the gasifier at 350 psia and $60^{\circ} \mathrm{F}\left(16^{\circ} \mathrm{C}\right)$. Purified oxygen is required rather than air to prevent introducing large quantities of nitrogen into the synthesis gas where it would act as an inert diluent. The mass flow rate of oxygen is varied to achieve a $1,600^{\circ} \mathrm{F}\left(871^{\circ} \mathrm{C}\right)$ gasifier outlet temperature. Steam is used to fluidize the gasifer bed and to provide a portion of the heat. The steam flow rate is $0.2 \mathrm{lb}$ of steam/lb of dried wood with $12 \mathrm{wt} \% \mathrm{H}_{2} \mathrm{O}$. The dried wood is fed using a lock hopper feeder system in which wood is dropped into a chamber, which is then sealed, and then filled with pressurized $\mathrm{CO}_{2}$ recovered from the gas purification and conditioning section of the plant. Once the chamber is pressurized, the wood is discharged from the lock hopper and fed to the gasifier. The $\mathrm{CO}_{2}$ used in the lock hopper is fed at a flow rate of $0.03 \mathrm{lb}$ of $\mathrm{CO}_{2} / \mathrm{lb}$ dried wood and compressed to $330 \mathrm{psia}$. A small amount of $\mathrm{MgO}$ is added to the gasifier to react with potassium in the ash to prevent agglomeration in the gasifier bed. 
The raw untreated gas from the gasifier is sent to a primary cyclone separator where char is captured and sent to the char combustor. The char is combusted in char combustor and the hot flue gas is sent to the biomass drying unit. The gas from the primary separator is then sent to a secondary cyclone separator to remove the ash and residual fines. The ash recovered from the secondary separator is cooled to $300^{\circ} \mathrm{F}$ $\left(149^{\circ} \mathrm{C}\right)$, and then water is added before the mixture is transported to a landfill for disposal. The raw syngas is sent to the tar reformer.

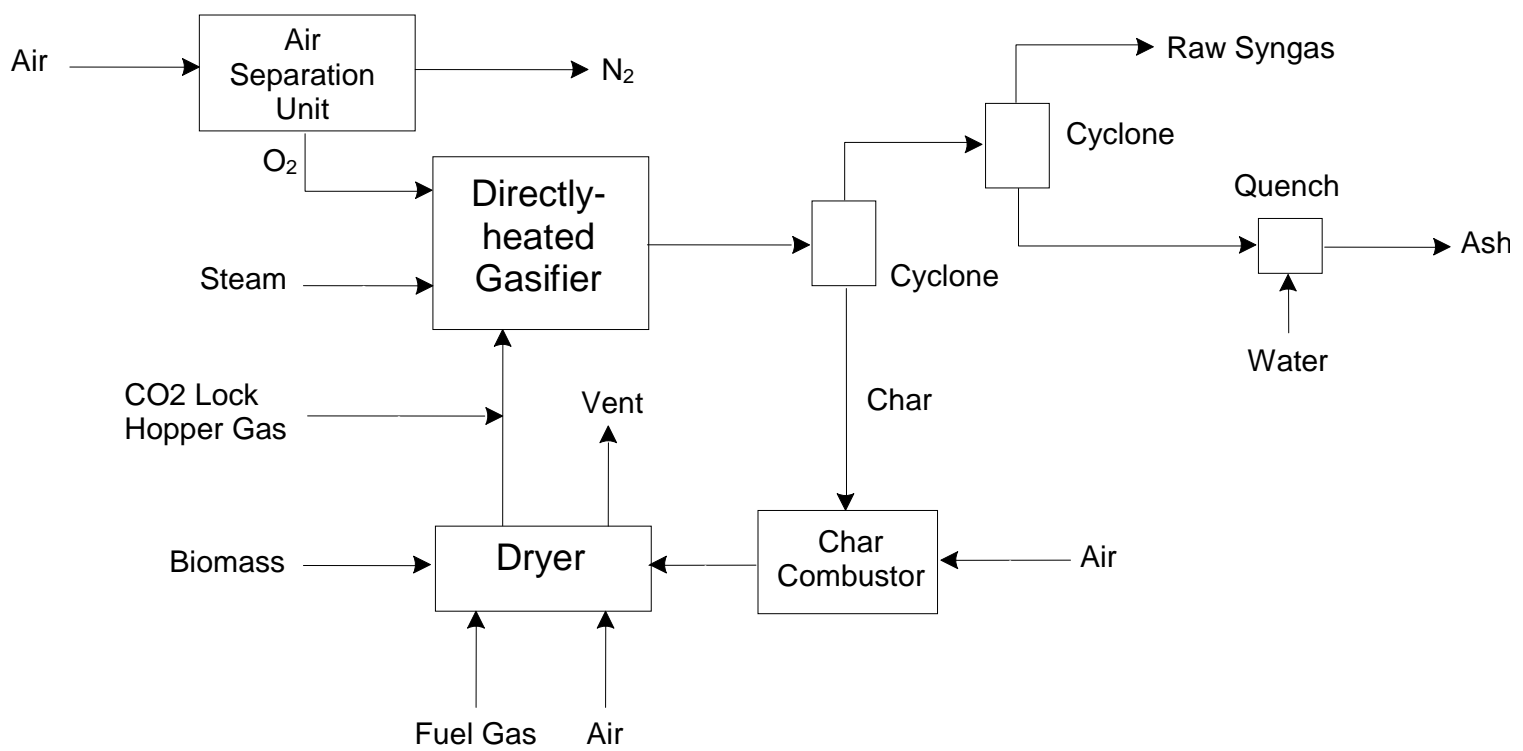

Figure 3-3 Simplified Flow Diagram of Directly-heated Gasifier and Feed Preparation

\subsection{Tar Reforming and Wet Scrubbing}

During gasification, a small fraction of the biomass is converted into tars that consist primarily of functionalized aromatic and poly-aromatic hydrocarbons. The tars will foul the downstream process equipment if allowed to condense. While they comprise only a small fraction of the wood feed, they contain significant quantities of carbon and hydrogen, which are important sources for $\mathrm{CO}$ and $\mathrm{H}_{2}$. Therefore, cracking these tars into small hydrocarbons is preferred over condensing them in the water scrubber and discharging them with the wastewater.

As shown in Figure 3-4, the raw gas from the cyclone separator in the gasifier section is sent to a catalytic tar cracker/reformer, which is assumed to be a bubbling fluidized-bed reactor. A portion of the tar, methane, and other light hydrocarbons in the raw gas react with steam and are converted to $\mathrm{CO}$ and $\mathrm{H}_{2}$, while $\mathrm{NH}_{3}$ is decomposed to $\mathrm{N}_{2}$ and $\mathrm{H}_{2}$. Benzene and naphthalene are used to represent the aromatic and polyaromatic $\left(\mathrm{C}_{10^{+}}\right)$tar components (Spath et al. 2005). The tar reformer is simulated by using a stoichimetric reactor model. The conversion of each compound is simulated by specifying conversion fractions for each reaction, which are based on Spath et al. (2005). The gas enters the tar reformer at the gasifier outlet temperature and exits the reformer at $1,383^{\circ} \mathrm{F}\left(750^{\circ} \mathrm{C}\right)$. The conversion percentages for tars and other hydrocarbons assumed in the tar reforming process are listed in Table 3.1. 
Table 3-1 Design Performance of Catalytic Tar Reforming

\begin{tabular}{lc}
\hline Compounds & Conversion Percentage \\
\hline Methane $\left(\mathrm{CH}_{4}\right)$ & $20 \%$ \\
Ethane $\left(\mathrm{C}_{2} \mathrm{H}_{6}\right)$ & $90 \%$ \\
Ethylene $\left(\mathrm{C}_{2} \mathrm{H}_{4}\right)$ & $50 \%$ \\
Tars $\left(\mathrm{C}_{10+}\right)$ & $95 \%$ \\
Benzene $\left(\mathrm{C}_{6} \mathrm{H}_{6}\right)$ & $70 \%$ \\
Ammonia $\left(\mathrm{NH}_{3}\right)$ & $70 \%\left(\right.$ Converts to $\mathrm{N}_{2}$ and $\left.\mathrm{H}_{2}\right)$ \\
Source: Spath et al. 2005 & \\
\hline
\end{tabular}

After tar and other organic impurities are reduced in the tar cracker, the gas is cooled to $300^{\circ} \mathrm{F}\left(149^{\circ} \mathrm{C}\right)$ using heat exchangers. The gas is then scrubbed and cooled in a venturi scrubber and a spray quench chamber to remove impurities such as particulates, $\mathrm{NH}_{3}$, and other residual tars. Most of the scrubber water is recirculated to the quench sprayers. The purged scrubber water with impurities is sent to a wastewater treatment facility. Because the low concentrations of unconverted tar components preclude condensation, the model assumes that these components pass through the scrubber.

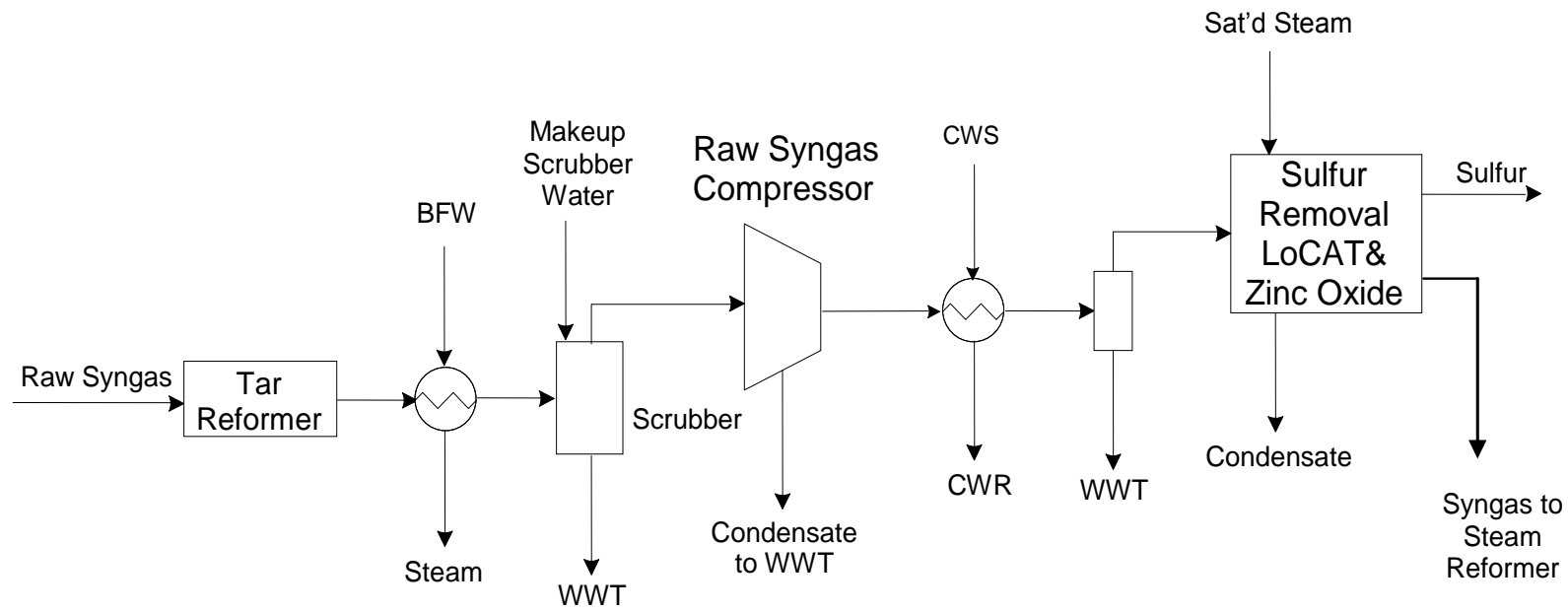

Figure 3-4 Simplified Flow Diagram of Tar Reforming and Gas Cleanup

\subsection{Syngas Compression and Gas Cleanup}

As shown in Figure 3-4, the cooled, scrubbed gas is compressed to 450 psia using a centrifugal compressor. For the indirectly heated gasifier, which operates at near ambient pressure, the compressor consists of five stages with interstage cooling and intercooler temperatures of $140^{\circ} \mathrm{F}\left(60^{\circ} \mathrm{C}\right)$. For each compressor stage, a small amount of water is condensed and collected from the gas in each interstage cooler. The directly heated gasifier operates at 300 psia and only requires a single-stage compressor. Any remaining water in the gas exiting the compressor for either system is removed in a knock-out pot. Water collected from the knock-out pot (and from the interstage coolers for the indirectly heated gasifier system) is sent to the steam cycle and electric power generation section of the plant. 
The pressurized gas contains a large amount of methane and other light hydrocarbons that represent a significant fraction of the total carbon and hydrogen in the biomass feed. Therefore, reforming is performed to convert these compounds to $\mathrm{CO}$ and $\mathrm{H}_{2}$. However, the cleaned gas contains approximately 100 ppmv $\mathrm{H}_{2} \mathrm{~S}$ and lesser amounts of other sulfur compounds (COS, $\mathrm{CS}_{2}$, mercaptans) that will poison reforming catalysts. The catalysts are sensitive to poisoning by sulfur and chlorides, reducing activity for the reactions in the steam reforming process. Therefore, a liquid-phase oxidation (Lo-Cat) process followed by a $\mathrm{ZnO}$ polishing bed is used for sulfur removal. The Lo-Cat process, removes the bulk of the sulfur (Spath et al. 2005), and is a liquid oxidation process licensed by Merichem (2008). In this process, $\mathrm{H}_{2} \mathrm{~S}$ is absorbed from a gas stream in a liquid solution and directly oxidized to sulfur in the solution. The gas is heated to $120^{\circ} \mathrm{F}\left(49^{\circ} \mathrm{C}\right)$, and then sent to the Lo-Cat process where $\mathrm{H}_{2} \mathrm{~S}$ is absorbed and converted to elemental sulfur in an iron chelate-based solution (Hiller et al. 2006, Merichem 2008). The Lo-Cat process is assumed to remove the sulfur to a concentration of $10 \mathrm{ppm} \mathrm{H}_{2} \mathrm{~S}$ (Spath et al. 2005). A fixed-bed $\mathrm{ZnO}$ desulfurization unit is used to polish the gas by reducing the sulfur level to less than 1 ppmv (Spath et al. 2005). $\mathrm{H}_{2} \mathrm{~S}$ is captured by the $\mathrm{ZnO}$ sorbent as shown:

$$
\mathrm{ZnO}+\mathrm{H}_{2} \mathrm{~S} \leftrightarrows \mathrm{ZnS}+\mathrm{H}_{2} \mathrm{O}
$$

The $\mathrm{ZnO}$ reactor includes a layer of hydrogenation catalyst, which converts the organic sulfur compounds to $\mathrm{H}_{2} \mathrm{~S}$ and other unsaturated hydrocarbons in the raw gas to saturated hydrocarbons (Hiller et al. 2006). Gas leaving the hydrogenation stage is heated to $707^{\circ} \mathrm{F}\left(375^{\circ} \mathrm{C}\right)$ using heat from the flue gas exiting the reformer furnace. Spent sorbent is disposed of as waste. Both the Lo-Cat system and the ZnO system are modeled with component separators.

\subsection{Steam Reforming and $\mathrm{CO}_{2}$ Removal}

As shown in Figure 3-5, syngas leaving the $\mathrm{ZnO}$ bed is sent to a steam reformer to convert the remaining tar, light hydrocarbons, and most of the methane to $\mathrm{CO}$ and $\mathrm{H}_{2}$. The ratio of $\mathrm{CO}$ and $\mathrm{H}_{2} \mathrm{O}$ is adjusted by the water gas shift reaction, in the presence of the nickel steam reforming catalyst to obtain the target $\mathrm{H}_{2}$ : $\mathrm{CO}$ ratio required by the fuel synthesis step. The main reactions of the steam reforming process can be represented as:

$$
\begin{aligned}
& \mathrm{C}_{\mathrm{n}} \mathrm{H}_{\mathrm{m}}+\mathrm{nH}_{2} \mathrm{O} \leftrightarrows(\mathrm{n}+\mathrm{m} / 2) \mathrm{H}_{2}+\mathrm{nCO} \\
& \mathrm{CO}+\mathrm{H}_{2} \mathrm{O} \leftrightarrows \mathrm{CO}_{2}+\mathrm{H}_{2}
\end{aligned}
$$

Before the gas is sent to the steam reformer, it is mixed with high-temperature steam from the steam system and in some cases, a portion of the $\mathrm{CO}_{2}$ from the amine unit located downstream of the steam reformer may be sent to the reformer to adjust the $\mathrm{H}_{2}: \mathrm{CO}$ ratio. The mixture is sent to the reformer, which consists of tubes filled with nickel catalyst. 


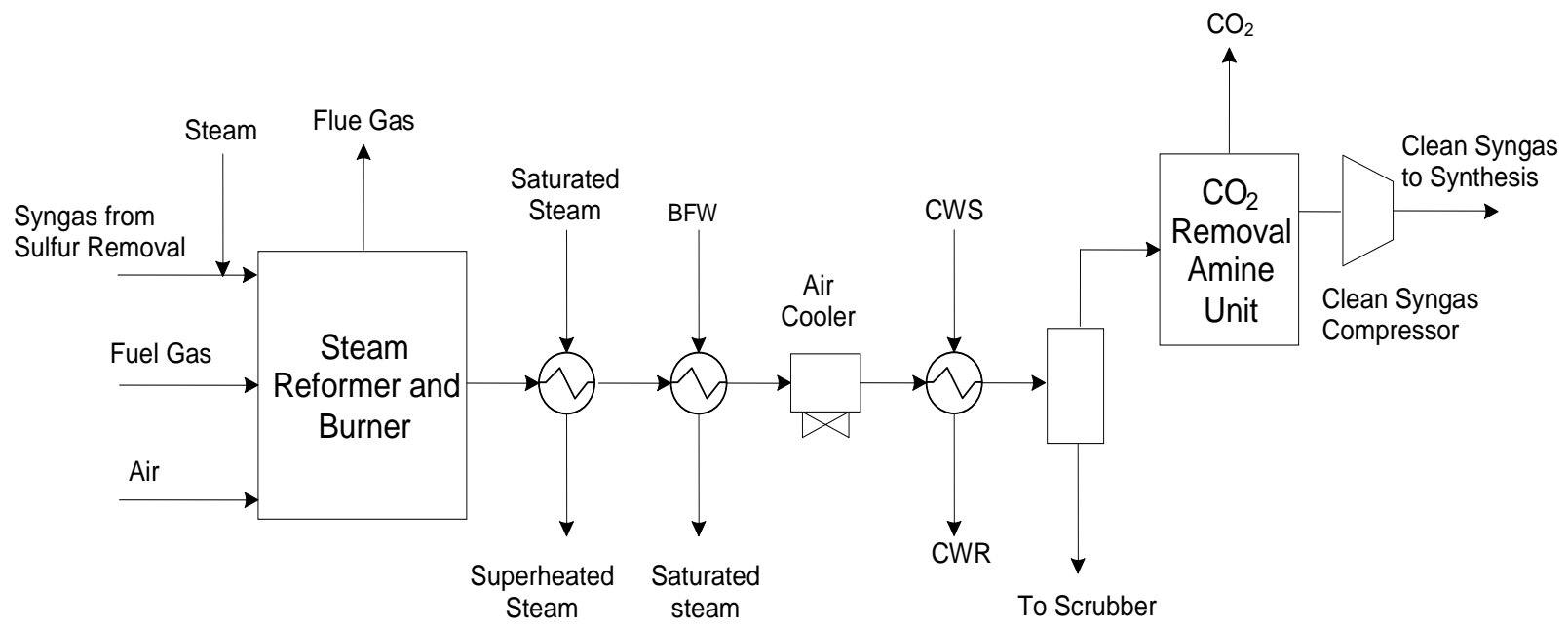

Figure 3-5 Simplified Flow Diagram of Steam Reforming and $\mathrm{CO}_{2}$ Removal

In general, steam reformers operate between 1,472 and $1,652^{\circ} \mathrm{F}\left(800\right.$ and $\left.900^{\circ} \mathrm{C}\right)$ (Häussinger et al. 2000). Higher operating temperatures favor the conversion of $\mathrm{CH}_{4}$, therefore the temperature of $1,652^{\circ} \mathrm{F}$ $\left(900^{\circ} \mathrm{C}\right)$ was used all processes. Conventional steam reformers operate between 200 and 600 psia. Operating pressures are assumed to be between 420 and 430 psia in the models. Even though the water gas shift reactions are exothermic, extra heat is required for the endothermic reforming reactions. The steam reformer is assumed to be a fired tubular reactor with heat supplied by combustion of the off-gas from the fuel synthesis process, supplemented by natural gas when needed (only in the cases of methanol and ethanol via acetic acid production using the directly-heated gasifier).

Heat from the hot flue gas in the reformer convection zone is recovered by providing reformer feed preheat and generating high pressure, superheated steam. The reformed syngas passes through several heat exchangers to recover heat by generating high-pressure steam, heating boiler feed water, or heating process steam. The cooled syngas from the reforming process is cooled further by an air cooler to $150^{\circ} \mathrm{F}$ $\left(66^{\circ} \mathrm{C}\right)$ and then trim cooled to $110^{\circ} \mathrm{F}\left(43^{\circ} \mathrm{C}\right)$ with cooling water. The condensed water from syngas is collected and returned to the scrubbing unit.

The steam reformer was modeled using two Gibbs type reactors in CHEMCAD. The heat duty estimated by the Gibbs reactor for the steam-reforming reactions is matched by the duty in the second Gibbs reactor simulating the burners with a bridgewall temperature of $1,800^{\circ} \mathrm{F}\left(982^{\circ} \mathrm{C}\right)$.

The dry, cool syngas is sent to an amine system to remove $99 \%$ of the $\mathrm{CO}_{2}$. Removing $\mathrm{CO}_{2}$ reduces the volume of syngas, which in turn reduces the downstream equipment sizes and compressor power consumption. In the amine process, $\mathrm{CO}_{2}$ reacts reversibly with the alkaline solvent to form carbonate. A portion of the absorbed $\mathrm{CO}_{2}$ is recovered for use elsewhere in the plant as needed. For example, in the indirectly-heated gasifier based mixed alcohol synthesis system, part of the captured $\mathrm{CO}_{2}$ is compressed and recycled to the reformer to adjust the $\mathrm{H}_{2}$ :CO ratio. For the directly heated gasifier mixed alcohol cases, $\mathrm{CO}_{2}$ is not needed to adjust the $\mathrm{H}_{2}$ : $\mathrm{CO}$ ratio. However, because of the high-pressure gasification operation, some recycle $\mathrm{CO}_{2}$ is compressed and used to pressurize the lock hopper and pneumatically convey and feed the dry wood into the gasifier for all directly heated gasifier cases. 
The treated syngas is sent to a multiple-stage, intercooled compressor and compressed to the target pressure required by the fuel synthesis process. Air intercooling between compressor stages is assumed to be $140^{\circ} \mathrm{F}\left(60^{\circ} \mathrm{C}\right)$.

\subsection{Steam Cycle and Power Generation}

The electricity is assumed to be generated by superheated steam expansion in an extraction steam turbine. High-pressure steam is recovered from the gas-cooling sections of the gasifier and steam reformer. Medium-pressure steam is generated by heat recovery of synthesis reaction or hot product streams cooling. The main differences in the steam systems for the indirectly heated and directly heated gasifier systems are the sources of high-pressure steam, and the disposition of medium- and low-pressure steam.

High-pressure saturated steam generated by heat recovery in the gasifier and steam reformer sections (and by a separate boiler in cases with surplus offgas) is superheated and sent to a high-pressure steam turbine to produce electricity. Medium-pressure steam leaving the high-pressure steam turbine is combined with medium-pressure steam recovered from the alcohol-synthesis reactor and passed through a second medium-pressure steam turbine to produce electricity. Medium-pressure steam is extracted from the turbine and sent to the steam reformer or other processes. Low-pressure steam leaving the mediumpressure steam turbine is extracted to provide heat for some of the distillation columns. Medium-pressure steam is used in the directly heated gasifier, while the indirectly heated gasifier uses low-pressure steam. Steam leaving the lowest pressure turbine stage is condensed and returned to the deaerator along with process heater condensate.

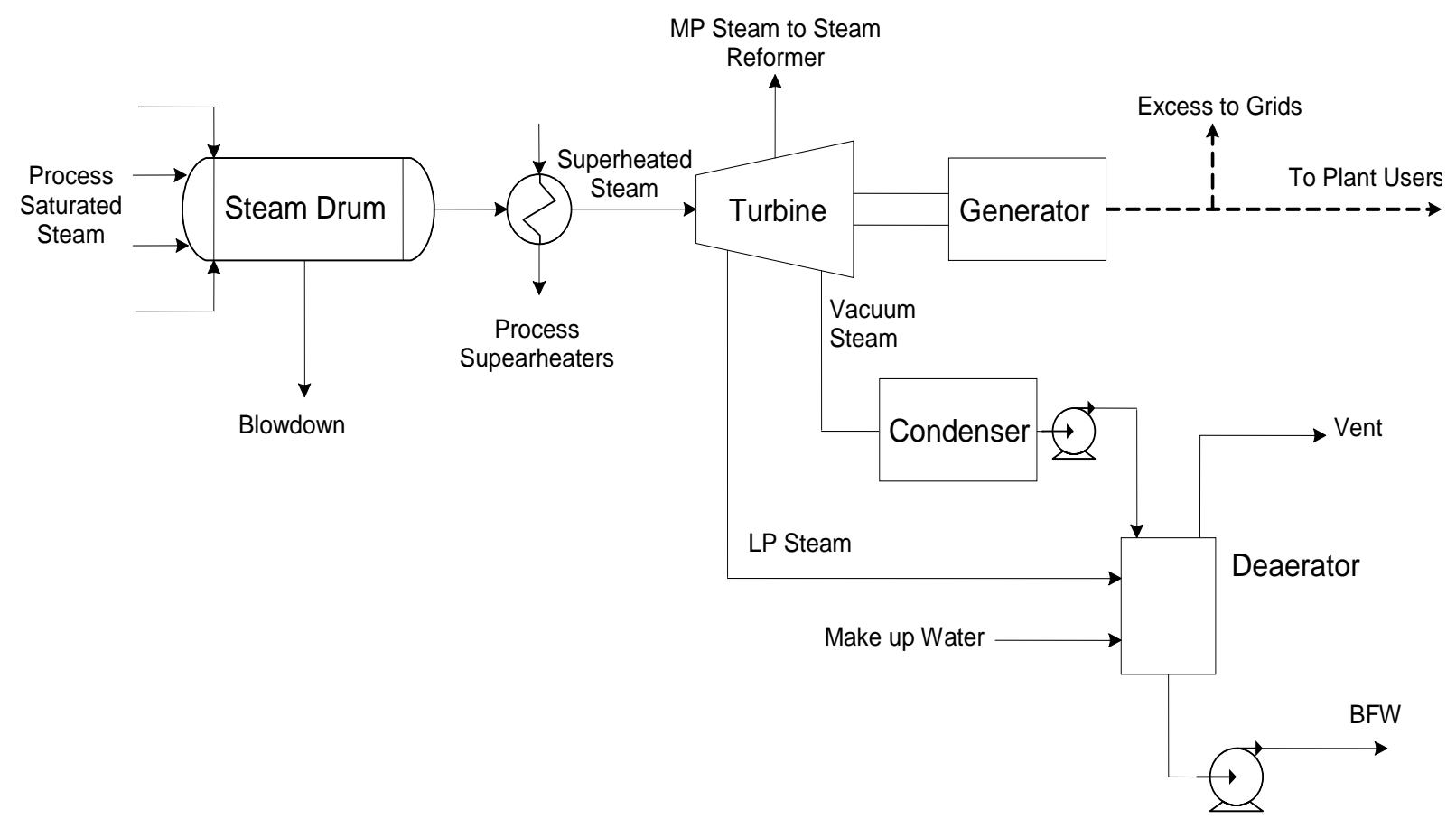

Figure 3-6 Simplified Flow Diagram of Steam Cycle and Power Generation 


\subsection{Fischer-Tropsch Diesel}

Fischer-Tropsch (FT) synthesis is a process for building liquid hydrocarbons from synthesis gas (carbon monoxide and hydrogen) using metal catalysts. It was invented by Professor Franz Fischer and Dr. Hans Tropsch in 1925 and was initially used in Germany, during the Second World War (Stranges 2003). It has since found wide use in South Africa, where the Arab oil embargos of 1973 were not lifted until 1993 and Iranian exports ceased from 1979 until 1994 (Lowenberg and Kaempfer 1998). Interest in FT synthesis is usually associated with oil boycotts or the need to convert remote natural gas reserves into transportable liquids (Hamelinck et al. 2003).

The synthesis gas feed may be obtained by reforming natural gas or by gasifying solid feedstocks such as coal, petroleum coke, or biomass. Sasol, in South Africa, has used coal to generate FT products (also referred to as coal-to-liquids, or CTL) on a commercial scale of approximately 150,000 bpd ("Sasol II" and "Sasol III") (van de Venter 2007). Mossgas, a state-owned South African FT plant on the order of $45,000 \mathrm{bpd}$ has been commercialized for synthesis gas generation from natural gas (also referred to as gas-to-liquids, or GTL) (van de Venter 2007). A 12,500 bpd GTL FT plant is operated by Shell, in Malaysia and a 34,000 bpd plant Sasol venture with Qatar Petroleum has operated since 2006. Additional, larger GTL plants are under construction in the Middle East by Sasol-Chevron and by Shell. Chevron is also building a 34,000 bpd GTL plant in Nigeria. Interest in CTL is increasing in many parts of the world, including the US and China (Shell 2009).

FT synthesis is typically described as a polymerization process resulting in a distribution of carbon chain lengths across a range from methane to waxes. There are three main types of FT reactors: fluidized bed, fixed bed, and slurry phase reactors. Differences between the different reactors and their associated benefits and drawbacks, as they apply to biomass synthesis gas conversion are reported in literature (Tijmensen et al. 2002, Bartholomew 1990, Sie and Krishna 1999). All three reactors have been used commercially (Hamelinck et al. 2003).

Catalyst formulations using iron or cobalt are typically employed to activate FT synthesis. Iron formulations have been developed to operate at high temperature $\left(\sim 650^{\circ} \mathrm{F}\left(340^{\circ} \mathrm{C}\right)\right)$ as well as low temperature $\left(\sim 450^{\circ} \mathrm{F}\left(230^{\circ} \mathrm{C}\right)\right)$ in order to target different products. Higher temperatures are used to obtain olefins and oxygenates; useful components for chemicals. Lower temperatures yield the mostly linear saturated hydrocarbons extending through the wax phase. Cobalt formulations have higher selectivity and operate at lower temperatures $\left(\sim 450^{\circ} \mathrm{F}\left(230^{\circ} \mathrm{C}\right)\right)$, but have greater susceptibility to poisoning. Cobalt catalysts produce much fewer olefins and oxygenates than iron catalysts.

This section evaluates FT synthesis via gasification of biomass, as described in Section 3. Both the indirectly-heated and directly-heated gasification scenarios are presented, for comparison. The following subsections provide a description of the overall process design, and describe the main performance and cost simulation results for the biomass to-diesel via FT synthesis.

\subsection{Process Design Description}

A simplified block diagram of the biomass to FT liquids process is given in Figure 4-1. The processing steps include: 
- Feed handling and preparation

- Gasification (and air separation, in the directly-heated gasifier cased)

- Tar reforming and scrubbing

- Syngas cleanup and steam reforming

- FT synthesis and product purification

- $\quad$ Steam cycle and power generation

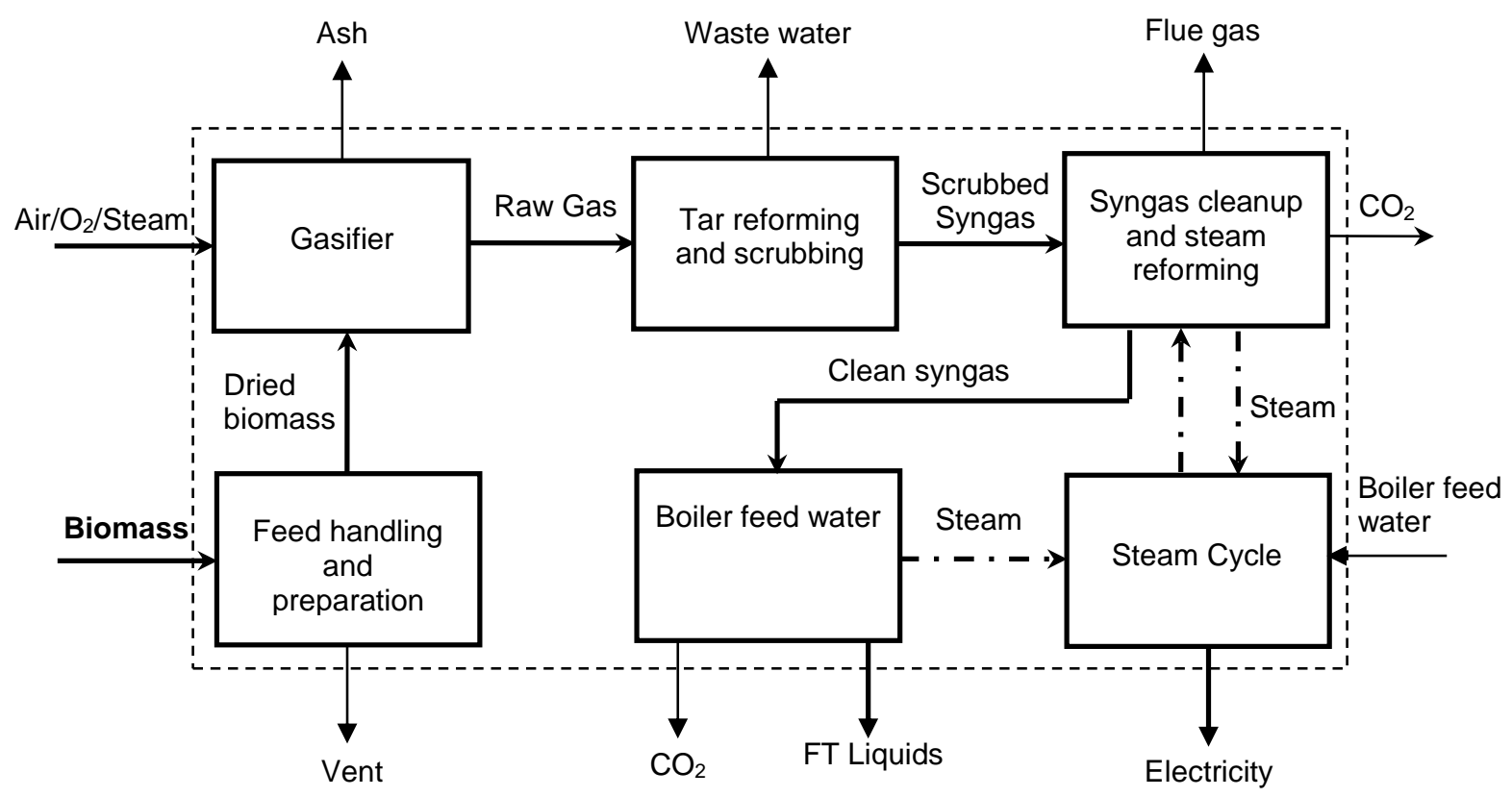

Figure 4-1 Biomass-to-FT Liquids Block Diagram

As described in Section 3, as-received biomass is dried and gasified and the syngas is conditioned prior to steam reforming, as shown in Figure 4-1. Adequate levels of tar and steam methane reforming (where some water gas shift also occurs) yields synthesis gas with excess $\mathrm{H}_{2}$ for hydrocracking and hydrotreating operations downstream from the FT synthesis reactor. Filtered, scrubbed, and reformed synthesis gas is passed through a membrane filter to adjust the $\mathrm{H}_{2}$ to $\mathrm{CO}$ ratio before it is sent to the FT reactor. Light, medium, and heavy FT products are separated for use as fuel gas, hydrotreating, and hydrocracking operations, respectively. Hydrotreated and hydrocracked products are separated to yield additional fuel gas, a naphtha fraction, a diesel fraction, and heavier distillates that are recycled back to the hydrocracker.

Moderate pressure (220 psia) steam is raised by the exothermic FT reactor. Additional moderate pressure, high pressure (850 psia) steam, and superheated steam are raised using hot reformer and burner offgas streams. Generated steam is used to heat process streams, fluidize the gasifier bed, and to feed gasification and reformer/water gas shift reactions. Superheated steam is used to generate power.

The feed handling and preparation, gasifiers (indirectly- and directly-heated), tar reformer, synthesis gas scrubbing, and sulfur removal operations used in this study are described above, in Sections 3.1-3.4. The following subsections give details for downstream operations specific to the FT liquids production models. 


\subsubsection{Steam Reforming and Hydrogen Membrane}

Tar-free synthesis gas that has been scrubbed and cleared of sulfur is combined with steam to reform $\mathrm{CH}_{4}$ and other small hydrocarbons, over a catalyst, into $\mathrm{CO}$ and $\mathrm{H}_{2}$. The details of a generic steam reforming process have been described in Section 3.

Operating temperatures for steam methane reformers are reported to be between 1,472 and $1,652^{\circ} \mathrm{F}(800$ to $900^{\circ} \mathrm{C}$ ) (Häussinger et al. 2000). Higher operating temperatures favor conversion of $\mathrm{CH}_{4}$, therefore an end of run temperature of $1,652^{\circ} \mathrm{F}\left(900^{\circ} \mathrm{C}\right)$ is used in this study. Conventional steam reformers operate between 200 and 600 psia. Operating pressures between 420 and 430 psia were used in this study, due to maximum operating pressures of approximately 400 psia for the downstream hydrogen membrane (Jack 2009).

The ratio of $\mathrm{H}_{2}$ to $\mathrm{CO}$ required for FT synthesis, according to Equation 4-1, is approximately 2.1 to 1 . Iron based FT catalysts are also active for shift and can thus operate at the lower ratio. Cobalt based FT catalyst operate at ratios at or above 2. Since a cobalt type FT catalyst is assumed, a $\mathrm{H}_{2}$ to $\mathrm{CO}$ ratio just over 2.1 is targeted so that $\mathrm{H}_{2}$, in excess of that required by the FT synthesis reactor, may be recovered for hydrocracking and hydrotreating. Steam required for this shift is extracted from the steam cycle, at 450 psia. The excess hydrogen is recovered using a hydrogen transport membrane and compressed for use during hydrotreating, as described in Section 4.1.3. Hot, reformed, and shifted synthesis gas is passed through heat exchangers to raise high pressure, saturated steam as well as high pressure superheated steam. Additional cooling is required to meet amine system inlet temperatures of approximately $120^{\circ} \mathrm{F}$. This is done using an air fin cooler and cooling water. Water in the synthesis gas stream is condensed out and $90 \%$ of the $\mathrm{CO}_{2}$ is removed to minimize the presence of inert components during FT synthesis.

\subsubsection{Fischer-Tropsch (FT) Synthesis}

The FT synthesis step involves competing chemical reactions that lead to a suite of desirable and undesirable products. A generalized equation describing FT synthesis is given in Equation 4-1.

$$
(2 \mathrm{n}+1) \mathrm{H}_{2}+\mathrm{nCO} \leftrightarrow \mathrm{C}_{\mathrm{n}} \mathrm{H}_{(2 \mathrm{n}+2)}+\mathrm{nH}_{2} \mathrm{O}
$$

The chains comprise linear paraffins and olefins, a natural fit for compression ignition engines. Thus product distribution targets are often set by tuning catalyst compositions and operating conditions to maximize the yield of liquids and waxes. The waxes can be hydrocracked to yield hydrocarbons in the diesel range. The distribution of products may be described using the Anderson-Schulz-Flory (ASF) distribution, as shown in Equation 4.2,

$$
C_{n}=\alpha^{n-1}(1-\alpha)
$$

where $n$ is the length of the hydrocarbon, $C$ is the molar yield of a given carbon number $(n), \alpha$ is the probability of chain growth, and $(1-\alpha)$ is the probability of chain growth termination. The yield of $\mathrm{C}_{1}-\mathrm{C}_{4}$ decreases with increasing selectivity for liquid yields, and $\mathrm{C}_{1}-\mathrm{C}_{4}$ in the synthesis offgas is used as fuel gas. The FT catalyst is assumed to be cobalt, and produces predominately straight-chained saturated 
hydrocarbons. Catalyst poison tolerance is low and requires synthesis gas that is free from sulfur and nitrogen compounds, resulting in sulfur and nitrogen free fuel.

A process flow diagram for the FT synthesis area is shown in Figure 4-2. The clean syngas (S461) from the steam reforming process is sent to a hydrogen membrane process (M-470). A small stream of hydrogen (S470) is separated from the clean syngas and will be used in hydrotreating and hydrocracking process. The remaining syngas is heated by the effluent from the FT reactor and then sent to the reactor (R-500). The FT reactor is assumed to be a tubular fixed bed reactor with cobalt catalyst in the tubes. Synthesis gas is assumed to make a once through pass through the FT reactor, with a CO conversion efficiency of $70 \%$ (SRI International 2006, Tijmensen et al. 2002). The reactor has an outlet temperature of approximately $465^{\circ} \mathrm{F}\left(241^{\circ} \mathrm{C}\right)$ and operates at approximately 450 psia. The FT synthesis reaction temperature is controlled by heating medium pressure (MP) boiler feed water (BFW) at 220 psia (S785) and generating MP steam (S1958) for processes use and power generation. The FT effluents are first cooled by the feed stream and then cooled to $120^{\circ} \mathrm{F}$ by air. Trim cooling water is used to remove $\mathrm{C}_{1}-\mathrm{C}_{4}$ compounds that are used as fuel gas. The cooled raw product (S520) is sent to a high pressure (HP) flash tank (V-511) to separate condensate from the gaseous stream. The gas product from the flash tank is further cooled to $40^{\circ} \mathrm{F}\left(4^{\circ} \mathrm{C}\right)$ by a chiller. The chilled product flow is sent to a medium pressure (MP) flash tank (V-513). The condensate is combined with the liquid phase from HP flash tank and sent to a low pressure (LP) flash tank (V-530). The product steam is separated to three phases: gas, water, and waxy oil. The gaseous stream (S532) from this flash tank is combined with the gases from the MP flash tank and used as fuel gas for process use. The water stream (S531) from the LP tank is sent to wastewater treatment. The crude oil stream (S534) is heated by medium pressure steam to $250^{\circ} \mathrm{F}\left(121^{\circ} \mathrm{C}\right)$, which is sent to the primary distillation column in the hydrotreating and hydrocracking process.

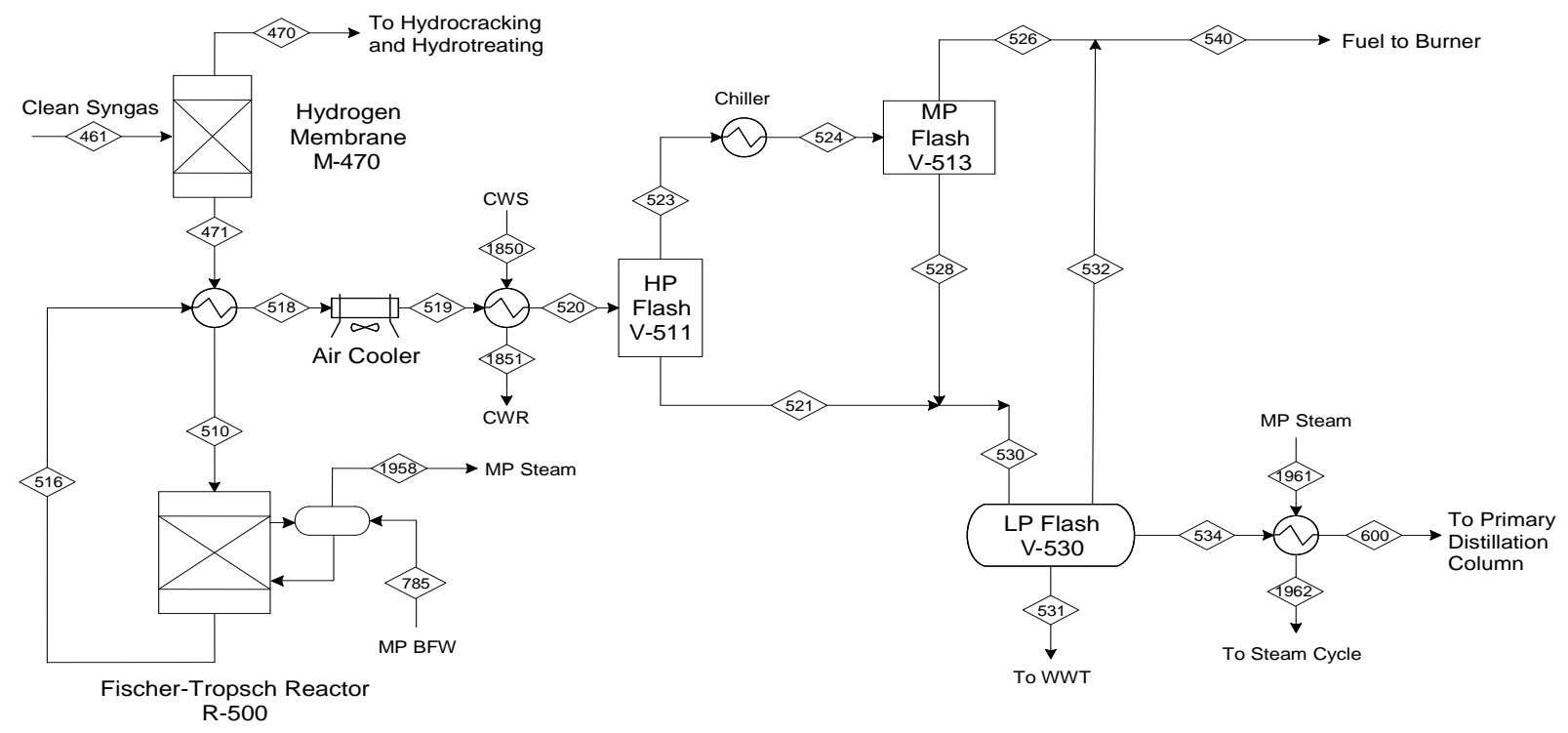

Figure 4-2 Process Flow Diagram for FT synthesis 
For ease of modeling the complex synthesis reactions, all hydrocarbon synthesis products are assumed to be saturated, linear hydrocarbons ranging from $\mathrm{C}_{1}-\mathrm{C}_{36}$, with some production of $\mathrm{CO}_{2}$ and $\mathrm{H}_{2} \mathrm{O}$. This also facilitates $\mathrm{H}_{2}$ accounting. The excess $\mathrm{H}_{2}$ stream, from the hydrogen membrane, is used to remove "virtual" double bonds and catalytically crack the FT wax product to diesel range fuel.

\subsubsection{Hydrocracking and Hydrotreating}

Once the FT products have been cooled and condensed, they are separated into light (initial boiling point of $\left.50^{\circ} \mathrm{F}\left(10^{\circ} \mathrm{C}\right), 14.5 \mathrm{psia}\right)$, medium (initial boiling at $\left.99^{\circ} \mathrm{F}\left(37^{\circ} \mathrm{C}\right), 14.5 \mathrm{psia}\right)$, and heavy (liquid at $740^{\circ} \mathrm{F}$ $\left.\left(393^{\circ} \mathrm{C}\right), 14.5 \mathrm{psia}\right)$ fractions, that are sent to the fuel gas system, the hydrotreater, and the hydrocracker, respectively. A process flow diagram, for the hydrotreating, hydrocracking, and product separation area is given in Figure 4-3.

As noted above, in Section 4.1.2, the targeted FT products are $\mathrm{C}_{5+}$. These products are mostly linear paraffins and some olefins, with potential for a small amount of oxygenate formation. Oxygenates, olefins and long chain paraffins $\left(\mathrm{C}_{19+}\right)$ must be further treated to meet diesel product specifications. The hydrotreater converts any oxygenates present to olefins and then saturates them into paraffins. The hydrocracker cracks $\mathrm{C}_{19+}$ hydrocarbons into $\mathrm{C}_{2}-\mathrm{C}_{19}$ saturated hydrocarbons.

The hydrocracker (R-610) operates at 1015 psia, with an outlet temperature of approximately $750^{\circ} \mathrm{F}$ $\left(399^{\circ} \mathrm{C}\right)$, The hydrotreater $(\mathrm{R}-615)$ operates at $990 \mathrm{psia}$, with a reactor outlet temperature of $485^{\circ} \mathrm{F}$ $\left(252^{\circ} \mathrm{C}\right)$, (SRI 2006). Hydrocracked and hydrotreated FT products are combined (S617) and cooled by raising high pressure saturated steam and are further cooled by an air fin cooler and cooling water. Noncondensable components are recovered for use as fuel gas. Condensed components are further separated using distillation columns, as described below.

\subsubsection{Product Separation and Purification}

A small $\mathrm{C}_{3} / \mathrm{C}_{4}$ fraction is formed during hydrocracking and hydrotreating, which remains with the condensed products. This is removed in an initial column, referred to as the debutanizer, and sent to the fuel gas system. A second column is used to recover the naphtha fraction of the FT products. Finally, the middle distillates (diesel fraction) are recovered. The bottoms from this column are recycled to the hydrocracker for reprocessing.

\subsubsection{Steam Cycle and Power Generation}

As noted above, in Section 4.1, moderate pressure (220 psia) steam is raised by the exothermic FT reactor. Additional moderate pressure, high pressure ( $850 \mathrm{psia})$ steam, and superheated steam are raised using hot reformer and burner offgas streams. The saturated steam is used to heat process streams, fluidize the gasifier bed, and to feed gasification and reformer/water gas shift reactions. Superheated steam is sent to a turbine to generate power. In the indirectly-heated gasification case, fuel gas left over after firing the steam reformer and column reboilers is used to fire a steam boiler and raise additional high pressure, superheated steam. 


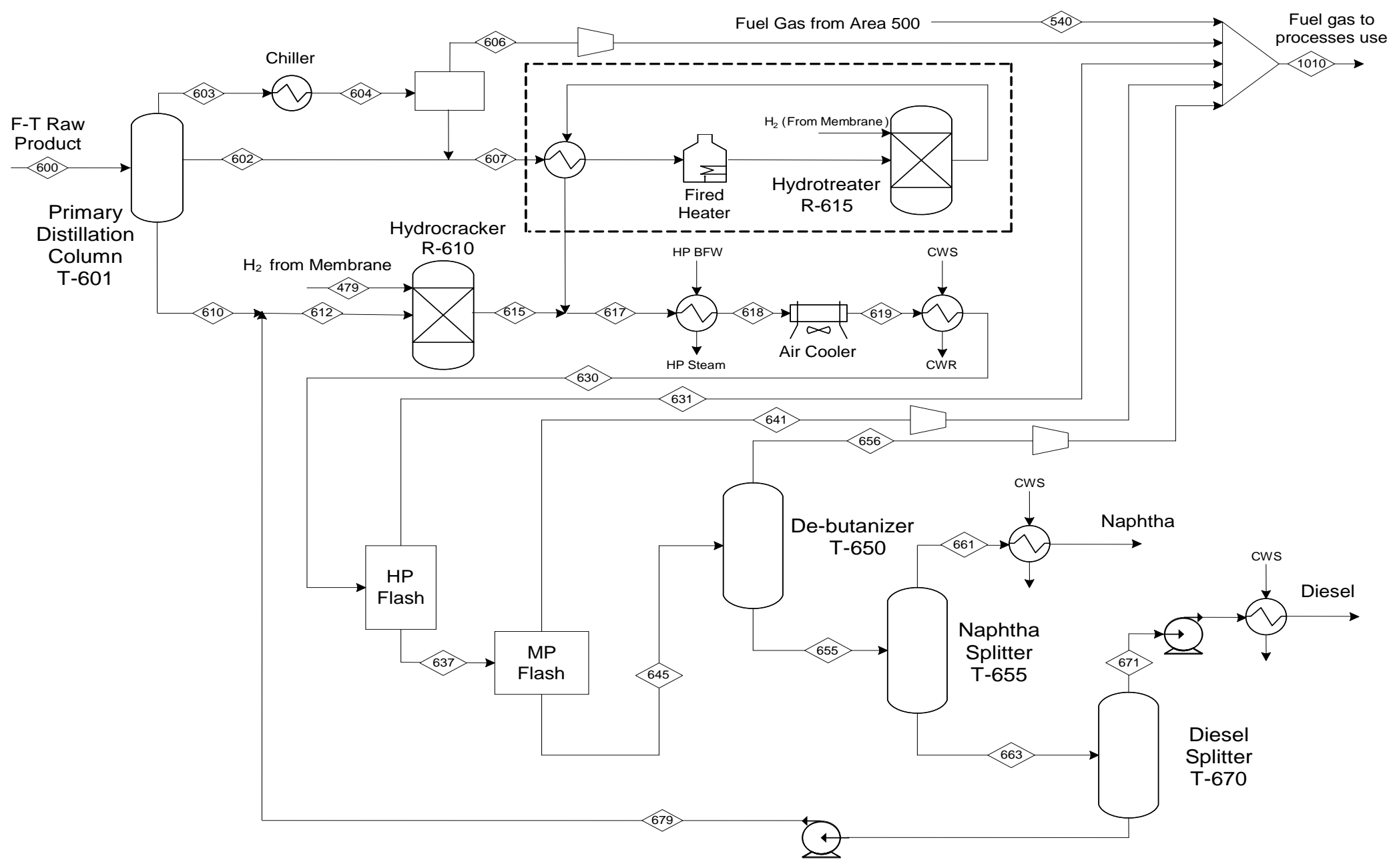

Figure 4-3 Process Flow Diagram for Hydrocracking, Hydrotreating, and Product Separation 


\subsection{Key System Assumptions}

Major system assumptions and operating conditions, for both the indirectly-heated gasification case and the directly-heated gasification case are given in Table 4-1.

Table 4-1 Major System Assumptions for Biomass-to-Diesel via Fischer-Tropsch

\begin{tabular}{|c|c|c|}
\hline \multicolumn{3}{|c|}{ Gasification } \\
\hline Gasifier type & Indirectly-Heated Gasifier & Directly-Heated Gasifier \\
\hline Gasifier pressure, psia & 23 & 330 \\
\hline Gasifier temperature, ${ }^{\circ} \mathrm{C}\left({ }^{\circ} \mathrm{F}\right)$ & $870(1598)$ & $871(1600)$ \\
\hline Biomass feed, metric ton/d, dry basis & 2000 & 2000 \\
\hline Oxidant & Air & Oxygen \\
\hline Moisture fraction of dried biomass, wt $\%$ & 12 & 12 \\
\hline \multicolumn{3}{|c|}{ Tar Cracking } \\
\hline Reactor outlet temperature, ${ }^{\circ} \mathrm{C}\left({ }^{\circ} \mathrm{F}\right)$ & $717(1323)$ & $717(1323)$ \\
\hline Reactor outlet pressure, psia & 20 & 327 \\
\hline Space velocity, $\mathrm{hr}^{-1}$ & 2,476 & 2,476 \\
\hline \multicolumn{3}{|c|}{ Steam Reforming } \\
\hline Reformer outlet temperature, ${ }^{\circ} \mathrm{C}\left({ }^{\circ} \mathrm{F}\right)$ & $900(1652)$ & $900(1652)$ \\
\hline Reformer outlet pressure, psia & 423 & 430 \\
\hline Space velocity, $\mathrm{hr}^{-1}$ & 2,627 & 2,627 \\
\hline Reformed gas $\mathrm{H}_{2} / \mathrm{CO}$ & 2.1 & 2.1 \\
\hline \multicolumn{3}{|c|}{ Fischer-Tropsch Process } \\
\hline Reactor outlet temperature, ${ }^{\circ} \mathrm{C}\left({ }^{\circ} \mathrm{F}\right)$ & $240(464)$ & $240(464)$ \\
\hline Reactor outlet pressure, psia & 447 & 447 \\
\hline CO conversion efficiency, $\%$ & 70 & 70 \\
\hline Space velocity, $\mathrm{hr}^{-1}$ & 1000 & 1000 \\
\hline \multicolumn{3}{|c|}{ Hydrocracking } \\
\hline Reactor outlet temperature, ${ }^{\circ} \mathrm{C}\left({ }^{\circ} \mathrm{F}\right)$ & $400(752)$ & $400(752)$ \\
\hline Reactor outlet pressure, psia & 1015 & 1015 \\
\hline Space velocity, $\mathrm{hr}^{-1}$ & 1 & 1 \\
\hline \multicolumn{3}{|c|}{ Hydrotreating } \\
\hline Reactor outlet temperature, ${ }^{\circ} \mathrm{C}\left({ }^{\circ} \mathrm{F}\right)$ & $252(485)$ & $252(485)$ \\
\hline Reactor outlet pressure, psia & 990 & 990 \\
\hline Space velocity, $\mathrm{hr}^{-1}$ & 2.5 & 2.5 \\
\hline \multicolumn{3}{|c|}{ Steam Cycle } \\
\hline Boiler feed water condition, ${ }^{\circ} \mathrm{C}\left({ }^{\circ} \mathrm{F}\right) / \mathrm{psia}$ & $113(235) / 870$ & $113(235) / 870$ \\
\hline Superheated steam condition, ${ }^{\circ} \mathrm{C}\left({ }^{\circ} \mathrm{F}\right) / \mathrm{psia}$ & $432(900) / 850$ & $482(900) / 850$ \\
\hline
\end{tabular}




\subsection{Results and Analysis}

The performance results for the indirectly-heated and the directly-heated gasification model are shown in Table 4-2. Economic analysis results are given in Table 4-3.

\subsubsection{Performance Results}

Table 4-2 Performance Results for Biomass-to-FT Diesel System

\begin{tabular}{|c|c|c|c|}
\hline \multicolumn{2}{|l|}{ Case } & Indirectly-heated gasifier & Directly-heated gasifier \\
\hline \multicolumn{4}{|l|}{ Feed } \\
\hline \multicolumn{2}{|c|}{ Dry wood chips, tpd (mtpd) } & $2200(2000)$ & $2200(2000)$ \\
\hline \multicolumn{2}{|c|}{ Natural gas, scf/hr } & - & - \\
\hline \multicolumn{4}{|c|}{ Products } \\
\hline \multicolumn{2}{|c|}{ Diesel, mmgal/y } & 24 & 28 \\
\hline \multicolumn{4}{|l|}{ By-products } \\
\hline \multicolumn{2}{|c|}{ Naphtha, mmgal/y } & 8 & 9 \\
\hline \multicolumn{4}{|c|}{ Power consumption, MW } \\
\hline \multicolumn{2}{|c|}{ Air separation unit } & - & 8.6 \\
\hline \multicolumn{2}{|c|}{ Lock hopper gas compressor } & - & 0.2 \\
\hline \multicolumn{2}{|c|}{ Dryer air blower } & - & 0.1 \\
\hline \multicolumn{2}{|c|}{ Char burner air compressor } & 4.7 & 0.9 \\
\hline \multicolumn{2}{|c|}{ Syngas compressor } & 16.2 & 1.9 \\
\hline \multicolumn{2}{|c|}{ Reformer air compressor } & 1.1 & 2.7 \\
\hline \multicolumn{2}{|c|}{ Reformer flue gas blower } & 0.7 & 1.0 \\
\hline \multicolumn{2}{|c|}{ Clean syngas compressor } & 0.3 & 0.5 \\
\hline \multicolumn{2}{|c|}{ Hydrogen compressor } & 0.1 & 0.1 \\
\hline \multicolumn{2}{|c|}{ Fuel gas compressors } & 0.1 & 0.01 \\
\hline \multicolumn{2}{|c|}{ Boiler air \& flue gas blower } & 0.9 & 0.1 \\
\hline \multicolumn{2}{|c|}{ Steam turbine auxiliaries } & 0.5 & 0.6 \\
\hline \multicolumn{4}{|c|}{ Power generation, MW } \\
\hline \multicolumn{2}{|c|}{ Steam turbines } & 46.8 & 41.2 \\
\hline \multicolumn{2}{|l|}{ Net power, MW } & 22.2 & 24.5 \\
\hline \multicolumn{4}{|c|}{ Water demand, gpm } \\
\hline \multicolumn{2}{|c|}{ Cooling tower makeup } & 490 & 677 \\
\hline \multicolumn{2}{|c|}{ Total water demand } & 901 & 1167 \\
\hline Wastewater, gp & & 536 & 540 \\
\hline Carbon balance & & & \\
\hline Feeds & Biomass & $100 \%$ & $100 \%$ \\
\hline & Natural Gas & $0 \%$ & $0 \%$ \\
\hline & Sum & $100 \%$ & $100 \%$ \\
\hline Fuel products & Diesel & $17.9 \%$ & $20.2 \%$ \\
\hline & Naphtha & $5.2 \%$ & $6.1 \%$ \\
\hline & Sum & $23.1 \%$ & $26.3 \%$ \\
\hline Wastes & Dryer exhaust & $30.4 \%$ & $11.0 \%$ \\
\hline & Flue gas & $20.5 \%$ & $17.9 \%$ \\
\hline & $\mathrm{CO}_{2}$ & $25.8 \%$ & $44.3 \%$ \\
\hline & Wastewater & $0.2 \%$ & $0.5 \%$ \\
\hline & Sum & $76.9 \%$ & $73.7 \%$ \\
\hline Thermal efficie & $\mathbf{y}, \%$ LHV basis & $39.8 \%$ & $45.6 \%$ \\
\hline
\end{tabular}


The indirectly-heated gasification case yields approximately $24 \mathrm{mmgal} / \mathrm{yr}$ diesel and $8 \mathrm{mmgal} / \mathrm{yr}$ naphtha products. The yield of the directly-heated gasification case is approximately $28 \mathrm{mmgal} / \mathrm{yr}$ diesel and 9 $\mathrm{mmgal} / \mathrm{yr}$ naphtha. Power consumption, by the indirectly-heated gasification and directly-heated gasification cases is 24.6 and $16.7 \mathrm{MW}$, respectively. The greater power consumption, in the indirectlyheated gasification case is due to synthesis gas compression needs. This is because the gasifier is operated at atmospheric pressure. Thus, even though the directly-heated gasification case generates less power (41.2 MW, versus 46.8 MW for the indirectly-heated gasification case), the net power output is greater for the directly-heated gasification case. The total water demand is greater for the directly-heated gasification case, at a rate of $540 \mathrm{gpm}$. The thermal efficiencies, based on higher heating values, are $39.7 \%$ and $45.5 \%$ for the indirectly-heated and directly-heated gasification cases, respectively.

\subsubsection{Cost Results}

Table 4-3 Cost Results for Biomass-to-FT Diesel System

\begin{tabular}{|c|c|c|c|c|}
\hline Case & \multicolumn{2}{|c|}{ Indirectly-heated gasifier } & \multicolumn{2}{|c|}{ Directly-heated gasifier } \\
\hline Capital costs & $\mathrm{mm} \$$ & $\%$ of total & $\mathrm{mm} \$$ & $\%$ of tota \\
\hline Air separation unit & -- & -- & 10.3 & $7 \%$ \\
\hline Feed prep and drying & 11.2 & $11 \%$ & 12.3 & $9 \%$ \\
\hline Gasification with tar reforming and heat & & & & \\
\hline recovery & 15.2 & $15 \%$ & 39.5 & $27 \%$ \\
\hline Syngas cleanup and steam reforming & 26.3 & $26 \%$ & 29.3 & $20 \%$ \\
\hline Fischer-Tropsch Synthesis & 16.3 & $16 \%$ & 18.0 & $12 \%$ \\
\hline Hydrocracking and Product Separation & 19.9 & $20 \%$ & 21.6 & $15 \%$ \\
\hline Steam system and power generation & 10.7 & $11 \%$ & 10.8 & $7 \%$ \\
\hline Remainder off-site battery limits (OSBL) & 2.1 & $2 \%$ & 2.3 & $2 \%$ \\
\hline $\begin{array}{l}\text { Total Purchased Equipment Cost (TPEC), } \\
\text { mm\$ }\end{array}$ & 102 & $100 \%$ & 144 & $100 \%$ \\
\hline Total Installed Cost (TIC), mm\$ & \multicolumn{2}{|c|}{251} & \multicolumn{2}{|c|}{355} \\
\hline Total Indirect Cost, mm\$ & \multicolumn{2}{|c|}{128} & \multicolumn{2}{|c|}{181} \\
\hline Total Project Investment, mm\$ & \multicolumn{2}{|c|}{379} & \multicolumn{2}{|c|}{537} \\
\hline Operating costs & \$/gal product & $\%$ of total & \$/gal product & $\%$ of total \\
\hline Biomass & 1.78 & $42 \%$ & 1.56 & $32 \%$ \\
\hline Natural gas & 0.00 & $0 \%$ & 0.00 & $0 \%$ \\
\hline Catalysts \& chemicals & 0.17 & $4 \%$ & 0.21 & $4 \%$ \\
\hline Waste disposal & 0.07 & $2 \%$ & 0.06 & $1 \%$ \\
\hline $\begin{array}{l}\text { Utilities (cooling water, boiler water, } \\
\text { electricity) }\end{array}$ & -0.43 & $-10 \%$ & -0.41 & $-9 \%$ \\
\hline Co-product credits & -0.78 & $-18 \%$ & -0.81 & $-17 \%$ \\
\hline Fixed Costs & 0.82 & $19 \%$ & 0.94 & $19 \%$ \\
\hline Capital Depreciation & 0.78 & $18 \%$ & 0.96 & $20 \%$ \\
\hline Average Income Tax & 0.55 & $13 \%$ & 0.66 & $14 \%$ \\
\hline Average Return on Investment & 1.34 & $31 \%$ & 1.67 & $34 \%$ \\
\hline MFSP, \$/gal & \multicolumn{2}{|c|}{4.29} & \multicolumn{2}{|c|}{4.85} \\
\hline MFSP ethanol equivalent LHV basis, $\$ / \mathrm{gal}$ & \multicolumn{2}{|c|}{2.81} & \multicolumn{2}{|c|}{3.17} \\
\hline
\end{tabular}


The cost analysis results for the biomass-to-FT diesel systems based on both of the indirectly-heated and directly-heated gasifiers are listed in Table 4-3. Greater efficiency, rates of naphtha, diesel, and power production indicate that the directly-heated gasifier case may be preferred over the indirectly-heated gasifier case. However, the directly-heated gasifier case also requires more water input and significantly more capital. The total purchased equipment cost, for the directly-heated gasification case, is nearly $41 \%$ higher than that for indirectly-heated gasification.

The improved performance of the directly-heated gasification case is due to pressurized operation of the directly-heated gasifier, which reduces the synthesis gas compression requirements downstream. The higher capital costs are mostly associated with the air separation unit and the directly-heated gasification reactor, itself.

Operating credits from the sale of excess electricity and co-product naphtha are essentially the same for both gasifer cases. The minimum fuel selling price for directly-heated gasification to FT diesel is $\$ 0.56$ higher than selling price for indirectly-heated gasification.

\subsubsection{Sensitivity Analysis}

The sensitivity of the minimum fuel selling price (MFSP) to different Internal Rates of Return (IRR) and feedstock prices is shown in Figures 4-5 and 4-6 for the indirectly-heated and directly-heated gasifier based FT systems. The MSFP was calculated for IRRs of 10\%, 15\%, and 20\%, with feedstock cost of $\$ 30, \$ 60, \$ 80$, and $\$ 100$ per dry ton. The 2008 average diesel price, $\$ 3.13 /$ gal, is also shown in the graphs for comparison (retail sales by refiners data for No. 2 diesel, Energy Information Administration 2009b).

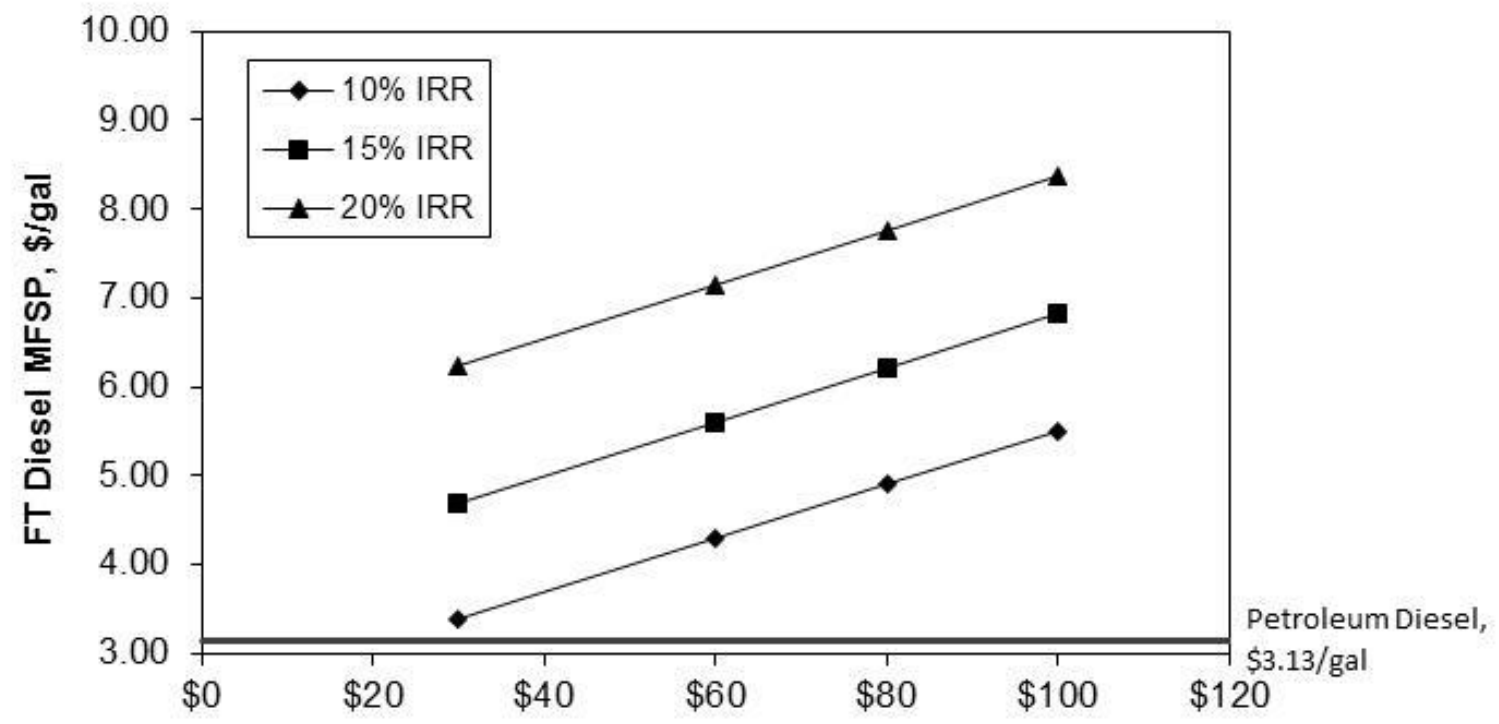

Feedstock Price, \$/dry ton

Figure 4-4 Effects of Feedstock Cost and IRR on FT Diesel MFSP (Indirectly-Heated Gasifier) 
For both gasification cases, with the increase in IRR, the increases in MFSP become bigger, which means the impacts of IRR on the production cost become greater. The directly-heated gasification case is slightly more affected by increased IRR on investment than the indirectly-heated gasification case. The relationship between feedstock cost and minimum fuel selling price is linear, for both gasification cases. An increase in feedstock cost has slightly more impact on the indirectly-heated gasification case economics than on the directly-heated gasification case.

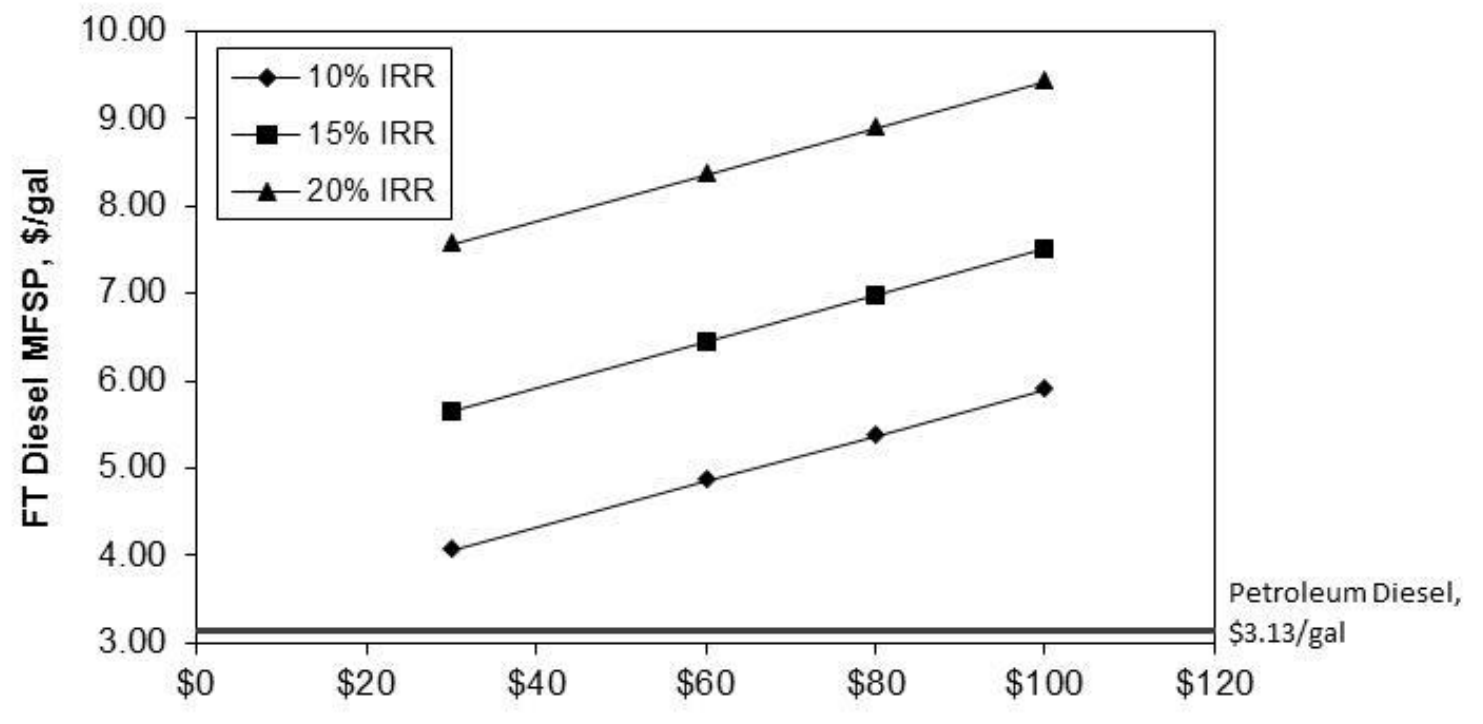

Feedstock Price, \$/dry ton

Figure 4-5 Effects of Feedstock Cost and IRR on FT Diesel MFSP (Directly-Heated Gasifier)

\subsection{Potential Improvements}

The current technology in this study assumes a single pass FT synthesis process with a conversion efficiency of $70 \%$. The disadvantage is that a significant amount of methane, carbon dioxide, and hydrogen are used as fuel gas. Single pass conversion above $70 \%$ is unlikely due to mass transfer limitations in the reactor. Higher conversion efficiency can be achieved by using series reactors or by recycling the gas. Each, however, incur a higher capital cost. Another potential improvement is to recycle FT offgas to the tar reformer as was done in the NREL design studies by Phillips et al. (2007) and Dutta and Phillips (2009) for biomass-to-mixed alcohol systems In addition, these references incorporate an improved tar reformer that has higher methane and tars conversion than that of the current technology. These improvements are listed in Table 4.4. High tar reformer conversion eliminates the steam reformer used in the base case, increases the conversion of methane, enabling more carbon to be available for synthesis. Lastly, reducing the moisture content of the feed from $12 \mathrm{wt} \%$ in the base case to $5 \mathrm{wt} \%$ (Phillips et al. 2007, Dutta and Phillips 2009) reduces the heat load of downstream equipment. 
Table 4-4 Tar Reformer Design Performance for the Current and Target Cases

\begin{tabular}{lccc}
\hline \multirow{2}{*}{ Compounds } & $\begin{array}{c}\text { Current } \\
\text { technology }\end{array}$ & $\begin{array}{c}\text { Conversion Efficiencies } \\
\text { Target - Indirectly- } \\
\text { heated Gasifier }\end{array}$ & $\begin{array}{c}\text { (b) } \\
\text { Target - Directly- } \\
\text { heated Gasifier }\end{array}$ \\
\hline Methane $\left(\mathrm{CH}_{4}\right)$ & $20 \%$ & $80 \%$ & $46.2 \%$ \\
Ethane $\left(\mathrm{C}_{2} \mathrm{H}_{6}\right)$ & $90 \%$ & $99 \%$ & $99 \%$ \\
Ethylene $\left(\mathrm{C}_{2} \mathrm{H}_{4}\right)$ & $50 \%$ & $90 \%$ & $90 \%$ \\
Tars $\left(\mathrm{C}_{10+}\right)$ & $95 \%$ & $99.9 \%$ & $99.9 \%$ \\
Benzene $\left(\mathrm{C}_{6} \mathrm{H}_{6}\right)$ & $70 \%$ & $99 \%$ & $99 \%$ \\
Ammonia $\left(\mathrm{NH}_{3}\right)$ & $70 \%$ & $90 \%$ & $78 \%$ \\
Operating Temperature, ${ }^{\circ} \mathrm{F}$ & 1,383 & 1,600 & 1,633 \\
Source: ${ }^{\left({ }^{(a)}\right.}$ Spath et al. $2005 ;{ }^{(b)}$ Phillips et al. $2007 ;{ }^{(\mathrm{c})}$ Dutta and Phillips 2009 \\
\hline
\end{tabular}

Incorporating these improvements increases the FT yield by about $40 \%$ and $20 \%$ for the indirectly and directly-heated gasifier based systems, respectively. The directly heated gasifier yield is lower because the tar reformer converts less methane and has a higher heat input requirement. The higher heat requirement results from the higher tar production of the directly-heated gasifier than the indirectly heated one. The FT diesel MFSP for the indirectly-heated gasifier case with potential improvements is $\$ 3.42$ /gallon, which is $20 \%$ lower than the current technology. For the directly-heated gasifier system, the potential improvements reduce the cost by $8 \%$ from the current technology.

For both types of gasifiers, recycling FT offgas back to the tar reformer increases FT diesel yields, but also increases the size of the syngas compressor and the FT synthesis area and thus the cost of these processes. Power generation decreases as well. However, these disadvantages are off-set by the significant increase in final product yield and thus there is an overall reduction in cost. 


\subsection{Methanol}

Methanol plays an important role in many industries. It is one of the largest volume commodity chemicals produced globally (Cheng and Kung 1994). Methanol usage ranges from automobile fuel to chemical precursors to other applications such as crop enhancement and antifreeze. Methanol has an octane number of 100, and can be used as fuel on its own. Methanol blends with gasoline potentially offers several advantages over petrol fuel: higher fuel efficiency, reduced carbon monoxide (CO) emission, and reduced exhaust temperature (Nag 2008). In China, high methanol-gasoline blends (M85, 85 vol\% of methanol and $15 \mathrm{vol} \%$ of gasoline, and M100, 100vol\% methanol) are used in taxi and bus fleets as alternative transportation fuel (Dolan 2008). However, it is not used as a fuel in the United States and it is not infrastructure compatible. In addition, methanol can be used in fuel cell such as Direct Methanol Fuel Cell (DMFC) to produce electricity. Methanol can be converted to fuels, such as, gasoline, and dimethyl ether (DME). Methanol is also a precursor for many chemicals that are used in paints, adhesives, polymers, construction materials, olefins, and many more.

Methanol can be produced in several ways, for example, from syngas, from reductive hydrogenation conversion of carbon dioxide $\left(\mathrm{CO}_{2}\right)$, and from oxidative conversion of methane $\left(\mathrm{CH}_{4}\right)$. At present, most of methanol production is via syngas (Olah et al. 2006). This analysis assumes methanol production from syngas. The first half of the process is detailed in Chapter 3 . The remaining steps are discussed in the next sections.

\subsection{Process Design Description}

A simplified block diagram for the Biomass to Methanol system is shown in Figure 5-1.

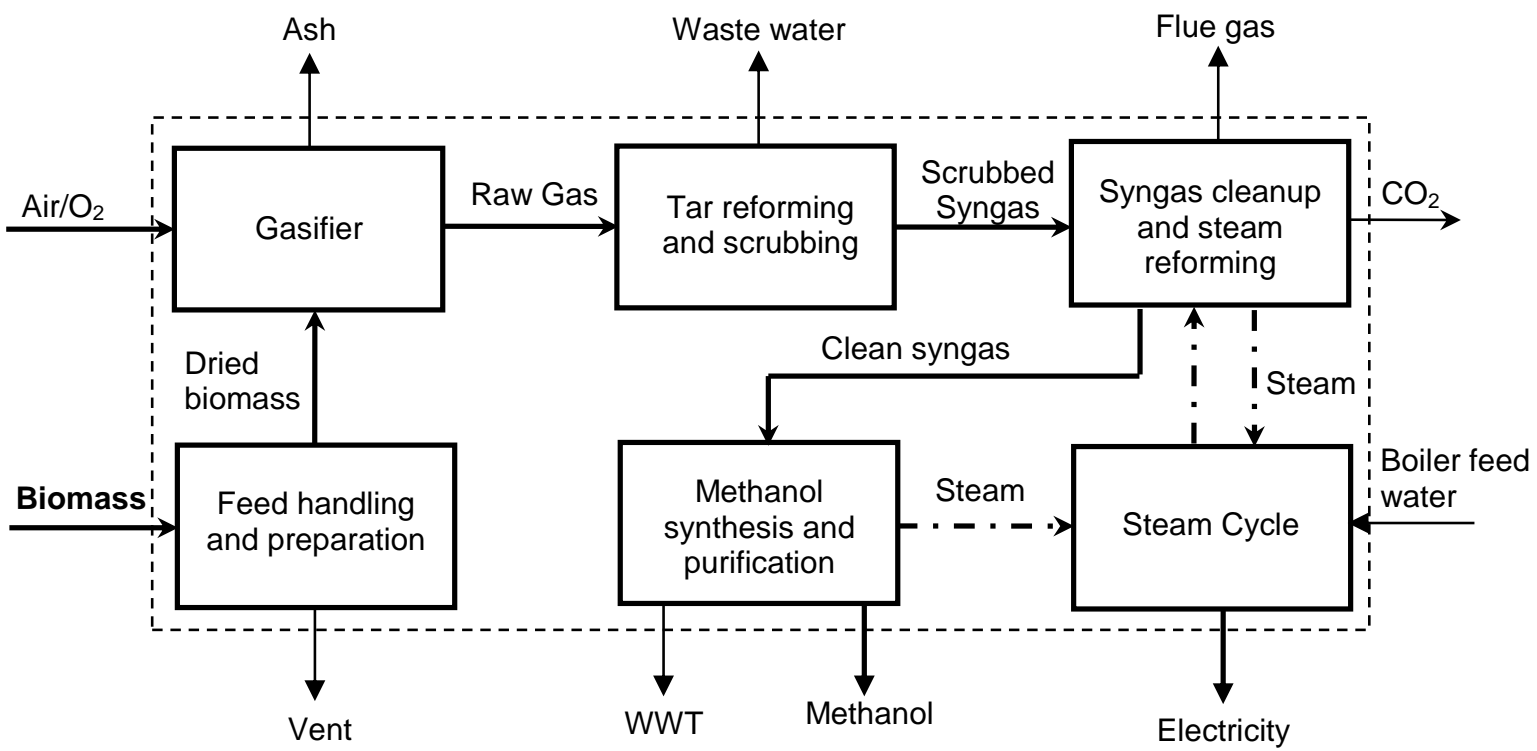

Figure 5-1 Biomass-to-Methanol Block Diagram 
As described in Section 3, biomass is dried and gasified and the syngas is conditioned prior to steam reforming. A steam reformer is used to convert the remaining tar, light hydrocarbons, and $\mathrm{CH}_{4}$ to $\mathrm{H}_{2}$ and $\mathrm{CO}$, and to adjust the $\mathrm{H}_{2} / \mathrm{CO}$ ratio to that required by methanol synthesis. Excess $\mathrm{CO}_{2}$ is removed in an amine unit. The clean syngas is then compressed and sent to methanol synthesis section to produce crude methanol. Crude methanol is delivered to distillation units to purify it to the highest grade of methanol. Part of the purge gas from methanol synthesis and volatiles from distillation columns are used as fuels for steam reformer burner, and biomass dryer for the directly-heated gasifier based system. Steam generated throughout the process is collected and sent to the steam cycle for power generation and for direct usage in steam reforming and other processes. The following sections will discuss in more detail the methanol synthesis process starting from the steam reforming to the methanol purification.

\subsubsection{Steam Reforming and Clean Gas Compression}

A detailed design of gasification, gas cleanup, and steam reforming processes has been described in Section 3. For the methanol system, the syngas is first mixed with medium pressure steam coming from the steam cycle and the methanol synthesis section. The steam reformer is fired with off-gases from the methanol synthesis purge and distillation column volatiles. For the directly-heated gasifier system, natural gas supplements the fuel gas system to meet the energy demand. The $\mathrm{H}_{2}: \mathrm{CO}$ ratio is adjusted to about 2, as required by the methanol synthesis reaction. This adjustment is done by controlling the amount of steam coming to the reformer. The converted syngas passes through several heat exchangers to recover heat by generating both saturated and superheated high pressure steam. The syngas is further cooled by air and cooling water. Excess $\mathrm{CO}_{2}$ is removed in an amine unit. The clean syngas is then compressed to 900 psia before entering the methanol reactor. The hot flue gas coming out of the steam reformer burner is used to generate superheated steam and to heat the syngas stream leaving the LO-CAT process.

\subsubsection{Methanol Synthesis}

The compressed syngas, combined with the recycled portion of methanol reactor purge, is sent to the methanol synthesis process. The principle reactions are:

$$
\begin{aligned}
\mathrm{CO}+2 \mathrm{H}_{2} \leftrightarrow \mathrm{CH}_{3} \mathrm{OH} \\
\mathrm{CO}_{2}+3 \mathrm{H}_{2} \leftrightarrow \mathrm{CH}_{3} \mathrm{OH}+\mathrm{H}_{2} \mathrm{O}
\end{aligned}
$$

The first reaction is the primary methanol synthesis reaction, and the second represents a small fraction of carbon dioxide in the feed that acts as a promoter for the primary reaction. There are minor side reactions occurring as well, which are the formation of higher alcohols and dimethyl ether. These reactions:

$$
\begin{aligned}
& \mathrm{nCO}+2 \mathrm{nH}_{2} \leftrightarrow \mathrm{C}_{\mathrm{n}} \mathrm{H}_{2 \mathrm{n}+1} \mathrm{OH}+(\mathrm{n}-1) \mathrm{H}_{2} \mathrm{O} \\
& 2 \mathrm{CH}_{3} \mathrm{OH} \leftrightarrow \mathrm{H}_{2} \mathrm{O}+\mathrm{CH}_{3} \mathrm{OCH}_{3}
\end{aligned}
$$

Methanol synthesis temperatures and pressures typically range between 446 to $578{ }^{\circ} \mathrm{F}$ ( 230 to $270{ }^{\circ} \mathrm{C}$ ) and 735 to 1470 psia, respectively (Cheng and Kung 1994, Fiedler et al. 2007). 
A process flow diagram for the methanol synthesis and purification process is given in Figure 5-2. The methanol synthesis is assumed to take place in the gas phase at $500^{\circ} \mathrm{F}$, and relatively low pressure $(850$ psia). The reactor ( $\mathrm{R}-500)$ is assumed to be a shell-and-tube type with $\mathrm{ZnO} / \mathrm{CuO}$ catalyst in the tubes. The methanol synthesis reaction is highly exothermic and heat is removed by generating medium pressure steam on the shell side of the reactor. The hot reactor product vapor (S505) is cooled by heat exchanging with the compressed syngas (S501) from the steam reformer and further cooled by air and cooling water. The product stream (S520) is sent to a flash tank where liquid raw methanol is separated from the noncondensable gases. Because the methanol synthesis reaction has a relatively low per pass conversion, unconverted syngas recirculation is needed to achieve a reasonable yield (Cheng and Kung 1994). Approximately ninety-five percent of the vapor phase (S535) is compressed and recycled to the methanol reactor in indirectly-heated gasifier case.

For the directly-heated gasifier system, only eighty-eight percent is recycled back to methanol reactor. The remaining vapor stream is combined with other volatile streams and sent as fuel to fire the steam reformer (S630). For the directly-heated gasifier case, fuel gas is also burned to provide heat to the biomass drier. The liquid product (S524) is further reduced in pressure and flashed to produce raw methanol (S528) at about 95 wt\% purity.

\subsubsection{Product Separation and Purification}

The methanol stream exiting the medium pressure flash unit is at $95 \mathrm{wt} \%$ purity. US federal grade specification O-M-232e classifies three grades of methanol: Grade $\mathrm{C}$ for methanol used in denaturing, Grade A for use as a solvent, and the purest Grade AA methanol which requires greater than $99.85 \mathrm{wt} \%$ methanol (Cheng and Kung 1994). As the standard for methanol purity in industry, Grade AA methanol is chosen as the final product standard in this study. Table 5-1 lists the specification for Grade AA methanol. The final methanol product can also be produced at fuel grade, i.e. M100 (100\% fuel methanol), which has lower purity requirement than those of Grade AA methanol. The different purity requirements of different grades methanol products affect the purification cost and thus the selling price, which is described in details in Section 5.3.3.2.

Table 5-1 U.S. Federal Grade AA Methanol Specifications

\begin{tabular}{lc}
\hline Component & \\
\hline Ethanol, $\mathrm{mg} / \mathrm{kg}$ & $<10$ \\
Acetone, $\mathrm{mg} / \mathrm{kg}$ & $<20$ \\
Total acetone and aldehyde, $\mathrm{mg} / \mathrm{kg}$ & $<30$ \\
Acetic acid, $\mathrm{mg} / \mathrm{kg}$ & $<30$ \\
Color index (APHA) & $<5$ \\
Sulfuric acid test (APHA) & $<30$ \\
Boiling point range, I ${ }^{\circ} \mathrm{C}$ & $<1$ \\
Dry residue, $\mathrm{mg} / \mathrm{L}$ & $<10$ \\
Density $\left(20^{\circ} \mathrm{C}\right), \mathrm{g} / \mathrm{cm} 3$ & 0.7928 \\
Permanganate number, min & $>30$ \\
Methanol content, wt\% & $>99.85$ \\
Water content & $<0.10$ \\
\hline Source: Cheng and Kung 1994 & \\
\hline
\end{tabular}




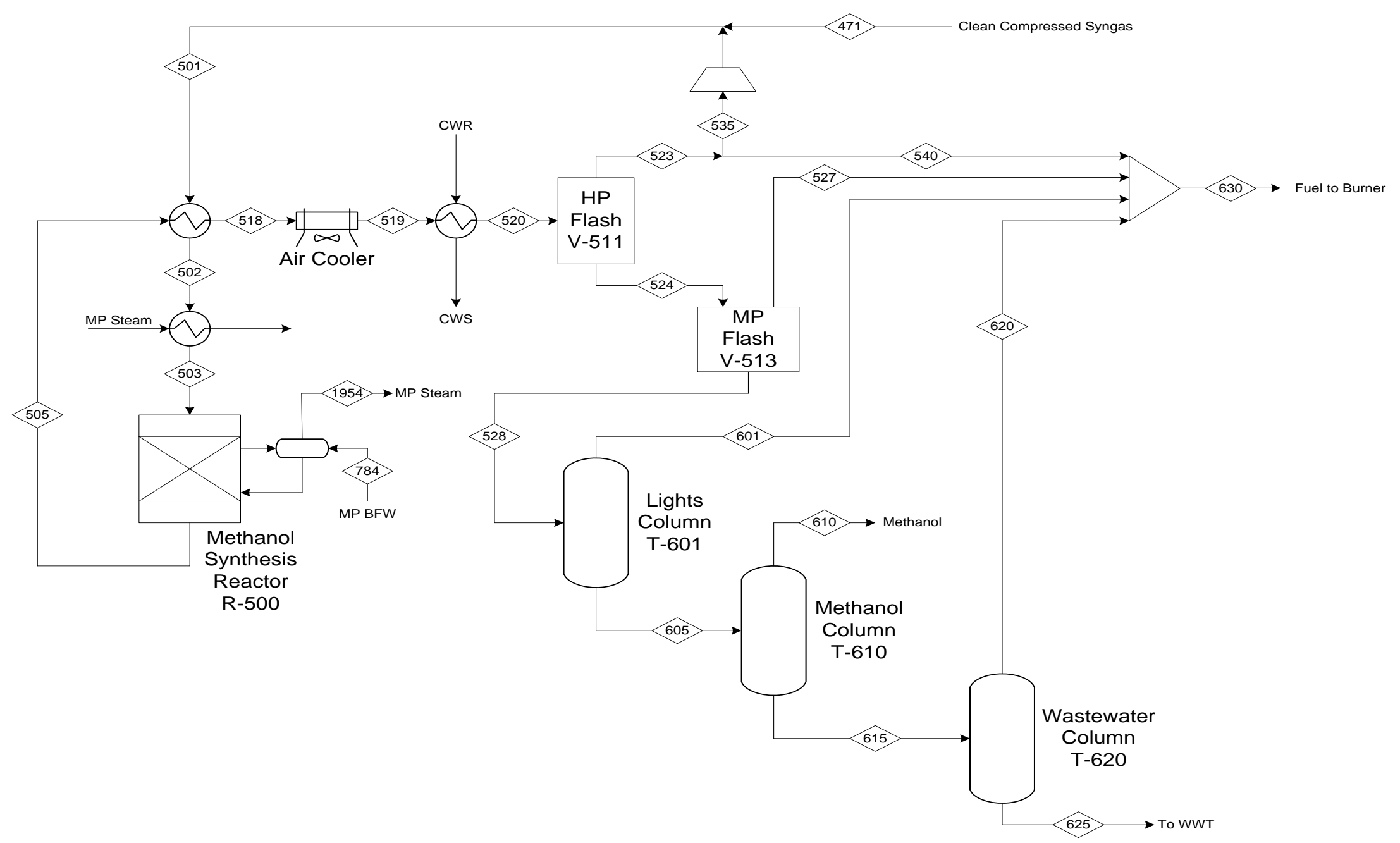

Figure 5-2 Process Flow Diagram for Methanol Synthesis and Purification Process 
Separation by distillation of methanol from by-product ethanol (and higher alcohols) and water is difficult to achieve because of their close boiling points, and ethanol and higher alcohols form an azeotrope with water. Thus many stages are needed to achieve high purity methanol. Ethanol is present at approximately $0.1 \mathrm{wt} \%$ before entering the distillation columns. Grade AA requires the ethanol content to be less than 10 ppmw. The overall purification step requires three columns: the first two are to purify the methanol and the last column is to separate water from impurities before it is sent to wastewater treatment.

The first distillation column (D-601) is the topping column. Its purpose is to remove the light ends (ethers, aldehydes, ketones) and any dissolved gases. Thirty stages are needed to achieve this separation with feed stream entering at tray 20 . The overhead stream from this column is sent to the fuel gas system. The bottoms stream is sent to the next distillation column which is called the refining column. The condenser cooling requirement is fulfilled by supplying cooling water.

The main purpose of the refining column (D-610) is to separate high purity methanol from water and the higher alcohols. Because of the difficult separation between ethanol and methanol, it requires 75 stages for the direct gasification system and 70 stages for the indirect gasification system. The efficiency of each tray is assumed to be $70 \%$. Condenser cooling is achieved with an air-fin condenser and followed by a cooling water supplied trim cooler. Grade AA methanol containing less than 10 ppmw ethanol and greater than $99.85 \mathrm{wt} \%$ methanol comes out of the top of the column.

The last column (D-620) separates residual alcohols from water using thirty stages. Water coming out from the bottom (S625) is sent to the wastewater treatment. The overhead stream, which is mostly higher alcohols, is sent to the fuel gas system. All three column's reboilers heat duties are met by condensing low pressure steam.

\subsubsection{Steam Cycle and Power Generation}

The exothermic methanol reaction generates medium pressure steam, which is used to fluidize the gasifier bed, preheat the feed entering Lo-Cat oxidizer, and fulfill some of the steam requirements in the steam reformer. High pressure steam is generated by cooling the fuel gas exiting the gasifier (in the directlyheated gasifier case only), syngas exiting the steam reformer, and raw syngas leaving the tar reformer. This steam is superheated by exchanging heat with hot exhaust gas and hot syngas from the steam reformer. The superheated steam is used to generate electricity, and the saturated steam is used to fulfill the remaining steam reformer requirements, preheat the syngas to the methanol reactor, and heat column reboilers.

\subsection{Key System Assumptions}

The major assumptions used in the indirectly and directly-heated gasifier for biomass-to-methanol conversion are listed in Table 5-2. The main differences between the two cases are gasifier pressure, gasifier oxidant, and tar reformer pressure. 
Table 5-2 Major System Assumptions for Biomass-to-Methanol

\begin{tabular}{|c|c|c|}
\hline \multicolumn{3}{|c|}{ Gasification } \\
\hline Gasifier type & Indirectly-Heated Gasifier & Directly-Heated Gasifier \\
\hline Gasifier pressure, psia & 23 & 330 \\
\hline Gasifier temperature, ${ }^{\circ} \mathrm{C}\left({ }^{\circ} \mathrm{F}\right)$ & $870(1598)$ & $871(1600)$ \\
\hline Biomass feed, metric ton/d, dry basis & 2000 & 2000 \\
\hline Oxidant & Air & Oxygen \\
\hline Moisture fraction of dried biomass, wt $\%$ & 12 & 12 \\
\hline \multicolumn{3}{|c|}{ Tar Cracking } \\
\hline Reactor outlet temperature, ${ }^{\circ} \mathrm{C}\left({ }^{\circ} \mathrm{F}\right)$ & $750(1383)$ & $750(1383)$ \\
\hline Reactor outlet pressure, psia & 20 & 327 \\
\hline Space velocity, $\mathrm{hr}^{-1}$ & 2,476 & 2,476 \\
\hline \multicolumn{3}{|c|}{ Steam Reforming } \\
\hline Reformer outlet temperature, ${ }^{\circ} \mathrm{C}\left({ }^{\circ} \mathrm{F}\right)$ & $900(1652)$ & $900(1652)$ \\
\hline Reformer outlet pressure, psia & 422 & 422 \\
\hline Space velocity, $\mathrm{hr}^{-1}$ & 2,627 & 2,627 \\
\hline Reformed gas $\mathrm{H}_{2} / \mathrm{CO}$ & 2.1 & 2.1 \\
\hline \multicolumn{3}{|c|}{ Methanol Synthesis and Purification } \\
\hline Reactor outlet temperature, ${ }^{\circ} \mathrm{C}\left({ }^{\circ} \mathrm{F}\right)$ & $260(500)$ & $260(500)$ \\
\hline Reactor outlet pressure, psia & 800 & 800 \\
\hline $\mathrm{kg} / \mathrm{h}$ methanol/L catalyst & 0.9 & 0.9 \\
\hline Methanol recycle weight fraction & 0.88 & 0.95 \\
\hline \multicolumn{3}{|c|}{ Steam Cycle } \\
\hline Boiler feed water condition, ${ }^{\circ} \mathrm{C}\left({ }^{\circ} \mathrm{F}\right) / \mathrm{psia}$ & $113(236) / 870$ & $113(236) / 870$ \\
\hline Superheated steam condition, ${ }^{\circ} \mathrm{C}\left({ }^{\circ} \mathrm{F}\right) / \mathrm{psia}$ & $482(900) / 850$ & $482(900) / 850$ \\
\hline
\end{tabular}

\subsection{Results and Analysis}

In this section, the major performance and cost analysis results for the biomass-to-methanol systems are presented and discussed.

\subsubsection{Performance Result}

The performance results for the biomass-to-methanol based on indirectly-heated and directly-heated systems are listed in Table 5-3. 
Table 5-3 Performance Results for Biomass-to-Methanol

\begin{tabular}{|c|c|c|c|}
\hline \multicolumn{2}{|r|}{ Case } & Indirectly-Heated Gasifier & Directly-Heated Gasifier \\
\hline \multicolumn{4}{|l|}{ Feed } \\
\hline \multicolumn{2}{|c|}{ Dry wood chips, tpd (mtpd) } & $2200(2000)$ & $2200(2000)$ \\
\hline \multicolumn{2}{|c|}{ Natural gas, $\mathrm{scf} / \mathrm{hr}$} & 0 & 104,357 \\
\hline \multicolumn{4}{|c|}{ Products } \\
\hline \multicolumn{2}{|c|}{ Methanol, mmgal/y } & 95 & 100 \\
\hline \multicolumn{4}{|c|}{ Power Consumption, MW } \\
\hline \multicolumn{2}{|c|}{ Air separation unit } & 0.0 & 8.6 \\
\hline \multicolumn{2}{|c|}{ Lock hopper gas compressor } & 0.0 & 0.2 \\
\hline \multicolumn{2}{|c|}{ Dryer air blower } & 0.0 & 0.1 \\
\hline \multicolumn{2}{|c|}{ Char burner air compressor } & 4.7 & 0.5 \\
\hline \multicolumn{2}{|c|}{ Syngas compressor } & 15.9 & 1.9 \\
\hline \multicolumn{2}{|c|}{ Reformer air compressor } & 1.2 & 1.6 \\
\hline \multicolumn{2}{|c|}{ Reformer flue gas blower } & 2.4 & 4.2 \\
\hline \multicolumn{2}{|c|}{ Clean syngas compressor } & 3.9 & 4.7 \\
\hline \multicolumn{2}{|c|}{ Methanol syn. recycle compressor } & 2.2 & 1.5 \\
\hline \multicolumn{2}{|c|}{ Steam turbine auxiliaries } & 0.4 & 0.5 \\
\hline \multicolumn{4}{|c|}{ Power Generation, MW } \\
\hline \multicolumn{2}{|c|}{ Steam turbines } & 23.3 & 32.3 \\
\hline \multicolumn{2}{|l|}{ Net Power, MW } & -7.4 & 8.5 \\
\hline \multicolumn{4}{|c|}{ Water Demand, gpm } \\
\hline \multicolumn{2}{|c|}{ Cooling tower makeup } & 530 & 646 \\
\hline \multicolumn{2}{|c|}{ Boiler feed water makeup } & 424 & 489 \\
\hline \multicolumn{2}{|c|}{ Total water demand } & 954 & 1,135 \\
\hline \multicolumn{2}{|c|}{ Wastewater, gpm } & 363 & 418 \\
\hline \multicolumn{4}{|c|}{ Carbon balance } \\
\hline \multirow[t]{3}{*}{ Feeds } & Biomass & $100 \%$ & $96.6 \%$ \\
\hline & Natural Gas & $0 \%$ & $3.4 \%$ \\
\hline & Sum & $100 \%$ & $100 \%$ \\
\hline \multirow[t]{2}{*}{ Fuel products } & Methanol & $32.4 \%$ & $33.1 \%$ \\
\hline & Sum & $32.4 \%$ & $33.1 \%$ \\
\hline \multirow[t]{5}{*}{ Wastes } & Dryer exhaust & $30.4 \%$ & $9.4 \%$ \\
\hline & Flue gas & $13.3 \%$ & $19.2 \%$ \\
\hline & $\mathrm{CO}_{2}$ & $23.7 \%$ & $37.8 \%$ \\
\hline & Wastewater & $0.2 \%$ & $0.4 \%$ \\
\hline & Sum & $67.6 \%$ & $66.9 \%$ \\
\hline Thermal Effici & cy, \%, LHV basis & $48.1 \%$ & $50.4 \%$ \\
\hline
\end{tabular}

The indirectly-heated gasifier based system has slightly lower methanol yields compared to the directlyheated one because of the lower syngas yield of the indirectly-heated gasifier. However, compared to indirectly-heated gasifier based case, the directly-heated case uses natural gas to provide extra heat for the steam reformer resulting from higher syngas flow rate. The power generation and consumption of for the two cases are significantly different. The indirectly-heated gasifier case does not generate enough electricity in the steam cycle to meet the plant demand and thus requires purchased power. Syngas compression is the major part of the power demand. The indirectly-heated gasifier operates at low pressure, which in turn requires more power to compress the syngas to a pressure suitable for methanol synthesis. The directly-heated gasifier based plant, in contrast, requires less power for raw syngas 
compression because of the high operating pressure of the directly-heated gasifier. In addition, this case generates more power in the steam. The excess net power is assumed to be sold to the grid and is taken as an operating credit.

The water makeup requirement and the waste water generation are slightly lower in the indirectly-heated gasifier system. The carbon efficiency between the two cases is quite similar: $32.4 \%$ and $33.1 \%$ for the indirectly-heated and directly-heated gasifier based systems, respectively. In terms of thermal efficiency, the directly heated gasifier case is slightly more efficient than the indirect case, as a result of lower power consumption, higher power generation, and higher methanol yield.

\subsubsection{Cost Results}

Table 5-4 lists the capital and operating costs for both the indirectly and directly heated gasifier plants. The largest contribution to the capital cost in the indirectly-heated gasifier system is the syngas cleanup and compression. This covers almost $36 \%$ of the total purchased equipment cost (TPEC). The large syngas compressor is the main reason for this high capital cost. In the directly-heated gasifier plant, the syngas clean up and compression section is still a major contributor to the capital cost, but the gasification section contributes highest to the capital cost, or about 33\% of TPEC. The directly-heated gasification section (including tar reforming and wet scrubbing) is much more expensive than the indirectly-heated gasifier, because of the higher equipment cost for pressurized units.

The directly-heated gasifier plant requires 450 million dollar of capital investment, which is considerably larger than the indirectly heated one with 296 million dollar in capital cost. It results from the much more expensive gasification section and the extra air separation unit, which contributes to an additional 10 million dollar in TPEC. For each process, the capital cost is also higher in the directly-heated gasifier case than the indirectly-heated gasifier case due to higher syngas rate.

Biomass cost contributes to the highest portion in operating cost for both cases. In the directly-heated gasifier case, electricity sold to the grid generates an operating cost credit. However, the high capital cost and the extra cost for natural gas of the directly-heated gasifier system exceeds the profit generated from selling the excess electricity. Therefore, the MFSP of methanol of the indirectly-heated gasifier case is less than the directly-heated gasifier plant. 
Table 5-4 Cost Results for Biomass-to-Methanol

\begin{tabular}{|c|c|c|c|c|}
\hline \multirow{2}{*}{$\begin{array}{l}\text { Case } \\
\text { CAPITAL COSTS }\end{array}$} & \multicolumn{2}{|c|}{ Indirectly-Heated Gasifier } & \multicolumn{2}{|c|}{ Directly-Heated Gasifier } \\
\hline & $\mathrm{mm} \$$ & $\%$ of total & $\mathrm{mm} \$$ & $\%$ of total \\
\hline Air separation unit & -- & -- & 10.3 & $9 \%$ \\
\hline Feed prep and drying & 11.2 & $14 \%$ & 12.3 & $10 \%$ \\
\hline \multicolumn{5}{|l|}{ Gasification with tar reforming, heat } \\
\hline recovery, scrubbing & 15.2 & $19 \%$ & 39.4 & $33 \%$ \\
\hline Syngas cleanup \& compression & 28.7 & $36 \%$ & 31.7 & $26 \%$ \\
\hline Methanol synthesis \& purification & 12.6 & $16 \%$ & 13.4 & $11 \%$ \\
\hline Steam system and power generation & 9.4 & $12 \%$ & 11.4 & $9 \%$ \\
\hline \multicolumn{5}{|l|}{ Remainder off-site battery limits } \\
\hline (OSBL) & 2.2 & $3 \%$ & 2.2 & $2 \%$ \\
\hline $\begin{array}{l}\text { Total Purchased Equipment Cost } \\
\text { (TPEC), mm\$ }\end{array}$ & 79.3 & $100 \%$ & 121 & $100 \%$ \\
\hline Total Installed Cost (TIC), mm\$ & \multicolumn{2}{|c|}{196} & \multicolumn{2}{|c|}{298} \\
\hline Total Indirect Cost, $\mathbf{m m \$}$ & \multicolumn{2}{|c|}{100} & \multicolumn{2}{|c|}{152} \\
\hline Total Project Investment, mm\$ & \multicolumn{2}{|c|}{296} & \multicolumn{2}{|c|}{450} \\
\hline OPERATING COSTS & $\$ /$ gal MeOH & $\%$ of total & \$/gal MeOH & $\%$ of total \\
\hline Biomass & 0.46 & $36 \%$ & 0.43 & $28 \%$ \\
\hline Natural Gas & 0.00 & $0 \%$ & 0.08 & $5 \%$ \\
\hline Catalysts \& Chemicals & 0.03 & $3 \%$ & 0.07 & $4 \%$ \\
\hline Waste Disposal & 0.02 & $1 \%$ & 0.02 & $1 \%$ \\
\hline $\begin{array}{l}\text { Utilities (cooling water, boiler water, } \\
\text { electricity) }\end{array}$ & 0.05 & $4 \%$ & -0.03 & $-2 \%$ \\
\hline Fixed Costs & 0.18 & $14 \%$ & 0.23 & $15 \%$ \\
\hline Capital Depreciation & 0.16 & $12 \%$ & 0.22 & $14 \%$ \\
\hline Average Income Tax & 0.11 & $9 \%$ & 0.15 & $10 \%$ \\
\hline Average Return on Investment & 0.28 & $22 \%$ & 0.40 & $25 \%$ \\
\hline MMSP, \$/gal & \multicolumn{2}{|c|}{1.28} & \multicolumn{2}{|c|}{1.57} \\
\hline $\begin{array}{l}\text { MMSP ethanol equivalent LHV basis, } \\
\text { \$/gal }\end{array}$ & \multicolumn{2}{|c|}{1.71} & \multicolumn{2}{|c|}{2.10} \\
\hline
\end{tabular}

According to the Methanex methanol price (Methanex 2009), the average 2008 methanol selling price is $\$ 1.65$ per gallon. The MFSP of methanol in this study is not competitive, especially for the directlyheated gasifier case. In addition, the methanol price fluctuates significantly depending on the methanol offers and demands. For example, in July 2009, the average methanol selling price was listed at $\$ 0.68$ per gallon (Methanex 2009). Therefore, improvements in the technology and efficiency of the process need to be pursued further to make this competitive. However, methanol synthesis is very mature. Therefore cost reductions would need to come from improved gasification and syngas conditioning. 


\subsubsection{Sensitivity Analysis}

Sensitivities to internal rate of return (IRR), feedstock cost, and final methanol product grade requirement on the methanol production cost are investigated. For the directly-heated gasifier case, the effect of eliminating supplemental natural gas usage by reducing recycled vapor to methanol reactor is also considered.

\subsubsection{Sensitivity over Feedstock Cost and Internal Rate of Return}

The capital and operating costs presented in the previous section assume a feedstock cost of $\$ 60$ per dry ton of wood chips and an internal rate of return (IRR) of 10\%. Since the biomass cost contributes about $28-36 \%$ to the methanol MFSP, sensitivity to feedstock cost is considered.

Figure 5-3 shows the methanol MFSP for the indirectly-heated gasifier case assuming biomass prices ranging from $\$ 30$ to $\$ 100$ per dry short ton, and an internal rate of return from 10 to $20 \%$.

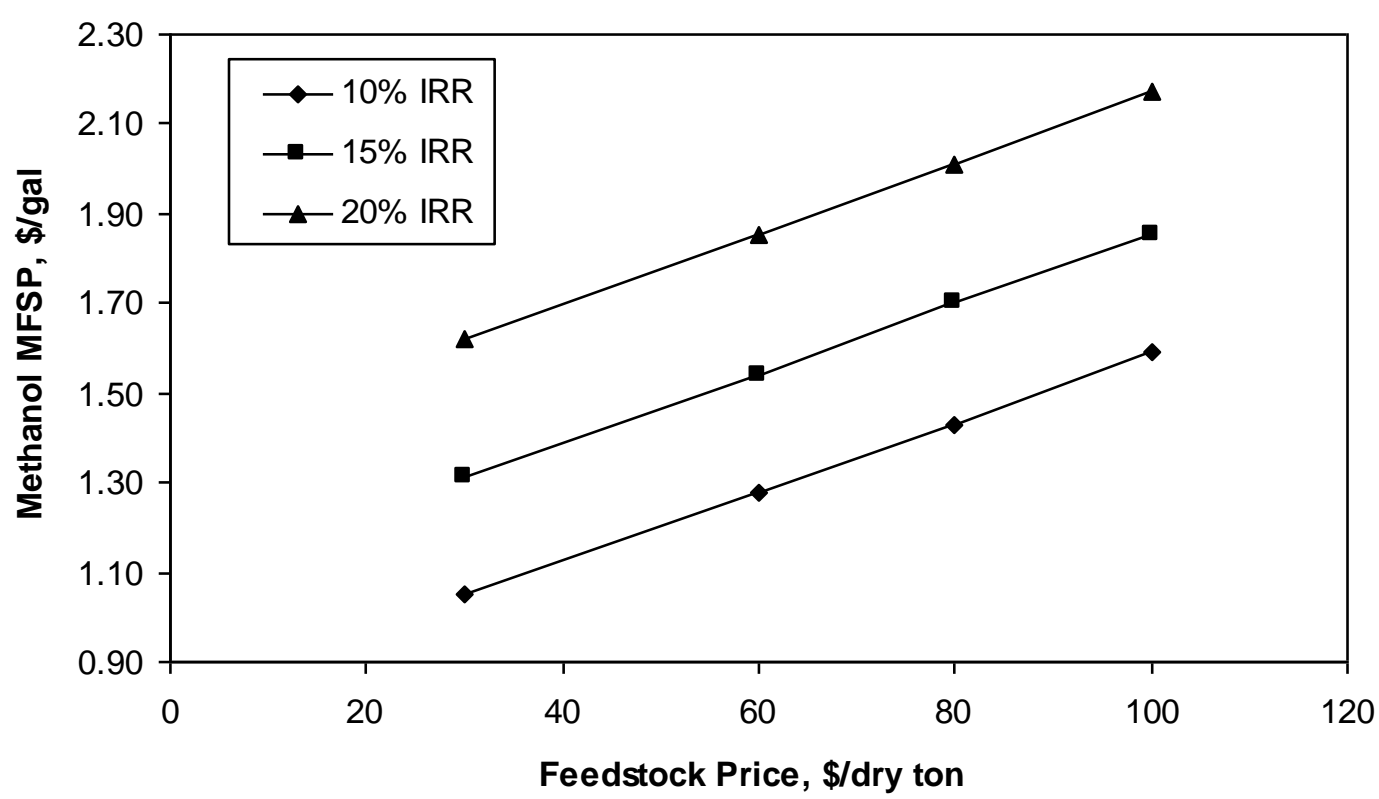

Figure 5-3 Effects of Feedstock Cost and IRR on Methanol MFSP (Indirectly-heated Gasifier)

The higher the internal rate of return, the more profitable the overall process would be. Therefore, a higher methanol selling price is expected. As shown in Figure 5-3, the methanol MFSP increases with the increase in IRR. Feedstock cost also highly determines the minimum methanol selling price. Based on Figure 5-3, the methanol MFSP shows a positive linear dependency on the feedstock cost for the range observed. If the price of the feedstock escalates to $\$ 100$ per ton, the methanol production cost will rise to $\$ 1.59$ per gallon assuming 10\% IRR. The average Methanex methanol price ranged from a high of $\$ 1.65$ per gallon in 2008 and a low of $\$ 0.68$ per gallon in July 2009 (Methanex 2009). If the price of the feedstock is reduced to $\$ 30$ per ton, the MFSP drops to $\$ 1.05$ per gallon, which is competitive only at the highest methanol price. 


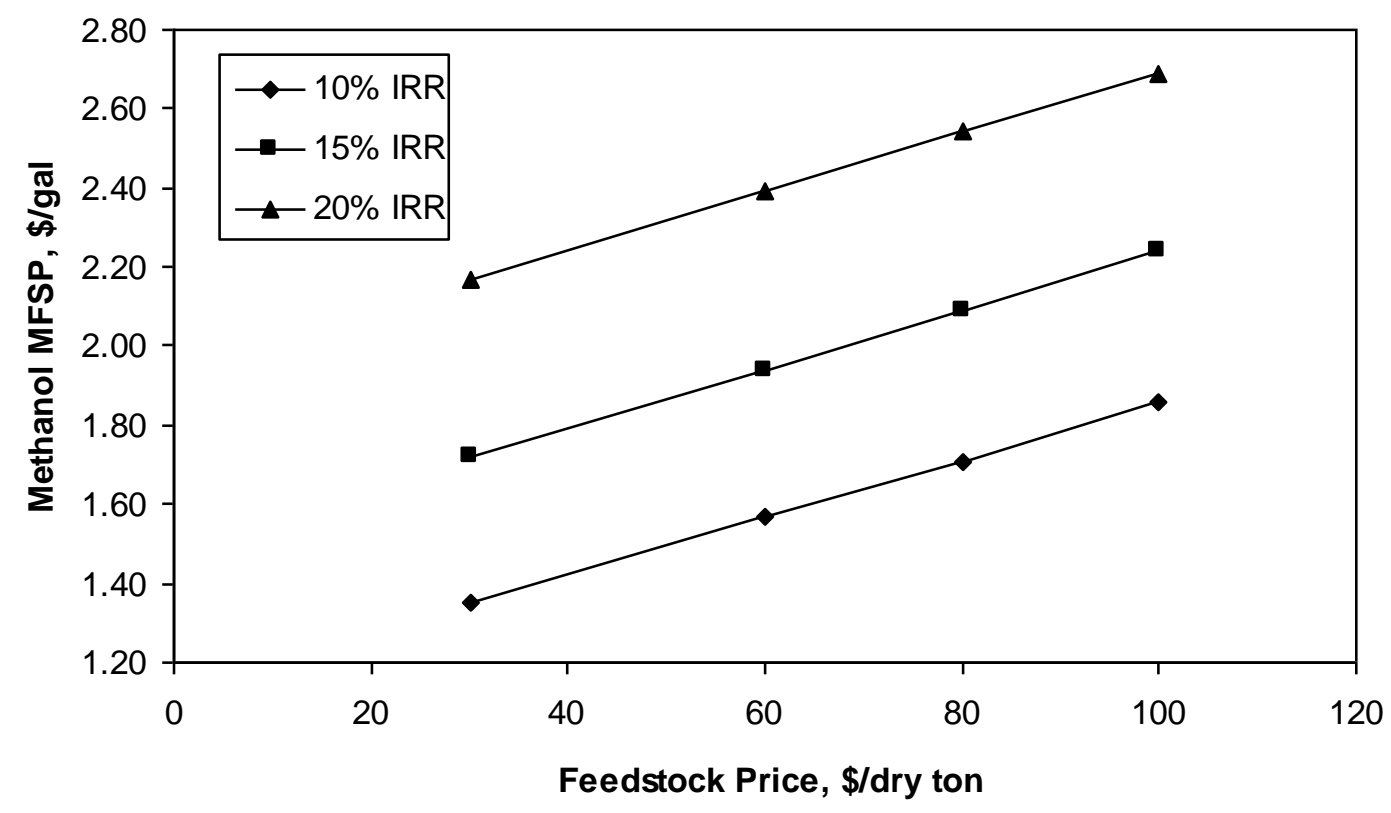

Figure 5-4 Effects of Feedstock Cost and IRR on Methanol MFSP (Directly-heated Gasifier)

For the directly-heated gasification system, the effect of feedstock cost and IRR on the methanol selling price (Figure 5-4) is similar to the indirectly-heated gasifier case. For a feedstock cost of $\$ 60$ per dry ton, the methanol selling price increases to $\$ 2.39$ per gallon for a $20 \%$ IRR. If the feedstock cost is changed to $\$ 100$ per ton biomass, methanol will need to be priced at $\$ 1.86$ (10\% IRR).

\subsubsection{Methanol for Fuel Grade Production}

In this study, the highest grade of methanol (Grade AA) standard is assumed to be the requirement for the final product. This grade of methanol is suitable for a starting material for further processing. The purity requirement is lower than Grade AA (Liao et al. 2006, Cheng and Kung 1994). The M100 (100\% fuel methanol) specifications as developed by the California Air Resources Board (CARB) in 1994 sets the methanol purity at $96 \mathrm{vol} . \%$, with maximum alcohol and ether contents of $2 \mathrm{wt} \%$, maximum hydrocarbon content of $2 \mathrm{wt} \%$, and maximum acetic acid of $0.1 \mathrm{wt} \%$ (Cheng and Kung 1994). Lower purity requirements suggest that one or more of the distillation columns could be eliminated from the base case. This will reduce the operating and capital costs and hence lower the methanol selling price. Methanol exiting the medium pressure flash (stream 528 in Figure 5-2) is expected to be suitable as a fuel product. The three tall distillation columns might then be replaced by a small stripper column. However, eliminating the columns only decreases the MFSP from $\$ 1.28$ to $\$ 1.24$ per gallon for the indirectly-heated case. Similarly, the directly-heated case methanol price per gallon is reduced from $\$ 1.57$ to $\$ 1.52$. This drop is still not significant enough to achieve competitive fuel prices. 


\subsubsection{Directly-Heated Gasification without Employing Natural Gas}

The directly-heated gasifier case uses natural gas to supplement the plant fuel gas requirements. Natural gas use can be eliminated by purging more of the methanol synthesis recycle gas to the fuel gas system. The trade-off is then lower methanol yield. This sensitivity is shown in Table 5-5.

Table 5-5 Comparison of Directly-Heated Gasifier Cases with and without Natural Gas

\begin{tabular}{lcc}
\hline \multicolumn{1}{c}{ Directly Heated Gasifier Case } & With Natural Gas & Without Natural Gas \\
\hline Feed & & $2200(2000)$ \\
$\quad$ Dry wood chips, tpd (mtpd) & 104,357 & 0 \\
$\quad$ Natural gas, scf/hr & & \\
Products & 100 & 90 \\
$\quad$ Methanol, mmgal/y & 8.5 & 9.1 \\
Net power, MW & 1,135 & 1,128 \\
Water demand, gpm & 418 & 414 \\
Wastewater, gpm & $33 \%$ & $31 \%$ \\
Carbon efficiency, \% & & $51.7 \%$ \\
Thermal efficiency, \%, higher heating value & $53.4 \%$ & 1.65 \\
(HHV) basis & & 2.21 \\
Methanol MFSP ,\$gal & 1.57 & 2.10 \\
MFSP ethanol equivalent LHV basis, \$/gal & & \\
\hline
\end{tabular}

Without using natural gas, more unreacted gas from the methanol synthesis section needs to be diverted from methanol synthesis recycle to the fuel gas system. This in turn reduces the methanol annual production rate from 100 million gallons per year methanol compared to 90 million gallons per year. Electricity is still produced in excess and could be sold to the grid. In terms of efficiency, without natural gas, the overall process is slightly less carbon and energy efficient. The methanol production cost is higher for the directly-heated gasifier case without natural gas, which means that the savings generated by eliminating natural gas usage cannot counteract the loss of producing less methanol.

\subsection{Potential Improvements}

Improvements similar to those described in Section 4.4 are assumed for the methanol synthesis system. The multiple -pass methanol synthesis process is change to single pass and the unconverted syngas is recycled to the tar reforming process to further convert the methane and increase the conversion of $\mathrm{CO}$. In the current technology, the methanol synthesis used a multiple-pass synthesis loop, which has high recycle ratio and thus the $\mathrm{CO}$ conversion is high. In addition, a fraction of raw syngas and unconverted syngas needs to be sent to the tar reforming catalyst regeneration process for combustion to provide heat for the tar reforming process. However, this affords only a modest increase in methanol yield. The simulation results of the target cases shows that the methanol yield increases about $4 \%$ for the indirectlyheated gasifier based system and about $5 \%$ for the directly-heated gasifier based system. The major advantage of the potential improvements is the cost for methanol synthesis decreases because of the elimination of the recycle syngas compressor and the lower syngas flow ratio resulting from single pass design. The cost estimation results show that the methanol MFSP decreases $10 \%$ and $6 \%$ for the 
indirectly-heated and directly-heated gasifier based systems. The tar reformer for the directly-heated gasifier based system is more expensive because of the high tar content in raw syngas. 


\subsection{Dimethyl Ether}

Dimethyl ether (DME), $\mathrm{CH}_{3} \mathrm{OCH}_{3}$, has been used primarily as a propellant and as a precursor for dimethyl sulfate production, but has gained increasing attention in recent years as an alternative transportation fuel. In this light, DME is promising for its use in diesel engines, which require only moderate modification to utilize DME (Ohno 2007). Countries currently involved in the development of DME as transportation fuel include China, Japan, and Sweden. China, the largest producer of DME, has carried out a DME development and demonstration project involving collaboration of government, universities, as well as auto and oil/gas companies (Zhen and Taupy 2008). As a result of this project, two large cities (Linyi and Shanghai) now have fleets of buses powered by DME.

DME has a higher cetane number than diesel (55-60 versus 40-55 for diesel) and results in lower particulate, $\mathrm{NO}_{\mathrm{x}}$, and $\mathrm{SO}_{\mathrm{x}}$ emissions when compared to diesel combustion. Some studies have estimated carbon emissions to be significantly lower for DME than gasoline and diesel (Landälv 2008). DME is also non-toxic, non-carcinogenic and non-corrosive, making it desirable from a health and safety perspective. In addition to its use as a transportation fuel, DME has a potentially large market as a substitute for liquefied petroleum gas (LPG) in stationary combustion applications. Some disadvantages of DME as fuel is that it must be stored under pressure, which can be costly, and it is not infrastructure compatible.

DME is conventionally produced via methanol dehydration. Licensors that offer this technology include Mitsubishi Gas Chemical, Toyo Engineering Corporation, Haldor Topsoe, Uhde and Lurgi (Nexant 2008). Methanol produced from syngas (see Section 5.0 for details) is first treated to remove most of the dissolved gases prior to the DME process. It is possible to use a feed of raw methanol up to Grade AA methanol, depending on the final DME purity requirements needed. In this analysis, a feed of approximately $98 \%$ methanol is used.

It should be noted that several companies are working on commercializing a one-step syngas-to-DME process that combines methanol production and dehydration into one reactor. The one-step process is in the earlier stages of commercialization and is not the focus of this study.

\subsection{Process Design Description}

A simplified block diagram of the biomass to dimethyl ether (DME) process is given in Figure 6-1. The processing steps include:

- Feed handling and preparation

- Gasification

- Tar reforming and scrubbing

- Syngas cleanup and steam reforming (and water-gas shift for directly-heated gasifier system)

- Clean syngas compression

- Methanol production and purification

- DME production and purification

- Steam cycle and power generation 


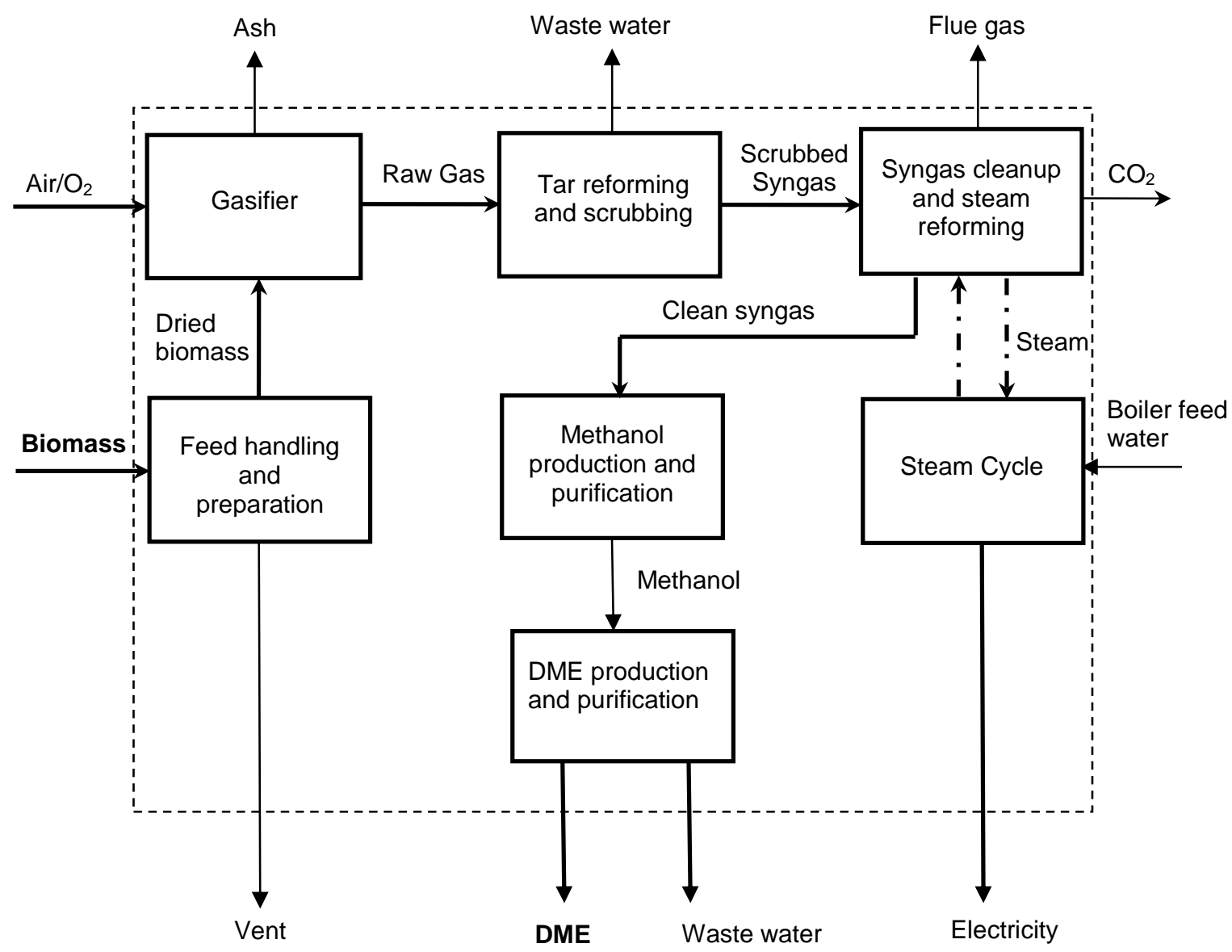

Figure 6-1 Biomass-to-Dimethyl Ether (DME) Block Diagram

As described in Section 3, as-received biomass is dried and gasified and the syngas is conditioned prior to steam reforming as shown in Figure 6-1. The particulate and sulfur free syngas is fed to a steam reformer to adjust the $\mathrm{H}_{2} / \mathrm{CO}$ ratio to approximately 2 for methanol production. The bulk of $\mathrm{CO}_{2}$ in reformed syngas is removed in an amine unit. The clean syngas is then compressed and sent to the methanol synthesis process. The methanol reactor is similar to that described in Section 5. The purified methanol stream ( $98 \%$ methanol) is then sent to the DME process. In the DME reactor, methanol is catalytically dehydrated. High purity DME (99.85\%) is then separated from water and unreacted methanol. Finally, methanol is separated and recycled back to the reactor, and water is sent to wastewater treatment. A portion of the unreacted methanol for recycle is split off and used for fuel gas to the steam reformer burners.

In the following sections, the design details of methanol purification, DME synthesis and purification, and the steam cycle process are described. The gasification and methanol production processes have been described in detail in Sections 3.0 and 5.0, respectively. 


\subsubsection{Methanol Synthesis and Purification}

Methanol is produced via the process previously described in section 5.1.2, with two differences for the DME process. Firstly, for the DME synthesis process, natural gas feed is not necessary as additional feed for the directly-heated gasifier case. Secondly, methanol of crude grade up to high purity may be used for DME synthesis and therefore, the methanol purification process requires only one column to provide adequate feed composition for the DME process. As described previously in section 5.1.3, the topping column separates light ends from the methanol reactor product, yielding a $98 \%$ methanol $/ 2 \%$ water feed that is sent to the DME synthesis and purification section. The lights from this column are used as fuel gas in the steam reformer burners.

\subsubsection{DME Synthesis and Purification}

Methanol is converted to dimethyl ether (DME) via the following dehydration reaction:

$$
2 \mathrm{CH}_{3} \mathrm{OH} \rightarrow \mathrm{CH}_{3} \mathrm{OCH}_{3}+\mathrm{H}_{2} \mathrm{O}
$$

The process can utilize feedstock methanol ranging from high purity ( $>99.85 \mathrm{wt} \%$ ) to crude grade (e.g., $94 \mathrm{wt} \%$ ) (Ekstrand and Jorgensen 2007, Uhde 2005). The DME synthesis temperature is typically between 482 to $752^{\circ} \mathrm{F}\left(250\right.$ and $\left.400^{\circ} \mathrm{C}\right)$ and pressures are between about 145 to 365 psia (Konishi and Ishiwada 2004). The design of the production of DME from methanol in this study is based on information from industry (Ekstrand and Jorgensen 2007, Konishi and Ishiwada 2004, Mii and Uchida 2005, Uhde 2005) and a design case described in the literature (Turton et al. 1998 and van der Lee et al. 2002).

A flow diagram of the simulated DME synthesis and purification process in this study is shown in Figure 6-2. Raw methanol product (S528) is purified to $97.9 \mathrm{wt} \%$ methanol (S605). The purified methanol is pumped and heated to the reaction pressure and temperature necessary for conversion to DME via exchange with the reactor effluent (S805) and additional heating with medium pressure (450 psia) steam from the steam cycle. The reactor feed temperature and pressure are assumed to be $450^{\circ} \mathrm{F}\left(232^{\circ} \mathrm{C}\right)$ and 280 psia. The reaction is carried out adiabatically in a gas-phase fixed bed reactor (R-805), typically over an aluminum oxide $\left(\gamma-\mathrm{Al}_{2} \mathrm{O}_{3}\right)$ catalyst or zeolite (silica-alumina). A $\gamma-\mathrm{Al}_{2} \mathrm{O}_{3}$ catalyst in pellet form has a minimum life time of approximately 2 years (Uhde 2005). Information from the industry indicates that one-pass methanol conversion values range from $70-85 \%$ and selectivity of methanol to DME in the reactor is approximately $99.9 \%$ (Mii and Uchida 2005). For this design, a one-pass conversion of $85 \%$ is assumed and no significant side-reactions are assumed to occur. The DME synthesis reaction results in a temperature rise of approximately $250^{\circ} \mathrm{F}\left(121^{\circ} \mathrm{C}\right)$ over the length of the reactor (resulting in $710^{\circ} \mathrm{F}$ $\left(377^{\circ} \mathrm{C}\right)$ exit temperature). 


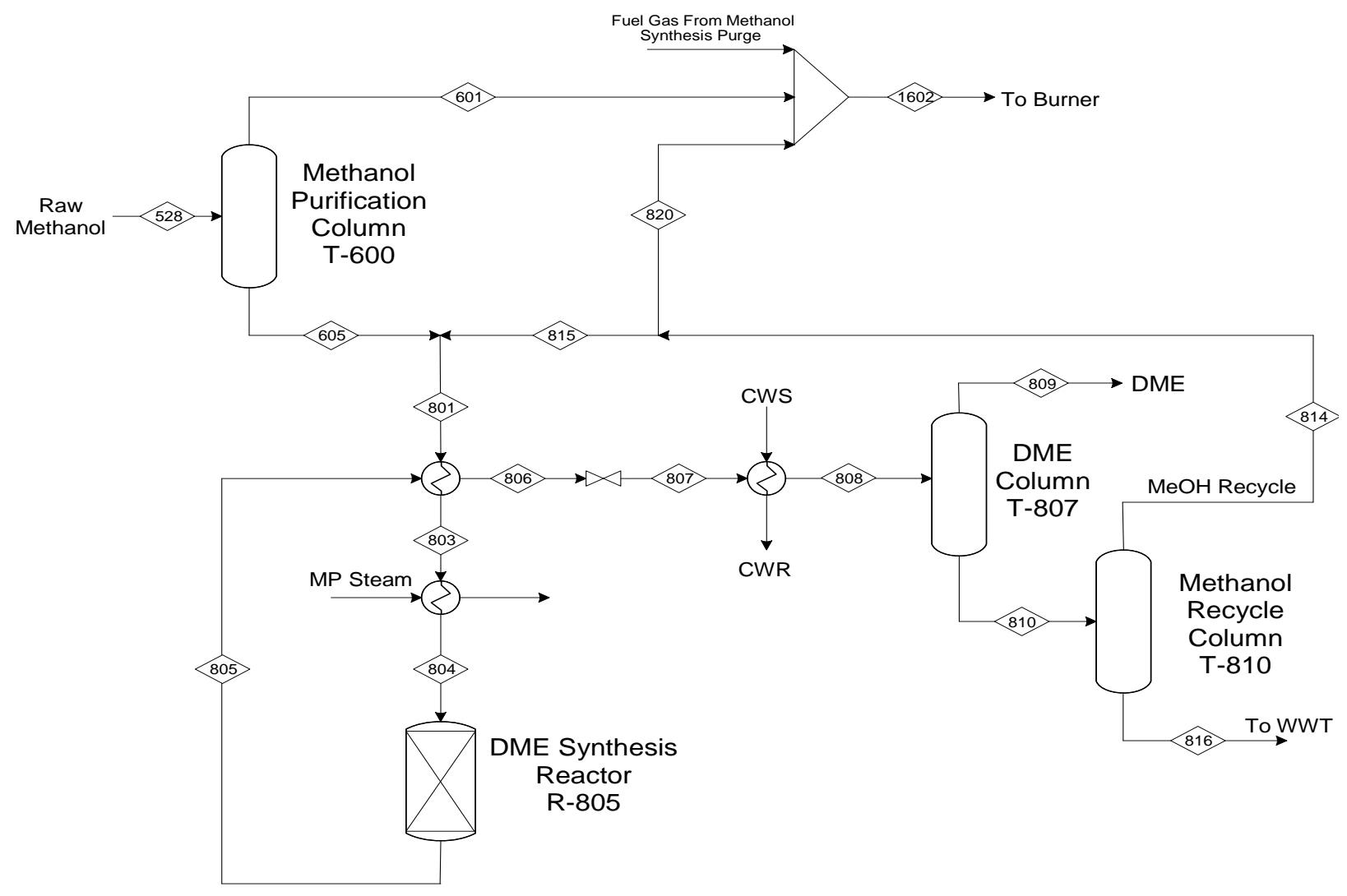

Figure 6-2 Process Flow Diagram for Dimethyl Ether (DME) Synthesis and Purification

Produced DME (S805) with by-product water and unconverted methanol is used to heat the reactor feed and further cooled to a temperature of $190^{\circ} \mathrm{F}\left(88^{\circ} \mathrm{C}\right)$ by cooling water before being fed to the DME column (T-807). This column is operated at 150 psia and provides for separation of product DME from methanol and water. The separation requires 20 stages, with the feed stream entering at the upper section of the tower. Condenser cooling requirement for this column is supplied by cooling water. The overhead (S809) from the column, which contains $99.85 \mathrm{wt} \%$ DME with $0.15 \mathrm{wt} \%$ methanol, is sent to storage at 150 psia and $115^{\circ} \mathrm{F}\left(46^{\circ} \mathrm{C}\right)$ as the final DME product. Purity specifications for engine fuel-grade DME are still in development. In 2000, the International Energy Agency (IEA) proposed a tentative transportation fuel standard for DME (Klintbom 2008), as shown in Table 6-1. The proposed IEA standard has not been formally updated and/or adopted. Although the product DME from this study contains slightly above the proposed methanol specification, it meets the total impurity requirement and should be adequate for transportation fuel purposes. In addition, the product contains no impurities other than methanol and should therefore be cleaner burning than a product containing more impurities, such as the higher organics. Other DME standards also include a tentative standard for DME as civil gas (heating fuel) developed in Japan (Japanese Industrial Standard, JIS) that specifies $\geq 99.0 \%$ DME, $\leq 1.0 \%$ methanol and $<1.0 \%$ water (and others). China appears to be applying a similar standard for these purposes (Jiutai Energy 2008). The compositions of DME product simulated in this model also meet these standards. 
Table 6-1 Proposed IEA DME Vehicle Fuel Standard

\begin{tabular}{lcc}
\hline \multicolumn{1}{c}{ Item } & $\begin{array}{c}\text { IEA Proposed DME Fuel } \\
\text { Specification (wt\%) }\end{array}$ & $\begin{array}{c}\text { DME Product } \\
\text { from Model (wt\%) }\end{array}$ \\
\hline DME & 99.6 & 99.85 \\
Methanol & $<0.05$ & 0.15 \\
Water & $<0.01$ & -- \\
Methyl ethyl ethanol & $<0.05$ & - \\
Higher (fatty) alcohol & $<0.05$ & - \\
Higher (fatty) ether & $<0.05$ & -- \\
Ketone & $<0.05$ & -- \\
\hline Source: Klintbom 2008 & & \\
\hline
\end{tabular}

The bottoms stream (S810) from the DME column (containing approximately $36 \mathrm{wt} \%$ methanol, $60 \%$ water, and 0.4-2.4\% ethanol) is fed to a second distillation column (T-810) operated at 27 psia, where methanol is separated from water and recycled back to the DME reactor. This column requires twentyeight stages. Condenser cooling is achieved with an air cooler. The overhead stream (S814), containing approximately $90 \mathrm{wt} \%$ methanol, is split and a large fraction (S815) of it is recycled to the DME reactor. The remaining (S820) is combined with the other fuel gas streams from methanol synthesis for use in the steam reformer burner. It is also used in the biomass dryer burner in the directly-heated gasification case. The bottoms stream (S816) is sent to wastewater treatment. The heat for the reboilers for both DME purification columns is provided by condensing low pressure (150 psia) steam.

\subsubsection{Steam Cycle and Power Generation}

The steam cycle and power generation process for the Biomass-to-DME process is essentially the same as the process for the Biomass-to-Methanol process, as previously described in Section 5.1.4. The only additional point to note is that low pressure steam of 150 psia is used to supply the reboiler heat duties in the DME and methanol columns.

\subsection{Key System Assumptions}

The major system assumptions for the Biomass-to-DME systems based on indirectly and directly-heated gasifier systems are listed in Table 6-2. Key assumptions for the design include temperature, pressure and other specifications for each main process. The design basis for each process is described in the previous section. 
Table 6-2 Major System Assumptions for Biomass-to-DME Models

\begin{tabular}{|c|c|c|}
\hline \multicolumn{3}{|c|}{ Gasification } \\
\hline Gasifier type & Indirectly-Heated Gasifier & Directly-Heated Gasifier \\
\hline Gasifier pressure, psia & 23 & 330 \\
\hline Gasifier temperature, ${ }^{\circ} \mathrm{C}\left({ }^{\circ} \mathrm{F}\right)$ & $870(1598)$ & $871(1600)$ \\
\hline Biomass feed, metric ton/d, dry basis & 2000 & 2000 \\
\hline Oxidant & Air & Oxygen \\
\hline Moisture fraction of dried biomass, wt $\%$ & 12 & 12 \\
\hline \multicolumn{3}{|c|}{ Tar Cracking } \\
\hline Reactor outlet temperature, ${ }^{\circ} \mathrm{C}\left({ }^{\circ} \mathrm{F}\right)$ & $750(1383)$ & $750(1383)$ \\
\hline Reactor outlet pressure, psia & 20 & 327 \\
\hline Space velocity, $\mathrm{hr}^{-1}$ & 2,476 & 2,476 \\
\hline \multicolumn{3}{|c|}{ Steam Reforming } \\
\hline Reformer outlet temperature, ${ }^{\circ} \mathrm{C}\left({ }^{\circ} \mathrm{F}\right)$ & $900(1652)$ & $900(1652)$ \\
\hline Reformer outlet pressure, psia & 422 & 422 \\
\hline Space velocity, $\mathrm{hr}^{-1}$ & 2,627 & 2,627 \\
\hline Reformed gas $\mathrm{H}_{2} / \mathrm{CO}$ & 2.1 & 2.1 \\
\hline \multicolumn{3}{|c|}{ Methanol Synthesis and Purification } \\
\hline Reactor outlet temperature, ${ }^{\circ} \mathrm{C}\left({ }^{\circ} \mathrm{F}\right)$ & $260(500)$ & $260(500)$ \\
\hline Reactor outlet pressure, psia & 800 & 800 \\
\hline $\mathrm{kg} / \mathrm{h}$ methanol/L catalyst & 0.9 & 0.9 \\
\hline Methanol recycle weight fraction & 0.88 & 0.95 \\
\hline \multicolumn{3}{|c|}{ DME Synthesis } \\
\hline Reactor outlet temperature, ${ }^{\circ} \mathrm{C}\left({ }^{\circ} \mathrm{F}\right)$ & $375(710)$ & $375(710)$ \\
\hline Reactor outlet pressure, psia & 265 & 265 \\
\hline Space velocity, $\mathrm{hr}^{-1}$ & 15 & 15 \\
\hline \multicolumn{3}{|c|}{ Steam Cycle } \\
\hline Boiler feed water condition, ${ }^{\circ} \mathrm{C}\left({ }^{\circ} \mathrm{F}\right) / \mathrm{psia}$ & $113(237) / 870$ & $113(235) / 870$ \\
\hline Superheated steam condition, ${ }^{\circ} \mathrm{C}\left({ }^{\circ} \mathrm{F}\right) / \mathrm{psia}$ & $482(900) / 850$ & $482(900) / 850$ \\
\hline
\end{tabular}

\subsection{Results and Analysis}

In this section, the major performance and cost analysis results for the biomass-to-DME models are summarized and discussed. Sensitivity analysis is implemented to evaluate the effects of key cost assumptions on the system cost.

\subsubsection{Performance Results}

The performance results for the Biomass-to-DME process via indirectly-heated and directly-heated gasifiers are presented in Table 6-3. 
Table 6-3 Major Performance Results for Biomass-to-DME

\begin{tabular}{|c|c|c|c|}
\hline & Case & Indirectly-Heated Gasifier & Directly-Heated Gasifier \\
\hline \multicolumn{4}{|l|}{ Feed } \\
\hline \multicolumn{2}{|c|}{ Dry wood chips, tpd (mtpd) } & $2200(2000)$ & $2200(2000)$ \\
\hline \multicolumn{2}{|c|}{ Natural gas, scf/hr } & 0 & 0 \\
\hline \multicolumn{4}{|c|}{ Products } \\
\hline \multicolumn{2}{|c|}{ DME, mmgal/y } & 81 & 76 \\
\hline \multicolumn{4}{|c|}{ Power Consumption, MW } \\
\hline \multicolumn{2}{|c|}{ Air separation unit } & -- & 8.6 \\
\hline \multicolumn{2}{|c|}{ Lock hopper gas compressor } & -- & 0.2 \\
\hline \multicolumn{2}{|c|}{ Dryer air blower } & -- & 0.1 \\
\hline \multicolumn{2}{|c|}{ Char burner air compressor } & 4.8 & 0.5 \\
\hline \multicolumn{2}{|c|}{ Syngas compressor } & 15.9 & 1.9 \\
\hline \multicolumn{2}{|c|}{ Reformer air compressor } & 1.2 & 1.6 \\
\hline \multicolumn{2}{|c|}{ Reformer flue gas blower } & 0.4 & 0.5 \\
\hline \multicolumn{2}{|c|}{ Clean syngas compressor } & 3.9 & 4.7 \\
\hline \multicolumn{2}{|c|}{ Methanol syn. recycle compressor } & 2.2 & 1.3 \\
\hline \multicolumn{2}{|c|}{ DME process pump } & 0.04 & 0.03 \\
\hline \multicolumn{2}{|c|}{ Steam turbine auxiliaries } & 0.4 & 0.5 \\
\hline \multicolumn{4}{|c|}{ Power Generation, MW } \\
\hline \multicolumn{2}{|l|}{ Steam turbines } & 23.3 & 34.2 \\
\hline \multicolumn{2}{|l|}{ Net Power, MW } & -5.5 & 14.3 \\
\hline \multicolumn{4}{|c|}{ Water Demand, gpm } \\
\hline \multicolumn{2}{|c|}{ Cooling tower makeup } & 634 & 730 \\
\hline \multicolumn{2}{|c|}{ Boiler feed water makeup } & 423 & 489 \\
\hline \multicolumn{2}{|c|}{ Total water demand } & 1,057 & 1,219 \\
\hline \multicolumn{2}{|c|}{ Wastewater, gpm } & 421 & 475 \\
\hline \multicolumn{4}{|l|}{ Carbon balance } \\
\hline \multirow[t]{2}{*}{ Feeds } & Biomass & $100 \%$ & $100 \%$ \\
\hline & Sum & $100 \%$ & $100 \%$ \\
\hline \multirow[t]{2}{*}{ Fuel products } & DME & $32.5 \%$ & $30.5 \%$ \\
\hline & Sum & $32.5 \%$ & $30.5 \%$ \\
\hline \multirow[t]{5}{*}{ Wastes } & Gasifier flue and ash & $30.4 \%$ & $9.8 \%$ \\
\hline & Reformer flue gas & $13.2 \%$ & $20.1 \%$ \\
\hline & $\mathrm{CO}_{2}$ & $23.7 \%$ & $39.1 \%$ \\
\hline & Wastewater & $0.2 \%$ & $0.4 \%$ \\
\hline & Sum & $67.5 \%$ & $69.5 \%$ \\
\hline Thermal Effici & ncy, \% LHV basis & $50.6 \%$ & $51.5 \%$ \\
\hline
\end{tabular}

Raw syngas entering the syngas compression and clean up section is higher in the directly-heated gasifier case than the indirectly-heated one. However, the indirectly-heated gasifier process results in a greater DME yield, because less methanol synthesis purge gas and less recycle methanol within the DME process are needed for the fuel gas to the steam reformer burner. In the directly-heated gasifier case, approximately $15 \%$ of methanol synthesis offgas and $50 \%$ of the methanol recycle are split off for reformer fuel gas, while only $5 \%$ and $10 \%$, respectively, are required in the indirectly-heated gasifier case. 
Power consumption results for the two cases for DME production differ significantly. The directlyheated gasifier case sells 14.3 MW of electricity to the grid, while the indirectly-heated case buys 5.5 MW from the grid. This is primarily due to the large power need for the syngas compressor in the indirectlyheated case, and because of significantly more power generated in the steam turbines with the directlyheated case.

The indirectly-heated gasifier system requires less water make up and generates less waste water. Both cases result in similar carbon efficiencies, which are $32.5 \%$ and $30.5 \%$ for the indirectly-heated and directly-heated gasifier based systems, respectively. The lower DME yield for the directly-heated gasifier case results in a slightly higher percentage of carbon going to waste streams and thus lowers the carbon efficiency for this case. The directly-heated gasification case produces more $\mathrm{CO}_{2}$ which comes from the steam reformer burners but is slightly more thermal efficient than the indirect case, as a result of producing excess electricity.

\subsubsection{Cost Results}

The cost results for the two cases are listed in Table 6-4. The total project investment for the directlyheated gasifier case is $57 \%$ higher than that of the indirectly-heated gasifier based system. The main reason is the extra equipment cost for the air separation unit and much higher cost for the gasification unit. The largest contribution to the overall capital cost is the syngas cleanup and steam reforming process equipment for the indirectly-heated gasifier system. For the directly-heated gasifier system, the gasification section (including tar reforming and wet scrubbing) is the largest contributor to capital investment. The DME synthesis section requires little capital investment relative to the overall biomassto-fuel process, accounting for only about $4 \%$ and $2 \%$ of the TPEC for the indirectly-heated gasifier and directly-heated gasifier cases, respectively. Biomass feed cost accounts for the greatest portion of the operating costs for both systems.

The MFSP for DME production is $\$ 1.50$ per gallon for the indirectly-heated case and $\$ 1.91$ per gallon for the directly-heated case. Although the directly-heated system has higher power output and thus a higher utility credit, the MFSP of this system is significantly higher, primarily due to the lower DME yield and higher equipment costs resulting from the need for an air separation unit.

DME is not currently sold as fuel in the United States, and therefore, it is difficult to estimate an applicable market price with which to compare the calculated MFSP results for this process. However, since DME is a potential substitute for diesel, comparison of prices for these fuels provides insight into the economic viability of the DME process. The U.S. No. 2 diesel wholesale/resale price was between $\$ 1.47$ and \$3.89/gallon with an average of \$2.98/gallon in 2008 (Energy Information Administration 2009b). Compared to the 2008 diesel price, the DME MFSP for both cases are competitive, and are at the lower end of the price range for diesel. However, because DME and diesel have very different heating values, it is more appropriate to compare the fuels on an energy-basis. The LHV for U.S. conventional diesel is 128,450 Btu/gallon (Hydrogen Analysis Resource Center 2008) and the LHV for DME in this study is $69,749 \mathrm{Btu} / \mathrm{gallon}$. The 2008 diesel wholesale price ranges from $\$ 11.44$ to $\$ 30.28 / \mathrm{mmBtu}$ (LHV) with an average of $\$ 23.20 / \mathrm{mmBtu}$, while the DME MFSP is $\$ 21.51 / \mathrm{mmBtu}$ and $\$ 27.38 / \mathrm{mmBtu}$ (LHV) for the indirectly-heated and directly-heated cases, respectively. Therefore, on this basis, DME produced via the indirectly-heated gasifier system is competitive with the diesel market prices since the DME price 
is lower than the average diesel price in unit of $\$ / \mathrm{mmBtu}$ based on LHV. The DME price of the directlyheated one is at the high end of the diesel price range.

Table 6-4 Major Cost Results for Biomass-to-DME

\begin{tabular}{|c|c|c|c|c|}
\hline Case & \multicolumn{2}{|c|}{ Indirectly-Heated Gasifier } & \multicolumn{2}{|c|}{ Directly-Heated Gasifier } \\
\hline CAPITAL COSTS & $\mathrm{mm} \mathrm{\$}$ & $\%$ of total & $\mathrm{mm} \mathrm{\$}$ & $\%$ of total \\
\hline Air separation unit & -- & -- & 10.3 & $9 \%$ \\
\hline Feed prep and drying & 11.2 & $15 \%$ & 12.3 & $10 \%$ \\
\hline $\begin{array}{l}\text { Gasification with tar reforming, heat } \\
\text { recovery, scrubbing }\end{array}$ & 13.7 & $18 \%$ & 41.4 & $35 \%$ \\
\hline Syngas cleanup and steam reforming & 28.7 & $37 \%$ & 31.7 & $26 \%$ \\
\hline Methanol synthesis and separation & 8.3 & $11 \%$ & 7.7 & $6 \%$ \\
\hline DME synthesis and separation & 2.8 & $3 \%$ & 2.6 & $2 \%$ \\
\hline $\begin{array}{l}\text { Steam system and power generation } \\
\text { Remainder off-site battery limits }\end{array}$ & 9.7 & $13 \%$ & 11.7 & $10 \%$ \\
\hline (OSBL) & 2.2 & $3 \%$ & 2.3 & $2 \%$ \\
\hline $\begin{array}{l}\text { Total Purchased Equipment Cost } \\
\text { (TPEC), mm\$ }\end{array}$ & 76.6 & $100 \%$ & 120 & $100 \%$ \\
\hline Total Installed Cost (TIC), mm\$ & \multicolumn{2}{|c|}{189} & \multicolumn{2}{|c|}{297} \\
\hline Total Indirect Cost, $\mathbf{m m \$}$ & \multicolumn{2}{|c|}{97} & \multicolumn{2}{|c|}{151} \\
\hline Total Project Investment, mm\$ & \multicolumn{2}{|c|}{286} & \multicolumn{2}{|c|}{448} \\
\hline OPERATING COSTS & $\$ /$ gal product & $\%$ of total & \$/gal product & $\%$ of total \\
\hline Biomass & 0.53 & $36 \%$ & 0.57 & $30 \%$ \\
\hline Natural Gas & 0.00 & $0 \%$ & 0.00 & $0 \%$ \\
\hline Catalysts \& Chemicals & 0.08 & $6 \%$ & 0.09 & $5 \%$ \\
\hline Waste Disposal & 0.02 & $1 \%$ & 0.02 & $1 \%$ \\
\hline $\begin{array}{l}\text { Utilities (cooling water, boiler water, } \\
\text { electricity) }\end{array}$ & 0.05 & $3 \%$ & -0.08 & $-4 \%$ \\
\hline Fixed Costs & 0.20 & $13 \%$ & 0.30 & $16 \%$ \\
\hline Capital Depreciation & 0.18 & $12 \%$ & 0.29 & $15 \%$ \\
\hline Average Income Tax & 0.12 & $8 \%$ & 0.20 & $11 \%$ \\
\hline Average Return on Investment & 0.31 & $21 \%$ & 0.51 & $27 \%$ \\
\hline MFSP, \$/gal & \multicolumn{2}{|c|}{1.50} & \multicolumn{2}{|c|}{1.91} \\
\hline $\begin{array}{l}\text { MFSP ethanol equivalent LHV basis, } \\
\text { \$/gal }\end{array}$ & \multicolumn{2}{|c|}{1.64} & \multicolumn{2}{|c|}{2.10} \\
\hline
\end{tabular}

\subsubsection{Sensitivity Analysis}

A sensitivity analysis is performed to observe the effect of varying biomass price, which is the highest contributor to DME production cost, and Internal Rate of Return (IRR) on the minimum selling price of 
DME. The possibility of using one-step methanol and DME production will be also be discussed in this section to evaluate its advantages and disadvantages over the current two-step DME process.

Figure 6-3 shows the effect of varying biomass price and IRR to DME MFSP for the indirectly-heated gasification system.

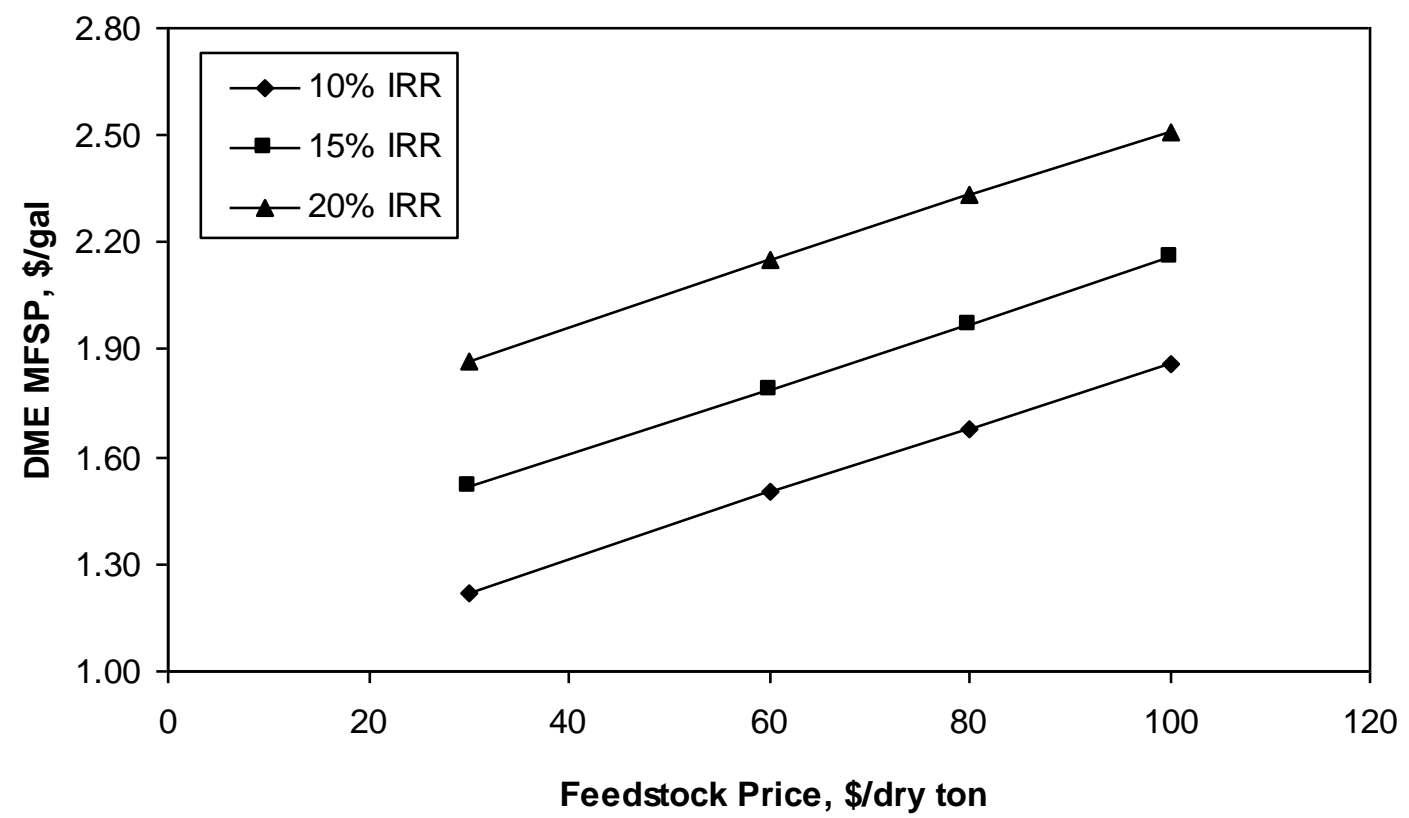

Figure 6-3 Effects of Feedstock Cost and IRR on DME MFSP (Indirectly-Heated Gasifier)

Figure 6-3 shows the dependency of MFSP on feedstock price is linear. For a low feedstock price of $\$ 30$ per dry ton, the DME MFSP drops to 1.22 \$/gallon or 17.49 \$/MMBtu(LHV), which is lower than the diesel wholesale average price of 23.20 \$/MMBtu (LHV) in 2008. Internal Rate of Return (IRR) measures how fast the return on investment would be. Therefore, MFSP is higher with higher IRR. For a feedstock price of 60 \$/dry ton, a 20\% IRR will result in the DME MFSP of \$2.1/gallon.

Figure 6-4 shows the effect of changing IRR and biomass price to DME directly-heated gasification plant MFSP. The same trends seen with the indirectly-heated case are expected, with slightly higher prices because of lower DME production and higher capital costs (see section 6.3.2). For a feedstock cost of $\$ 60$ per dry ton, increasing the IRR from $10 \%$ to $20 \%$ increases the MFSP from $\$ 1.91$ to $\$ 2.99 /$ gallon. If the feedstock cost is to lowered by half to $\$ 30$ per dry ton, the MFSP drops to $\$ 1.62 /$ gallon or $\$ 23.23$ /mmBTU (LHV). This is insufficient to be economic. 


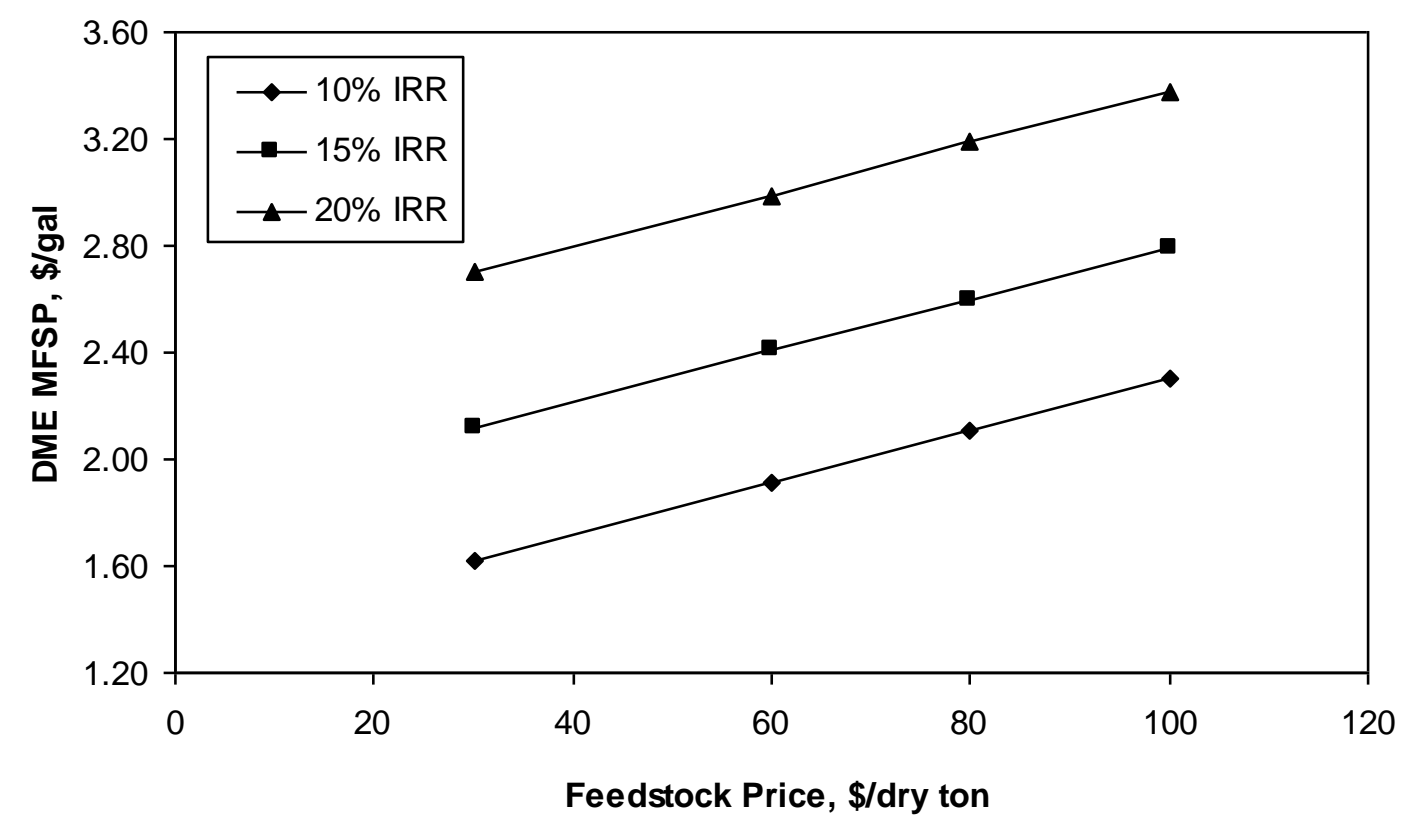

Figure 6-4 Effects of Feedstock Cost and IRR on DME MFSP (Directly-Heated Gasifier)

\subsection{Potential Improvements}

The same potential improvements for methanol synthesis are assumed for the DME cases. That is, recycling purge gas back to the improved tar reformer and eliminating the steam reformer. The details of the potential improvements have been described in Section 5. With this design, the methanol yields increase and thus the DME yields increase proportionally. The cost analysis results show that the DME price decreases about $6 \%$ and $4 \%$ for the indirectly-heated and directly-heated gasifier based system.

Another potential improvement for DME production is to combine methanol synthesis and dehydration to DME in one reactor. Evaluating this option in detail is outside the scope of this project. However, it is noted here because of its potential to reduce costs. As previously mentioned, several companies are working on this technology. The process uses a bi-functional catalyst system. The primary equations occurring in the reactor are:

$$
\begin{aligned}
& 2 \mathrm{H}_{2}+\mathrm{CO} \rightarrow \mathrm{CH}_{3} \mathrm{OH} \\
& 2 \mathrm{CH}_{3} \mathrm{OH} \rightarrow \mathrm{CH}_{3} \mathrm{OCH}_{3}+\mathrm{H}_{2} \mathrm{O} \\
& \mathrm{CO}+\mathrm{H}_{2} \mathrm{O} \rightarrow \mathrm{CO}_{2}+\mathrm{H}_{2}
\end{aligned}
$$

The first reaction is the methanol synthesis reaction, the second is the methanol dehydration, and the last is the water-gas shift reaction. Combining these three equations, the overall reaction becomes:

$$
3 \mathrm{CO}+3 \mathrm{H}_{2} \rightarrow \mathrm{CH}_{3} \mathrm{OCH}_{3}+\mathrm{CO}_{2}
$$


The single pass conversion for syngas is improved because methanol is being reacted away (Eq. 6-3) as it is being produced (Eq. 6-2) and thus, effectively shifting the equilibrium of Eq. (6-2) to produce more methanol. In addition, when the syngas is rich in $\mathrm{CO}$, water produced from methanol dehydration leads to $\mathrm{H}_{2}$ production via the water gas shift reaction (Eq. 6-4), and thus drives the production of methanol in Eq. (6-2). This synergistic effect is seen as a great advantage of the one-step DME process, as greater productivity generally leads to smaller DME reactors and associated costs (Peng et al. 2002). The enhanced productivity along with the elimination of a second reactor is the main advantages of the onestep process. However, the disadvantage is that downstream separation operations are more complex and costly compared to the two-step process (Peng et al. 1999). The major challenge is separation of unconverted syngas for recycle from the product DME and carbon dioxide, which is proposed to be achieved by scrubbing with DME, methanol, or a combination of both (Peng et al. 2002). It is recommended that a detailed techno-economic analysis of the one-step DME process should be performed to elucidate the differences between the two options. 


\subsection{Hydrothermal Liquefaction}

In recent years, with the depletion of fossil fuel and increasing demand for transport fuel, direct liquefaction of biomass feedstocks into liquid oils has aroused intensive interest. The direct conversion of biomass to liquid fuel and the relatively high liquid fuel yields compared to other indirect conversion methods make direct liquefaction attractive (Elliot 2007, Xu and Lad 2008). Examples of direct liquefaction processes include fast pyrolysis and high-pressure hydrothermal liquefaction (Elliot 2007, Oasmaa and Kuoppala 2003). The fast pyrolysis process is commercially demonstrated, whereas, HTL is at the pilot scale. Compared to the pyrolysis oil, the bio-oil produced in the HTL process has lower oxygen/water content and thus much higher caloric values, which is comparable to that of fossil fuel (Goudriaan et al. 2001, Elliot 2007).

In the HTL process, biomass is converted to crude bio-oil in liquid water at high temperatures from 572 $662^{\circ} \mathrm{F}\left(300\right.$ to $\left.350^{\circ} \mathrm{C}\right)$ and high pressures from 1,740 to $2,610 \mathrm{psia}$ (12 to $\left.18 \mathrm{MPa}\right)$. The residence time is 5-20 minutes (Zhong et al. 2002). In this process, biomass is liquefied in liquid water and the main products are bio crude, gas, water and dissolved organics. The key in biomass liquefaction is removing oxygen. Biomass contains typically 40-45\%w (DAF, dry and ash free basis) of oxygen. About $85 \%$ of oxygen is removed mainly as $\mathrm{CO}_{2}$ and water in the HTL process. Oxygen removal increases the heating value, which results in a bio-oil product with an oxygen content as low as 10-18 wt \%. The biocrude is not miscible with water and it has a lower heating value of 12,900 to $15,050 \mathrm{Btu} / \mathrm{lb}$ (30 to $35 \mathrm{MJ} / \mathrm{kg}$ )

(Goudriaan et al. 2001). The biocrude can potentially be upgraded by hydrotreating and hydrocracking to produce diesel and gasoline. An advantage of the HTL process is that no feedstock drying is required and wet biomass can be used in this process.

The HTL process was developed in the early 1980's by Shell Research (Goudriaan et al. 2001). Some technical and economic analyses have been carried out to evaluate the feasibility of the development of HTL technologies (Goudriaan et al. 2001, Xu and Lad 2008). However, the HTL process has not yet been commercialized. Furthermore, upgrading the HTL oil to stable oil or to gasoline and diesel fuel has not been demonstrated. In this study, a techno-economic analysis for the biomass-to-liquid fuel via HTL processing is performed. Two final products are considered. One is stable oil and another one is diesel and gasoline. In the biomass-to-stable oil system, the stable oil is produced via the HTL and hydrotreating processes. For the biomass-to-diesel/gasoline system, the heavy compounds in the stable oil are separated and further processed via hydrocracking to produce diesel and gasoline. The main products yields and selling prices for the two products are estimated.

\subsection{Process Design Description}

A simplified block diagram of the HTL process is given in Figure 7-1. The processing steps include:

- $\quad$ Feedstock preteatment

- Hydrothermal liquefaction to bio-oil

- Hydrotreating of the bio-oil to a stable hydrocarbon oil

- Hydrocracking of the heavy portion of the stable hydrocarbon oil and product separation to gasoline and diesel fuel blendstocks. 
- Steam reforming of the process offgas and supplemental natural gas to produce hydrogen for the hydrotreating and hydrocracking steps.

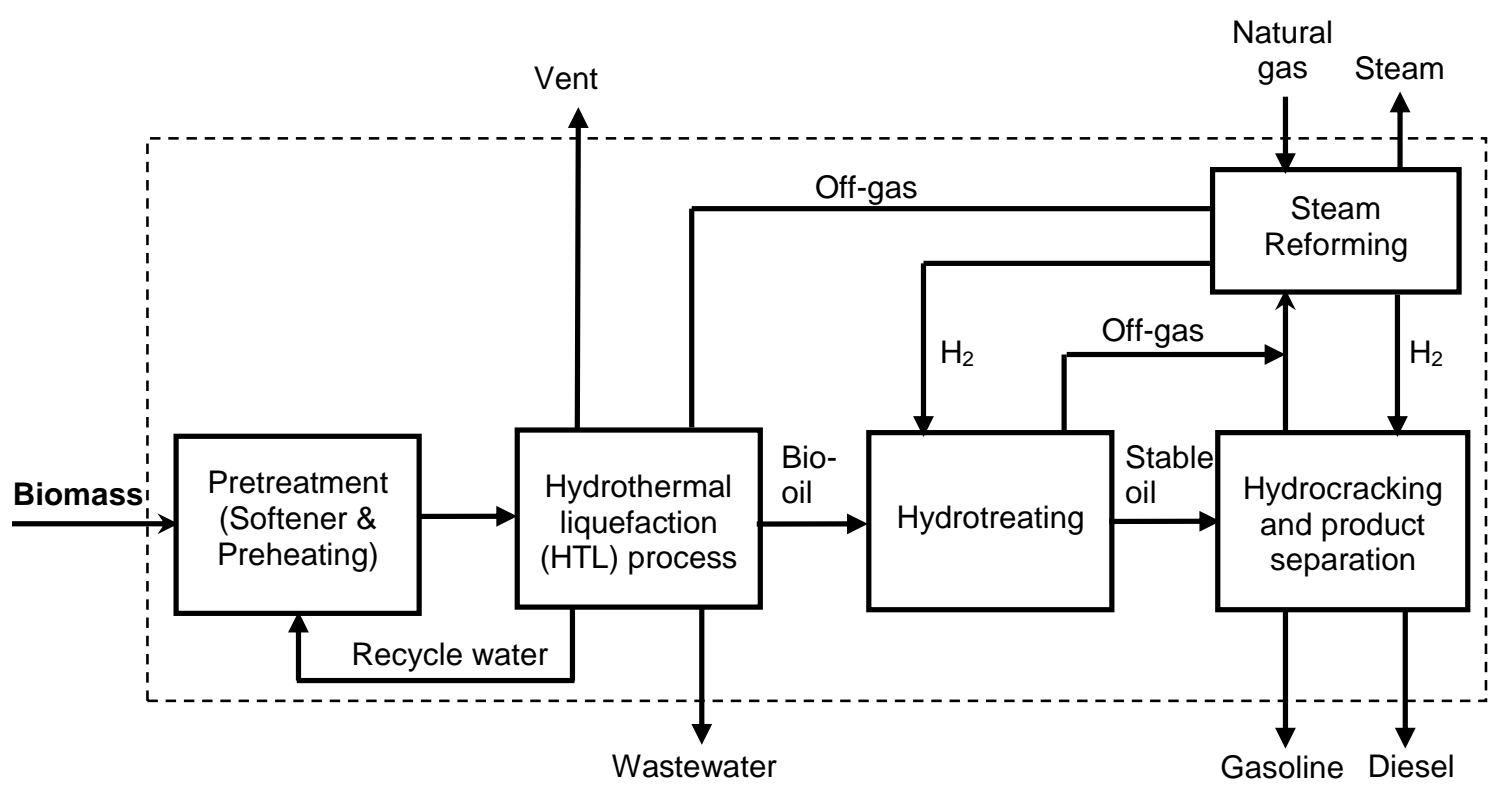

Figure 7-1 Block Diagram for Production of Stable Oil or Gasoline/Diesel from Biomass via HTL

Wood chips with 50wt\% moisture are softened by direct injection of hot recycle water and preheated by cooling the product gas from the HTL process. The heated biomass is converted in the HTL reactor to produce biocrude, water with dissolved light organics, and gas. The product stream is cooled and separated as gas phase and two liquid phases, bio-oil and water. The bio-oil is then sent to a hydrotreating process to convert the oxygenated compounds in the bio-oil to hydrocarbons and water plus carbon dioxide. Then hydrocarbon oil is stabilized by cooling and distillation. The heavy compounds in the stable oil are separated and further converted to light compounds in a hydrocracker. Gasoline and diesel range products are separated by distillation. In this study, two cases are considered: one that produces stable oil product (e.g., for insertion into an existing petroleum refinery) and one that produces gasoline and diesel products. Here, stable oil refers to one that is highly deoxygenated ( $<2 \%$ oxygen content).

\subsubsection{Feed Pretreatment and Hydrothermal Liquefaction}

Figure 7-2 shows the process flow diagram for feedstock pretreatment and hydrothermal liquefaction (HTL) processes. The wet biomass is first pumped to 2,610 psia, the operating pressure of the HTL reactor. Then the biomass is sent to the softener. Hot recycle water (S-137) from the HTL reactor is directly injected to the softener and mixed with the feed biomass for softening and effective heat transfer. With hot water mixing, the biomass is softened to be a paste-like substance (Goudriaan et al. 2001). 


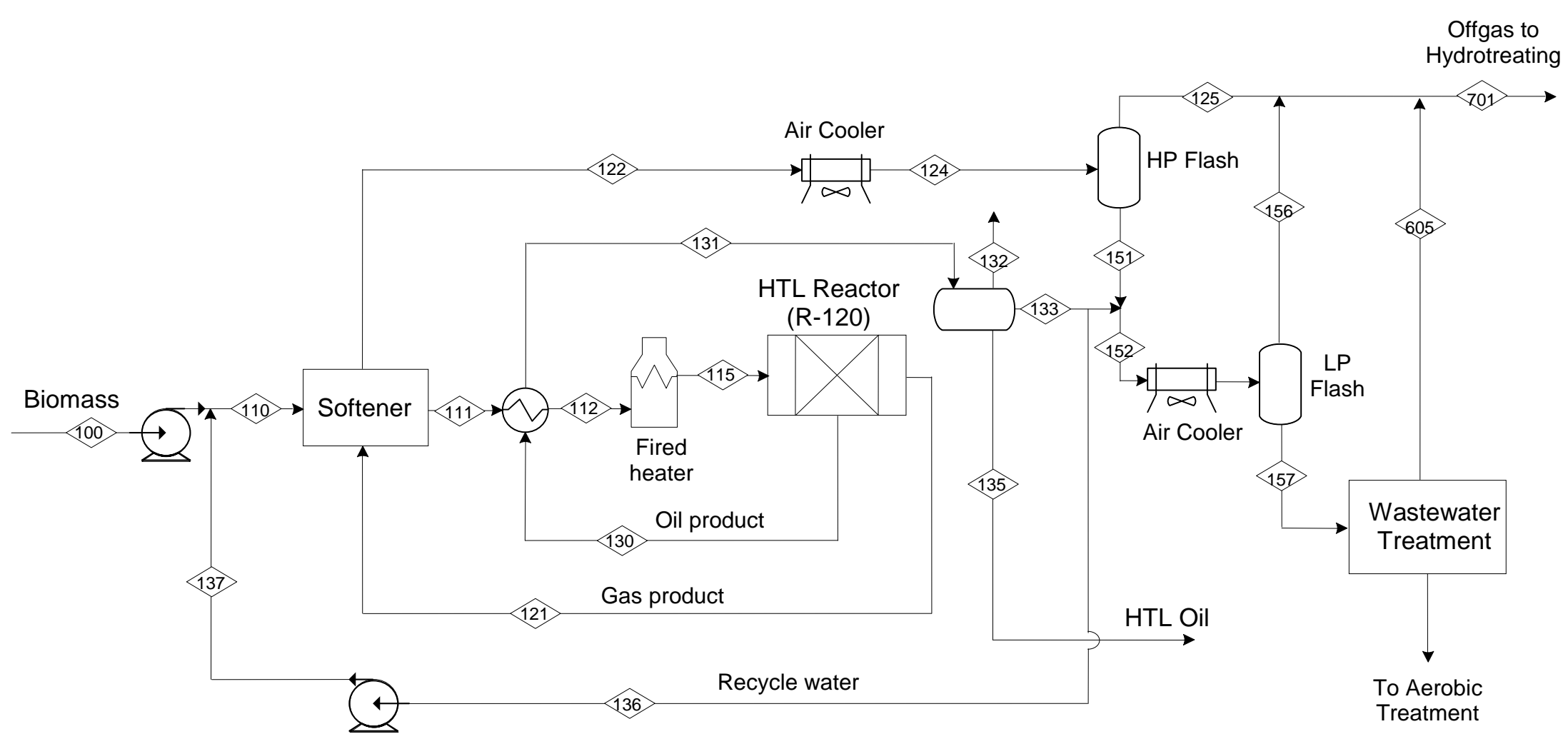

Figure 7-2 Process Flow Diagram for Feed Pretreatment and Hydrothermal Liquefaction 
The softened biomass is preheated to $482^{\circ} \mathrm{F}\left(250^{\circ} \mathrm{C}\right)$ by hot exhaust gas (S-121) from the HTL reactor in the softener. The biomass softening enables the biomass to flow freely through the heat exchangers and thus allowing effective heat transfer between the hot gas product and the softened biomass feedstock. The residence time required in the reactor is 2 to 100 minutes (Goudriaan et al. 2001).

The preheated and softened biomass feedstock is first heated by the hot oil product (S-130) to $608^{\circ} \mathrm{F}$ and then heated by a process fire heater to $662^{\circ} \mathrm{F}\left(350^{\circ} \mathrm{C}\right)$. The heated wet biomass flow is sent to the HTL reactor and the hydrothermal liquefaction reactions take place at 2611 psia and $662^{\circ} \mathrm{F}\left(350^{\circ} \mathrm{C}\right)$. The main reason for the high pressure operating is that subcritical water has enhanced solvent properties that cause the formation of liquid products. In this study, the HTL reactor is simulated by using a stoichiometric reactor unit block in ChemCad. The stoichiometric coefficients of the reactants are calculated based on biomass compositions and target products compositions data from references (Feng et al. 2004).

The HTL reactor generates an oil phase, an aqueous phase, and a gas product. The aqueous phase consists of water and dissolved organics. The HTL oil represents about 45 to $50 \mathrm{wt} \%$ of the feedstock on dry basis, and is the main product (Naber and Goudriaan 2005). It has an oxygen content of about 10 to 20 wt\% (Naber and Goudriaan 2005, Zhong et al. 2002). The gaseous compounds include carbon dioxide, carbon monoxide, and some methane and hydrogen. The light organics dissolved in the water phase consist mainly of acetic acid, acetone, and components such as methyl-cyclopentenone and hydroxypyridine (Goudriaan et al. 2001). In Table 7-1, the main HTL process modeling results and related reference data are listed.

The oil product is first cooled by the incoming feedstock to about $480^{\circ} \mathrm{F}\left(249^{\circ} \mathrm{C}\right)$. Then the cooled stream is separated into a gas phase, a water phase and HTL oil. The gaseous compounds are cooled and recovered as fuel gas. Ninety percent of the water phase (S-134) from the separator is pumped and recycled to the softener to mix with the biomass feedstock. The remaining water is combined with the process condensate (S-151) from the high pressure flash tank of the gas product and further cooled by air cooling.

The gas product (S-121) is first used to preheat the softened biomass feedstock. The gas stream is cooled to about $500^{\circ} \mathrm{F}\left(260^{\circ} \mathrm{C}\right)(\mathrm{S}-122)$ and then further cooled to $212^{\circ} \mathrm{F}\left(100^{\circ} \mathrm{C}\right)$ by air cooling. The cooled stream (S-124) is sent to a separator and the condensate (S-151) is collected. The condensate water and the remaining water from the liquid product separator are further cooled by air coolers to $150^{\circ} \mathrm{F}\left(66^{\circ} \mathrm{C}\right)$. The cooled stream is sent to another separator and the condensate, mostly water, is sent to a wastewater treatment process. Anaerobic digestion is used to treat the organics in the waste water and most of the organics in the water phase are assumed to be converted to methane and carbon dioxide. The off-gases from the HTL reaction (S-125 and S-156) are combined with the effluents (S-605) from the wastewater treatment and used as fuel gas (S-701). 
Table 7-1 HTL Process Conditions and Products Characterization

\begin{tabular}{|c|c|c|}
\hline & Model & Reference Data \\
\hline \multicolumn{3}{|l|}{ HTL conditions } \\
\hline Temperature, ${ }^{\circ} \mathrm{C}\left({ }^{\circ} \mathrm{F}\right)$ & $350(662)$ & 572 to 662 \\
\hline Pressure, psig & 2,610 & 1,740 to 2,610 \\
\hline \multicolumn{3}{|l|}{ Yields, lb/100 lb dry wood } \\
\hline Biocrude & 49.1 & 45 to 50 \\
\hline Gas & 24.0 & 25 to 30 \\
\hline Water & 14.9 & 15 to 20 \\
\hline Dissolved organics & 9.2 & 5 to 10 \\
\hline \multicolumn{3}{|l|}{ Bio-oil composition, wt $\%$} \\
\hline $\mathrm{C}$ & 74.6 & 75 to 82 \\
\hline $\mathrm{H}$ & 6.7 & 6 to 8.1 \\
\hline $\mathrm{O}$ & 18.7 & 10 to 20 \\
\hline Bio oil $\mathrm{H} / \mathrm{C}$ molar ratio & 1.1 & 1.0 to 1.3 \\
\hline Bio oil LHV (lower heating value), Btu/lb & 12,700 & 12,900 to 15,050 \\
\hline \multicolumn{3}{|l|}{ Gas composition, wt $\%$} \\
\hline $\mathrm{CO}_{2}$ & 85.0 & 93 to 94 \\
\hline $\mathrm{CO}$ & 12.0 & 2 to 6 \\
\hline $\mathrm{CH}_{4}$ & 2.5 & 0.6 to 4 \\
\hline $\mathrm{H}_{2}$ & 0.5 & 0.2 to 0.3 \\
\hline Thermal efficiency, \% HHV (higher heating value) & 82 & 70 to 90 \\
\hline
\end{tabular}

\subsubsection{Hydrotreating to Stable Oil}

The bio-oil produced from the HTL process is a heavy organic liquid with about $16 \mathrm{wt} \%$ oxygen, and thus, not strictly a hydrocarbon-like product. HTL oil can be stabilized and converted to a conventional hydrocarbon fuel by removing the oxygen through hydrotreating. Hydrotreating to remove nitrogen and sulfur from hydrocarbons is a common and well established refinery process. Oxygen removal from HTL bio oil has not been demonstrated at any scale. It is assumed to be similar to the upgrading of fast pyrolysis oil, which has been demonstrated at the lab scale.

The upgrading step involves contacting the HTL oil with hydrogen under pressure and at moderate temperatures $\left(<750^{\circ} \mathrm{F}\left(400^{\circ} \mathrm{C}\right)\right)$ over a fixed bed reactor. Upgrading fast pyrolysis oil requires two-stage hydrotreating as single stage hydrotreating has proved to be difficult, producing a heavy, tar-like product. Dual stage processing, where mild hydrotreating is followed by more severe hydrotreating has been found to overcome the reactivity of fast pyrolysis oil (Solantuasta 2006). Since HTL oil has a much lower oxygen content than fast pyrolysis oil, single stage is likely sufficient. Overall, the HTL oil is almost completely deoxygenated by a combination of hydrodeoxygenation and decarboxylation:

$$
\mathrm{C}_{\mathrm{n}} \mathrm{COOH} \stackrel{\text { Catalyst } / 3 \mathrm{H}_{2}}{\longrightarrow} \quad \mathrm{C}_{\mathrm{n}+1}+2 \mathrm{H}_{2} \mathrm{O} \quad \text { Hydrodeoxygenation }
$$




$$
\mathrm{C}_{\mathrm{n}} \mathrm{COOH} \stackrel{\text { Catalyst } / \mathrm{H}_{2}}{\longrightarrow} \mathrm{C}_{\mathrm{n}}+\mathrm{CO}_{2} \quad \text { Decarboxylation }
$$

Figure 7-3 shows the process flow diagram of the HTL oil hydrotreating to stable oil process. The HTL oil product from the HTL unit is combined with compressed hydrogen from a steam reforming process and preheated with reactor effluent. A single catalytic reaction stage is used. The product stream is cooled and sent to a separator. Water and off-gas are separated from oil. The water phase contains some dissolved organics, while the off-gas contains light hydrocarbons, excess hydrogen and carbon dioxide.

The hydrotreated oil is stabilized by removing the butane and lighter components in a lights removal column. The overhead in the gas phase containing light organics is combined with off-gas from the HTL and wastewater treatment processes. The stable oil is assumed to be sold as a synthetic crude product or further processed to produce conventional fuels, such as diesel and gasoline. Both of the options are considered.

The offgas from the hydrotreaters is sent to a Pressure Swing Adsorption (PSA) system for recovery of the hydrogen gas. The recovered hydrogen is recycled back to the reactors. The low pressure PSA tail gas stream, which is rich in by-product light hydrocarbons, is combined with the offgas from the HTL process. A portion of the off-gas is sent to the HTL process as the fuel for the fire heater for preheating the biomass feedstock. 


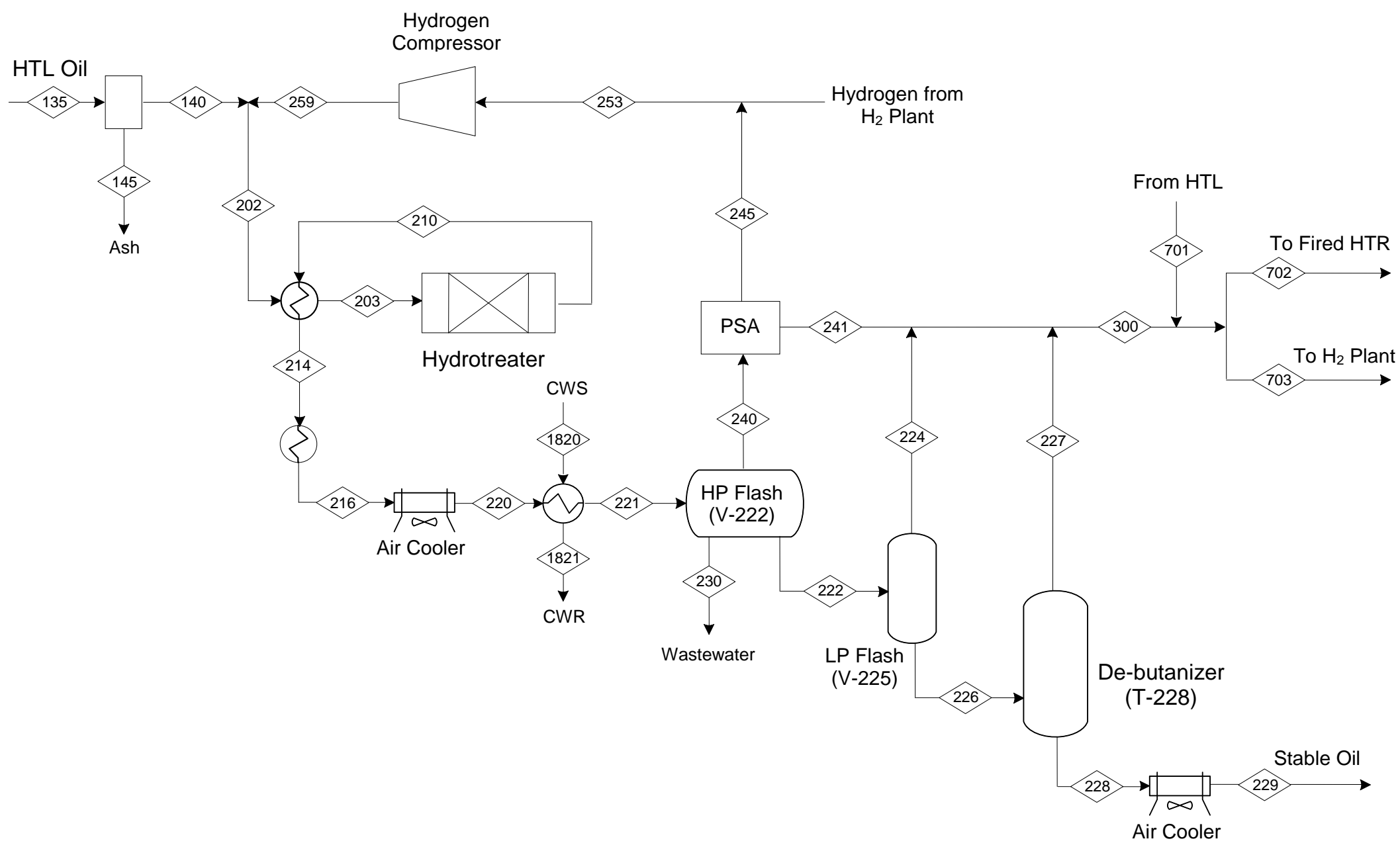

Figure 7-3 Process Flow Diagram for HTL Oil Hydrotreating 


\subsubsection{Hydrocracking and Product Separation}

The hydrocracking process is a catalytic cracking process to convert heavy hydrocarbons to light components in the presence of hydrogen on metal sulfide catalysts. The purpose is to increase the yield of light products rich in hydrogen, i.e. gasoline, from heavy crude. Conventional refinery hydrocracking reactions usually take place at about $752^{\circ} \mathrm{F}\left(400^{\circ} \mathrm{C}\right)$ and 1,160 to 2,175 psia (Alfke et al. 2007). By adding hydrogen, heavy hydrocarbons are rearranged and broken to produce high quality products, i.e. fuel oils, diesel, gasoline, and LPG.

As shown in Figure 7-4, the stable oil stream is first sent to two distillation tower to be separated into a light and heavy fraction. The first distillation tower serves to remove the gasoline boiling range fraction. (S-305). The bottoms stream (S-306) feeds the next distillation tower, which serves as a diesel splitter (S$309)$. The heavy fraction $(\mathrm{S}-308)$ that boils above $662^{\circ} \mathrm{F}\left(350^{\circ} \mathrm{C}\right)$ is sent to the hydrocracker to completely convert the oil to gasoline and diesel blend components. Hydrogen (S-532) produced from the hydrogen plant is compressed to 1,314 psi and then preheated by the hot product stream (S-512) from the hydrocracking reactor. The heated hydrogen at $670^{\circ} \mathrm{F}$ is mixed with the heavy fraction from the diesel splitter and sent to the hydrocracking unit. The heavy oil is converted to light components. The product is a mixture of liquids spanning the gasoline and diesel range and some by-product gas. The product stream (S-512) is first cooled by inlet hydrogen and then cooled by providing heat for the reboiler of the final distillation tower. The product stream is further cooled by air and cooling water to $110^{\circ} \mathrm{F}\left(43^{\circ} \mathrm{C}\right)$. The cooled stream is sent to flash units to separate condensate and gas components. The offgas from the hydrocracking unit is partly recycled (S-523) to the reactor. The purged offgas is mixed with the offgas from the HTL and hydrotreating processes, which is used as fuel gas in process heaters and for hydrogen production (S-703). The liquid product from the hydrocracker is sent to the final product separation tower and to distill products into the gasoline (S-542) and diesel (S-545) range. These products are assumed to be suitable for blending into finished fuel. This assumption needs to be verified through research and testing.

\subsubsection{Hydrogen Production}

The off-gas by itself is insufficient to produce sufficient hydrogen via steam reforming as required by the hydrotreaters and hydrocrackers, thus supplemental natural gas is used. Most of the off-gas is used to fire the steam reformer. However, a portion of the off-gas is compressed and mixed with makeup natural gas which is then hydrodesulfurized (HDS) before being reformed into syngas. The syngas hydrogen content is increased by high temperature shift (HTS). After condensing out the water the hydrogen is purified by pressure swing adsorption (PSA). Off-gas from the PSA is recycled to the reformer burners. The simulation of steam reforming process is based on SRI International (2003) and Meyers (2004).

Saturated steam at 660 psia and superheated steam at $700^{\circ} \mathrm{F}\left(371^{\circ} \mathrm{C}\right)$ is generated by recuperating heat from the reformer exhaust and during syngas cooling. The steam is used in the reformer and as heat for process heaters and distillation column reboilers. The remaining steam is assumed to be used to provide power for onsite compressor and pump drivers. Plant power is assumed to be purchased from the grid. 


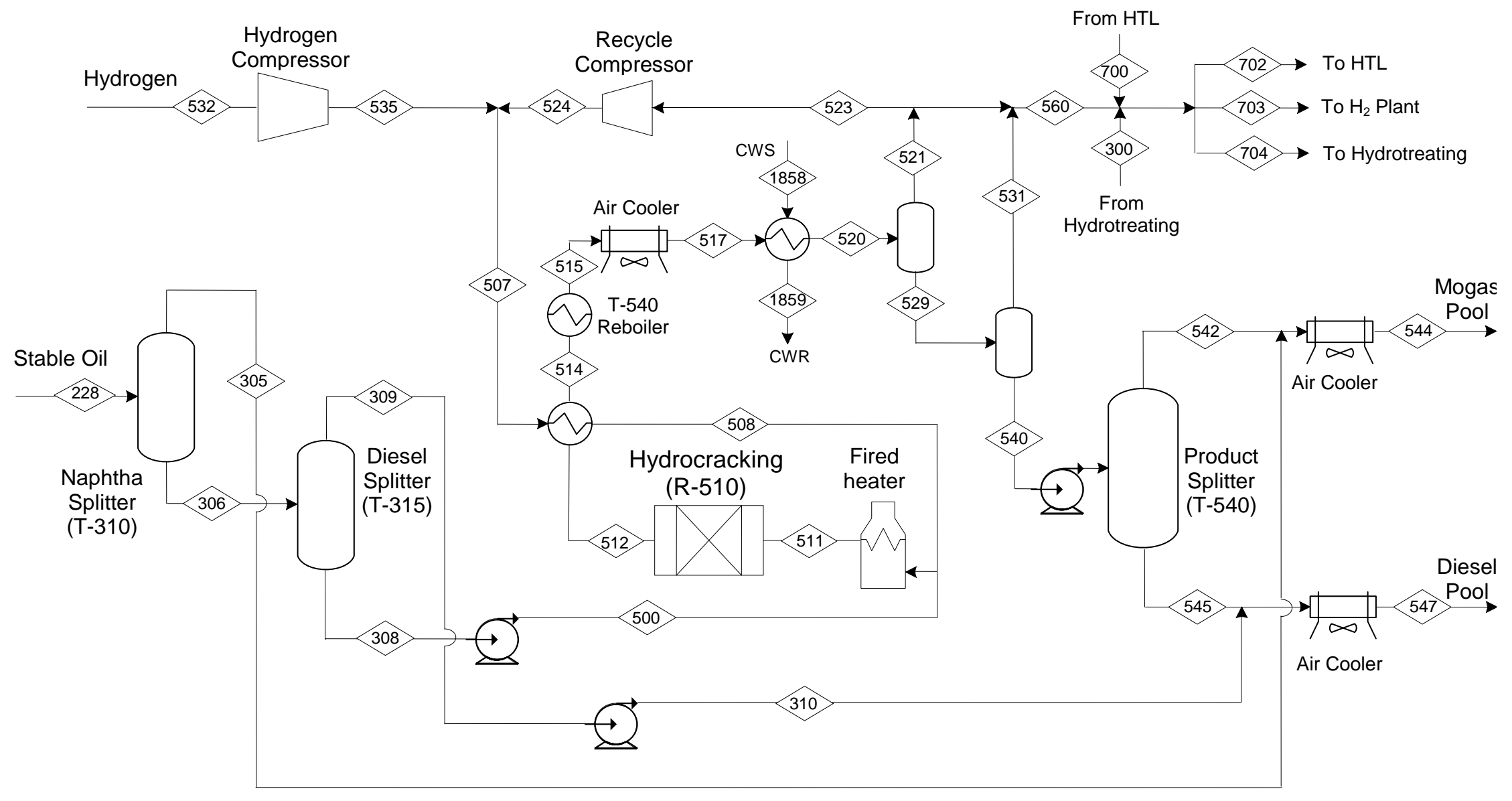

Figure 7-4 Process Flow Diagram for Hydrocracking and Product Separation 


\subsection{Key System Assumptions}

The major system assumptions for the biomass HTL are shown in Table 7-2.

Table 7-2 Major System Assumptions for Hydrothermal Liquefaction

\begin{tabular}{|c|c|c|}
\hline Case & Biomass-to-Stable Oil & $\begin{array}{c}\text { Biomass-to-Gasoline } \\
\text { and Diesel }\end{array}$ \\
\hline \multicolumn{3}{|c|}{ Preheating } \\
\hline Dry wood chips, tpd (mtpd) & $2200(2000)$ & $2200(2000)$ \\
\hline Pressure, psia & 2,610 & 2,610 \\
\hline Temperature, ${ }^{\circ} \mathrm{C}\left({ }^{\circ} \mathrm{F}\right)$ & $250(482)$ & $250(482)$ \\
\hline \multicolumn{3}{|c|}{ Hydrothermal Liquefaction (HTL) } \\
\hline Reactor outlet temperature, ${ }^{\circ} \mathrm{C}\left({ }^{\circ} \mathrm{F}\right)$ & $350(662)$ & $350(662)$ \\
\hline Reactor outlet pressure, psia & 2,610 & 2,610 \\
\hline \multicolumn{3}{|c|}{ Hydrotreating } \\
\hline $1^{\text {st }}$ Stage & Adiabatic & Adiabatic \\
\hline Outlet temperature, ${ }^{\circ} \mathrm{C}\left({ }^{\circ} \mathrm{F}\right)$ & $250(480)$ & $250(480)$ \\
\hline Outlet pressure, psia & 2515 & 2515 \\
\hline Space velocity, $\mathrm{hr}^{-1}$ & 1 & 1 \\
\hline $2^{\text {nd }}$ Stage & Isothermal & Isothermal \\
\hline Outlet temperature, ${ }^{\circ} \mathrm{C}\left({ }^{\circ} \mathrm{F}\right)$ & $360(800)$ & $360(800)$ \\
\hline Outlet pressure, psia & 2515 & 2515 \\
\hline Space velocity, $\mathrm{hr}^{-1}$ & 0.14 & 0.14 \\
\hline \multicolumn{3}{|l|}{ Yields targets, lb /100 lb wet HTL bio oil } \\
\hline Stable Oil & 65 & 65 \\
\hline Water & 27 & 27 \\
\hline Gas & 8 & 8 \\
\hline Offgas hydrogen recovery by PSA, $\%$ & 80 & 80 \\
\hline \multicolumn{3}{|c|}{ Hydrocracking } \\
\hline Reactor inlet temperature, ${ }^{\circ} \mathrm{C}\left({ }^{\circ} \mathrm{F}\right)$ & & $427(750)$ \\
\hline Reactor inlet pressure, psia & & 1290 \\
\hline Space velocity, $\mathrm{hr}^{-1}$ & & 1 \\
\hline \multicolumn{3}{|c|}{ Hydrogen Plant } \\
\hline Steam reformer outlet temperature, ${ }^{\circ} \mathrm{C}\left({ }^{\circ} \mathrm{F}\right)$ & $850(1562)$ & $850(1562)$ \\
\hline Steam reformer outlet pressure, psia & 330 & 330 \\
\hline Boiler feed water condition, ${ }^{\circ} \mathrm{C}\left({ }^{\circ} \mathrm{F}\right) / \mathrm{psia}$ & $122(251) / 660$ & $122(251) / 660$ \\
\hline Export steam conditions, ${ }^{\circ} \mathrm{C}\left({ }^{\circ} \mathrm{F}\right) / \mathrm{psia}$ & $371(700) / 660$ & $371(700) / 660$ \\
\hline
\end{tabular}

The equipment sizing and cost reference information used are summarized in Table 7-3.

Table 7-3 Literature Capital Cost Basis for HTL System

\begin{tabular}{|c|c|c|c|c|}
\hline Equipment & Cost Year & Scaling stream & Base size & Base Cost, MM\$ \\
\hline HTL process ${ }^{\text {(a) }}$ & 1999 & Biomass feed rate & 430 short ton/d & 30 \\
\hline Hydrocracker ${ }^{(b)}$ & 2005 & Oil to hydrocracker & $2250 \mathrm{barrel} / \mathrm{d}$ & 30 \\
\hline Hydrogen plant ${ }^{(\mathrm{c})}$ & May 2003 & $\mathrm{H}_{2}$ product & 49.9 MMscf/d & 62 \\
\hline
\end{tabular}




\subsection{Results and Analysis}

In this section, the performance and cost results are listed and discussed.

\subsubsection{Performance Results}

The main performance results for the two cases are shown in Table 7-4. The two largest power consumers are the feed treatment and hydrotreating. The biggest water demand is the hydrogen plant boiler feed water. The carbon balance shows that the hydrogen plant exhaust represents the most carbon waste.

Table 7-4 Performance Results for Hydrothermal Liquefaction

\begin{tabular}{|c|c|c|c|}
\hline \multicolumn{2}{|r|}{ Case } & Biomass-to-Stable Oil & Biomass-to-Gasoline and Diesel \\
\hline \multicolumn{4}{|l|}{ Feed } \\
\hline \multicolumn{2}{|c|}{ Dry wood chips, tpd (mtpd) } & $2200(2000)$ & $2200(2000)$ \\
\hline \multicolumn{2}{|c|}{ Natural gas, $1000 \mathrm{scf} / \mathrm{h}$} & 250 & 263 \\
\hline \multicolumn{4}{|c|}{ Products } \\
\hline \multicolumn{2}{|c|}{ Stable oil, mmgal/y } & 76 & -- \\
\hline \multicolumn{2}{|c|}{ Gasoline, $\mathrm{mmgal} / \mathrm{y}$} & -- & 22 \\
\hline \multicolumn{2}{|c|}{ Diesel, mmgal/y } & -- & 55 \\
\hline \multicolumn{2}{|c|}{ Total, mmgal/y } & 76 & 78 \\
\hline \multicolumn{4}{|c|}{ Power Consumption, MW } \\
\hline \multicolumn{2}{|c|}{ Feed Pretreatment } & 12.0 & 12.0 \\
\hline \multicolumn{2}{|c|}{ HTU oil production } & 0.0 & 0.0 \\
\hline \multicolumn{2}{|c|}{ Hydrotreating } & 10.0 & 10.0 \\
\hline \multicolumn{2}{|c|}{ Hydrocracking } & -- & 1.1 \\
\hline \multicolumn{2}{|c|}{ Hydrogen plant } & 2.6 & 3.4 \\
\hline \multicolumn{2}{|c|}{ Other auxiliary } & 0.1 & 0.1 \\
\hline \multicolumn{4}{|c|}{ Power Generation, MW } \\
\hline \multicolumn{2}{|c|}{ Power from steam of hydrogen plant } & 8.0 & 7.0 \\
\hline \multicolumn{2}{|c|}{ Net power, MW } & -16.7 & -19.6 \\
\hline \multicolumn{4}{|c|}{ Water Demand, gpm } \\
\hline \multicolumn{2}{|c|}{ Cooling tower makeup } & 83.5 & 84.8 \\
\hline \multicolumn{2}{|c|}{$\begin{array}{l}\text { Hydrogen plant boiler feed water } \\
\text { makeup }\end{array}$} & 252 & 230 \\
\hline \multicolumn{2}{|l|}{ Total } & 336 & 315 \\
\hline \multicolumn{2}{|c|}{ Wastewater, gpm } & 451 & 451 \\
\hline \multicolumn{4}{|c|}{ Carbon balance } \\
\hline \multirow[t]{3}{*}{ Feeds } & Biomass & $92.2 \%$ & $91.8 \%$ \\
\hline & Natural Gas & $7.8 \%$ & $8.2 \%$ \\
\hline & Sum & $100 \%$ & $100 \%$ \\
\hline \multirow{4}{*}{$\begin{array}{l}\text { Fuel } \\
\text { products }\end{array}$} & Stable oil & & \\
\hline & & $55.3 \%$ & -- \\
\hline & Gasoline and Diesel & -- & $55.1 \%$ \\
\hline & Sum & $55.3 \%$ & $55.1 \%$ \\
\hline \multirow[t]{5}{*}{ Wastes } & HTL wastewater & $0.4 \%$ & $0.4 \%$ \\
\hline & Hydrotreating wastewater & $6.8 \%$ & $6.8 \%$ \\
\hline & Process heaters exhaust & $3.8 \%$ & $3.8 \%$ \\
\hline & Hydrogen plant exhaust & $33.7 \%$ & $33.9 \%$ \\
\hline & Sum & $44.7 \%$ & $44.9 \%$ \\
\hline Thermal & ency, \% LHV basis & 63.3 & 62.8 \\
\hline
\end{tabular}




\subsubsection{Cost Results}

The equipment and capital costs results for the two systems are shown in Table 7-5. The HTL system has the highest capital cost, followed by the hydrogen plant. Biomass and natural gas account for more than one third of the operating costs. The January to December 2008 average gasoline wholesale/resale prices range from $\$ 1.06$ to $\$ 3.42 /$ gallon. The 2008 annual average is $\$ 2.58 /$ gallon (Energy Information Administration 2009b). The U.S. No. 2 diesel wholesale/resale price is between $\$ 1.47$ and $\$ 3.89 /$ gallon with an average of \$2.98/gallon in 2008 (Energy Information Administration 2009b). The gasoline and diesel MFSP produced by the HTL system is lower than the average gasoline and diesel price in 2008. This suggests that HTL technology may be economically competitive for fuel production assuming the technical viability of upgrading the oil can be proven.

Table 7-5 Cost Results for Hydrothermal Liquefaction

\begin{tabular}{|c|c|c|c|c|}
\hline \multirow{2}{*}{$\begin{array}{l}\text { Case } \\
\text { CAPITAL COSTS }\end{array}$} & \multicolumn{2}{|c|}{$\begin{array}{c}\text { Biomass-to-Upgraded } \\
\text { HTL Oil }\end{array}$} & \multicolumn{2}{|c|}{$\begin{array}{c}\text { Biomass-to-Gasoline and } \\
\text { Diesel }\end{array}$} \\
\hline & $\mathrm{mm} \$$ & $\%$ of total & $\mathrm{mm} \$$ & $\%$ of total \\
\hline Hydrothermal liquefaction(HTL) & 64.3 & $53 \%$ & 64.3 & $48 \%$ \\
\hline Hydrotreating & 16.7 & $14 \%$ & 16.7 & $12 \%$ \\
\hline Hydrocracking and separation & -- & -- & 12.6 & $9 \%$ \\
\hline Hydrogen plant & 36.9 & $30 \%$ & 37.8 & $28 \%$ \\
\hline Wastewater treatment & 1.8 & $2 \%$ & 1.9 & $1 \%$ \\
\hline Remainder OSBL & 1.6 & $1 \%$ & 1.8 & $1 \%$ \\
\hline \multicolumn{5}{|l|}{ Total Purchased Equipment Cost } \\
\hline (TPEC), mm\$ & 121 & $100 \%$ & 135 & $100 \%$ \\
\hline Total Installed Cost (TIC), mm\$ & \multicolumn{2}{|c|}{300} & \multicolumn{2}{|c|}{334} \\
\hline Total Indirect Cost, $\mathbf{m m \$}$ & \multicolumn{2}{|c|}{106} & \multicolumn{2}{|c|}{123} \\
\hline Total Project Investment, mm\$ & \multicolumn{2}{|c|}{406} & \multicolumn{2}{|c|}{456} \\
\hline OPERATING COSTS & $\$ /$ gal product & $\%$ of total & \$/gal product & $\%$ of total \\
\hline Biomass & 0.57 & $25 \%$ & 0.56 & $23 \%$ \\
\hline Natural Gas & 0.25 & $11 \%$ & 0.26 & $11 \%$ \\
\hline Catalysts \& Chemicals & 0.12 & $5 \%$ & 0.12 & $5 \%$ \\
\hline Waste Disposal & 0.01 & $0 \%$ & 0.01 & $0 \%$ \\
\hline $\begin{array}{l}\text { Utilities (cooling water, boiler water, } \\
\text { electricity) }\end{array}$ & 0.12 & $5 \%$ & 0.14 & $6 \%$ \\
\hline Fixed Costs & 0.27 & $12 \%$ & 0.30 & $12 \%$ \\
\hline Capital Depreciation & 0.27 & $12 \%$ & 0.29 & $12 \%$ \\
\hline Average Income Tax & 0.18 & $8 \%$ & 0.20 & $8 \%$ \\
\hline Average Return on Investment & 0.49 & $21 \%$ & 0.53 & $22 \%$ \\
\hline MFSP, \$/gal & \multicolumn{2}{|c|}{2.28} & \multicolumn{2}{|c|}{2.40} \\
\hline $\begin{array}{l}\text { MFSP ethanol equivalent LHV basis, } \\
\text { \$/gal }\end{array}$ & \multicolumn{2}{|c|}{1.57} & \multicolumn{2}{|c|}{1.69} \\
\hline
\end{tabular}




\subsubsection{Sensitivity Analysis}

Sensitivity analysis was conducted to investigate the effects of different cost assumptions.

\subsubsection{Feedstock Price and Internal Rate of Return}

The sensitivity of the MFSP to different Internal Rates of Return (IRR) and feedstock prices is shown in Figures 7-5 and 7-6. The MSFP was calculated for IRRs of 10\%, 15\%, and 20\%, with feedstock cost of $\$ 30, \$ 60, \$ 80$, and $\$ 100$ per dry ton. The feedstock price was chosen because it represents the greatest percentage of the production cost as shown in Table 7-5.

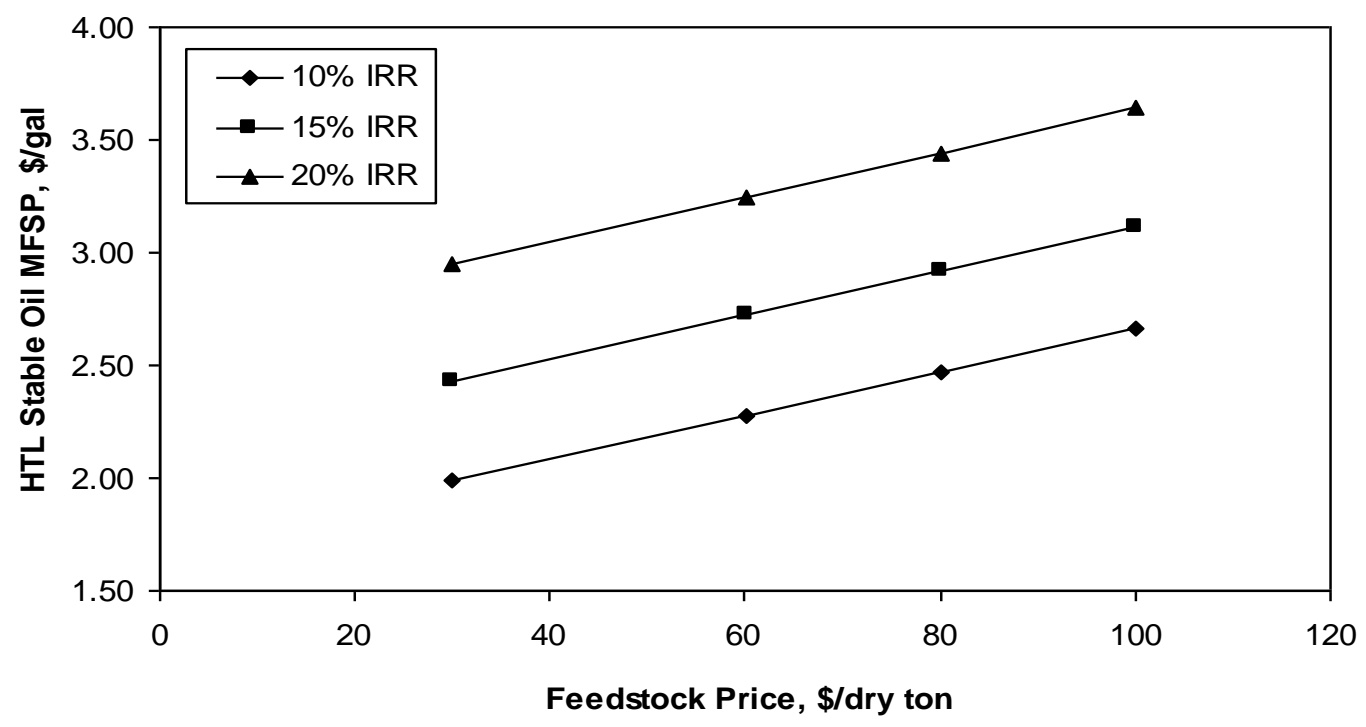

Figure 7-5 Effects of Feedstock Cost and IRR on HTL Stable Oil MFSP

As shown in Figure 7-5, the stable oil price and diesel and gasoline price both increase with the increase in biomass feedstock prices and IRR. The 2008 crude oil price ranges from $\$ 0.90$ to $\$ 3.07 /$ gallon with an average of $\$ 2.25 /$ gallon (Energy Information Administration 2009c). The stable oil price is within this range when the IRR is $10 \%$ with biomass price varying from $\$ 30$ to $\$ 100 /$ dry ton. When the IRR is $15 \%$, the stable oil price falls to the high end of the crude oil price range. When IRR is $20 \%$, the stable oil price is higher than the crude oil price even when the biomass price is $\$ 30 /$ dry ton. Compared to the 2008 gasoline wholesale/resale price range of $\$ 1.06$ to $\$ 3.42$ /gallon and the No. 2 diesel wholesale/resale price range of $\$ 1.47$ to $\$ 3.89 /$ gallon (Energy Information Administration 2009b), with IRR of $10 \%$, the gasoline and diesel MFSP for the HTL system falls into the range of the 2008 gasoline and diesel price even when the biomass price is $\$ 100 /$ dry ton. Therefore, the HTL system for stable oil or gasoline and diesel production may be competitive technology again assuming the technical viability of upgrading the HTL oil. 


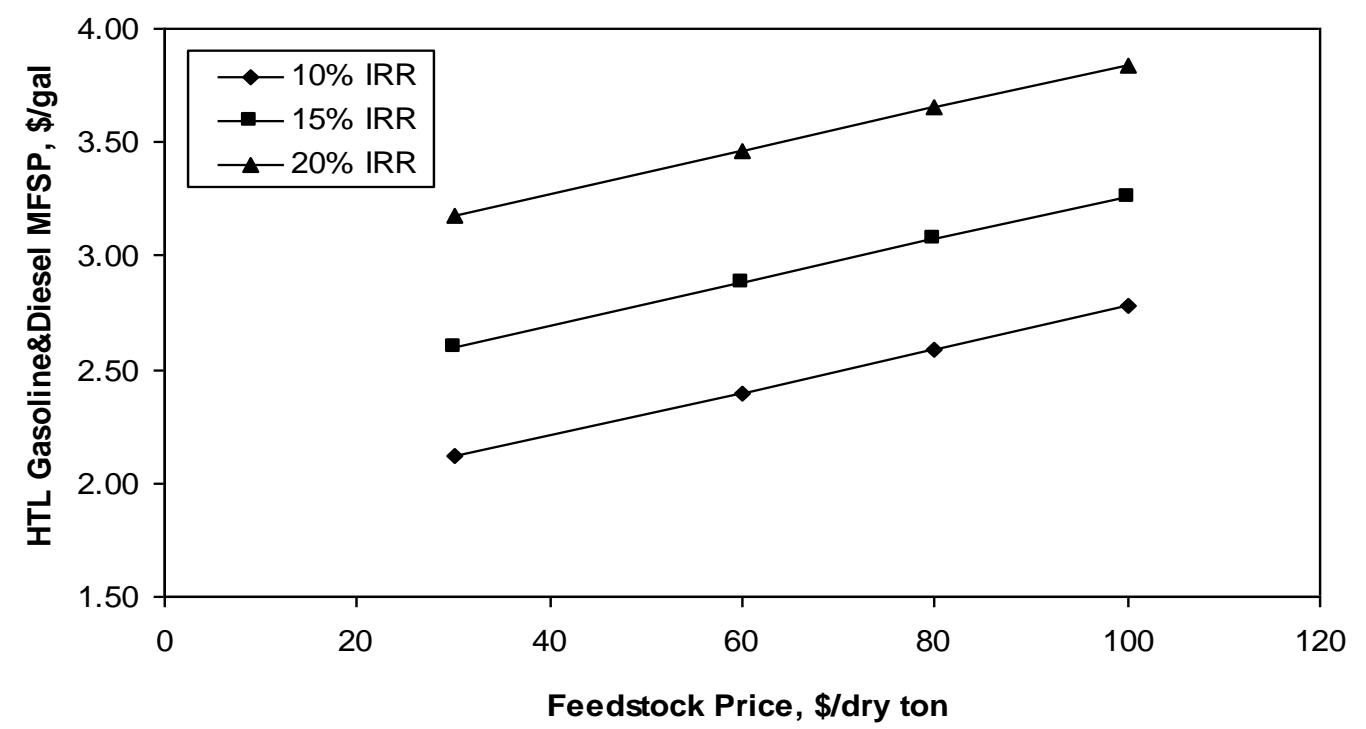

Figure 7-6 Effects of Feedstock Cost and IRR on HTL Gasoline and Diesel MFSP

\subsubsection{Hydrogen Consumption}

The base cases assume that hydrogen is generated in a conventional steam reformer based hydrogen plant using HTL plant off-gas and supplemental natural gas. Hydrogen could also be purchased. The Energy Information Administration estimates hydrogen production costs by various means range from $\$ 1.21$ to $\$ 7.26 / \mathrm{kg}$ (\$0.55-\$3.30/lb)(Energy Information Administration 2008a). Hydrogen required for the HTL process is assumed to be purchased in the above price range. The offgas is assumed to be a byproduct and sold as fuel gas at the price for natural gas on a higher heating value adjusted basis. The results are shown in Figure 7-7. Purchasing hydrogen only makes sense when hydrogen is less than $\$ 1.7 / \mathrm{kg}(\$ 0.77 / \mathrm{lb})$. Therefore, on-site hydrogen generation is preferred unless the hydrogen price is low. 


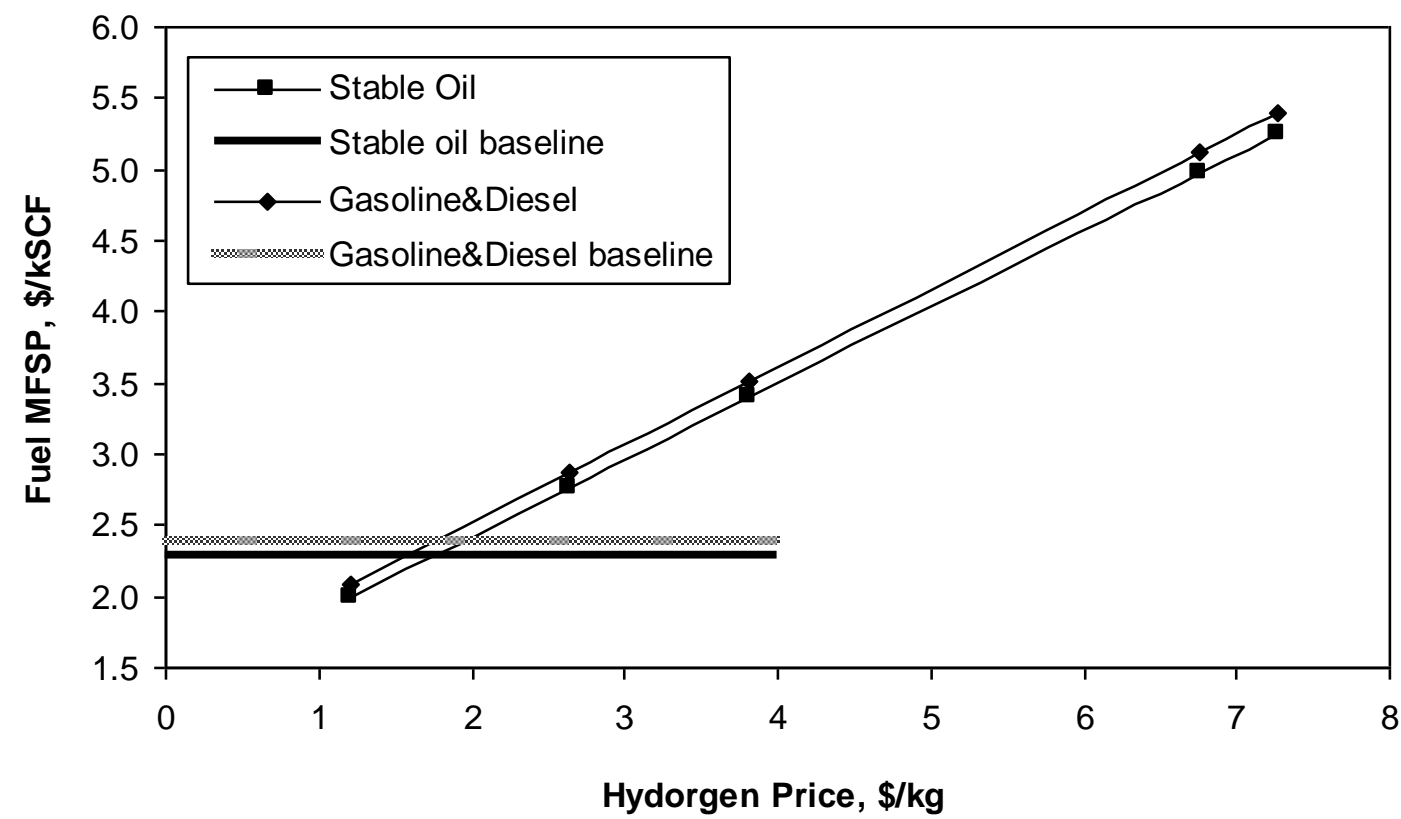

Figure 7-7 Effect of Hydrogen Price on HTL Stable Oil and Fuel MFSP

\subsection{Potential Improvements}

Since the hydrogen plant represents an important part of the capital cost of the HTL system, a potential way to reduce the HTL system cost is to co-locate the HTL process and hydrotreating process with a refinery. This method eliminates the need for a hydrogen plant in the HTL system if the upgrading unit off-gas can be sent to a refinery for hydrogen generation. In return, the upgrading unit receives refinery hydrogen at a lower cost. The stable oil can be sent to the refinery for fuel upgrading and then the hydrocracking and product separation units can be removed in the HTL plant. The capital cost calculations for the integration design of HTL and refinery assume that the refinery equipment is fully depreciated and only operating costs apply to the refinery side. Compared to the current technology of the biomass HTL to gasoline and diesel system, the capital cost of the integration design decreases about $31 \%$ and the stable oil MFSP becomes \$1.81/gallon, which is lower than the crude oil average price in 2008. Compared to the HTL to gasoline and diesel plant, the MFSP of the integrated plant is about $25 \%$ lower. Therefore, building a HTL plant close to a refinery would be a cost-effective way to reduce the HTL fuel production cost. 


\subsection{Ethanol, Gasoline and Diesel by Other Processes}

Four other biomass conversions to fuel pathways are described in this section. These systems, detailed in earlier reports, include biomass-to-ethanol via mixed alcohol synthesis, biomass-to-ethanol via acetic acid synthesis, biomass-to-gasoline via methanol-to-gasoline (MTG), and biomass-to-gasoline and diesel via fast pyrolysis systems. In these systems, major biomass conversion technologies include gasification (both indirectly-fired and directly-fired as described in Section 3) and pyrolysis. Consistent with the systems previously discussed, all cases are based on a feedstock of 2000 dry metric tons/day of hybrid poplar wood chips and cost analyses assume an " $\mathrm{n}$ "th" plant scenario where equipment is fully developed and readily available.

\subsection{Ethanol via Mixed Alcohol Synthesis}

Ethanol can be produced from lignocellulosic feedstock thermochemically by gasification (see Section 3) and conversion of clean syngas into mixed alcohols. The details of the design and simulation of this conversion pathway have been described in Zhu et al. (2009). The indirectly-heated gasifier system produces 43 million gallons/yr ethanol and 14 million gallons/yr propanol, with a standalone " $n$ th" plant capital cost of $\$ 356$ million (2008 dollar). At a $10 \%$ internal rate of return (IRR), the minimum fuel selling price is $\$ 2.71 /$ gal. The directly-heated gasifier system produces 45 million gallons/yr ethanol and 15 million gallon/yr propanol, with a standalone "nth" plant capital cost of $\$ 480$ million.

\subsubsection{Results and Analysis}

The performance results for the biomass-to-ethanol via mixed alcohol synthesis systems are listed in Table 8-1. The directly-heated gasifier has slightly higher product yields (and thus, overall carbon efficiency) than the indirectly-heated gasifier. The primary reason is that more char is produced in the indirectly-heated gasifier and thus less syngas is used for mixed alcohol synthesis, which leads to lower yields. The indirectly-heated gasifier has a lower overall net power for the plant, primarily due to the extra syngas compressor duty required to bring the syngas from atmospheric pressure to synthesis pressure. The combined lower fuel yields and lower net power for the indirectly-fired gasifier case also results in lower system thermal efficiency relative to the directly-fired case. Also of note is the indirectlyheated gasifier system has higher water demand than the directly-heated gasifier system because of higher cooling water consumption for the wet scrubber and amine units and higher boiler water makeup. More wastewater is generated in the indirectly-heated gasifier system because of higher wastewater from the scrubbing unit and cooling water blowdown.

Table 8-1 Performance Results for Biomass-to-Ethanol via Mixed Alcohol Synthesis

\begin{tabular}{lcc}
\hline \multicolumn{1}{c}{ Case } & Indirectly-Heated Gasifier & Directly-Heated Gasifier \\
\hline $\begin{array}{l}\text { Feed } \\
\quad \text { Dry wood chips, tpd (mtpd) }\end{array}$ & $2200(2000)$ & $2200(2000)$ \\
$\begin{array}{l}\text { Products } \\
\quad \text { Ethanol, mmgal/y } \\
\text { Byproducts }\end{array}$ & 43 & 45 \\
$\quad \begin{array}{l}\text { Propanol plus, mmgal/y } \\
\text { Power Consumption, MW }\end{array} \quad 14$ & 15 \\
$\quad$ Air separation unit & -- & 8.6 \\
\hline
\end{tabular}




\begin{tabular}{|c|c|c|c|}
\hline \multicolumn{2}{|c|}{ Lock hopper gas compressor } & -- & 0.2 \\
\hline \multicolumn{2}{|c|}{ Dryer air blower } & -- & 0.2 \\
\hline \multicolumn{2}{|c|}{ Char burner air compressor } & 4.8 & 0.9 \\
\hline \multicolumn{2}{|c|}{ Syngas compressor } & 16.1 & 1.9 \\
\hline \multicolumn{2}{|c|}{ Reformer air compressor } & 1.4 & 1.3 \\
\hline \multicolumn{2}{|c|}{ Reformer flue gas blower } & 1.0 & 0.9 \\
\hline \multicolumn{2}{|l|}{$\mathrm{CO}_{2}$ compressor } & 2.2 & -- \\
\hline \multicolumn{2}{|c|}{ Clean syngas compressor } & 7.5 & 8.3 \\
\hline \multicolumn{2}{|c|}{ Recycle syngas compressor } & 0.3 & 0.3 \\
\hline \multicolumn{2}{|c|}{ Boiler air and flue gas blower } & 0.9 & -- \\
\hline \multicolumn{2}{|c|}{ Steam turbine auxiliaries } & 0.5 & 0.5 \\
\hline \multicolumn{4}{|c|}{ Power Generation, MW } \\
\hline \multicolumn{2}{|l|}{ Steam turbines } & 30.2 & 26.8 \\
\hline \multicolumn{2}{|l|}{ Net Power, MW } & -3.6 & 3.6 \\
\hline \multicolumn{4}{|c|}{ Water Demand, gpm } \\
\hline \multicolumn{2}{|c|}{ Cooling tower makeup } & 735 & 672 \\
\hline \multicolumn{2}{|c|}{ Boiler feed water makeup } & 304 & 209 \\
\hline \multicolumn{2}{|c|}{ Sum } & 1,039 & 881 \\
\hline \multicolumn{2}{|l|}{ Wastewater, gpm } & 360 & 333 \\
\hline \multicolumn{4}{|l|}{ Carbon balance } \\
\hline \multirow[t]{2}{*}{ Feeds } & Biomass & $100 \%$ & $100 \%$ \\
\hline & Sum & $100 \%$ & $100 \%$ \\
\hline \multirow[t]{3}{*}{ Fuel products } & Ethanol & $20.4 \%$ & $21.5 \%$ \\
\hline & Propanol plus & $8.3 \%$ & $8.6 \%$ \\
\hline & Sum & $28.7 \%$ & $30.1 \%$ \\
\hline \multirow[t]{5}{*}{ Wastes } & Dryer exhaust & $30.4 \%$ & $11.8 \%$ \\
\hline & Flue gas & $15.1 \%$ & $14.5 \%$ \\
\hline & $\mathrm{CO}_{2}$ & $25.7 \%$ & $43.4 \%$ \\
\hline & & $0.2 \%$ & $0.2 \%$ \\
\hline & Sum & $71.3 \%$ & $69.9 \%$ \\
\hline \multicolumn{2}{|c|}{ Thermal Efficiency, \% LHV basis } & 41.5 & 44.8 \\
\hline
\end{tabular}

The cost results for the two systems are listed in Table 8-2. The total equipment cost of the directlyheated gasifier system is about $36.8 \%$ higher than the indirectly-heated gasifier system because of the need for an air separation unit and a more expensive gasifier. The indirectly-heated gasifier system has a slightly higher capital cost for the alcohol synthesis process than the directly-heated gasifier system because of a higher recycle ratio (and thus larger reactor) in the synthesis section, however, this is overshadowed by the difference in gasifier cost between the two systems.

Table 8-2 Cost Results for Ethanol via Mixed Alcohol Synthesis

\begin{tabular}{lcccc}
\hline Case & \multicolumn{2}{c}{ Indirectly-Heated Gasifier } & \multicolumn{2}{c}{ Directly-Heated Gasifier } \\
\hline CAPITAL COSTS & $\mathrm{mm} \$$ & $\%$ of total & $\mathrm{mm} \$$ & $\%$ of total \\
Air separation unit & -- & -- & 10.3 & $8 \%$ \\
Feed handling and drying & 11.2 & $12 \%$ & 12.3 & $10 \%$ \\
Gasification with tar reforming, heat & & & & \\
recovery, and scrubbing & 15.1 & $16 \%$ & 41.6 & $32 \%$ \\
Gas cleanup and steam reforming & 31.5 & $33 \%$ & 27.9 & $22 \%$ \\
Mixed alcohol synthesis & 23.4 & $24 \%$ & 22.7 & $18 \%$ \\
Mixed alcohol separation & 3.4 & $4 \%$ & 3.4 & $3 \%$ \\
\hline
\end{tabular}




\begin{tabular}{|c|c|c|c|c|}
\hline Steam cycle and power generation & 8.6 & $9 \%$ & 8.3 & $6 \%$ \\
\hline Remainder off-site battery limits & & & & \\
\hline (OSBL) & 2.3 & $2 \%$ & 2.3 & $2 \%$ \\
\hline Total Purchased Equipment Cost & & & & \\
\hline (TPEC), $\mathbf{m m \$}$ & 95.5 & $100 \%$ & 129 & $100 \%$ \\
\hline Total Installed Cost (TIC), mm\$ & \multicolumn{2}{|c|}{236} & \multicolumn{2}{|c|}{318} \\
\hline Total Indirect Cost, mm\$ & \multicolumn{2}{|c|}{120} & \multicolumn{2}{|c|}{162} \\
\hline Total Project Investment, mm\$ & \multicolumn{2}{|c|}{356} & \multicolumn{2}{|c|}{480} \\
\hline OPERATING COSTS & \$/gal Product & $\%$ of total & \$/gal Product & $\%$ of total \\
\hline Biomass & 1.01 & $37 \%$ & 0.96 & $31 \%$ \\
\hline Catalysts \& Chemicals & 0.11 & $4 \%$ & 0.12 & $4 \%$ \\
\hline Waste Disposal & 0.03 & $1 \%$ & 0.03 & $1 \%$ \\
\hline $\begin{array}{l}\text { Utilities (cooling water, boiler water, } \\
\text { electricity) }\end{array}$ & 0.07 & $3 \%$ & -0.02 & $-1 \%$ \\
\hline Co-product credits & -0.38 & $-14 \%$ & -0.38 & $-12 \%$ \\
\hline Fixed Costs & 0.44 & $16 \%$ & 0.53 & $17 \%$ \\
\hline Capital Depreciation & 0.41 & $15 \%$ & 0.53 & $17 \%$ \\
\hline Average Income Tax & 0.29 & $11 \%$ & 0.36 & $12 \%$ \\
\hline Average Return on Investment & 0.73 & $27 \%$ & 0.94 & $31 \%$ \\
\hline MFSP, \$/gal & \multicolumn{2}{|c|}{2.71} & \multicolumn{2}{|c|}{3.07} \\
\hline $\begin{array}{l}\text { MFSP ethanol equivalent LHV basis, } \\
\text { \$/gal }\end{array}$ & \multicolumn{2}{|c|}{2.71} & \multicolumn{2}{|c|}{3.07} \\
\hline
\end{tabular}

Because of the lower yields for fuel and byproducts and negative power output, the biomass cost and the total variable operating cost of the indirectly-heated gasifier system are higher than those of the directlyheated one. However, due to the lower capital cost and thus lower fixed costs, the ethanol MFSP for the indirectly-heated gasifier system is still lower than that of the directly-heated gasifier.

The annual average ethanol price for 2008 is $\$ 2.16 /$ gallon with the average prices ranging between a high of $\$ 2.70 /$ gallon and a low of $\$ 1.35 /$ gallon (ICIS Pricing 2009). Therefore, both gasifier cases using currently available technology are not economic.

\subsubsection{Potential Improvements}

The capital cost for gas cleanup and steam reforming is a significant contributor to the overall system cost for both the indirectly-heated and the directly-heated gasifier systems. Another key process for improvement area is in the mixed alcohol synthesis, which uses high recycle ratios to compensate for low per pass conversion, leading to large equipment sizes. Improvements leading to better economics were evaluated by NREL for an indirectly-heated based system (Phillips et al. 2007) and for a directly-heated gasifier based case (Dutta and Phillips 2009). For the indirectly-heated gasifier case, a target design with lower moisture content of dried biomass ( $5 \mathrm{wt} \%$ versus $12 \mathrm{wt} \%$ in the current case) and a tar reformer with higher conversion for methane, tars, and other hydrocarbons are assumed (see Table 4-4 for details). The latter eliminates the need for the steam reformer, significantly reducing capital expense. Improvements in 
the mixed alcohol section were also investigated, including higher alcohol selectivity, lower process pressure, and recycle of offgas to the tar reformer for higher syngas yields.

The target cases evaluated by NREL have MFSPs of $\$ 1.24 /$ gallon (2008 dollar) ${ }^{1}$ and $\$ 1.86 /$ gallon (2008 dollar) ${ }^{2}$, for the indirectly-heated and directly-heated gasifier based systems, respectively (Phillips et al. 2007; Dutta and Phillips 2009). Compared to the cases currently evaluated, this is a decrease in MFSP of $54 \%$ and $39 \%$ for the indirectly and directly-heated systems, respectively. With the potential improvements considered in the target case, the ethanol production with the indirectly-heated gasifier via mixed alcohol synthesis becomes economically competitive compared to 2008 average ethanol prices. Future work should focus on improving catalyst yield and selectivity.

\subsection{Ethanol via Acetic Acid Synthesis}

This system features the conversion of biomass to ethanol, through gasification (see Section 3) and synthesis of methanol and acetic acid, followed by hydrogenation of acetic acid to ethanol. The conversion of syngas to methanol and methanol to acetic acid are well-proven technologies with high conversions and yields. This study was undertaken to determine if this highly selective route to ethanol could provide an already established and economically attractive route to ethanol. The details of the design and simulation of this system have been described in Zhu and Jones (2009). The indirectly-heated gasifier system produces 129 million gallons/yr of ethanol, with a standalone " $\mathrm{n}$ "th" plant capital cost of $\$ 598$ million (2008 dollar). At a 10\% internal rate of return (IRR), the MFSP is \$3.38/gal (2008 dollars). The directly-heated gasifier system produces 158 million gallons/yr ethanol, with a capital cost of $\$ 806$ million and MFSP of \$3.47/gallon.

\subsubsection{Results and Analysis}

The performance results for the biomass-to-ethanol via acetic acid synthesis systems are listed in Table 83. Compared to the indirectly-heated gasifier based system, the directly-heated gasifier based system has higher syngas yields and thus higher ethanol yields, the reason being that less char is generated, leaving more carbon available for fuel synthesis. However, because of the higher syngas flow rate for fuel synthesis, the directly-heated gasifier based system also needs a higher feed rate for carbon monoxide, which is used for acetic acid synthesis, and higher hydrogen, which is used for hydrogenation of acetic acid to produce ethanol. Extra natural gas is required for the directly-heated gasifier system because less char is produced and thus supplemental fuel is needed for biomass drying and steam reformer heat.

Compared to the indirectly-heated gasifier system, the directly-heated gasifier system has higher power generation and positive net power output, which is primarily due to the use of supplemental natural gas and more steam generated in the steam reforming process. In addition, the indirectly-heated case operates and lower pressure and thus uses more power for syngas compression than the directly-heated case. The indirectly-heated gasifier based system has a lower water demand because of lower yields and lower power generation. If natural gas is replaced by a cut of produced syngas, the thermal efficiency for the directly-heated gasifier would decrease. In addition, if the carbon monoxide and hydrogen used in the acetic acid and ethanol steps were derived from the syngas rather than externally purchased, the yields and efficiencies for both systems would decrease.

\footnotetext{
${ }^{1}$ Converted from \$1.01/gallon in 2005 dollars (Phillips et al 2007).

${ }^{2}$ Converted from \$1.70/gallon in 2007 dollars (Dutta and Phillips 2009).
} 


\begin{tabular}{|c|c|c|c|}
\hline \multirow{2}{*}{\multicolumn{2}{|c|}{ Case }} & & \\
\hline & & Gasifier & Directly-Heated Gasifier \\
\hline \multicolumn{4}{|l|}{ Feed } \\
\hline \multicolumn{2}{|c|}{ Dry wood chips, tpd (mtpd) } & $2200(2000)$ & $2200(2000)$ \\
\hline \multicolumn{2}{|c|}{ Natural gas, $\mathrm{kscf} / \mathrm{h}$} & -- & 237 \\
\hline \multicolumn{2}{|c|}{ Hydrogen, kscf/h } & 1,935 & 2,370 \\
\hline \multicolumn{2}{|c|}{ Carbon monoxide, $\mathrm{kscf} / \mathrm{h}$} & 1,013 & 1,240 \\
\hline \multicolumn{4}{|c|}{ Products } \\
\hline \multicolumn{2}{|c|}{ Ethanol, mmgal/y } & 129 & 158 \\
\hline \multicolumn{4}{|c|}{ Power Consumption, MW } \\
\hline \multicolumn{2}{|c|}{ Air separation unit } & -- & 8.6 \\
\hline \multicolumn{2}{|c|}{ Lock hopper gas compressor } & -- & 0.2 \\
\hline \multicolumn{2}{|c|}{ Dryer air blower } & -- & 0.2 \\
\hline \multicolumn{2}{|c|}{ Char burner air compressor } & 4.8 & 0.9 \\
\hline \multicolumn{2}{|c|}{ Syngas compressor } & 16.0 & 1.9 \\
\hline \multicolumn{2}{|c|}{ Reformer air compressor } & 1.9 & 3.2 \\
\hline \multicolumn{2}{|c|}{ Reformer flue gas blower } & 0.7 & 1.3 \\
\hline \multicolumn{2}{|c|}{ Clean syngas compressor } & 3.8 & 4.7 \\
\hline \multicolumn{2}{|c|}{ Recycle syngas compressor } & 2.2 & 2.3 \\
\hline \multicolumn{2}{|c|}{ Hydrogen compressor } & 2.7 & 3.3 \\
\hline \multicolumn{2}{|c|}{ Steam turbine auxiliaries } & 0.6 & 0.6 \\
\hline \multicolumn{4}{|c|}{ Power Generation, MW } \\
\hline \multicolumn{2}{|c|}{ Steam turbines } & 26.0 & 36.4 \\
\hline \multicolumn{2}{|l|}{ Net Power, MW } & -6.8 & 9.3 \\
\hline \multicolumn{4}{|c|}{ Water Demand, gpm } \\
\hline \multicolumn{2}{|c|}{ Cooling tower makeup } & 908 & 1,016 \\
\hline Boiler feed wat & makeup & 426 & 493 \\
\hline Sum & & 1,334 & 1510 \\
\hline Wastewater, gp! & & 519 & 522 \\
\hline Carbon balance & & & \\
\hline Feeds & Biomass & $74.4 \%$ & $66.5 \%$ \\
\hline & $\mathrm{CO}$ & $25.6 \%$ & $28.1 \%$ \\
\hline & Natural gas & -- & $5.4 \%$ \\
\hline & Sum & $100 \%$ & $100 \%$ \\
\hline Fuel products & Ethanol & $45.3 \%$ & $49.7 \%$ \\
\hline & Sum & $45.3 \%$ & $49.7 \%$ \\
\hline Wastes & Dryer exhaust & $22.6 \%$ & $8.1 \%$ \\
\hline & Flue gas & $13.2 \%$ & $14.8 \%$ \\
\hline & $\mathrm{CO}_{2}$ & $17.6 \%$ & $27.2 \%$ \\
\hline & Wastewater & $1.3 \%$ & $1.5 \%$ \\
\hline & Sum & $54.7 \%$ & $51.5 \%$ \\
\hline Thermal Efficie & $\mathbf{y}, \%$ LHV basis & 54.5 & 58.3 \\
\hline
\end{tabular}


Table 8-4 shows the capital cost breakdown for each process and the variable and fixed operating costs for the two systems. The acetic acid production and separation sections have the highest equipment costs compared to other sections. The process having the second highest equipment cost is the directly-heated gasification process. The syngas cleanup and steam reforming process also have high equipment costs. The total equipment cost for the directly-heated gasifier based system is about $35 \%$ higher than that of the indirectly-heated gasifier based system. The primary reason is the higher cost for a pressurized gasifier and the extra cost for an air separation unit. In addition, as a result of higher syngas flow rates and greater fuel products yields for the directly-heated gasifier based system, the equipment costs for the acetic acid production and hydrogenation processes are higher than those of the indirectly-heated gasifier system.

Table 8-4 Cost Results for Ethanol via Acetic Acid

\begin{tabular}{|c|c|c|c|c|}
\hline Case & \multicolumn{2}{|c|}{ Indirectly-Heated Gasifier } & \multicolumn{2}{|c|}{ Directly-Heated Gasifier } \\
\hline CAPITAL COSTS & $\mathrm{mm} \$$ & $\%$ of total & $\mathrm{mm} \$$ & $\%$ of total \\
\hline Air separation unit & -- & -- & 10.3 & $5 \%$ \\
\hline Feed handling and drying & 11.2 & $7 \%$ & 12.3 & $6 \%$ \\
\hline $\begin{array}{l}\text { Gasification with tar reforming, heat } \\
\text { recovery, and scrubbing }\end{array}$ & 16.4 & $10 \%$ & 41.6 & $19 \%$ \\
\hline Gas cleanup and steam reforming & 30.8 & $19 \%$ & 34.6 & $16 \%$ \\
\hline Methanol synthesis and separation & 10.3 & $6 \%$ & 11.4 & $5 \%$ \\
\hline Acetic acid production and separation & 52.1 & $32 \%$ & 59.5 & $28 \%$ \\
\hline Hydrogenation and ethanol purification & 28.2 & $18 \%$ & 32.1 & $15 \%$ \\
\hline Steam cycle and power generation & 9.0 & $6 \%$ & 11.9 & $6 \%$ \\
\hline Remainder off-site battery limits & & & & \\
\hline (OSBL) & 2.5 & $2 \%$ & 2.5 & $1 \%$ \\
\hline $\begin{array}{l}\text { Total Purchased Equipment Cost } \\
\text { (TPEC), mm\$ }\end{array}$ & 160 & $100 \%$ & 216 & $100 \%$ \\
\hline Total Installed Cost (TIC), mm\$ & \multicolumn{2}{|c|}{397} & \multicolumn{2}{|c|}{534} \\
\hline Total Indirect Cost, mm\$ & \multicolumn{2}{|c|}{202} & \multicolumn{2}{|c|}{272} \\
\hline Total Project Investment, $\mathrm{mm} \$$ & \multicolumn{2}{|c|}{598} & \multicolumn{2}{|c|}{806} \\
\hline OPERATING COSTS & \$/gal Product & $\%$ of total & \$/gal Product & $\%$ of total \\
\hline Biomass & 0.34 & $10 \%$ & 0.27 & $8 \%$ \\
\hline Natural gas & 0.00 & $0 \%$ & 0.11 & $3 \%$ \\
\hline Catalysts \& chemicals (including $\mathrm{H}_{2}, \mathrm{CO}$ ) & 1.94 & $57 \%$ & 1.96 & $54 \%$ \\
\hline Waste disposal & 0.01 & $0 \%$ & 0.01 & $0 \%$ \\
\hline $\begin{array}{l}\text { Utilities (cooling water, boiler water, } \\
\text { electricity) }\end{array}$ & 0.04 & $1 \%$ & -0.02 & $-1 \%$ \\
\hline Fixed Costs & 0.22 & $7 \%$ & 0.23 & $7 \%$ \\
\hline Capital Depreciation & 0.23 & $7 \%$ & 0.25 & $7 \%$ \\
\hline Average Income Tax & 0.16 & $5 \%$ & 0.18 & $5 \%$ \\
\hline Average Return on Investment & 0.43 & $13 \%$ & 0.47 & $14 \%$ \\
\hline MFSP, \$/gal & \multicolumn{2}{|c|}{3.38} & \multicolumn{2}{|c|}{3.47} \\
\hline $\begin{array}{l}\text { MFSP ethanol equivalent LHV basis, } \\
\text { \$/gal }\end{array}$ & \multicolumn{2}{|c|}{3.38} & \multicolumn{2}{|c|}{3.47} \\
\hline
\end{tabular}


The total variable operating cost of the indirectly-heated gasifier system is less than the directly-heated gasifier primarily because of the extra operating cost for natural gas for the latter. The indirectly-heated gasifier also has slightly lower fixed operating cost than the directly-heated gasifier because of lower capital cost resulting from lower yields. The annual average ethanol price as for 2008 is $\$ 2.16 /$ gallon with the average prices ranging between a high of $\$ 2.7 /$ gallon and a low of $\$ 1.35 /$ gallon (ICIS 2009). Therefore, ethanol production from biomass via gasification and acetic acid using current technology is not competitive.

\subsubsection{Potential Improvements}

The costs of purchasing $\mathrm{H}_{2}$ and $\mathrm{CO}$ represent the largest percentage of total production costs, which are $51 \%$ and $49 \%$ for the two systems, respectively. Because of the high costs related to purchasing $\mathrm{H}_{2}$ and $\mathrm{CO}$ (\$7.2 and \$14.2/kscf, respectively), an alternative design was considered in Zhu and Jones (2009). The design assumed that $\mathrm{H}_{2}$ and $\mathrm{CO}$ were produced internally by separating $\mathrm{H}_{2}$ and $\mathrm{CO}$ from the clean syngas. Thus the syngas used for methanol synthesis was decreased and the ethanol yield was greatly reduced. This alternative system design was not simulated in process models, but the cost was estimated by reducing related equipment sizes proportionally and adding new equipment costs for $\mathrm{H}_{2}$ and $\mathrm{CO}$ production. The final results showed lower ethanol selling prices than the base design because the production cost of $\mathrm{H}_{2}$ and $\mathrm{CO}$ is lower than their purchased cost. Therefore, this alternative design should be considered for further investigation.

Another potential way for improving the system cost is selling the acetic acid intermediate as a byproduct, which was also investigated by Zhu and Jones (2009). The acetic acid co-production is approximately 9 $\mathrm{lb} /$ gallon of ethanol, which represents a production credit of $\$ 6.12$ /gallon ethanol when the acetic acid average price in 2008 is $\$ 0.68 / \mathrm{lb}$ (ICIS Pricing 2009). When $20 \%$ of the acetic acid is sold as by-product, the ethanol MFSP becomes $\$ 2.42$ and $\$ 2.54$ /gallon for the indirectly and directly-heated gasifier based cases, which represents a $28 \%$ and $27 \%$ decrease in the MFSP for the two systems, respectively. The credit of selling acetic acid byproduct is higher than converting it to ethanol and selling ethanol as the final product. Therefore co-production of acetic acid may be an economically attractive means of subsidizing ethanol production if sufficient acetic acid is diverted from ethanol production.

\subsection{Gasoline via Methanol-to-Gasoline (MTG)}

With gasification technology, biomass can be converted to gasoline via methanol synthesis and methanolto-gasoline (MTG) technologies. Producing a gasoline product that is infrastructure ready has much potential. Although the MTG technology has been commercially demonstrated with natural gas conversion, combining MTG with biomass gasification has not been demonstrated. Therefore, a technoeconomic evaluation for a biomass-to-ethanol via MTG process based on currently available technologies was implemented to provide information about benefits and risks of this technology. The details of the evaluation of biomass-to-gasoline via the MTG system are provided in Jones and Zhu (2009). The indirectly-heated gasifier system produces 40 million gallons/yr of gasoline (and 7 million gal/yr of LPG co-product), with a standalone " $n$ th" plant capital cost of $\$ 360$ million (2008 dollar). At a $10 \%$ internal rate of return (IRR), the MFSP is \$3.08/gal (\$2.12 on an ethanol-equivalent LHV basis) (2008 dollars). The directly-heated gasifier system also produces 40 million gallons/yr of gasoline (and no LPG), has a capital cost of $\$ 499$ million and MFSP of $\$ 3.94$ /gallon ( $\$ 2.68$ on an ethanol-equivalent LHV basis). 


\subsubsection{Results and Analysis}

The performance results for the biomass-to-gasoline via MTG systems are listed in Table 8-5.

Table 8-5 Performance Results for Methanol-to-Gasoline

\begin{tabular}{|c|c|c|c|}
\hline \multicolumn{2}{|c|}{ Case } & Indirectly-Heated Gasifier & Directly-Heated Gasifier \\
\hline \multicolumn{4}{|l|}{ Feed } \\
\hline \multicolumn{2}{|c|}{ Dry wood chips, tpd (mtpd) } & $2200(2000)$ & $2200(2000)$ \\
\hline \multicolumn{4}{|l|}{ Products } \\
\hline \multicolumn{2}{|c|}{ Gasoline, mmgal/y } & 40 & 40 \\
\hline \multicolumn{4}{|l|}{ Byproducts } \\
\hline \multicolumn{2}{|c|}{ Liquefied petroleum gas (LPG), mmgal/y } & 7 & 0 \\
\hline \multicolumn{4}{|c|}{ Power Consumption, MW } \\
\hline \multicolumn{2}{|c|}{ Air separation unit } & -- & 8.6 \\
\hline \multicolumn{2}{|c|}{ Lock hopper gas compressor } & -- & 0.2 \\
\hline \multicolumn{2}{|c|}{ Dryer air blower } & -- & 0.1 \\
\hline \multicolumn{2}{|c|}{ Char burner air compressor } & 4.8 & 0.5 \\
\hline \multicolumn{2}{|c|}{ Syngas compressor } & 16.0 & 1.9 \\
\hline \multicolumn{2}{|c|}{ Reformer air compressor } & 1.1 & 1.6 \\
\hline \multicolumn{2}{|c|}{ Reformer flue gas blower } & 0.5 & 0.6 \\
\hline \multicolumn{2}{|c|}{ Clean syngas compressor } & 3.8 & 4.6 \\
\hline \multicolumn{2}{|c|}{ Recycle syngas compressor } & 2.7 & 2.4 \\
\hline \multicolumn{2}{|l|}{ MTG } & 3.0 & 3.7 \\
\hline \multicolumn{2}{|c|}{ Steam turbine auxiliaries } & 0.4 & 0.5 \\
\hline \multicolumn{4}{|c|}{ Power Generation, MW } \\
\hline \multicolumn{2}{|l|}{ Steam turbines } & 24.4 & 37.8 \\
\hline \multicolumn{2}{|l|}{ Net Power, MW } & -7.8 & 13.1 \\
\hline \multicolumn{4}{|c|}{ Water Demand, gpm } \\
\hline \multicolumn{2}{|c|}{ Cooling tower makeup } & 655 & 644 \\
\hline \multicolumn{2}{|c|}{ Boiler feed water makeup } & 456 & 511 \\
\hline \multicolumn{2}{|l|}{ Sum } & 1,111 & 1,155 \\
\hline \multicolumn{2}{|c|}{ Wastewater, gpm } & 547 & 660 \\
\hline \multicolumn{4}{|l|}{ Carbon balance } \\
\hline Feeds & Biomass & $100 \%$ & $100 \%$ \\
\hline & Sum & $100 \%$ & $100 \%$ \\
\hline Fuel products & Gasoline & $28.9 \%$ & $28.8 \%$ \\
\hline & LPG & $2.7 \%$ & $0 \%$ \\
\hline & Sum & $31.6 \%$ & $28.8 \%$ \\
\hline Wastes & Dryer exhaust & $30.4 \%$ & $9.8 \%$ \\
\hline & Flue gas & $14.1 \%$ & $21.7 \%$ \\
\hline & $\mathrm{CO}_{2}$ & $23.8 \%$ & $39.4 \%$ \\
\hline & Wastewater & $0.0 \%$ & $0.2 \%$ \\
\hline & Sum & $68.4 \%$ & $71.2 \%$ \\
\hline Thermal Efficie & \% LHV basis & 45.6 & 44.2 \\
\hline
\end{tabular}

In general, one would expect that the directly-heated gasifier would produce more final product than an indirectly-heated gasifier because of the former's lower char production and thus higher syngas rate. However, the biomass dryer for the directly-heated gasifier needs an external burner to supply the dryer heat load. Fuel to the auxiliary burner is supplied by using all of the LPG plus a higher purge rate in the methanol synthesis step. The high methanol off-gas purge rate reduces the yield of methanol and hence 
reduces the final gasoline yield. This effect could be mitigated by 1) using natural gas in the dryer burner, or 2) by using an indirectly-heated dryer using steam as the heat source. Analysis of these options is beyond the scope of this work. Lack of LPG product in the directly-heated gasifier case reduces carbon and thermal efficiencies. However, the larger volumes of gas through the syngas generation and cleanup steps greatly increase the amount of steam recuperated, and thus results in a net export of power.

\section{Cost Results}

The capital cost breakdown for each section of the plants and the variable and fixed operating costs are listed in Table 8-6.

Table 8-6 Cost Results for Methanol-to-Gasoline

\begin{tabular}{|c|c|c|c|c|}
\hline Case & \multicolumn{2}{|c|}{ Indirectly-Heated Gasifier } & \multicolumn{2}{|c|}{ Directly-Heated Gasifier } \\
\hline CAPITAL COSTS & $\mathrm{mm} \$$ & $\%$ of total & $\mathrm{mm} \$$ & $\%$ of total \\
\hline Air separation unit & -- & -- & 10.3 & $8 \%$ \\
\hline Feed handling and drying & 11.2 & $11 \%$ & 12.3 & $9 \%$ \\
\hline $\begin{array}{l}\text { Gasification with tar reforming, heat } \\
\text { recovery, and scrubbing }\end{array}$ & 15.2 & $15 \%$ & 41.2 & $30 \%$ \\
\hline Gas cleanup and steam reforming & 28.3 & $29 \%$ & 26.8 & $20 \%$ \\
\hline Methanol synthesis \& separation & 10.5 & $11 \%$ & 8.4 & $6 \%$ \\
\hline Steam cycle and power generation & 7.5 & $8 \%$ & 10.9 & $8 \%$ \\
\hline Methanol-to-Gasoline (MTG) & 23.7 & $24 \%$ & 23.7 & $17 \%$ \\
\hline Remainder off-site battery limits (OSBL) & 2.0 & $2 \%$ & 1.9 & $1 \%$ \\
\hline $\begin{array}{l}\text { Total Purchased Equipment Cost (TPEC), } \\
\text { mm\$ }\end{array}$ & 98.3 & $100 \%$ & 136 & $100 \%$ \\
\hline Total Installed Cost (TIC), mm\$ & \multicolumn{2}{|c|}{236} & \multicolumn{2}{|c|}{326} \\
\hline Total Indirect Cost, mm\$ & \multicolumn{2}{|c|}{124} & \multicolumn{2}{|c|}{171} \\
\hline Total Project Investment, mm\$ & \multicolumn{2}{|c|}{360} & \multicolumn{2}{|c|}{499} \\
\hline OPERATING COSTS & \$/gal Product & $\%$ of total & \$/gal Product & $\%$ of total \\
\hline Biomass & 1.07 & $35 \%$ & 1.07 & $27 \%$ \\
\hline Catalysts \& chemicals & 0.30 & $10 \%$ & 0.39 & $10 \%$ \\
\hline Waste disposal & 0.04 & $1 \%$ & 0.05 & $1 \%$ \\
\hline $\begin{array}{l}\text { Utilities (cooling water, boiler water, } \\
\text { electricity) }\end{array}$ & 0.14 & $4 \%$ & -0.14 & $-3 \%$ \\
\hline Co-product credits & -0.31 & $-10 \%$ & -- & -- \\
\hline Fixed Costs & 0.48 & $15 \%$ & 0.61 & $16 \%$ \\
\hline Capital Depreciation & 0.45 & $14 \%$ & 0.62 & $16 \%$ \\
\hline Average Income Tax & 0.31 & $10 \%$ & 0.43 & $11 \%$ \\
\hline Average Return on Investment & 0.60 & $19 \%$ & 0.90 & $23 \%$ \\
\hline Gasoline MFSP, \$/gal & \multicolumn{2}{|c|}{3.08} & \multicolumn{2}{|c|}{3.94} \\
\hline MESP ethanol equivalent LHV basis, $\$$ /gal & \multicolumn{2}{|c|}{2.12} & \multicolumn{2}{|c|}{2.68} \\
\hline
\end{tabular}

Methanol and MTG synthesis, gas fractionation, and the heavy gasoline treater (HGT) represents about one-third of the total equipment cost. The total capital cost of the directly-heated gasifier based system is about $30 \%$ higher than that of the indirectly-heated gasifier based system. The directly-heated gasifier is pressurized and requires an ASU whereas the indirectly-heated gasifier is at atmospheric pressure. 
For both gasifier cases, approximately $30 \%$ of the production cost is feedstock related. The indirectlyheated gasifier based system has by-products credit of LPG and no export electricity. The directly-heated gasifier has credits from electricity production, and no LPG credit. Therefore, the selling price of gasoline for the indirectly-heated gasifier based system is lower than that of the directly-heated gasifier based system. Gasoline wholesale prices for 2008 range from $\$ 1.06$ to $\$ 3.42 /$ gallon, with an average of $\$ 2.58 /$ gallon (EIA 2009b). This corresponds to crude prices ranging from $\$ 38$ to $\$ 129 /$ barrel (EIA 2009c). Considering the gasoline MFSP of $\$ 3.08 /$ gal in this study and the current gasoline wholesale prices, only when crude oil is above $\$ 114 /$ barrel is the gasoline produced by biomass via MTG competitive with petroleum gasoline.

\subsubsection{Potential Improvements}

Jones and Zhu (2009) investigated the effects of reducing the capital costs for the syngas cleanup and for the MTG synthesis process on the gasoline production cost. This study suggested that an MTG reactor design that avoids large recycle streams for temperature control, such as fluid bed or shell and tube MTG reactors, can reduce capital costs in the synthesis area. Additionally, combined synthesis steps, such as once through methanol/DME production could potentially reduce capital costs and product losses. This sensitivity explores the effect of capital cost reductions. If all of the potential capital improvements are realized, and yield losses in the synthesis step are minimized, the system capital cost can be reduced by $50 \%$ and the yields can be increased about $20 \%$. The methanol-to-gasoline process estimated rack selling price can potentially be lowered to approximately $\$ 2.32 /$ gallon for the indirectly-heated gasifier system, which is lower than the average gasoline price in 2008, and thus this technology becomes economically attractive. The MFSP of the directly-heated gasifier based system can potentially be reduced to \$2.90/gallon.

\subsection{Diesel and Gasoline via Fast Pyrolysis}

This study investigates production of fast pyrolysis oil from biomass and the upgrading of that bio-oil as a means for generating infrastructure-ready renewable gasoline and diesel fuels. The analysis evaluates technology that has been demonstrated at the laboratory scale or is in early stages of commercialization. The fast pyrolysis of biomass is already commercialized on a small scale, while upgrading bio-oil to transportation fuels has only been demonstrated in the laboratory and at small engineering development scale. The analysis is futuristic in that it assumes larger fast pyrolysis units than are currently available and that sufficient progress has been made in the area of upgrading catalyst maintenance and product quality. In this respect the analysis is similar to the HTL oil analysis in that it assumes certain research goals have been achieved. It differs from the gasification based analysis, which assumes a more current state of technology. Design details can be found in Jones et al. (2009). The plant is designed to use 2000 dry metric tons/day of hybrid poplar wood chips to produce 76 million gallons/year of gasoline and diesel. The capital cost for a standalone "nth" plant is $\$ 332$ million (2008 dollar). At a $10 \%$ internal rate of return (IRR), the minimum fuels (gasoline + diesel) selling price is $\$ 2.48 /$ gal ( $\$ 1.62 /$ gal ethanol equivalent basis).

\subsubsection{Results and Analysis}

In this section, the performance and cost results for the biomass-to-gasoline and diesel via fast pyrolysis are described and discussed. 


\section{Performance Results}

The performance results for the biomass-to-gasoline and diesel via fast pyrolysis and upgrading systems are listed in Table 8-7. As shown in Table 8-7, natural gas is used together with offgas from pyrolysis and upgrading process for hydrogen generation.

Table 8-7 Performance Results for Gasoline and Diesel via Fast Pyrolysis and Upgrading

\begin{tabular}{|c|c|c|}
\hline \multicolumn{2}{|c|}{ Case } & \multirow[t]{2}{*}{ Fast Pyrolysis } \\
\hline \multicolumn{2}{|l|}{ Feed } & \\
\hline \multicolumn{2}{|c|}{ Dry wood chips, tpd (mtpd) } & $2200(2000)$ \\
\hline \multicolumn{2}{|c|}{ Natural gas, kscf/h } & 407 \\
\hline \multicolumn{3}{|c|}{ Products } \\
\hline \multicolumn{2}{|c|}{ Gasoline, mmgal/y } & 34 \\
\hline \multicolumn{2}{|c|}{ Diesel, mmgal/y } & 43 \\
\hline \multicolumn{2}{|c|}{ Total, mmgal/y } & 76 \\
\hline \multicolumn{3}{|c|}{ Power Consumption, MW } \\
\hline \multicolumn{2}{|l|}{ Fast pyrolysis } & 12.0 \\
\hline \multicolumn{2}{|c|}{ Upgrading to Stable Oil } & 10.0 \\
\hline \multicolumn{2}{|c|}{ Hydrocracking \& Product Separation } & 1.1 \\
\hline \multicolumn{2}{|c|}{ Hydrogen Generation } & 1.4 \\
\hline \multicolumn{2}{|l|}{ Auxiliaries } & 0.1 \\
\hline \multicolumn{3}{|c|}{ Power Generation, MW } \\
\hline \multicolumn{2}{|c|}{ Export steam from hydrogen plant } & 1.9 \\
\hline \multicolumn{2}{|l|}{ Net Power, MW } & -24.6 \\
\hline \multicolumn{3}{|c|}{ Water Demand, gpm } \\
\hline \multicolumn{2}{|c|}{ Cooling tower makeup } & 373 \\
\hline \multicolumn{2}{|c|}{ Steam reformer boiler feed water makeup } & 113 \\
\hline \multicolumn{2}{|l|}{ Sum } & 486 \\
\hline \multicolumn{2}{|c|}{ Wastewater, gpm } & 144 \\
\hline \multicolumn{3}{|c|}{ Carbon balance } \\
\hline \multirow[t]{3}{*}{ Feeds } & Biomass & $87.8 \%$ \\
\hline & Natural gas & $12.2 \%$ \\
\hline & Sum & $100 \%$ \\
\hline \multirow[t]{3}{*}{ Fuel products } & Gasoline & $23.0 \%$ \\
\hline & Diesel & $31.9 \%$ \\
\hline & Sum & $54.9 \%$ \\
\hline \multirow[t]{5}{*}{ Wastes } & Pyrolysis unit exhaust & $22.5 \%$ \\
\hline & Upgrading waste water & $0.3 \%$ \\
\hline & Upgrading heaters exhaust & $2.1 \%$ \\
\hline & Reformer exhaust & $20.2 \%$ \\
\hline & Sum & $45.1 \%$ \\
\hline \multicolumn{2}{|c|}{ Thermal Efficiency, \% LHV basis } & 63.7 \\
\hline
\end{tabular}

\section{Cost Results}


The capital cost breakdown for each section of the fast pyrolysis plant and the variable and fixed operating costs are listed in Table 7-8. The process with the most expensive capital cost is the hydrogen generation process. An alternative scenario is to purchase hydrogen eliminate the need for a hydrogen plant. Sensitivity analysis indicates that if hydrogen purchasing price is lower than $\$ 0.54 / \mathrm{lb}$, then purchasing is preferred. Feedstock cost is the major operating cost. The 2008 annual average gasoline and diesel wholesale/resale prices are \$2.58 and \$2.98/gal (EIA 2009b). This suggests that there are incentives to pursue motor fuels from biomass.

Table 8-8 Cost Results for Biomass-to-Gasoline and Diesel via Fast Pyrolysis

\begin{tabular}{|c|c|c|}
\hline \multirow{2}{*}{$\begin{array}{l}\text { Case } \\
\text { CAPITAL COSTS }\end{array}$} & \multicolumn{2}{|c|}{ Fast Pyrolysis } \\
\hline & $\mathrm{mm} \$$ & $\%$ of total \\
\hline Fast Pyrolysis & 27.0 & $27 \%$ \\
\hline Hydrotreating & 23.9 & $23 \%$ \\
\hline Hydrocracking and Separations & 8.6 & $8 \%$ \\
\hline Hydrogen Generation & 38.2 & $37 \%$ \\
\hline Utilities, etc. & 4.2 & $4 \%$ \\
\hline Total Purchased Equipment Cost (TPEC), mm\$ & 102 & $100 \%$ \\
\hline Total Installed Cost (TIC), mm\$ & \multicolumn{2}{|c|}{252} \\
\hline Total Indirect Cost, $\mathbf{m m \$}$ & \multicolumn{2}{|c|}{80} \\
\hline Total Project Investment, $\mathrm{mm} \$$ & \multicolumn{2}{|c|}{332} \\
\hline OPERATING COSTS & \$/gal Product & $\%$ of total \\
\hline Biomass & 0.57 & $24 \%$ \\
\hline Natural gas & 0.40 & $17 \%$ \\
\hline Catalysts \& chemicals & 0.18 & $8 \%$ \\
\hline Waste disposal & 0.01 & $0 \%$ \\
\hline Utilities (cooling water, boiler water, electricity) & 0.20 & $9 \%$ \\
\hline Fixed Costs & 0.24 & $10 \%$ \\
\hline Capital Depreciation & 0.22 & $9 \%$ \\
\hline Average Income Tax & 0.15 & $6 \%$ \\
\hline Average Return on Investment & 0.40 & $17 \%$ \\
\hline MFSP, \$/gal & \multirow{2}{*}{\multicolumn{2}{|c|}{$\begin{array}{l}2.36 \\
1.55\end{array}$}} \\
\hline MFSP ethanol equivalent LHV basis, \$/gal & & \\
\hline
\end{tabular}

\subsubsection{Potential Improvements}

Sensitivity analysis in Jones et al. (2009) investigated the effects of the fast pyrolysis plant co-locating with an existing refinery. Stable oil from the upgrading plant is sent to the refinery for fuel finishing. Colocation eliminates the need for a PSA unit in the hydrotreating process if the upgrading unit off-gas can be sent to refinery hydrogen generation. In return, the upgrading unit receives refinery hydrogen at a lower cost. The results indicated the MFSP will decrease about $15 \%$ for the co-located plant. 


\subsection{Summary and Conclusions}

Consistent assumptions for performance and cost analysis are used in this study for each biomass-to-fuel system. However, the state of readiness is different for gasification and liquefaction technologies. Since the gasification based systems are based on the current state of technologies and the liquefaction based systems are based on technology still under development, gasification and liquefaction cases are not directly compared with each other.

\subsection{Gasification based Systems}

The results for the gasification based systems are summarized in Tables 9-1 and 9-2. Table 9-1 shows fuels currently used in the U.S., while those shown in Table 9-2 are not. Fuel yields, carbon and thermal efficiency and fuel selling price are compared in Figures 9-1 to 9-3 respectively.

\section{PERFORMANCE}

Observations regarding yield, power, water demand and waste generation from the different gasificationbased fuels processes are as follows:

- As shown in Figure 9-1, the ethanol via acetic acid system has the highest liquid fuel yield, due to the use of externally sourced $\mathrm{CO}$ and $\mathrm{H}_{2}$. The methanol system has the second highest yield.

- Byproducts are produced in the mixed alcohols, ethanol from acetic acid, and FT diesel systems. The highest yield of byproducts is propanol plus from the mixed alcohol synthesis system.

- The FT diesel system produces the most power for export and has the lowest liquid fuel yield. This is due to the low conversion efficiency of single pass FT synthesis and thus a large amount unconverted syngas is not used for fuel synthesis, but for power generation.

- The ethanol via acetic acid system has the highest water demand because it has additional synthesis steps compared to the single step synthesis processes, e.g., methanol and mixed alcohols.

- Wastewater is primarily generated from the wet scrubbing unit, which receives its makeup water from the steam reformer water condenser. The mixed alcohol synthesis systems have the lowest wastewater generation because it requires a lower $\mathrm{H}_{2}: \mathrm{CO}$ ratio in the syngas, and thus less steam for reforming.

- As shown in Figure 9-2, the ethanol synthesis via acetic acid system has the highest carbon and thermal efficiency. This is primarily because of the addition of external $\mathrm{CO}$ and high conversion efficiency of acetic acid synthesis. The next most efficient is methanol synthesis because of the high conversion efficiency in the methanol synthesis step.

- As shown Figure 9-1, the directly-heated gasifier based systems have higher fuel and byproduct yields for most cases than the indirectly-heated gasifier systems. Yields are a function of how much of the biomass is lost to char and how much off-gas must be directed to the fuel gas system. The directlyheated gasifier based systems for all products have higher net power output than the indirectly-heated gasifier based systems. The primary reason is the latter systems have much higher power consumption for raw syngas compression resulting from the much lower gasification operating pressure and thus lower inlet pressure of the compressor.

- The directly-heated gasifier based systems generally have higher water demand. In addition, higher $\mathrm{CO}_{2}$ production in the directly-heated gasifier cases also leads to higher cooling water use in the amine unit.

- The directly-heated gasifier based systems generally have higher wastewater generation resulting from higher condensate water in the clean syngas after steam reforming. 
- As shown in Figure 9-2, the directly-heated gasifier based systems have higher carbon efficiencies except for DME and MTG systems. The reasons are the same as those for fuel yields.

- The directly-heated gasifier based systems have higher thermal efficiencies than those of indirectlyheated gasifier based systems primarily resulting from higher fuel yields and/or higher net power output. For the MTG system, the directly-heated gasifier based system has lower efficiency resulting from lower byproduct generation because the byproduct is used for the biomass drying and steam reformer burner.

\section{COST}

Tables 9-1 and 9-2, and Figure 9-3 show the MFSP and ethanol equivalent MESP for gasification based systems. A comparison of cost results for each fuel system suggests the following:

- For all liquid fuels, the indirectly-heated gasifier based methanol synthesis system has the lowest capital cost. The primary reason is that the methanol system has the lowest synthesis step cost of all the products. The FT diesel, DME, ethanol via acetic acid, and MTG systems all have two or three processing steps to reach the final product.

- The operating cost is calculated as \$/gallon of product. The largest portion of the operating cost is the biomass feedstock cost, which represents about $30 \%$ to $40 \%$ of the total production cost. For the ethanol via acetic acid system, the use of large amounts of $\mathrm{CO}$ and $\mathrm{H}_{2}$ increases the percentage of chemicals cost (56 to 57\%) in the total production cost and thus lower the percentage of the biomass feedstock cost (8 to10\%).

- For all the liquid fuel systems, methanol has the lowest variable operating cost per unit of product, which results from the high fuel product yield. For the similar reason, the DME system also has low variable operating cost. The next lowest is the mixed alcohols, which has high co-product credits and no natural gas cost. When the system has a low fuel yield (such as FT diesel) or high chemical cost (ethanol via acetic acid), the variable operating cost is high.

- The indirectly-heated gasifier methanol case at \$1.28/gal has the lowest MFSP, because of relatively low capital for the synthesis step and high product yields.

- Since different fuel products have different heating values, the MFSP equivalent ethanol (LHV basis) allows comparison on a common basis. Although the methanol system has the lowest liquid fuel MFSP, the ethanol equivalent MFSP of methanol is slightly higher than the indirectly-heated gasifier based DME system because of the lower LHV of methanol compared to DME. The highest ethanol equivalent MFSP goes to the directly-heated gasifier based FT system because of low fuel yields. The next highest equivalent cost is the directly-heated gasifier based ethanol via acetic acid system because of high operating cost.

- The directly-heated gasifier based systems always have higher capital costs than the indirectly-heated gasifier based systems. The directly-heated gasifier based systems requires an air separation unit, which accounts for 5 to $10 \%$ of the total capital cost, and the directly-heated gasifier and associated equipment has a much higher equipment cost (about $\$ 39$ million) than the indirectly-heated gasification process (about \$15 million).

- The directly-heated gasifier based systems have slightly lower variable operating cost than the indirectly-heated gasifier based systems except for the ethanol via acetic acid and MTG systems. The directly-heated gasifier based systems primarily have higher power output or higher yields and lead to lower operating cost. For the ethanol via acetic acid systems, the consumption of natural gas for biomass drying and other processes use increases the operating cost of the directly-heated, which offset 
the advantage of higher yield. For the MTG system, the byproduct (LPG) of the directly-heated gasifier is used as fuel gas for biomass drying and steam reforming, which reduces the co-product credit and leads to higher operating cost.

- Higher capital costs leads the directly-heated gasifier based systems always have a higher MFSP and ethanol equivalent MESP than the indirectly-heated gasifier based systems.

\section{IMPROVEMENTS}

\section{Mixed Alcohols}

The capital costs for gas cleanup and steam reforming are high fractions of the overall system cost for both indirectly-heated and directly-heated gasifier based systems. Another key plant area needing improvement is mixed alcohol synthesis, which uses a high recycling ratio and leads to the buildup of methane in the synthesis loop and thus leads to large equipment sizes and high capital/operating costs for this process. The potential technology improvements would focus on improving the gas cleanup and mixed alcohol synthesis processes. Based on the NREL design studies by Phillips et al. (2007) and Dutta and Phillips (2009), compared to the current design cases, the target cases with potential improvements lead to about $34 \%$ and $4 \%$ increase in the ethanol yields and about $54 \%$ and $39 \%$ decrease in the ethanol MFSP for the indirectly and directly-heated gasifier, respectively. Thus ethanol production based on the indirectly-heated gasifier via mixed alcohol synthesis becomes economically attractive.

The potential improvements and research and development for the biomass-to-mixed alcohol synthesis systems include:

- Developing an improved tar reforming process to increase the conversion of methane and thus reduce methane buildup in the mixed alcohol synthesis loop. In addition, the improved tar reforming process increases the $\mathrm{CO}$ and $\mathrm{H}_{2}$ yields and thus increases the final products yields,

- Developing low cost gas cleanup process, including low cost sulfur removal and $\mathrm{CO}_{2}$ removal processes, and elimination of the steam reformer,

- Developing a low pressure mixed alcohol synthesis process to reduce the cost for syngas compression,

- Developing alternative gasification technologies with syngas having low tars and low methane contents to reduce the cost for tar reforming. Producing an ideal $\mathrm{H}_{2}$ :CO ratio in the gasification island would reduce the downstream gas adjustment cost for mixed alcohol synthesis.

\section{MTG}

The highest capital cost area for the entire MTG process is in gas cleanup for the indirectly-heated gasifier based systems followed by the MTG synthesis step. For the directly-heated gasifier system, the gasification process has the highest capital cost followed by the gas cleanup process.

The potential improvements for the MTG system include:

- Improving the MTG reactor design to avoid large recycle streams for temperature control. Fluid bed or shell and tube MTG reactors can reduce capital costs in the synthesis area 
- Combining the synthesis steps, such as once through methanol/DME production could potentially reduce capital costs and product losses

Assuming that the potential capital improvements are realized and yield losses in the synthesis step are minimized, the system capital cost can be reduced by $50 \%$ and the yields can be increased about $20 \%$. The MFSP decreases about $25 \%$ to $26 \%$ for the indirectly-heated and directly-heated gasifier based systems.

\section{FT Diesel}

The production cost for the entire FT diesel system is the highest compared to other systems because of low fuel yields. The current technology single pass FT synthesis process with a conversion efficiency of $70 \%$ limits the yield by leaving large amounts of methane unconverted. The potential technology improvements would focus on improving the syngas conversion efficiencies and thus lower the system cost, which include:

- Recycling syngas to an improved tar reformer with higher conversion efficiencies of methane, tars, and other hydrocarbons. The benefits include reducing the size of the steam reformer, reducing methane buildup in the FT synthesis process and increasing $\mathrm{CO}$ and $\mathrm{H}_{2}$ production, and increasing $\mathrm{CO}$ conversion in the overall process by recycling unconverted syngas,

- Increasing biomass drying to reduce its moisture content and thus to reduce the heat absorbed by water during the gasification and combustion steps,

- Selling the heavy end wax into the chemical market. While this would eliminate the need for hydrocracking, this option is limited by the size of the chemicals market relative to that of fuels.

\section{Ethanol via Acetic Acid}

The costs of purchasing $\mathrm{H}_{2}$ and $\mathrm{CO}$ represent the largest percentage of total production costs for biomassto-ethanol via acetic acid systems. An alternative design assumes that $\mathrm{H}_{2}$ and $\mathrm{CO}$ are produced internally by separating $\mathrm{H}_{2}$ and $\mathrm{CO}$ from the clean syngas. This requires additional equipment (a PSA to remove $\mathrm{H}_{2}$ and a cold box to extract $\mathrm{CO}$ ) and reduces the product yield. This option was not modeled, however, an estimate suggests that this might lower ethanol production cost and thus should be studied further.

Another potential way for improving costs is to sell the acetic acid as a byproduct. The acetic acid coproduction is approximately $9 \mathrm{lb} /$ gallon of ethanol, which represents a production credit of $\$ 6.12 /$ gallon ethanol when the acetic acid average price in 2008 is $\$ 0.68 / 1 b$ (ICIS Pricing 2009). When $20 \%$ of the acetic acid is sold as by-product, the ethanol MFSP decreases about $28 \%$ and $27 \%$ for the two gasification systems. The credit for selling acetic acid as coproduced byproduct is higher than the ethanol MFSP for both indirectly-heated and directly-heated gasifier based baseline cases. While co-production of acetic may be an attractive means of subsidizing ethanol production, it is not an option for every ethanol plant because of the market size difference between fuels and acetic acid.

\section{Methanol}

This analysis assumes that the highest grade (Grade AA) methanol is produced, which is suitable for any kind of application. The specific conclusions are: 
- The current state of biomass-to-methanol technology investigated in this study is not commercially competitive at this scale. Further assessment needs to be done in terms of improved technology and better overall process efficiency to make this chemical conversion route more competitive,

- The main contributions to the capital costs are: gasification (with tar reforming, heat recovery, water scrubbing) for the directly-heated gasifier plant, and syngas cleanup and compression (compressor, sulfur and other impurities removal, steam reforming) for the indirectly-heated gasifier system. Cost improvements in these two areas would significantly reduce methanol production costs. Methanol synthesis from syngas is mature technology and unlikely to be a source for cost reduction,

- The indirectly heated gasifier system produces a lower cost methanol than the directly heated gasifier system because of the higher capital costs for the directly heated gasifier and its associated air separation unit,

- Sensitivity analysis indicated that:

a. Even with a low feedstock price (\$30/dry ton delivered), the current biomass-to-methanol production technology is still not commercially competitive.

b. For the direct gasification case, the elimination of natural gas usage results in a higher minimum methanol selling price, which reduces green house gas emissions. However, the reduced methanol production increases the minimum methanol selling price.

The potential improvements for the methanol systems include:

- Recycling unconverted syngas to an improved tar reforming process and using a single pass methanol synthesis process. These changes lead to methanol yield increases and a consequent methanol MFSP decrease of about $10 \%$ and $6 \%$ for the indirectly-heated and directly-heated gasifier based systems, respectively. The effects of the potential improvements on the methanol systems are not as significant as the FT and mixed alcohol systems. The current design of methanol synthesis already has a high CO conversion efficiency and no methane is produced. Thus the effects of recycling unconverted syngas are not as significant as the FT cases. The capital cost of the methanol synthesis of the current design is low compared to other processes and thus changing from the multiple pass to single pass only has limited cost saving effect.

\section{DME}

Similar to methanol, the gasification and syngas cleaning process have potential for improvement. Potential improvements for methanol synthesis lead to the increases in the methanol yields and thus the DME yields. The cost analysis results show that the DME price decreases about $6 \%$ and $4 \%$ for the indirectly-heated and directly-heated gasifier based systems. Another improvement includes a one-step process combining methanol and DME production. The main advantages of this design include enhanced productivity and the elimination of a second reactor. However, downstream separation may be more complex compared to the two-step process (Peng et al. 1999). The one-step DME process is a potential area for future research and techno-economic assessment for a probable route to reach a market competitive DME price. 
Table 9-1 Summary of Performance and Cost Results for Gasification to Ethanol, Gasoline and Diesel

\begin{tabular}{|c|c|c|c|c|c|c|c|c|}
\hline \multirow{2}{*}{$\begin{array}{l}\text { Case } \\
\text { Performance } \\
\text { Gasifier type }\end{array}$} & \multicolumn{2}{|c|}{$\begin{array}{c}\text { Mixed alcohol } \\
\text { synthesis }\end{array}$} & \multicolumn{2}{|c|}{$\begin{array}{l}\text { Methanol to } \\
\text { Gasoline } \\
\text { (MTG) }\end{array}$} & \multicolumn{2}{|c|}{ FT Diesel } & \multicolumn{2}{|c|}{$\begin{array}{l}\text { Ethanol via } \\
\text { Acetic Acid }\end{array}$} \\
\hline & Indirect & Direct & Indirect & Direct & Indirect & Direct & Indirect & Direct \\
\hline Dry wood chips, tpd & 2200 & 2200 & 2200 & 2200 & 2200 & 2200 & 2200 & 2200 \\
\hline Products & \multicolumn{2}{|c|}{ Ethanol } & \multicolumn{2}{|c|}{ Gasoline } & \multicolumn{2}{|c|}{ Diesel } & \multicolumn{2}{|c|}{ Ethanol } \\
\hline Yield, million gal/y & 43 & 45 & 40 & 40 & 24 & 28 & 129 & 158 \\
\hline Yield, gal/dry st feed & 60 & 63 & 56 & 56 & 34 & 39 & 178 & 218 \\
\hline Byproducts & \multicolumn{2}{|c|}{ Propanol+ } & \multicolumn{2}{|c|}{ LPG } & \multicolumn{2}{|c|}{ Naphtha } & & \\
\hline Yield, million gal/y & 14 & 15 & 7 & 0 & 8 & 9 & -- & -- \\
\hline Net Power, MW & -3.6 & 3.6 & -7.8 & 13 & 22 & 25 & -6.8 & 9.3 \\
\hline Water Demand, gpm & 1,039 & 881 & 1,111 & 1,155 & 901 & 1,167 & 1,334 & 1510 \\
\hline Wastewater, gpm & 360 & 333 & 547 & 660 & 536 & 540 & 519 & 522 \\
\hline Carbon efficiency, \% & 29 & 30 & 32 & 29 & 23 & 26 & 45 & 50 \\
\hline Thermal Efficiency, \% LHV & 42 & 45 & 46 & 44 & 40 & 46 & 55 & 58 \\
\hline \multicolumn{9}{|l|}{ Cost (2008 dollars) } \\
\hline $\begin{array}{l}\text { Total Purchased Equipment } \\
\text { Cost (TPEC), million \$ } \\
\text { Total Installed Cost (TIC), }\end{array}$ & 95 & 129 & 98 & 136 & 102 & 144 & 160 & 216 \\
\hline million $\$$ & 236 & 318 & 236 & 326 & 251 & 355 & 397 & 534 \\
\hline Total Indirect Cost, million \$ & 120 & 162 & 124 & 171 & 128 & 181 & 202 & 272 \\
\hline $\begin{array}{l}\text { Total Project Investment, } \\
\text { million } \$\end{array}$ & 356 & 480 & 360 & 499 & 379 & 537 & 598 & 806 \\
\hline Variable operating cost & \multicolumn{2}{|c|}{ \$/gal } & \multicolumn{2}{|c|}{ \$/gal } & \multicolumn{2}{|c|}{$\$ /$ gal } & \multicolumn{2}{|c|}{ \$/gal } \\
\hline Biomass & 1.0 & 1.0 & 1.1 & 1.1 & 1.8 & 1.6 & 0.34 & 0.27 \\
\hline Natural gas & -- & -- & -- & -- & -- & -- & -- & 0.11 \\
\hline Catalysts \& Chemicals & 0.1 & 0.1 & 0.3 & 0.4 & 0.2 & 0.2 & 1.9 & 2.0 \\
\hline Waste Disposal & 0.0 & 0.0 & 0.0 & 0.0 & 0.1 & 0.1 & 0.01 & 0.01 \\
\hline Utilities & 0.1 & 0.0 & 0.1 & -0.1 & -0.4 & -0.4 & -0.02 & -0.02 \\
\hline Co-product credits & -0.4 & -0.4 & -0.3 & 0 & -0.8 & -0.8 & -- & -- \\
\hline Sum & 0.8 & 0.7 & 1.2 & 1.4 & 0.8 & 0.6 & 2.3 & 2.3 \\
\hline \multicolumn{9}{|l|}{ Current technology case } \\
\hline $\begin{array}{l}\text { MFSP, \$/gal } \\
\text { MESP ethanol equivalent }\end{array}$ & 2.71 & 3.07 & 3.08 & 3.94 & 4.29 & 4.85 & 3.38 & 3.47 \\
\hline $\begin{array}{l}\text { LHV basis, \$/gal } \\
\text { MFSP, gasoline equivalent }\end{array}$ & 2.71 & 3.07 & 2.12 & 2.68 & 2.81 & 3.17 & 3.38 & 3.47 \\
\hline $\begin{array}{l}\text { LHV basis, \$/gal } \\
\text { Potential improvements } \\
\text { case }\end{array}$ & 4.70 & 4.12 & 3.08 & 3.94 & 4.12 & 4.67 & 5.16 & 5.31 \\
\hline $\begin{array}{l}\text { MFSP, \$/gal } \\
\text { MESP ethanol equivalent }\end{array}$ & 1.24 & 1.86 & 2.32 & 2.90 & 3.43 & 4.48 & 2.42 & 2.54 \\
\hline $\begin{array}{l}\text { LHV basis, } \$ / \text { gal } \\
\text { MFSP, gasoline equivalent }\end{array}$ & 1.24 & 1.86 & 1.60 & 1.97 & 2.24 & 2.93 & 2.42 & 2.54 \\
\hline LHV basis, \$/gal & 2.15 & 3.22 & 2.32 & 2.90 & 3.29 & 4.30 & 3.70 & 3.89 \\
\hline $\begin{array}{l}\text { Research areas to achieve } \\
\text { improvements }\end{array}$ & $\begin{array}{r}\text { Improve } \\
\text { cleanul } \\
\text { alcohol } \\
\text { cat }\end{array}$ & $\begin{array}{l}\text { yngas } \\
\text { nixed } \\
\text { thesis } \\
\text { st }\end{array}$ & $\begin{array}{r}\text { Impr } \\
\text { syngas } \\
\text { MTG s } \\
\text { cata }\end{array}$ & $\begin{array}{l}\text { ved } \\
\text { eanup, } \\
\text { thesis } \\
\text { yst }\end{array}$ & $\begin{array}{r}\text { Improve } \\
\text { cle }\end{array}$ & $\begin{array}{l}\text { syngas } \\
\text { up }\end{array}$ & $\begin{array}{r}\text { Improve } \\
\text { cleant } \\
\text { acetic } \\
\text { prod }\end{array}$ & $\begin{array}{l}\text { syngas } \\
20 \% \\
\text { id co- } \\
\text { ction }\end{array}$ \\
\hline
\end{tabular}


Table 9-2 Summary of Performance and Cost Results for Methanol and DME

\begin{tabular}{|c|c|c|c|c|}
\hline Case & \multicolumn{2}{|c|}{ Methanol } & \multicolumn{2}{|c|}{ DME } \\
\hline \multirow{2}{*}{$\begin{array}{l}\text { Performance } \\
\text { Gasifier type }\end{array}$} & \multirow[b]{2}{*}{ Indirect } & \multirow[b]{2}{*}{ Direct } & \multirow[b]{2}{*}{ Indirect } & \multirow[b]{2}{*}{ Direct } \\
\hline & & & & \\
\hline \multicolumn{5}{|l|}{ Feed } \\
\hline Dry wood chips, tpd & 2200 & 2200 & 2200 & 2200 \\
\hline Products & \multicolumn{2}{|c|}{ Methanol } & \multicolumn{2}{|c|}{ DME } \\
\hline Yield, million gal/y & 95 & 100 & 81 & 76 \\
\hline Yield, gal/dry st feed & 131 & 139 & 113 & 105 \\
\hline \multicolumn{5}{|l|}{ Byproducts } \\
\hline Yield, million gal/y & -- & -- & -- & -- \\
\hline Net Power, MW & -7.4 & 8.5 & -5.5 & 14 \\
\hline Water Demand, gpm & 954 & 1,135 & 1,057 & 1,219 \\
\hline Wastewater, gpm & 363 & 418 & 421 & 475 \\
\hline Carbon efficiency, $\%$ & 32 & 33 & 32 & 30 \\
\hline Thermal Efficiency, \% LHV & 48 & 50 & 51 & 52 \\
\hline \multicolumn{5}{|l|}{ Cost (2008 dollars) } \\
\hline \multicolumn{5}{|l|}{ Total Purchased Equipment } \\
\hline Cost (TPEC), million \$ & 79 & 121 & 77 & 120 \\
\hline \multicolumn{4}{|l|}{ Total Installed Cost (TIC), } & 297 \\
\hline Total Indirect Cost, million \$ & 100 & 152 & 97 & 151 \\
\hline \multicolumn{5}{|l|}{ Total Project Investment, } \\
\hline Variable operating cost & \multicolumn{2}{|c|}{ \$/gal } & \multicolumn{2}{|c|}{ \$/gal } \\
\hline Biomass & 0.46 & 0.43 & 0.53 & 0.57 \\
\hline Natural gas & 0 & 0.08 & -- & -- \\
\hline Catalysts \& Chemicals & 0.03 & 0.07 & 0.08 & 0.09 \\
\hline Waste Disposal & 0.02 & 0.02 & 0.02 & 0.02 \\
\hline Utilities & 0.05 & -0.03 & 0.05 & -0.08 \\
\hline Co-product credits & -- & -- & -- & -- \\
\hline Sum & 0.56 & 0.57 & 0.68 & 0.60 \\
\hline \multicolumn{5}{|l|}{ Current technology case } \\
\hline MFSP, \$/gal & 1.28 & 1.57 & 1.50 & 1.91 \\
\hline MESP ethanol equivalent & & & & \\
\hline LHV basis, \$/gal & 1.71 & 2.10 & 1.64 & 2.10 \\
\hline \multicolumn{5}{|l|}{$\begin{array}{l}\text { Potential improvements } \\
\text { case }\end{array}$} \\
\hline MFSP, \$/gal & 1.15 & 1.47 & 1.41 & 1.84 \\
\hline MESP ethanol equivalent & & & & \\
\hline LHV basis, \$/gal & 1.54 & 1.97 & 1.54 & 2.02 \\
\hline $\begin{array}{l}\text { Research areas to achieve } \\
\text { improvements }\end{array}$ & $\begin{array}{r}\text { Improv } \\
\mathrm{cl}\end{array}$ & $\begin{array}{l}\text { yngas } \\
\text { p }\end{array}$ & $\begin{array}{l}\text { Improv } \\
\text { cle } \\
\text { metha } \\
\text { synthes }\end{array}$ & $\begin{array}{l}\text { yngas } \\
\text { p, } \\
\text { DME } \\
\text { atalyst }\end{array}$ \\
\hline
\end{tabular}

Note: Biomass at \$60/dry ton, 2200 tpd dry. All values in 2008 USD, rounded to two significant figures. 


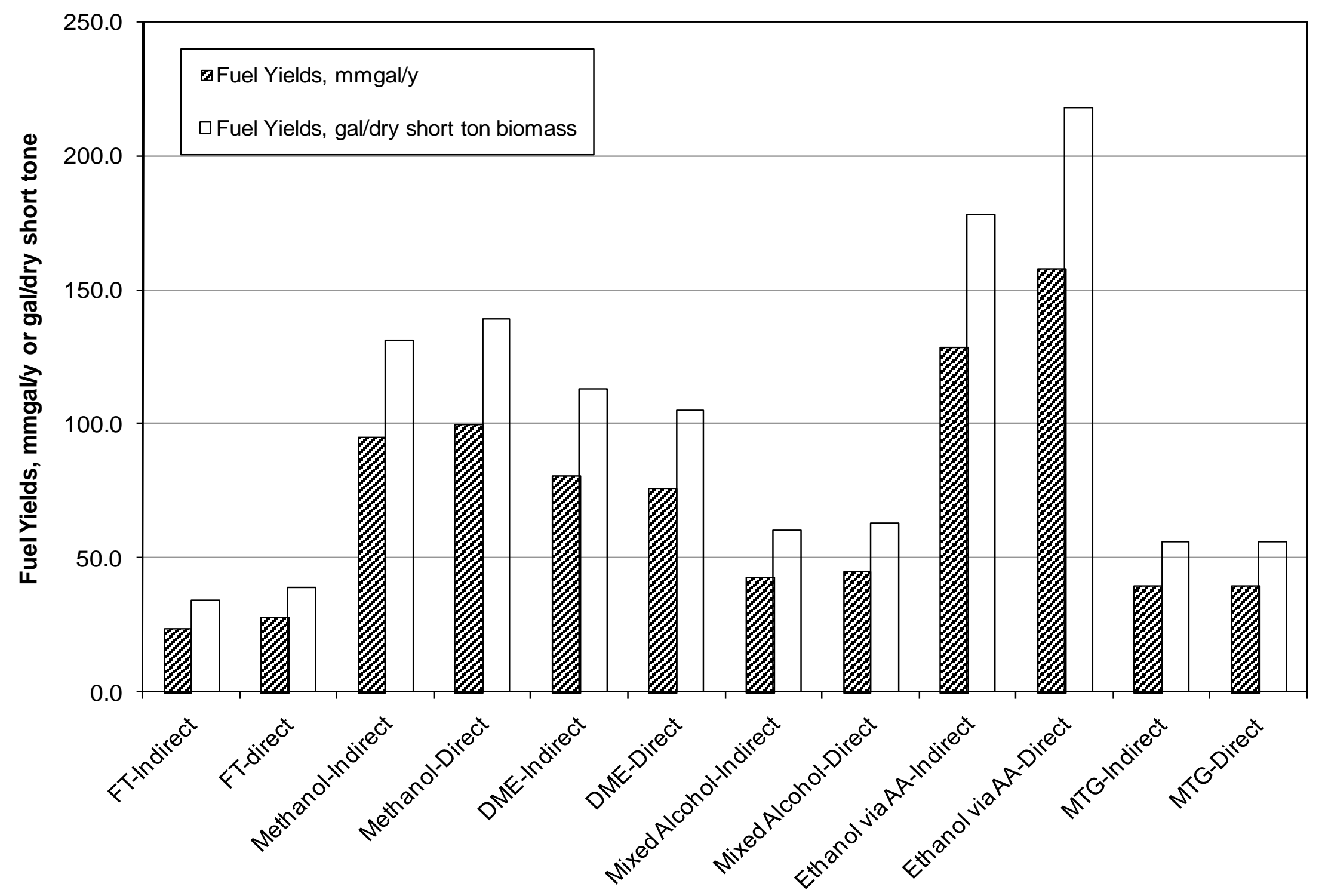

Figure 9-1 Fuel Yields of Gasification Based Biomass-to-Liquid Fuels Systems 


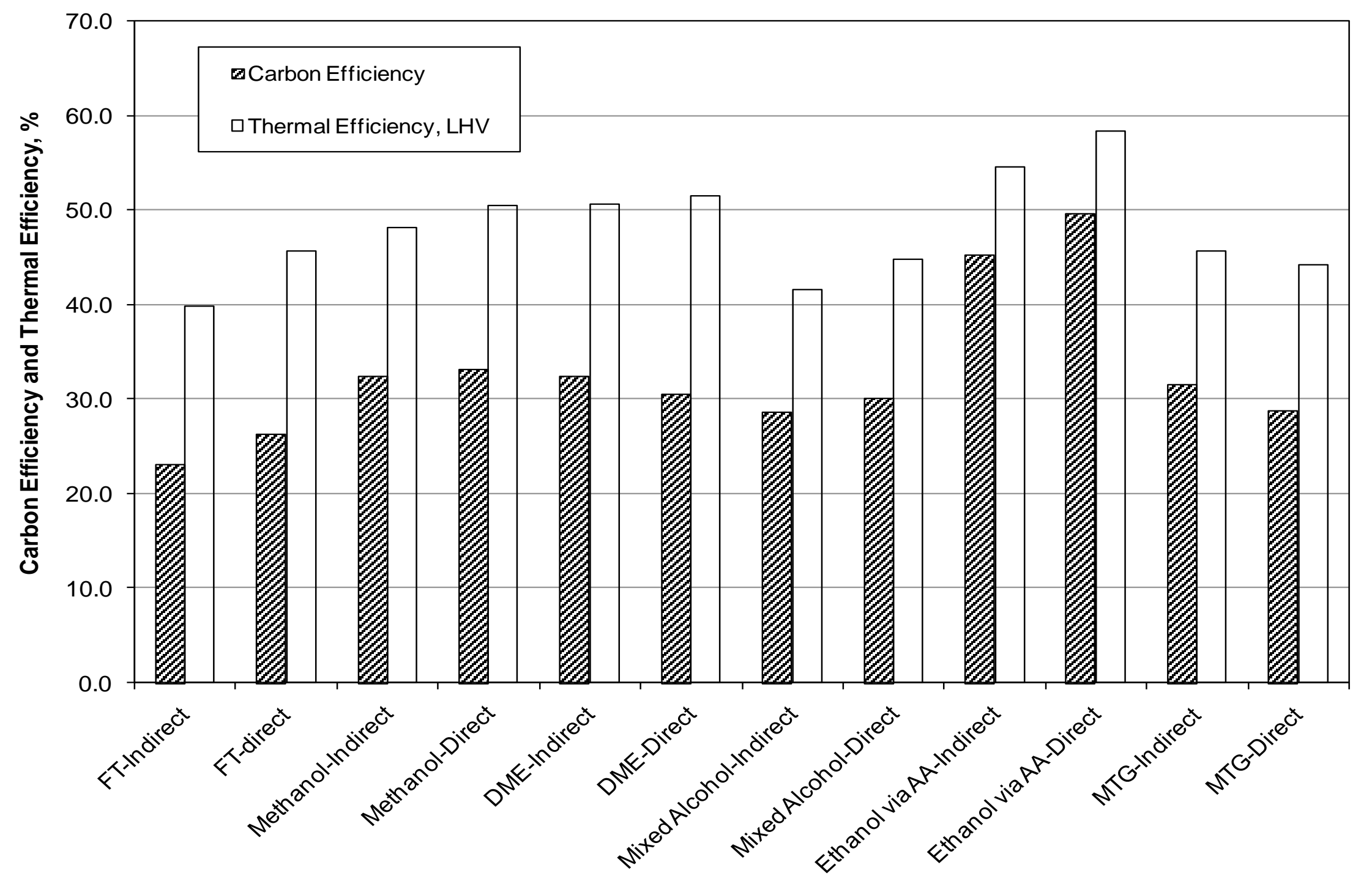

Figure 9-2 Carbon and Thermal Efficiencies of Gasification Based Fuels Systems 


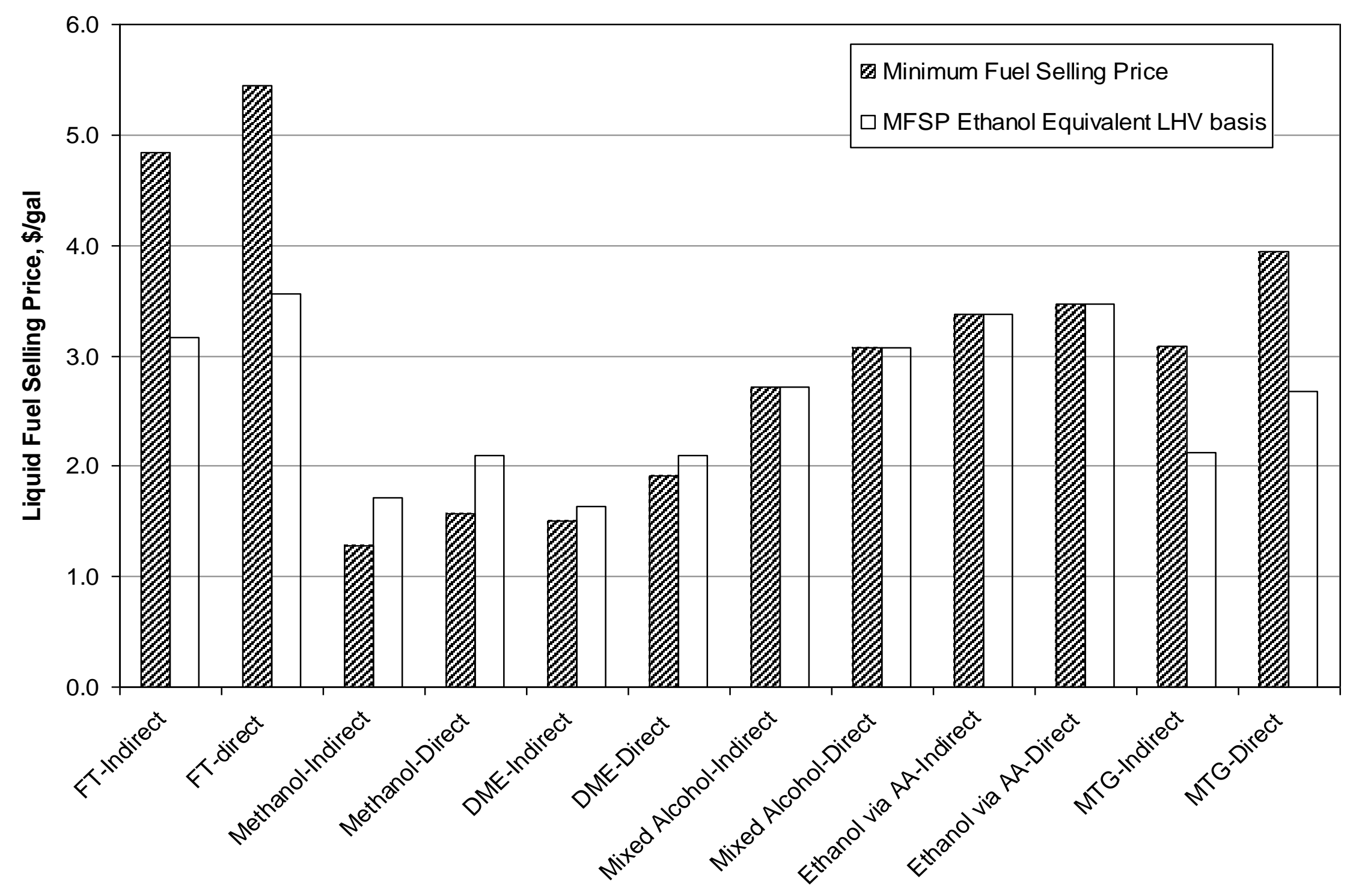

Figure 9-3 Cost Comparison of Gasification Based Biomass-to-Liquid Fuels Systems 


\subsection{Liquefaction based Systems}

The results for the liquefaction based systems are summarized in Table 9-3. As discussed earlier, the HTL and fast pyrolysis systems results are based on assumed future improvements. These technologies have nearly the same fuel yields and carbon and thermal efficiencies. The fast pyrolysis system produces less wastewater compared to the HTL system because it starts with nearly dry biomass. The capital costs of the HTL systems are potentially higher than that of the pyrolysis system. The higher capital cost of the HTL system leads to higher gasoline and diesel MFSP than that of the pyrolysis systems, though the two have almost the same yields.

Table 9-3 Summary of Performance and Cost Results for Liquefaction Based Fuels

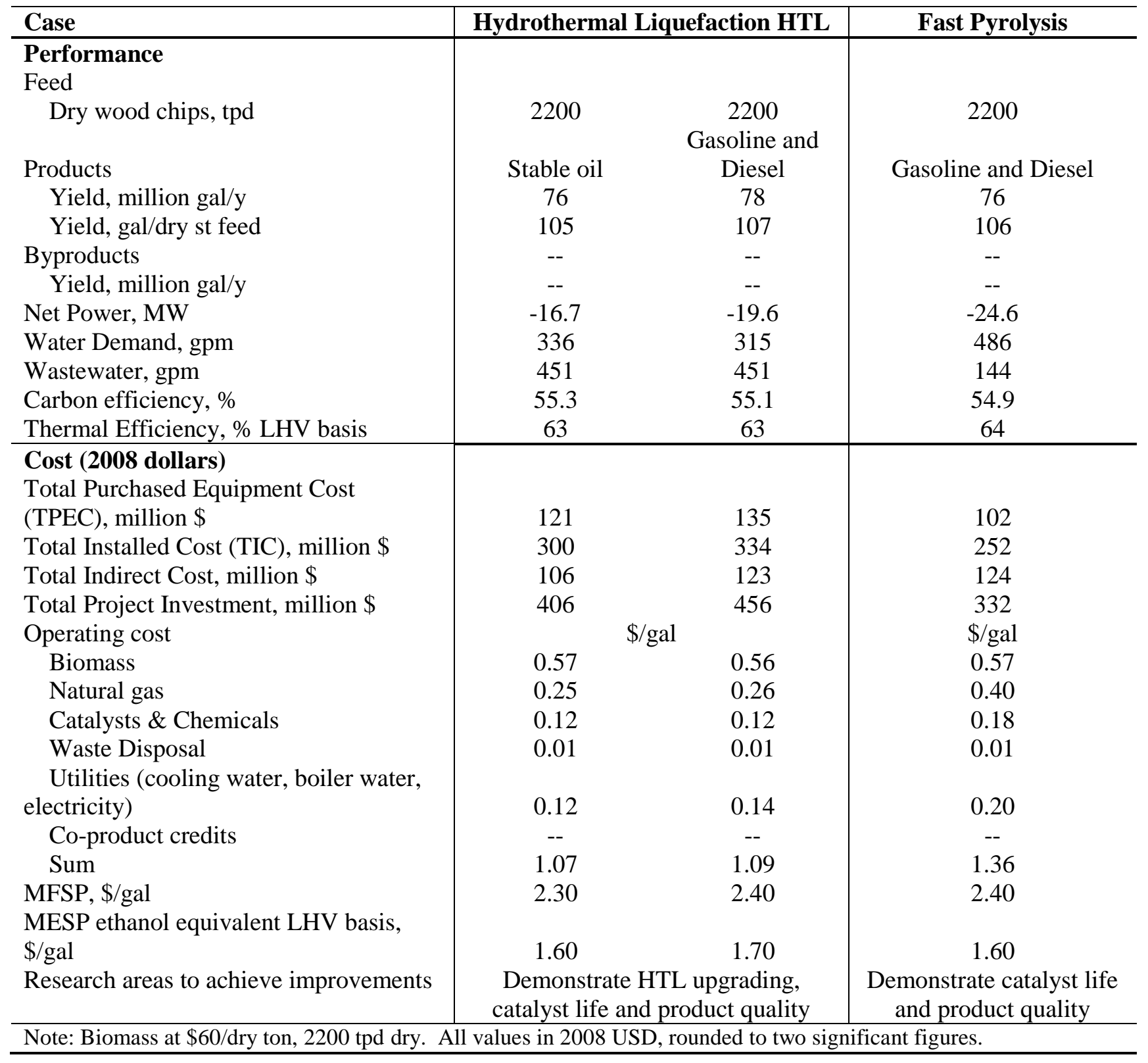




\section{IMPROVEMENTS:}

For HTL and pyrolysis systems, the analysis in this study described systems with technologies projected to be available in the future. Further research and development is needed to demonstrate the HTL upgrading, catalyst life, and product quality. Jones et al. (2009) suggests that the biggest impacts of technical improvements are in the area of catalysis as it relates to bio-oil upgrading. Catalyst lifetimes and performance are essential to the process and need additional development and testing. In addition, research on the direct liquefaction process that leads to a better quality bio-oil requiring less upgrading could potentially reduce product costs.

Another potential method to reduce costs of the HTL and pyrolysis systems is to co-locate the liquefaction and hydrotreating processes with a refinery. This eliminates the need for a hydrogen plant if the upgrading unit off-gas can be sent to refinery for hydrogen generation. In return, the upgrading unit receives refinery hydrogen at a lower cost. The stable oil can be sent to the refinery for fuel upgrading and then the hydrocracking and product separation units can be removed in the HTL plant. Compared to the current technology of the HTL and pyrolysis systems, the co-location with refinery design can reduce the MFSP about $25 \%$ for the HTL system and $15 \%$ for the pyrolysis system. Therefore, building a HTL or pyrolysis plant with stable production and close to a refinery would be a cost effective way for the development of these technologies, which is more economic than a standalone plant with gasoline and diesel production.

\subsection{Comparison with Current Fuel Market Prices}

The biomass based liquid fuel products investigated in this study include fuels currently available in the US market and fuels unavailable now but potentially available in the future. In this section, the fuels that are currently available (gasoline and diesel, ethanol) are compared with market prices.

\section{Gasoline and Diesel}

In this study, the technologies that convert biomass to gasoline and/or diesel are FT (diesel), MTG (gasoline), and liquefaction (gasoline and diesel). The gasoline wholesale/resale price ranges from 1.06 to $\$ 3.42$ gallon from January to December 2008 with an annual average of $\$ 2.58 /$ gallon. The U.S. No. 2 diesel wholesale/resale price range for 2008 is $\$ 1.47$ to $\$ 3.89 /$ gallon with an annual average of $\$ 2.98$ /gallon (Energy Information Administration 2009b). None of the existing technology gasification cases are competitive with market prices. However, the goal liquefaction cases and the goal cases for the indirectly-heated gasifier based FT system and the MTG systems for both gasifiers are potentially competitive.

\section{Ethanol}

In this study, ethanol is produced from biomass gasification via mixed alcohol synthesis or acetic acid synthesis and hydrogenation. The ethanol price as fuel is between $\$ 1.36$ and $\$ 2.79 /$ gallon with an annual average of $\$ 2.17 /$ gallon in 2008 (ICIS Pricing 2009). Compared to these values, the current technologies for ethanol production via mixed alcohol or acetic acid synthesis are both not competitive. With potential 
improvements, the indirectly-heated gasifier based biomass-to-mixed alcohol system has an ethanol MFSP of $\$ 1.24 /$ gallon, which is below than the 2008 average ethanol market price. On a gasoline gallon equivalent basis this system with improvements has a gasoline MFSP of $\$ 2.15 /$ gallon, which is also below the 2008 average gasoline market price.

\subsection{Overall Conclusions and Recommendations}

The main conclusions and recommendations are as follows:

- High overall conversion synthesis steps, such as in methanol and DME, have better thermal efficiency than lower conversion synthesis cases, such as FT diesel or ethanol.

- No gasification case in the present study, using current technology, is economically attractive. For the current technology gasification cases, the total project investment range from $\$ 260$ to $\$ 810$ million. For the gasification based liquid fuels, the indirectly-heated gasifier based methanol system has the lowest capital cost resulting from the simple direct low cost synthesis step and high selectivity.

- The directly heated gasifier systems require more capital than the indirectly heated systems.

- Chemical by-products improve process economics.

- Both liquefaction and gasification based systems need further reductions in cost to make them economically attractive.

The analysis suggests further work in the following areas:

For the gasification based systems:

- Improved gas cleanup technologies to achieve high methane and tar removals,

- Develop gasification technologies with syngas compositions that meet the desired synthesis requirements, i.e. syngas with low methane content for FT and mixed alcohol synthesis,

- Develop fuel synthesis catalysts and processes with improved conversions,

- Reduce the number of synthesis steps (such as single step syngas to gasoline).

For the liquefaction based systems:

- Improve raw bio-oil properties from the fast pyrolysis and HTL steps,

- Improve upgrading catalyst life,

- Determine desired final product qualities.

The results of this study provide a consistent basis for comparing different liquid fuels products from biomass, provide information about the key technical barriers and key factors affecting costs, and provide a comparison basis for new biomass conversion technologies. 


\subsection{References}

Aden A (2008), Biochemical Production of Ethanol from corn Stover: 2007 State of Technology Model. NREL/TP-510-43205. National Renewable Energy Laboratory, Golden, CO. May 2008.

http://www.nrel.gov/docs/fy08osti/43205.pdf

Aden A, Ruth M, Ibsen K, Jechura J, Neeves K, Sheehan J, Wallace B, Montague L, Slayton A, and Lukas J (2002), Lignocellulosic Biomass to Ethanol Process Design and Economics Utilizing Co-Current Dilute Acid Prehydrolysis and Enzymatic Hydrolysis for Corn Stover. NREL Report No. TP-510-32438. June 2002. http://www.nrel.gov/docs/fy02osti/32438.pdf

Aden A, P Spath, and A Atherton (2005), The Potential of Thermochemical Ethanol via Mixed Alcohol Production. Milestone Completion Report. FY05-684. October 2005

Alfke G, Irion W W, and Neuwirth O S (2007), 'Oil Refining', Section 3.5, in Ullmann's Encyclopedia of Industrial Chemistry, Electronic Release, $7^{\text {th }}$ Edition, Wiley-VCH: Weinheim. 2007. DOI:

10.1002/14356007.a18_051.pub2

Bartholomew, C H, 1990, Recent Technological Developments in Fischer-Tropsch Catalysis,. Catalysis Letters 7: 303-316

Bergin S P, Noel W, Schiewer S, Witmer D (2007), Demonstration of Fischer-Tropsch Diesel Fuel in Cold Climates, AK-26-7005.2007.01 Federal Transit Administration, U.S. Department of Transportation, Washington, DC, November 8, 2007

CRS Congressional Research Service (2007), Energy Independence and Security Act of 2007: A Summary of Major Provisions, RL34294, prepared for Congress, December 21, 2007.

http://energy.senate.gov/public/ files/RL342941.pdf, accessed in September 2009

Cheng W H and Kung H H (1994), Methanol Production and Use. Marcel-Dekker: New York, 1994.

Couper J R, Pennery W R, Fair J R, and Walas S M (2005), Chemical Process Equipment Selection and Design, $2^{\text {nd }}$ Ed. Elsevier Press. 2005

Dolan G (2008), 'China Takes Gold in Methanol Fuel,' Journal of Energy Security, October 6, 2008

Dutta A and Phillips S D (2009). Thermochemical Ethanol via Direct Gasification and Mixed Alcohol Synthesis of Lignocellulosic Biomass. NREL Report No. TP-510-45913, National Renewable Energy Laboratory, Golden, Colorado, July 2009

Elliott D C (2007), 'Historical Developments in Hydroprocessing Bio-oil,' Energy \& Fuels 21(2007): $1792-1815$

Ekstrand J and Jorgensen S L (2007), Cost Effective Topsoe DME Production Technology, Gasochem 2007 http://www.topsoe.com/Business_areas/Gasification-based/Processes/Dimethylether.aspx, accessed May 1, 2009 
Energy Information Administration (2008), Industrial Electricity Prices, Jan-Jun 2008 Average. Natural Gas Prices, 2008 annual average, http://www.eia.doe.gov/

Energy Information Administration (2008a), The Impact of Increased Use of Hydrogen on Petroleum Consumption and Carbon Dioxide Emissions, SR-OIAF-CNEAF/2008-04, August 2008, http://www.eia.doe.gov/oiaf/servicerpt/hydro/hydrogen.html, accessed July 2009.

Energy Information Administration (2009b), United States Gasoline and No.2 Diesel Wholesale/Resale Price by Refiners, http://205.254.135.7/dnav/pet/pet pri refoth dcu nus m.htm, accessed December 2011.

Energy Information Administration (2009c), U.S. Crude Oil Composite Acquisition Cost by Refiners (Dollars per Barrel), http://www.eia.gov/dnav/pet/pet pri rac2 dcu nus m.htm, accessed December 2011.

Evans R J, Knight R A, Onischak M, and Babu S P (1988), Development of Biomass Gasification to Produce Substitute Fuels. PNL-6518, Prepared by Institute of Gas Technology for Pacific Northwest Laboratory, Richland, Washington

Feng W, van der Kooi H J, de Swaan Arons J (2004), 'Biomass Conversions in Subcritical and Supercritical Water: Driving Force, Phase Equilibria, and Thermodynamic Analysis,' Chemical Engineering and Processing 43(2004): 1459-1467

Fiedler E, Grossmann G, Kersebohm D B, Weiss G, and Witte C (2007). 'Methanol', in Ullmann's Encyclopedia of Industrial Chemistry, Electronic Release, 7th ed., Wiley-VCH, Weinheim, 2007

Goudriaan F, van de Beld B, Boerefijn F R., Bos G M, Naber J E, van der Wal S, and Zeevalkink J A (2001), 'Thermal Efficiency of the HTU Process for Biomass Liquefaction' Thermochemical Biomass Conversion, Bridgwater, A.V., Ed.; Blackwell Science, LTD. Oxford, England, 2001, pp 1312-1325

Goudriaan F and Peferoen D G R (1990), 'Liquid Fuels from Biomass via a Hydrothermal Process,' Chemical Engineering Science, Vol. 45. No. 8, pp. 2729-2734, 1990

Hamelinck C, Faaij A PC, Uil HD, and Boerrigter H (2003), Production of FT transportation Fuels from Biomass; Technical Options, Process Analysis and Optimization, and Development Potential. Energy Research Centre of the Netherlands (ECN) Report NWS-E-2003-08

Hamelinck C N and Faaij A PC (2002), Future Prospects for Production of Methanol and Hydrogen from Biomass, Journal of Power Sources, 111 (2002): 1-22

Häussinger P, Lohmüller R, Watson A M (2000), 'Hydrogen,' in Ullmann's Encyclopedia of Industrial Chemistry, $7^{\text {th }}$ Edition, Wiley-VCH: Weinheim. DOI: 10.1002/14356007.a13_297

Hiller H, Reimert R et al. (2006), 'Gas Production,' in Ullmann's Encyclopedia of Industrial Chemistry, Electronic Release, $7^{\text {th }}$ Edition, Wiley-VCH: Weinheim. DOI: 10.1002/14356007.a12_169.pub2 
Hydrogen Analysis Resource Center (2008), Lower and Higher Heating Values of Fuels, Pacific Northwest National Laboratory, U.S. Department of Energy, 2008

http://hydrogen.pnl.gov/cocoon/morf/hydrogen/site_specific/fuel_heating_calculator?canprint=false, accessed September 2009

ICIS Pricing (2009), Acetic Acid and Ethanol Price History (01 Jan 2008 and 31 Dec 2008), Chemical price reports, Reed Business Information Limited, Sutton, Surrey, United Kingdom

Jack D (2009). Scale-up of Hydrogen Transport Membranes for IGCC and FutureGen Plants. DE-FC2605NT42469, Prepared for National Energy Technology Laboratory, Department of Energy, Boulder, CO, May 22, 2009

Jiutai Energy News Release (2008), 'Opinions on Approval of Applying Jiutai Energy DME and Yide Fuel Gas of Light Hydrocarbon and Air Mixture as Civil Fuel Gases,' March 29, 2008. http://www.chinajiutai.com/english/en/e\%20index.html, accessed August, 2009

Jones J H (2000), 'The Cativa ${ }^{\mathrm{TM}}$ Process for the Manufacture of Acetic Acid,' Platinum Metals Review, 44(3): 94-105

Jones S B, Holladay J E, Valkenburg C, Stevens D J, Walton C, Kinchin C, Elliott D C, Czernik S (2009), Production of Gasoline and Diesel from Biomass via Fast Pyrolysis, Hydrotreating and Hydrocracking: A Design Case, PNNL-18284 Rev. 1, Prepared for the U.S. Department of Energy, Washington, DC, February 2009

Jones S B and Zhu Y (2009), Techno-economic Analysis for the Conversion of Lignocellulosic Biomass to Gasoline via Methanol-to-Gasoline (MTG) Process, PNNL-18481, Pacific Northwest National Laboratory, Richland, WA. April 2009

Keeler C (2006), 'Substitute Natural Gas (SNG) - Scrubbing the Carbon in Coal and Petcoke,' Presented at the 2006 Gasification Technologies Conference, Gasification Technologies Council, Washington D.C., October 2, 2006

Konishi N and Ishiwada A (2004), 'Large Scale DME Production Technology and Economics,' Mitsubishi Gas Chemical Co., Inc., 2004, published online at Research Institute of Petroleum Industry (Iranian), http://www.ripi.ir, accessed May 2009

Landälv I (2006), 'Production of Biomass-Based DME and Methanol via Black Liquor Gasification,' presented at the 2006 Gasification Technologies Conference, Washington DC, October 1-4, 2006

Landälv I (2008), 'The BioDME Pilot Project,' Presented at the Solander Symposium, September 11-12, 2008, Pitea, Sweden. http://www.nolia.se/solandersymposium/presentation2008.php?id=9, Accessed May 2009

Liao S Y, Jiang D M, Cheng Q, Huang Z H and Zeng K (2006), ,Effect of Methanol Addition into Gasoline on the Combustion Characteristics at Relatively Low Temperatures,' Energy Fuels, 2006, 20 (1), pp.84-90, DOI: 10.1021/ef0502352 
Lowenberg A D and Kaempfer W H (1998). The Origins and Demise of South African Apartheid: A Public Choice Analysis. Ann Arbor, Michigan: University of Michigan Press, 1998

Marker T L, et al. (2005), Opportunities for Biorenewables in Oil Refineries, DOEGO15085Final. December 2005, http://www.osti.gov/energycitations/product.biblio.jsp?osti_id=861458

Merichem (2008). Lo-Cat process. Available at http://www.gtp-merichem.com/products/locat/diagrams/process.php.

Methanex Methanol Price July 2009. (http://www.methanex.com/products/methanolprice.html)

Meyers R A (2004), Handbook of Petroleum Refining Processes, $3^{\text {rd }}$ Ed. McGraw-Hill. 2004

Mii T and Uchida M (2005), 'Fuel DME Plant in East Asia,' Proceedings of $15^{\text {th }}$ Saudi-Japan Joint Symposium, Dhahran, Saudi Arabia, November 27-28, 2005

Naber J E and Goudriaan F (2005), HTU®-Diesel from Biomass, ACS Division of Fuel Chemistry, Washington DC, August 31, 2005

Nag A (2008), Biofuels Refining and Performance. McGraw Hill. 2008

Nexant (2006), Equipment Design and Cost Estimation for Small Modular Biomass Systems, Synthesis Gas Cleanup, and Oxygen Separation Equipment. Task 9: Mixed Alcohols From Syngas - State of Technology. Subcontract Report NREL/SR-510-39947, May 2006, San Francisco, California. http://www.nrel.gov/docs/fy06osti/39947.pdf, accessed August 2009

Nexant (2008), Dimethyl Ether Technology and Markets, ChemSystems PERP Program Report Abstract, PERP07/08-S3, December 2008, http://www.chemsystems.com/reports/index.cfm?catID=2\&yearnum=07-08, accessed August, 2009

Oasmaa A and Kuoppala E (2003), Fast Pyrolysis of Forestry Residue. 3. Storage Stability of Liquid Fuel, Energy Fuels, 2003, 17 (4), pp 1075-1084, DOI: 10.1021/ef030011o

Ohno Y (2007), 'New Clean Fuel DME', presented at the DeWitt Global Methanol \& MTBE Conference, Bankok, March 12-14, 2007. www.methanol.org/pdf/Ohno_DME_Dev_Co.pdf, accessed August 2009

Olah A G, Goeppert A, Surya Prakash G K (2006). Beyond Oil and Gas: The Methanol Economy. Verlag GmbH \& Co. KGaA: Weinheim, Germany, 2006

Peng X D, Diamond B W, Tsao T R, and Bhatt B L (2002), 'Separation Process for One-Step Production of Dimethyl Ether from Synthesis Gas,' U.S. Patent 6,458,856 B1, October 1, 2002.

Peng X D, Wang A W, Toseland B A, and Tijm P J A (1999), 'Single-Step Syngas-to-Dimethyl Ether Processes for Optimal Productivity, Minimal Emissions, and Natural Gas-Derived Syngas,' Ind. Eng. Chem. Res., 1999, 38 (11): 4381-438 
Peters M S and Timmerhaus K D (2003), Plant Design and Economics for Chemical Engineers. $5^{\text {th }}$ Edition, McGraw-Hill, Inc., New York.

Perry R H, Green D W, and Maloney J O (1984), Perry's Chemical Engineer's Handbook, $6^{\text {th }}$ Ed. McGraw-Hill. 1984.

Phillips S, A Aden, J Jechura, and D Dayton (2007), Thermochemical Ethanol Via Indirect Gasification and Mixed Alcohol Synthesis of Lignocellulosic Biomass. NREL/TP-510-41168. National Renewable Energy Laboratory, Golden, Colorado, April 2007

Phyllis Database for Biomass and Waste, Hybrid Poplar. Energy Research Center of the Netherlands. http://www.ecn.nl/phyllis

Klintbom P (2008), 'A tentative fuel specification of engine grade DME,' SES6-CT-2003-502705, RENEW, Göteborg, Sweden, July 2, 2008. www.renew-fuel.com/fs_documents.php, accessed August 2009

Shell (2009). Shell GTL plant in Bintulu, Malaysia. Retrieved August 19, 2009, from Shell Website: http://www.shell.com/home/content/qatar/bintulu/bintulu_malaysia_08102003_1230.html

Sie ST and Krishna R (1999), 'Fundamentals and selection of advanced Fischer-Tropsch reactors,' Applied Catalysis A: General, 186(1-2) 55-70

Solantuasta Y (2006), 'Co-Processing of Upgraded Bio-Liquids in Standard Refinery Units - BIOCOUP,' European Conference on Biorefinery Research Proceedings.

http://ec.europa.eu/research/energy/gp/gp events/biorefinery/article 3764 en.htm

Spath P, Aden A, Eggeman T, Ringer M, Wallace B, and Jechura J (2005), Biomass to Hydrogen Production Detailed Design and Economics Utilizing the Battelle Columbus Laboratory IndirectlyHeated Gasifier. NREL Report No. Number NREL/TP-510-37408. National Renewable Energy Laboratory, Golden, CO. May 30, 2005. http://www.nrel.gov/docs/fy05osti/37408.pdf

SRI International (2003), PEP Yearbook International. Menlo Park, CA, United States.

SRI International (2006). Advanced Gas-to-Liquids Process. SRI PEP 247A. Houston, TX: SRI Consulting

SRI International (2007), PEP Yearbook International. United States. Menlo Park, CA

SRI International (2007a), 'Hydrogen Production from Natural Gas,' PEP Yearbook International. Volume 1E. United States. Menlo Park, CA

Stiles D, Saffell B, Jones S, Stevens D, Orth R, and Zhu Y (2008), Biofuels in Oregon and Washington: A Business Case Analysis of Opportunities and Challenges, Prepared by Pacific Northwest National Laboratory, Richland, WA, February 2008 
Stranges A N (2003). 'Germany's Synthetic Fuel Industry 1927-1945,' AIChE National Spring Meeting, 2003, (p. Paper: 80a). New Orleans, LA

Tijmensen M JA, Faaija A PC, Hamelinck C N, van Hardeveld M RM (2002), 'Exploration of the Possibilities for Production of Fischer Tropsch Liquids and Power via Biomass Gasification,' Biomass and Bioenergy 23 (2002) $129-152$

Turton R, Bailie R C, Whiting W B, and Shaeiwitz J A (1998), Analysis, Synthesis, and Design of Chemical Processes, Prentice Hall: Upper Saddle River, NJ, 1998, pp. 709-716

Uhde (2005), Technology Profile Dimethyl ether (DME), http://www.uhde.eu/cgibin/byteserver.pl/pdf/technologies/TP_DME_2005.pdf, accessed August 2009

U.S. Department of Energy (2009), Biomass Multi-Year Program Plan. Office of the Biomass Program, Energy Efficiency and Renewable Energy, U.S. Department of Energy, Washington D.C. http://www1.eere.energy.gov/biomass/pdfs/mypp_july2009.pdf

Van der Lee J H, Young B R, and Syrcek W Y (2002), 'A Process Design and Control Strategy for Dimethyl Ether Production from a Methanol Feedstock,' Proceedings of the American Control Conference, Anchorage, AK, May 8-10, 2002, pp. 1585-1590

van de Venter E (2007). 'Overview of Sasol's acivities in CTL,' 2007 Gasification Technologies Conference. San Francisco, CA

Xu C and Lad N (2008), 'Production of Heavy Oils with High Caloric Values by Direct Liquefaction of Woody Biomass in Sub/Near-critical Water', Energy Fuels, 2008, 22 (1), pp 635-642, DOI: $10.1021 / \mathrm{ef} 700424 \mathrm{k}$

Zhen H and Taupy J (2008), 'DME (Di Methyl Ether) Perspectives in China,' presented at World Coalto-Liquids Conference, April 3-4, 2008. http://eficlient.kma.net/, accessed August 2009

Zhong C, Peters C J, Arons D S J (2002) 'Thermodynamic Modeling of Biomass Conversion Processes', Fluid Phase Equilibria 194-197 (30) 805-815, March 2002

Zhu Y, Gerber M A, Jones S B, and Stevens D J (2009), Analysis of the Effects of Compositional and Configurational Assumptions on Product Costs for Thermochemical Conversion of Lignocellulosic Biomass to Mixed Alcohols - FY 2007 Progress Report, PNNL-17949, Revision 1. Pacific Northwest National Laboratory, Richland, WA. February 2009

Zhu Y and Jones S (2009), Techno-economic Analysis for the Thermochemical Conversion of Lignocellulosic Biomass to Ethanol via Acetic Acid Synthesis, PNNL-18483, Pacific Northwest National Laboratory, Richland, WA. April 2009 


\title{
Appendix A. Heat and Material Balances
}

\author{
A.1 Gasification Processes
}




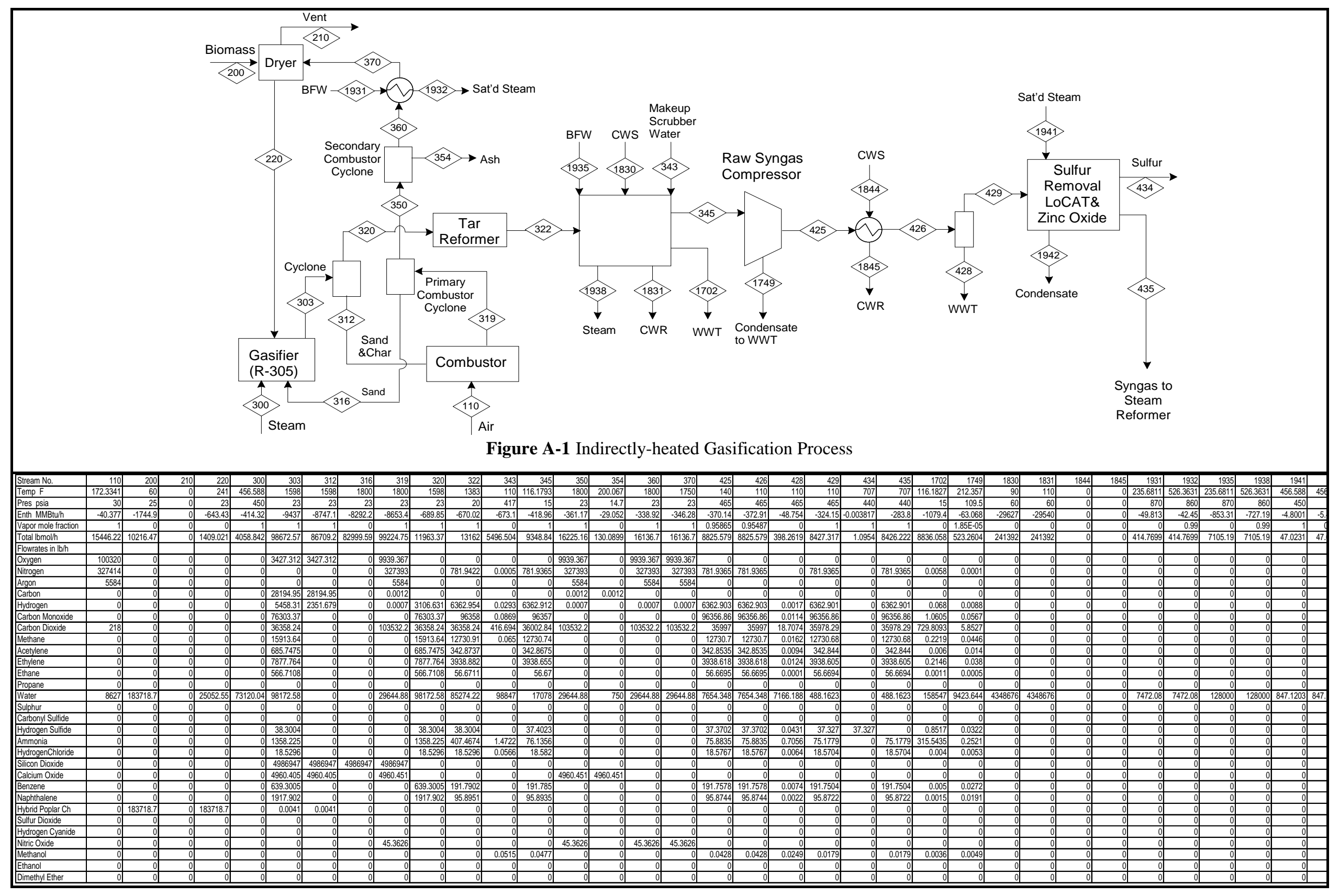




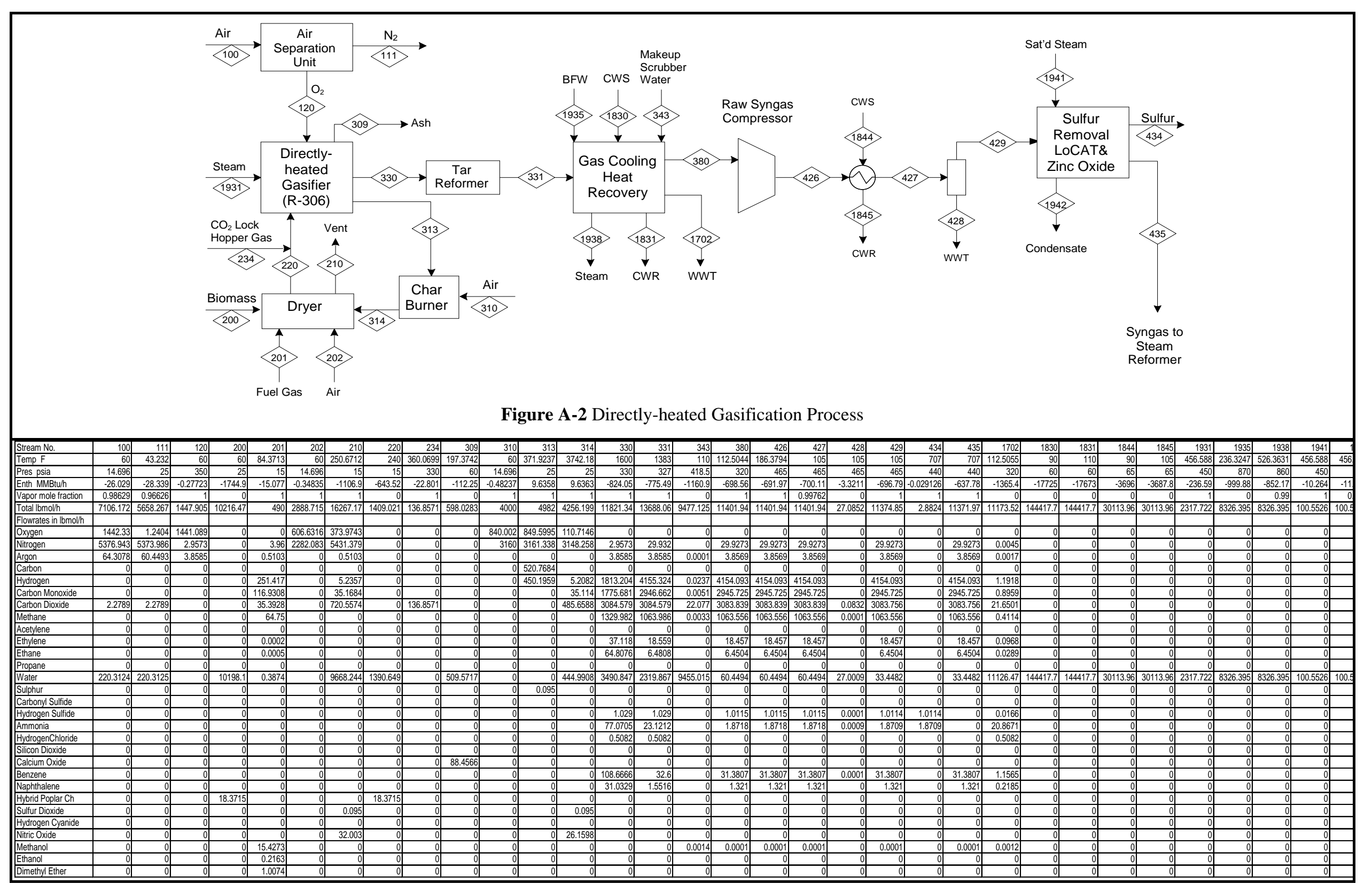


A.2 Fischer-Tropsch Diesel 


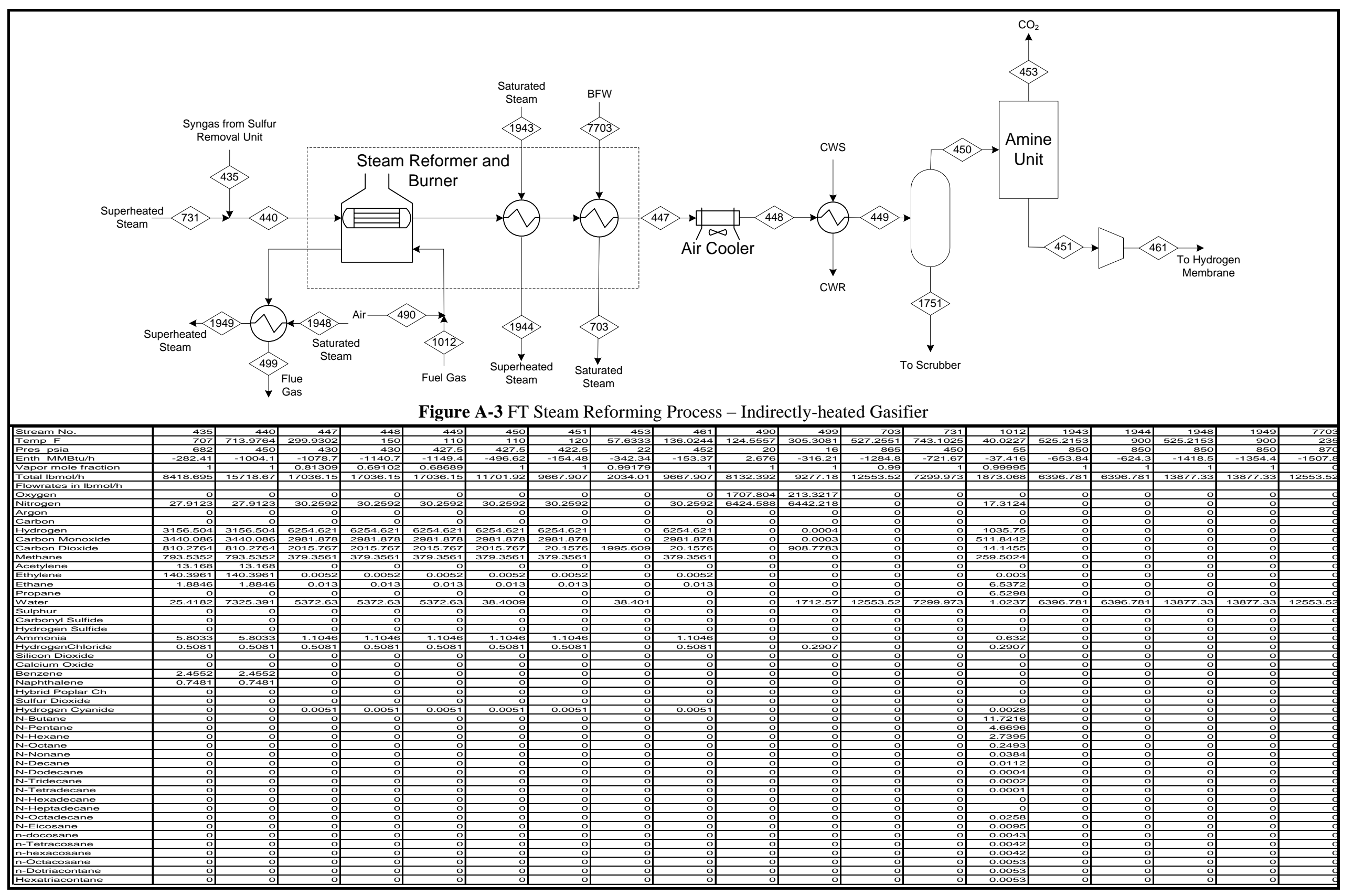




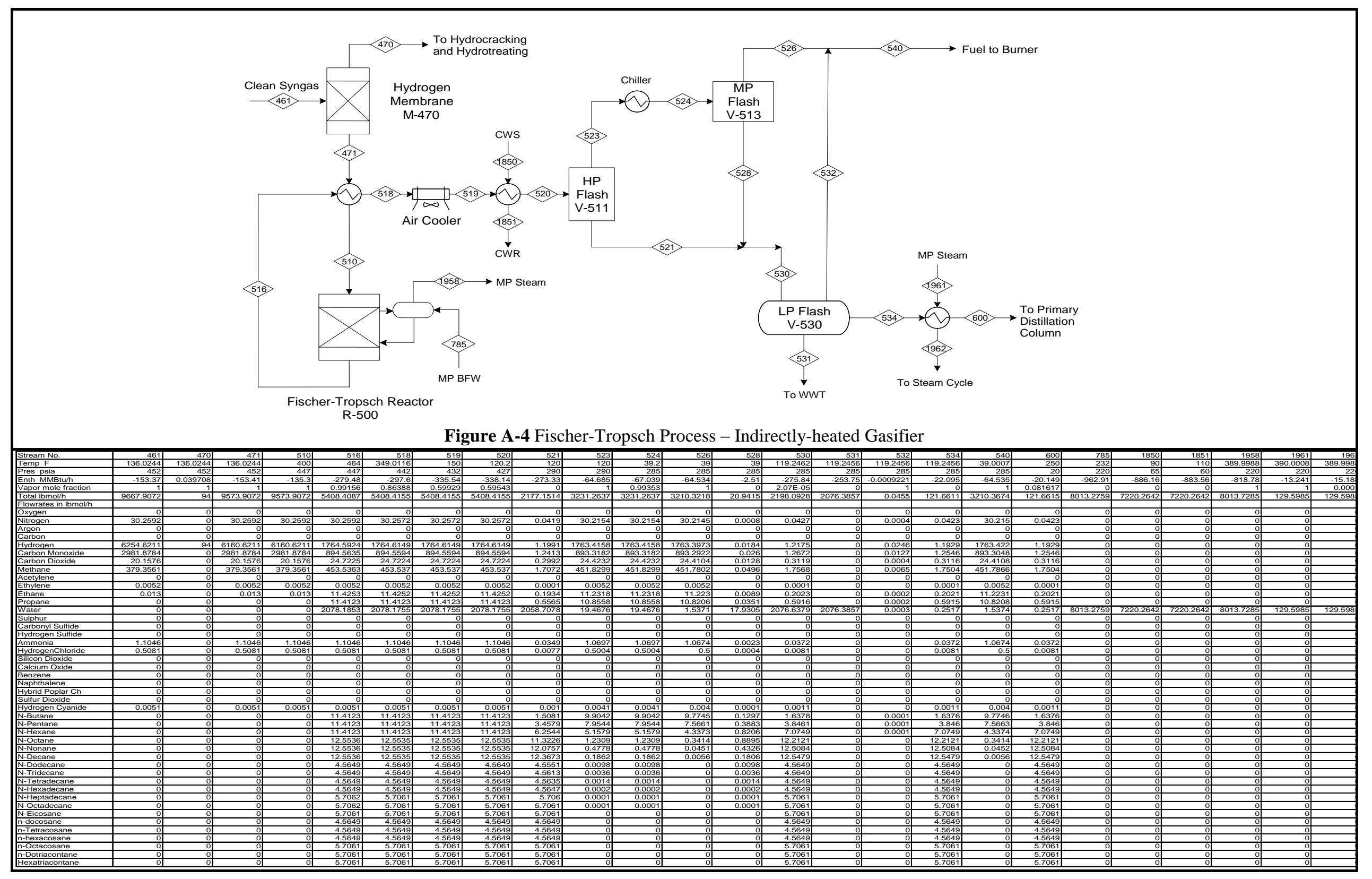




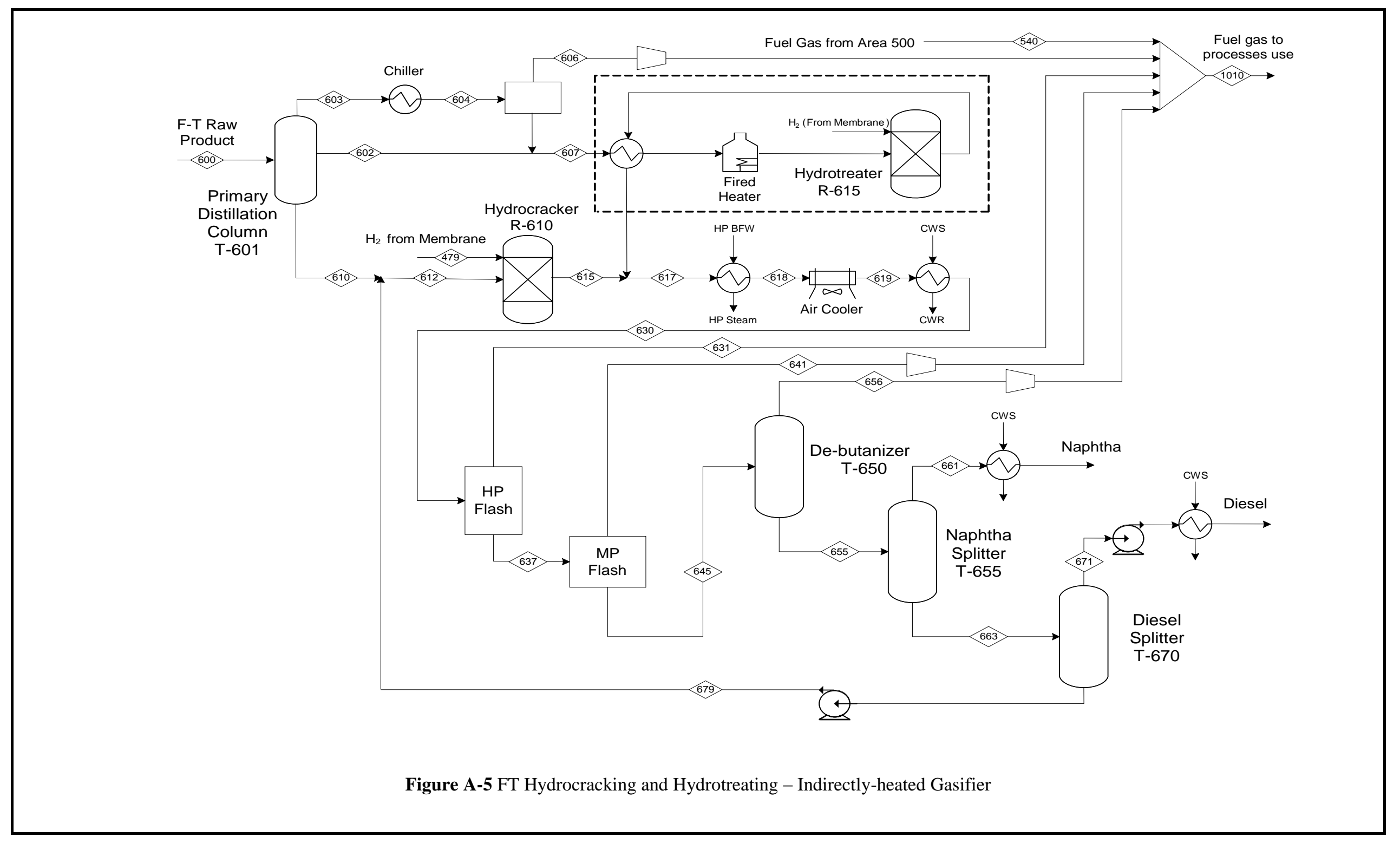




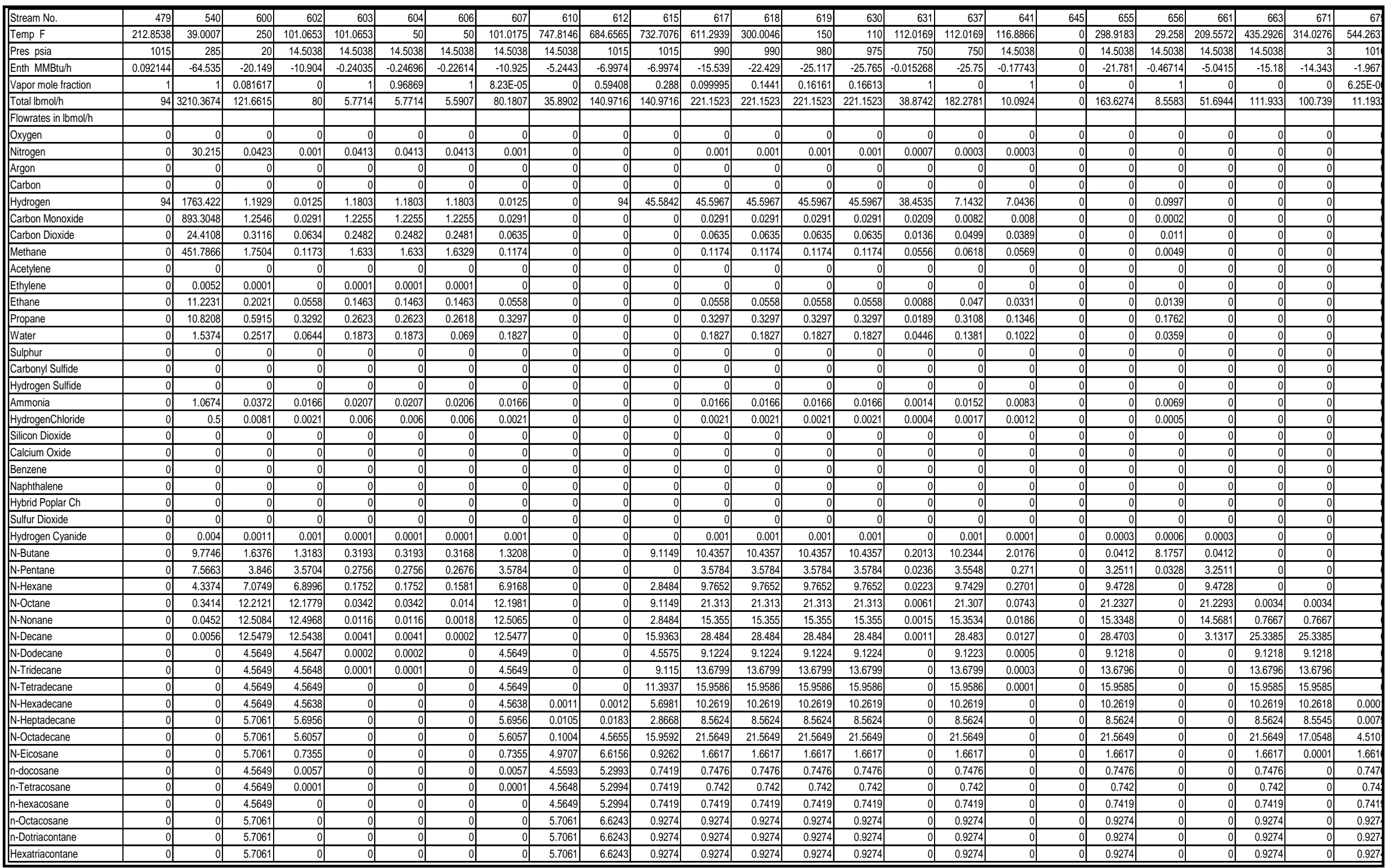




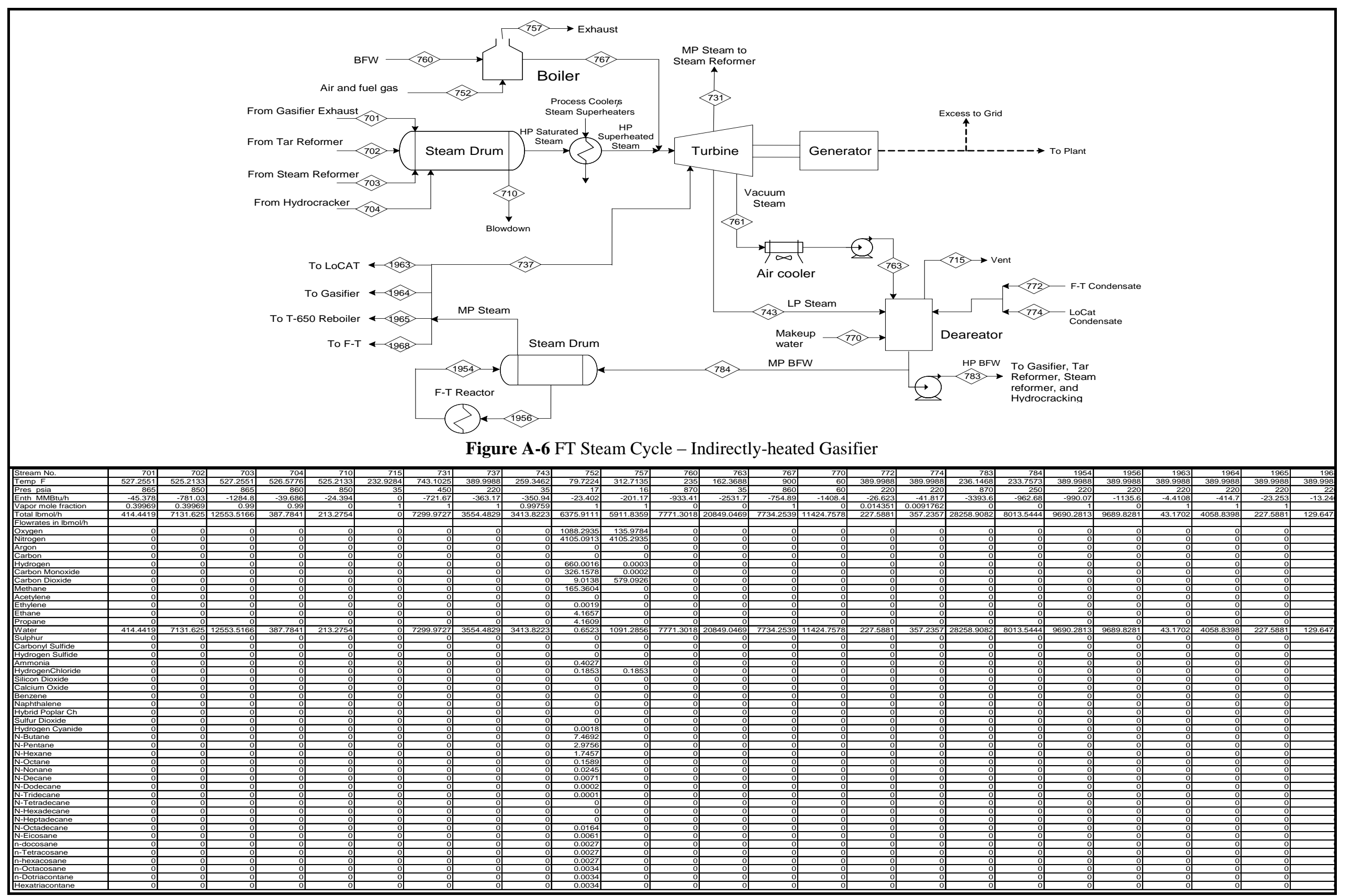




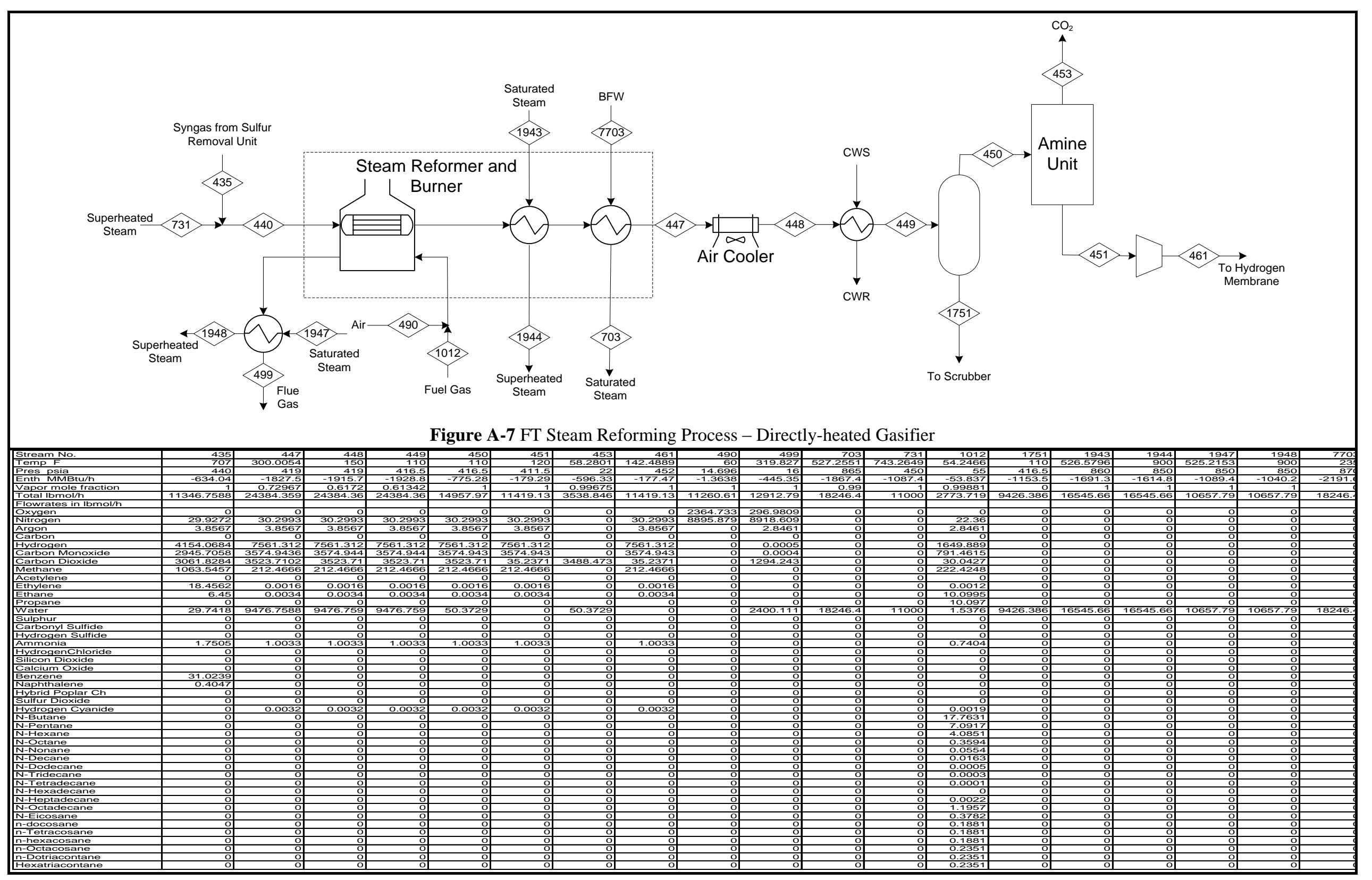




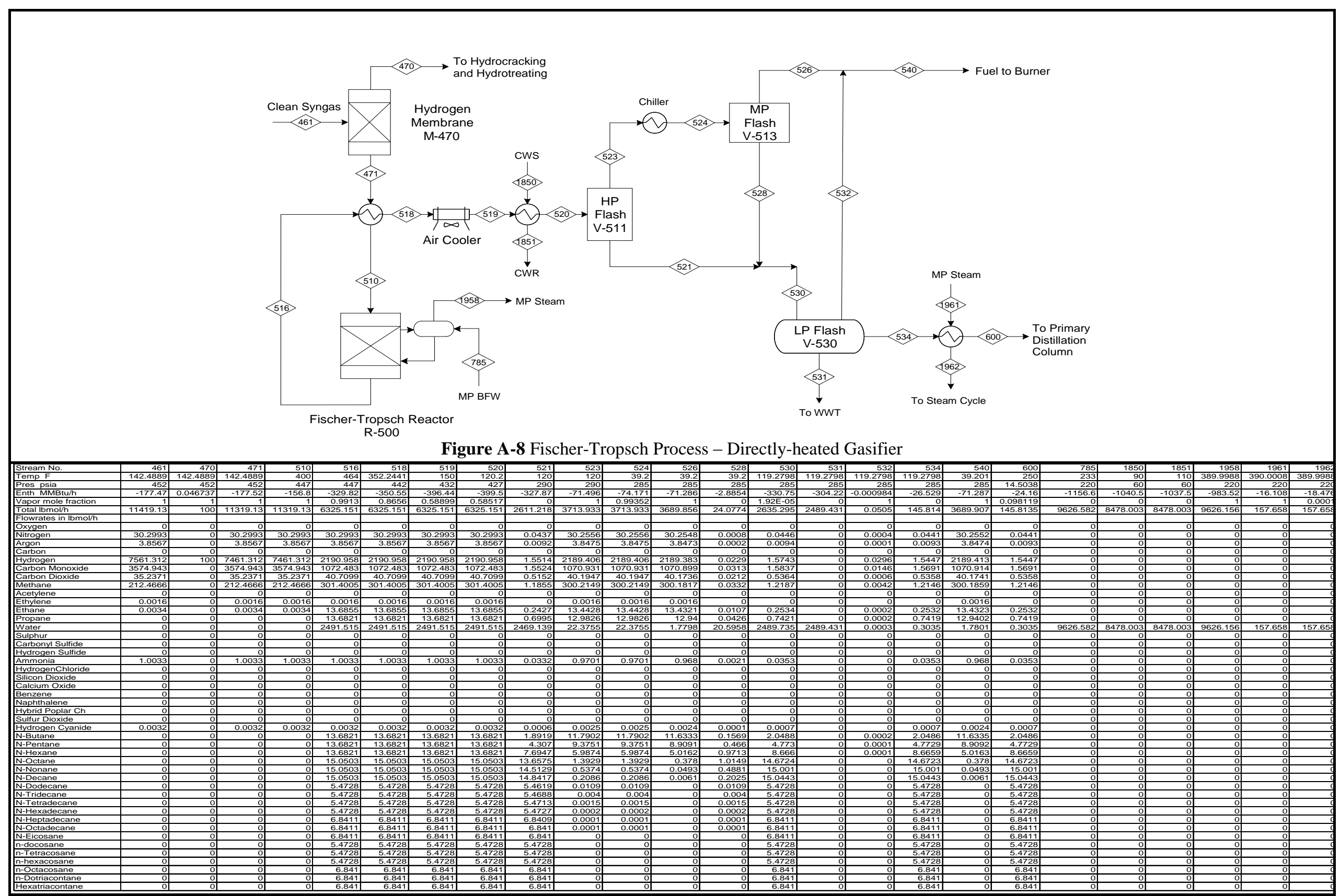




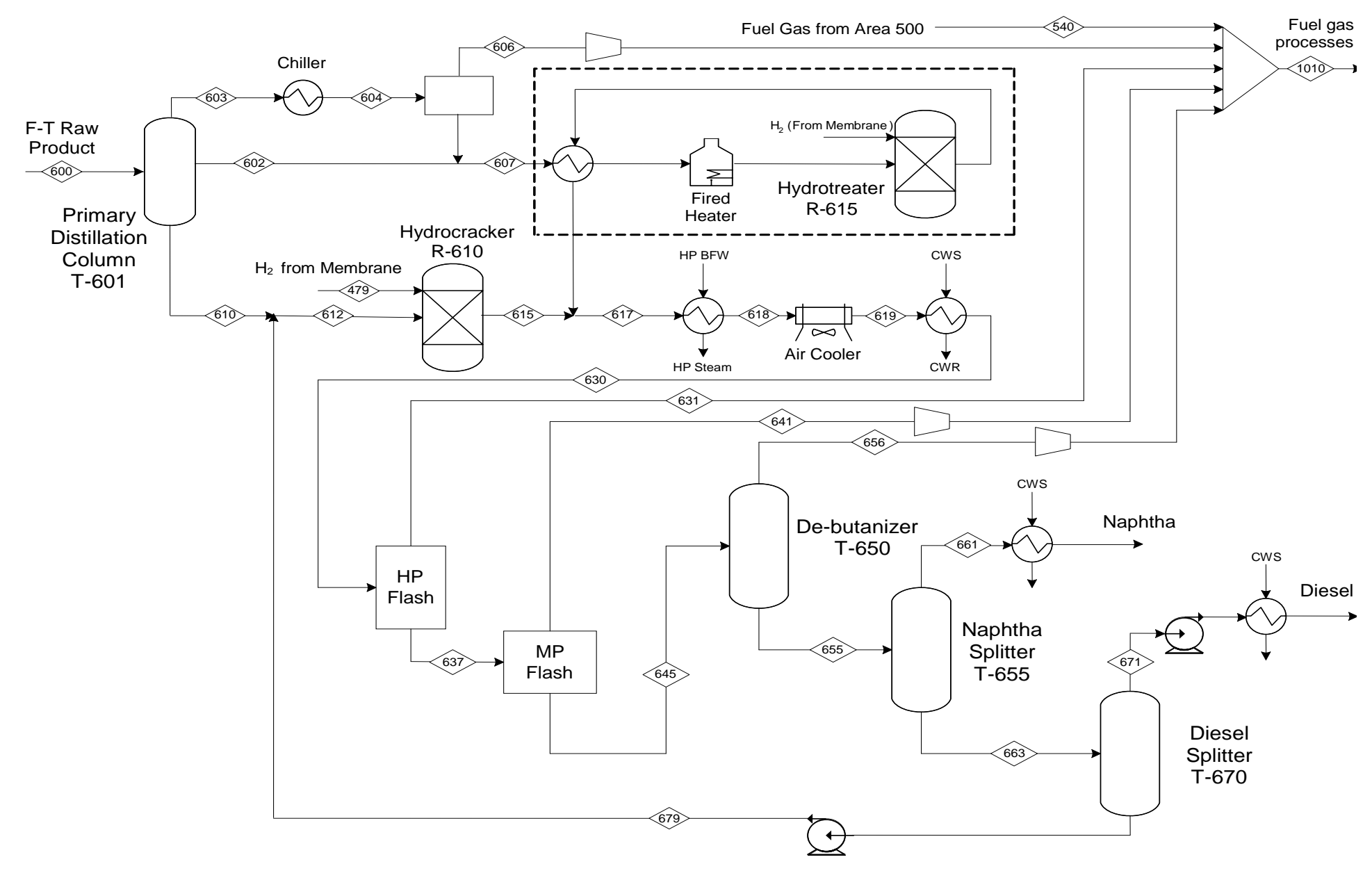

Figure A-9 FT Hydrocracking and Hydrotreating - Directly-heated Gasifier 


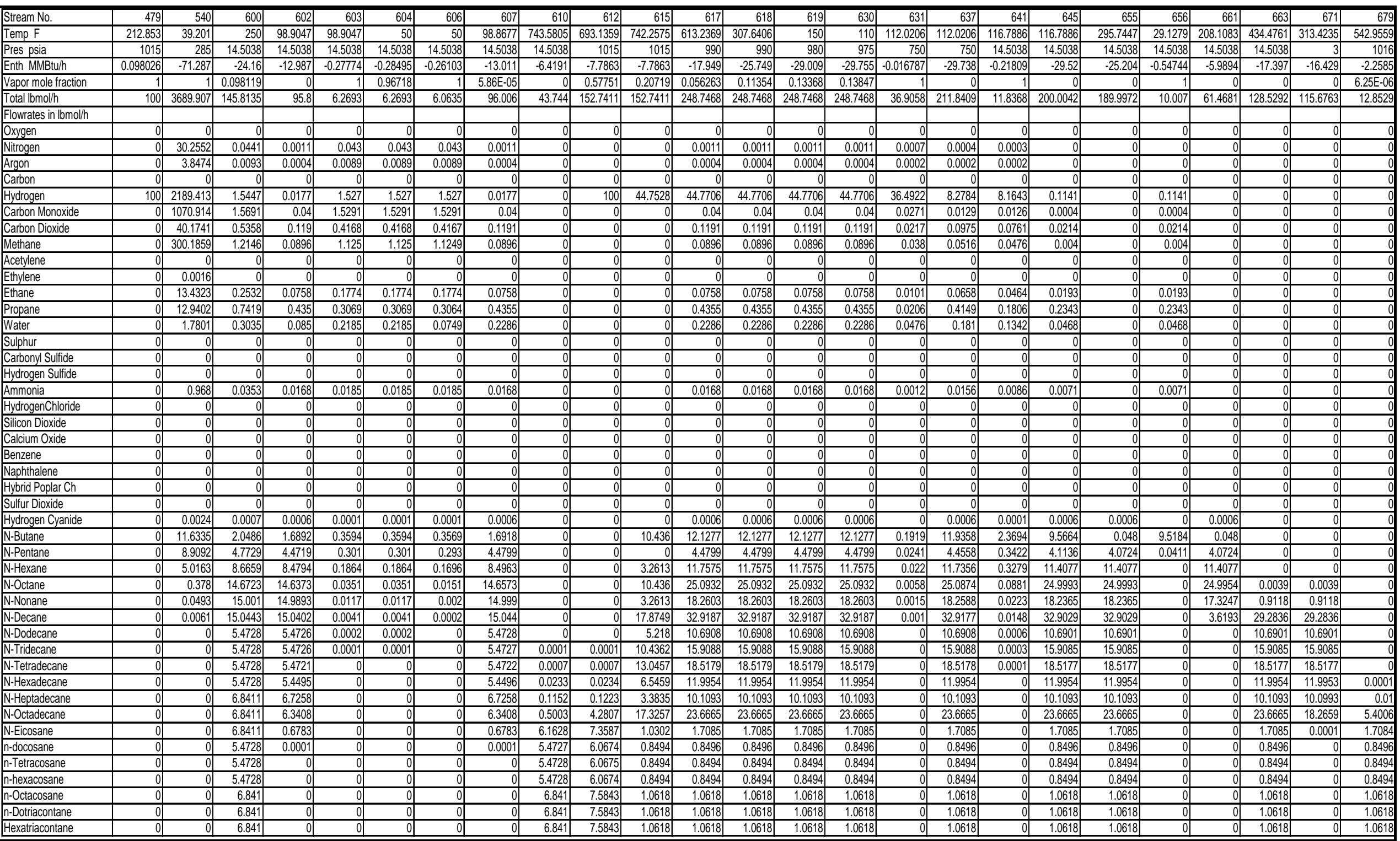




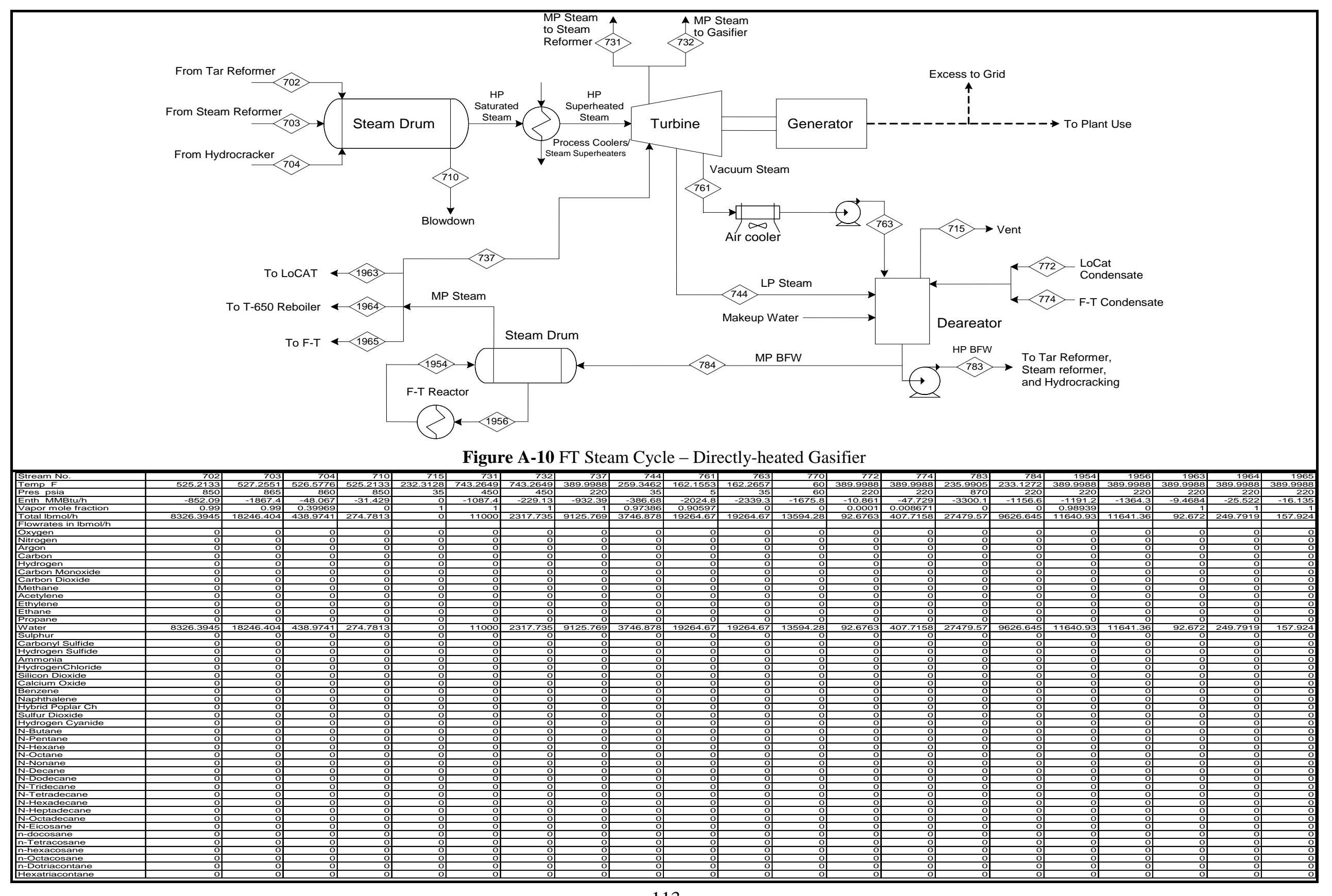


A.3 Methanol 


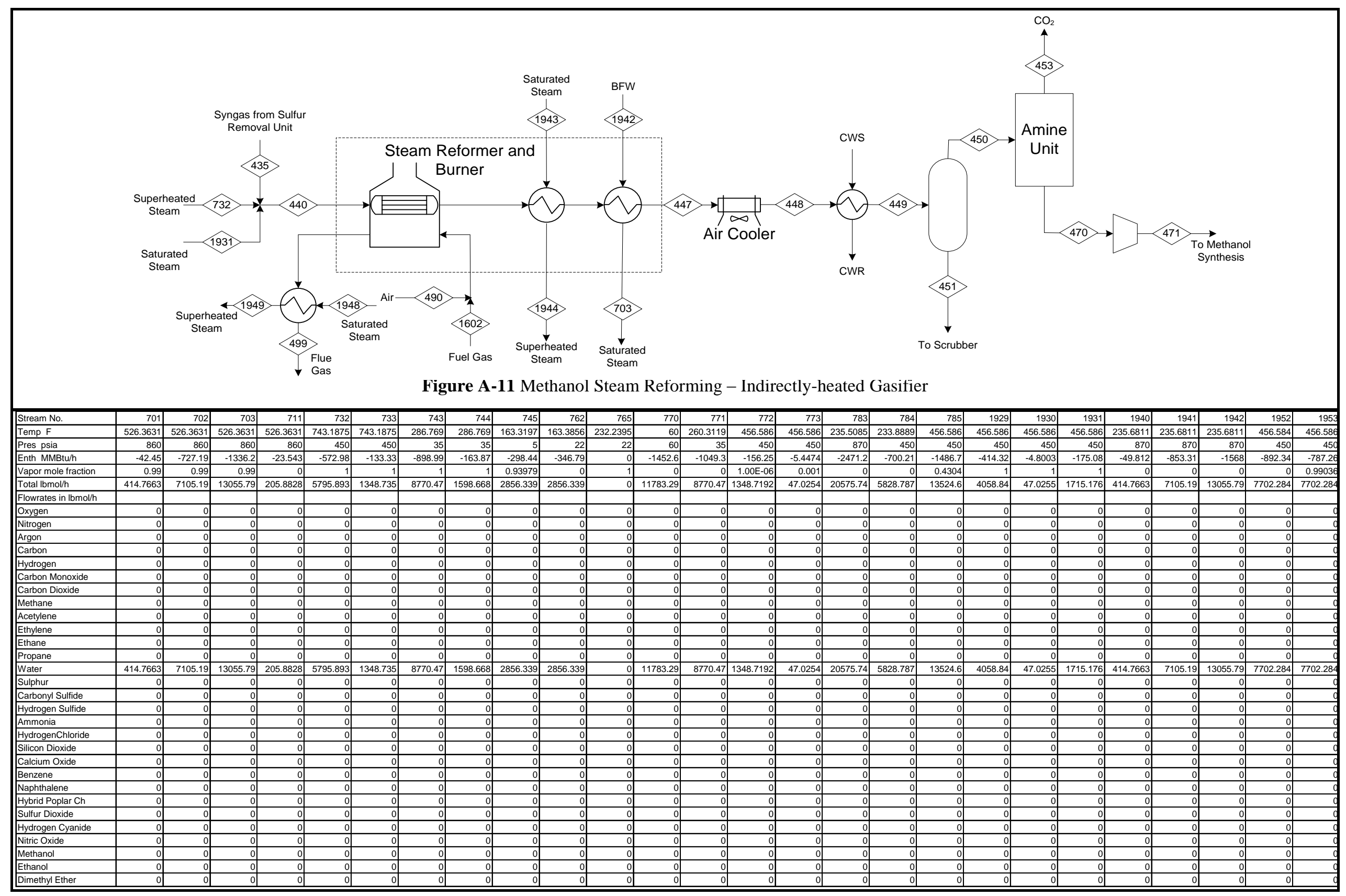









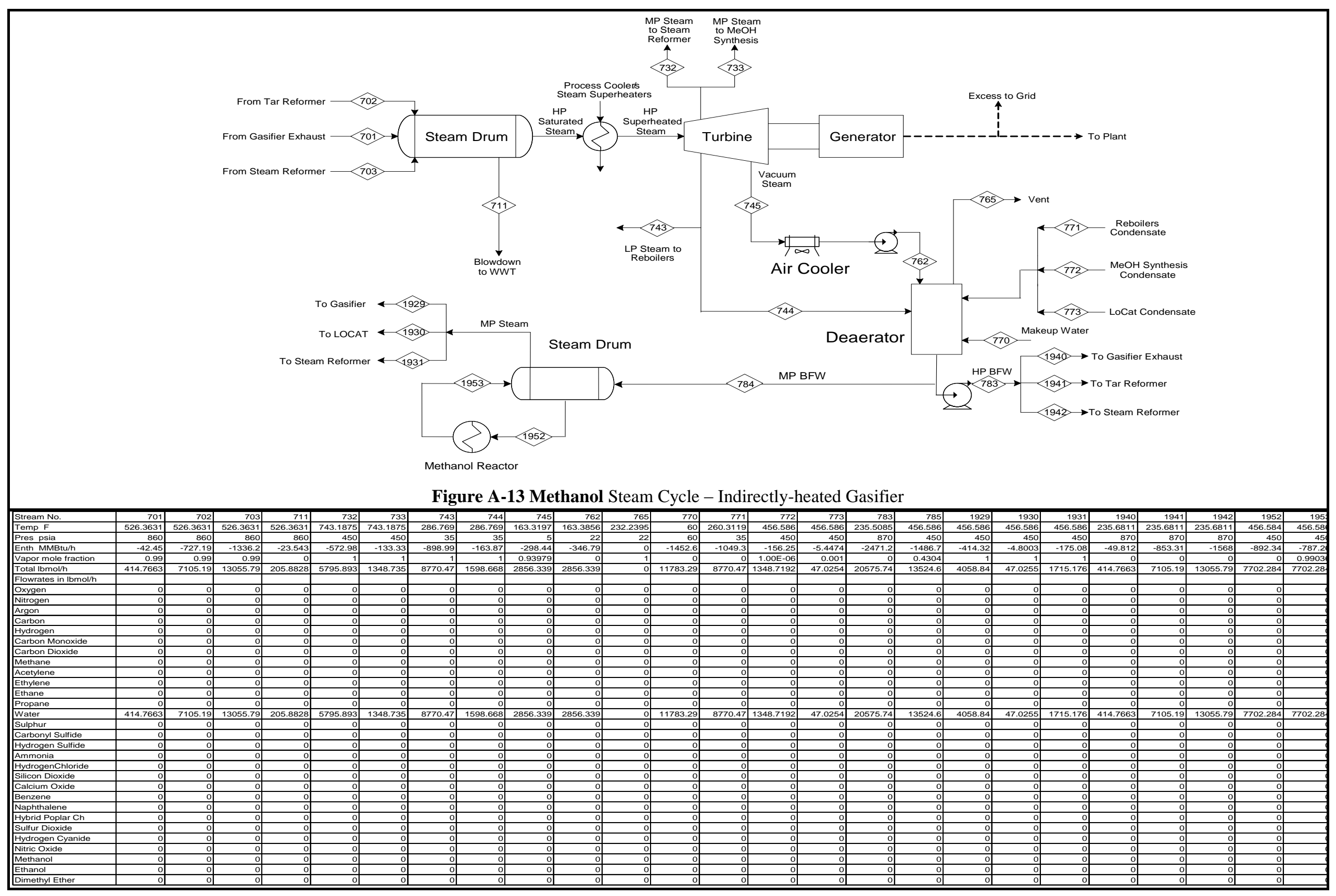




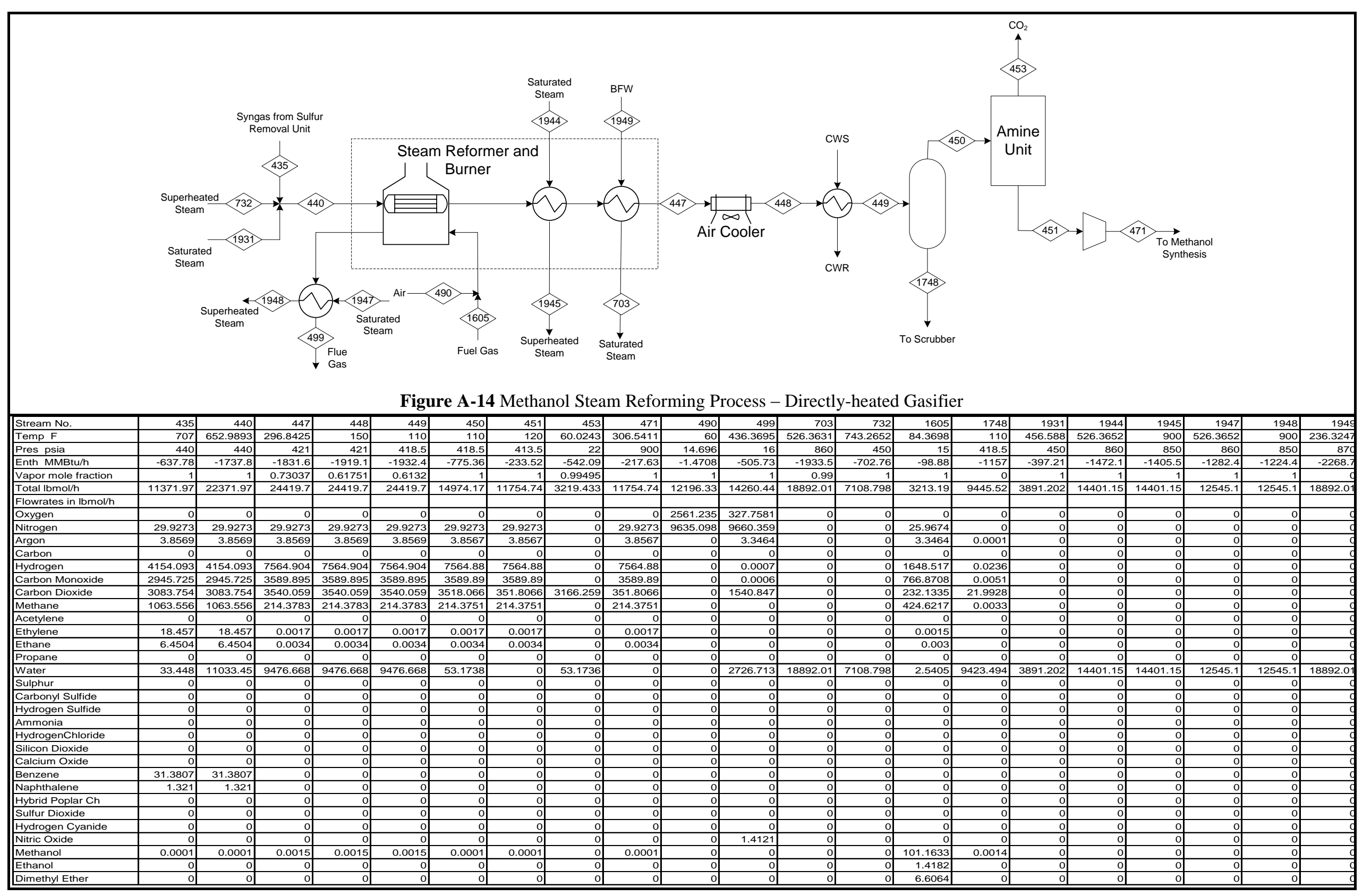




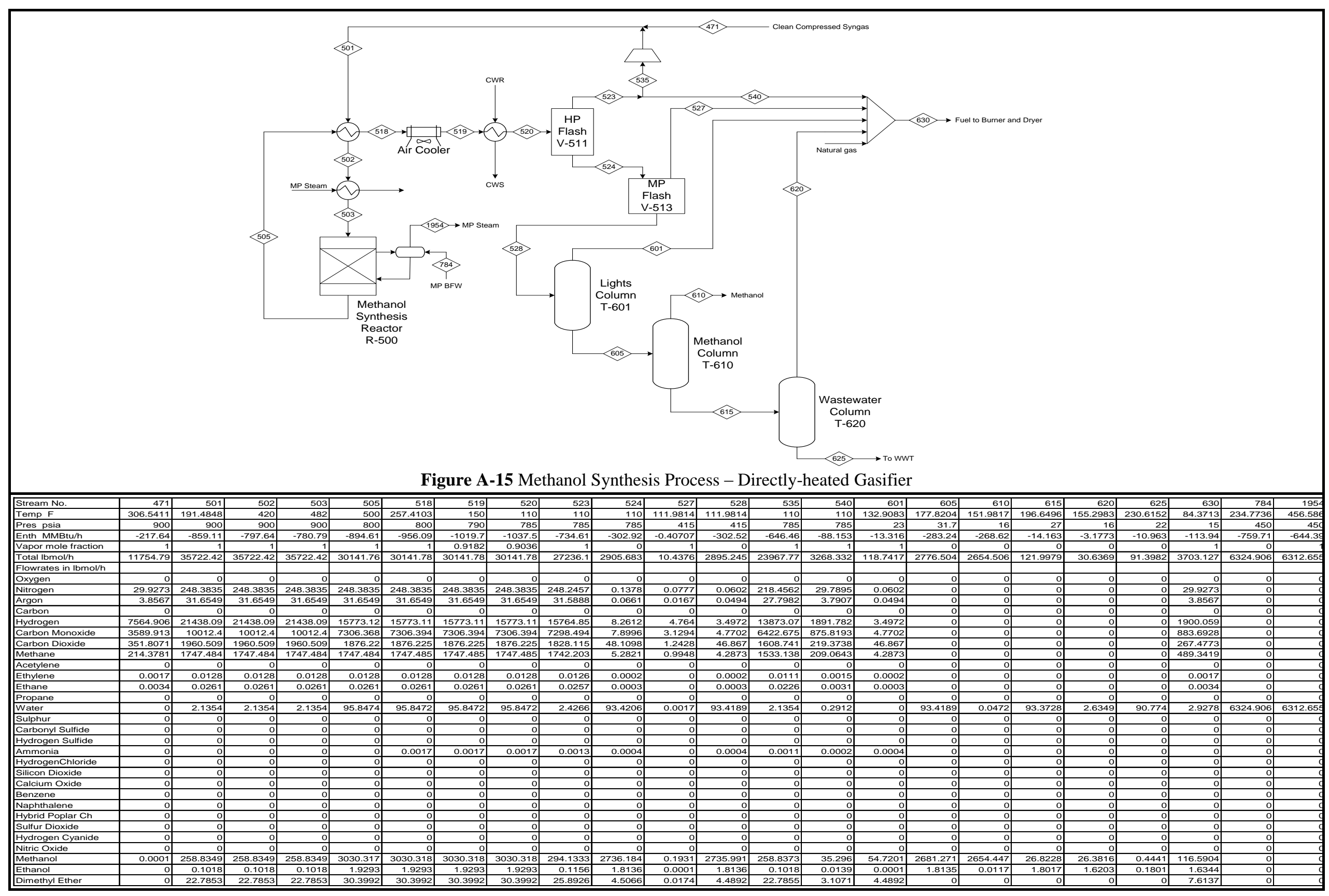




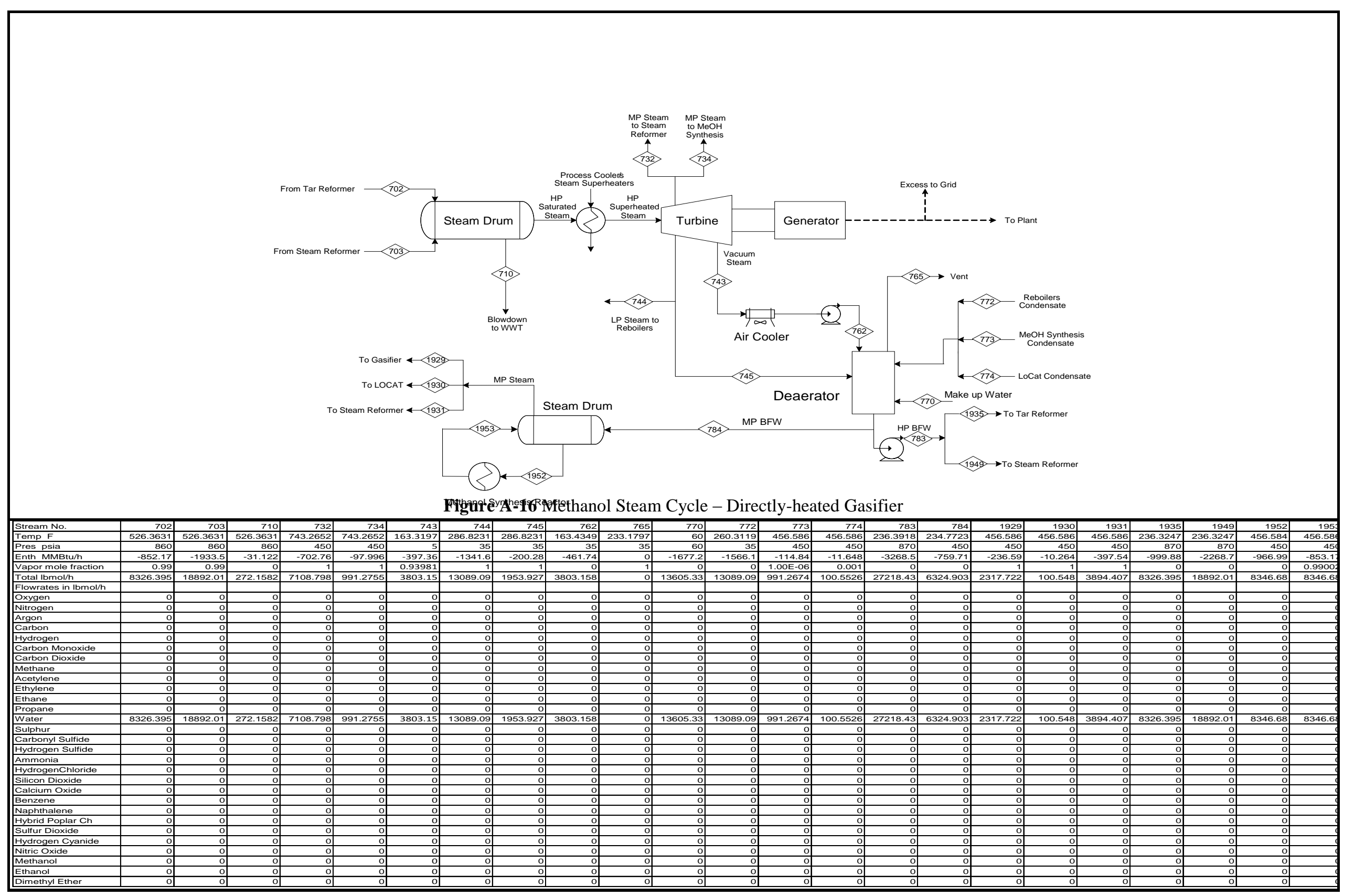


A.4 Dimethyl Ether 


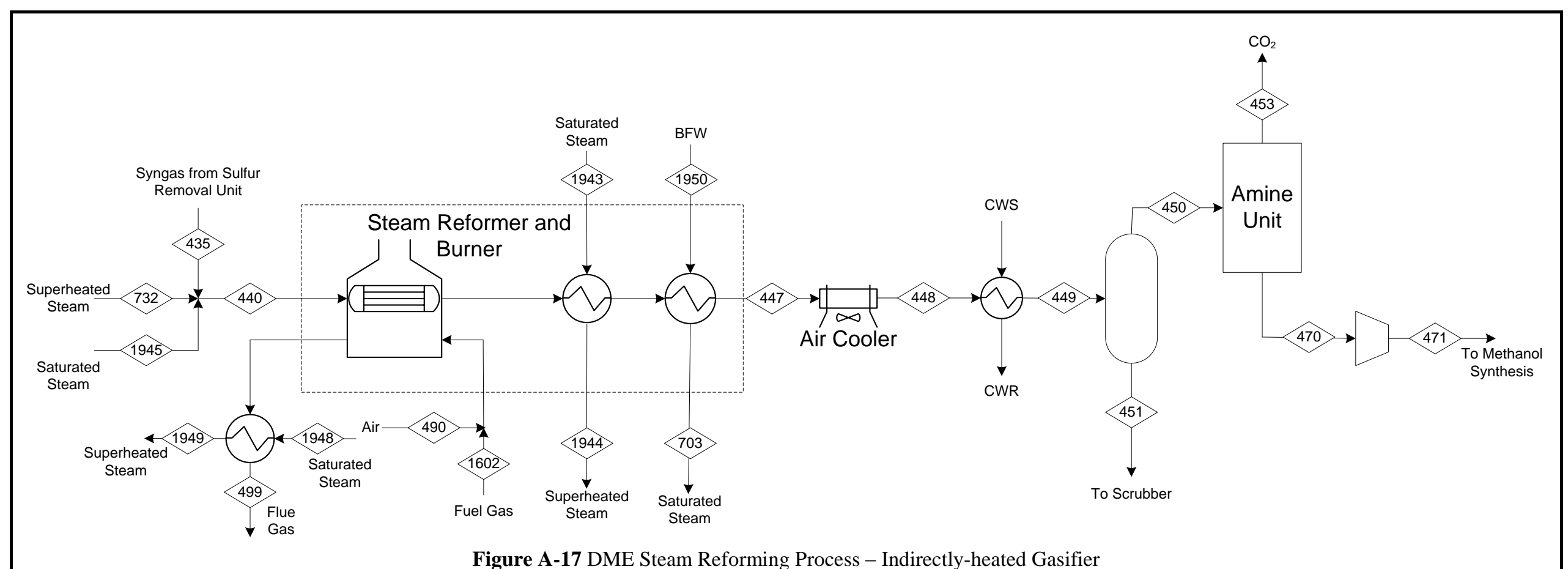

Figure A-17 DME Steam Reforming Process - Indirectly-heated Gasifier

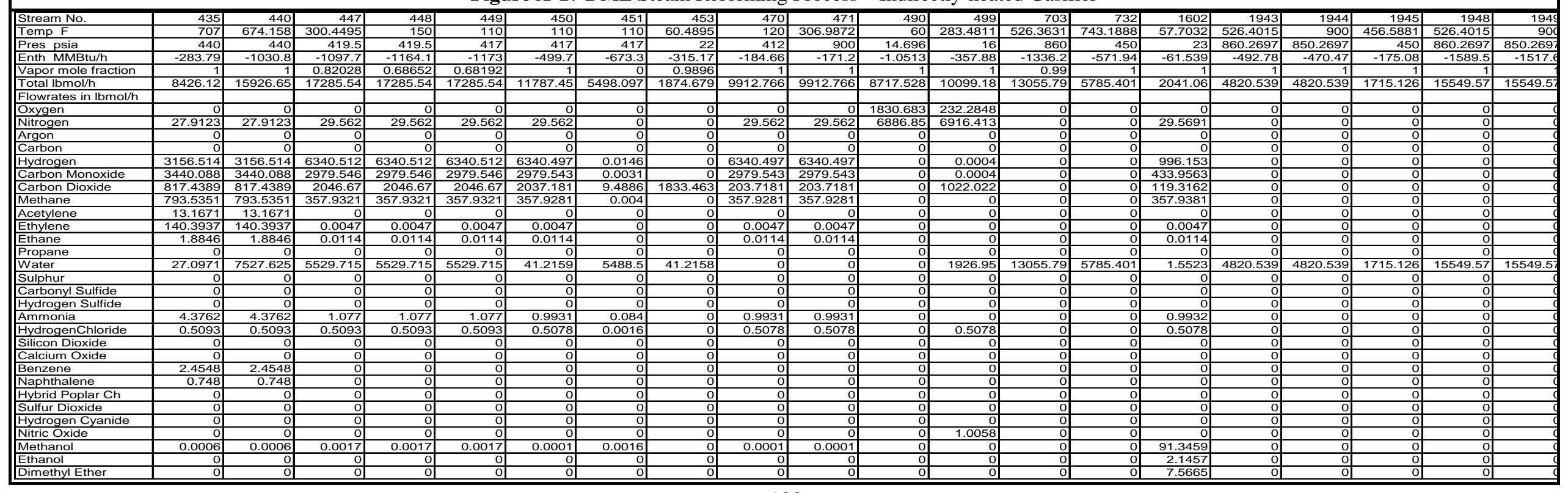




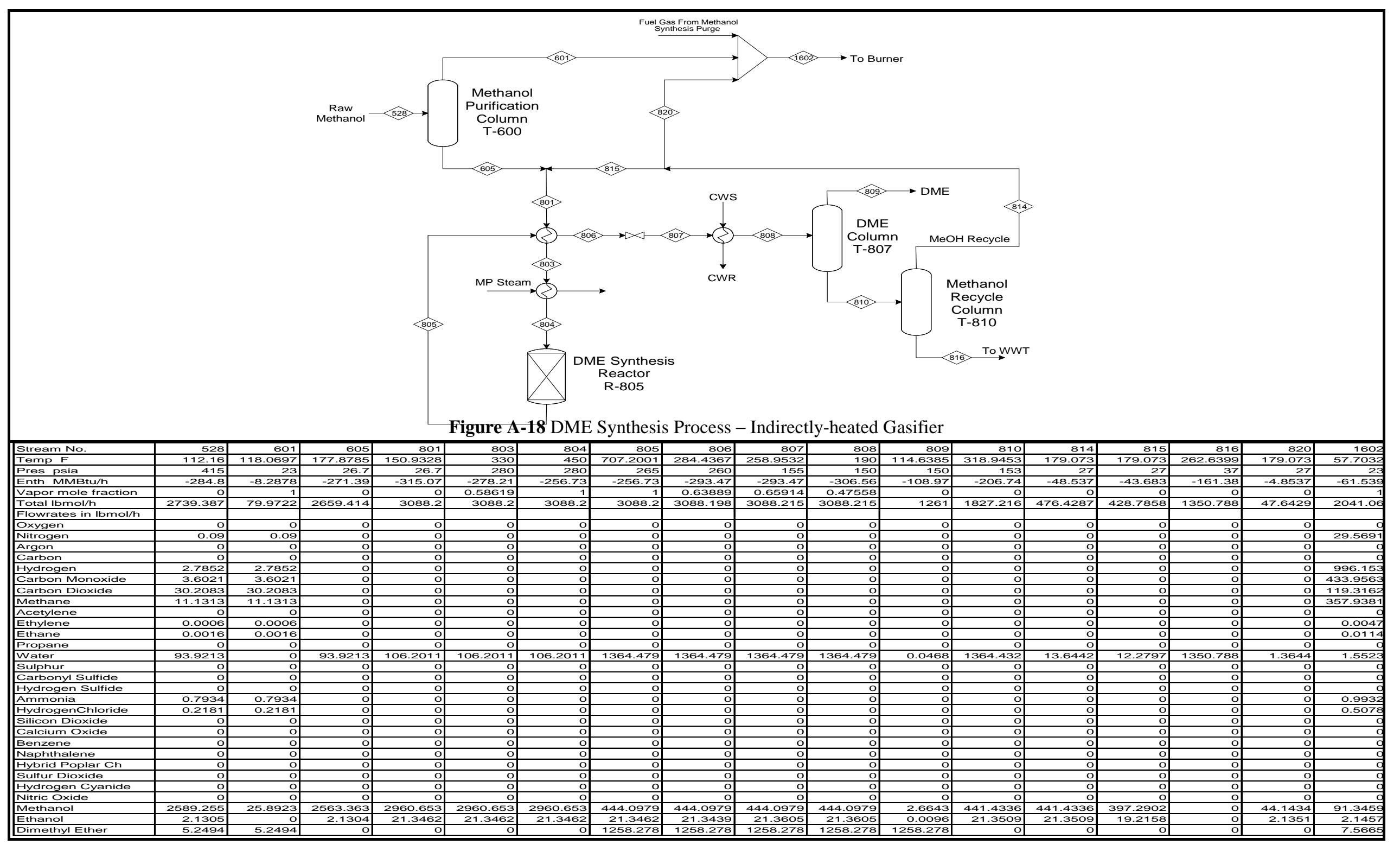




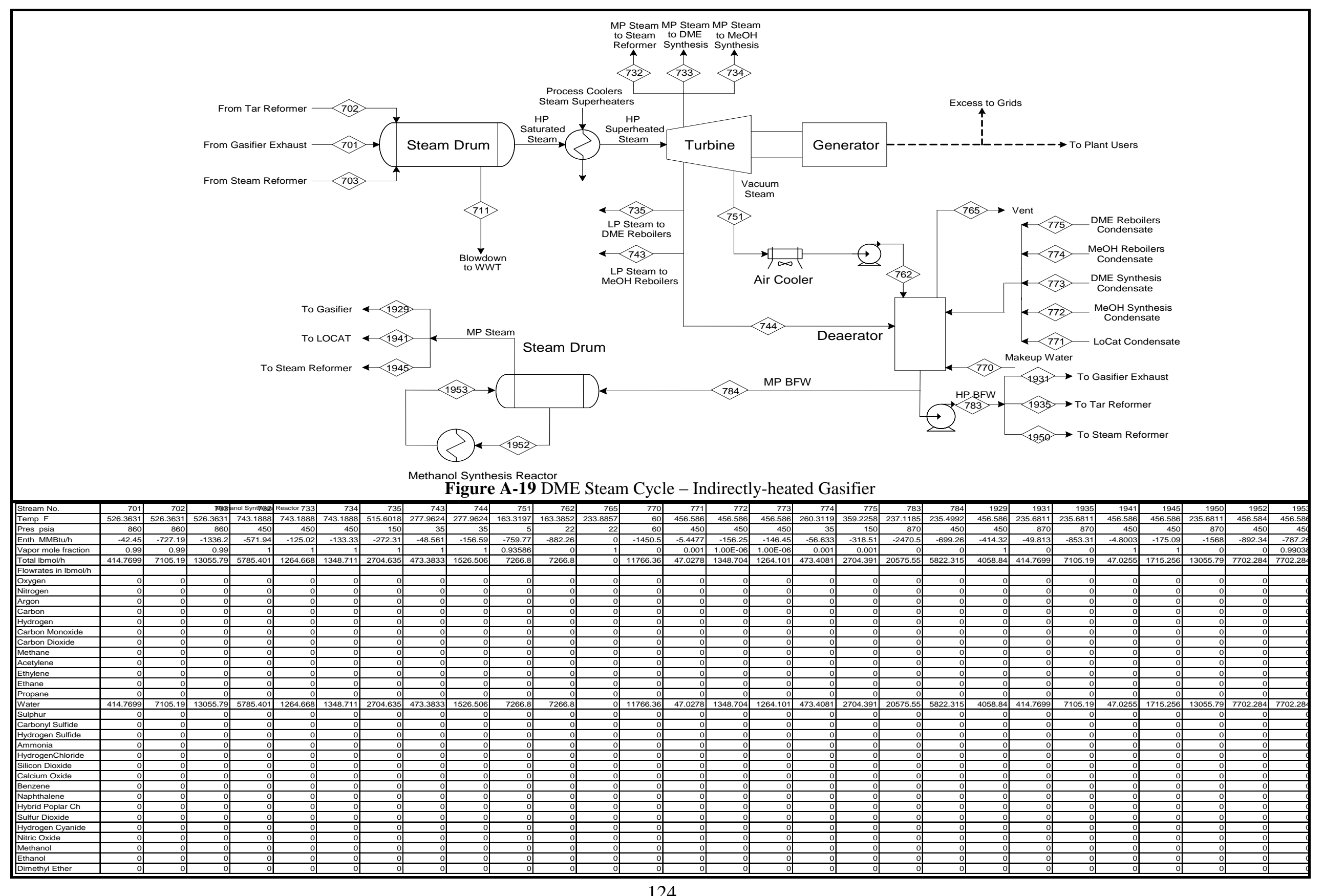




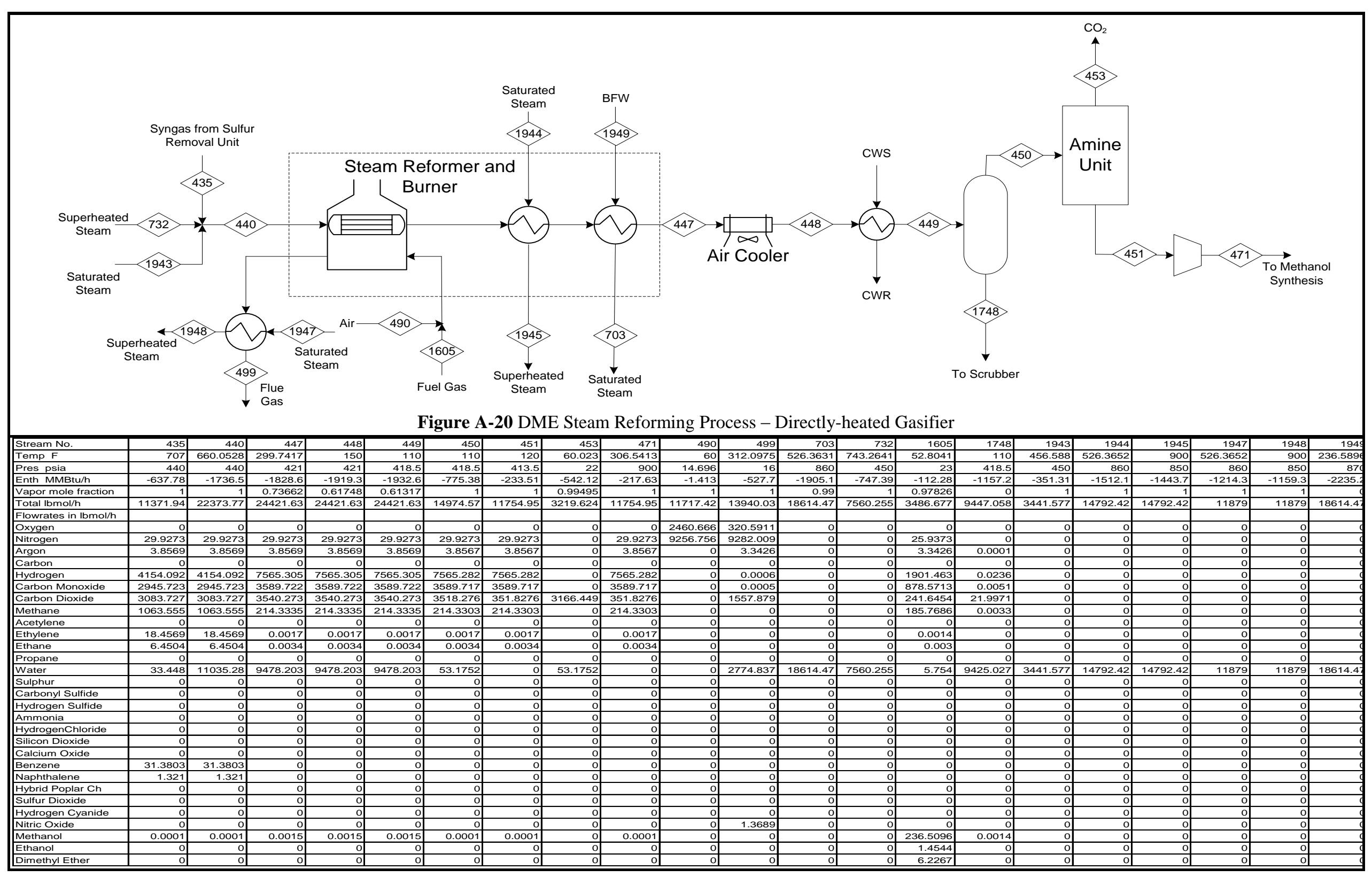




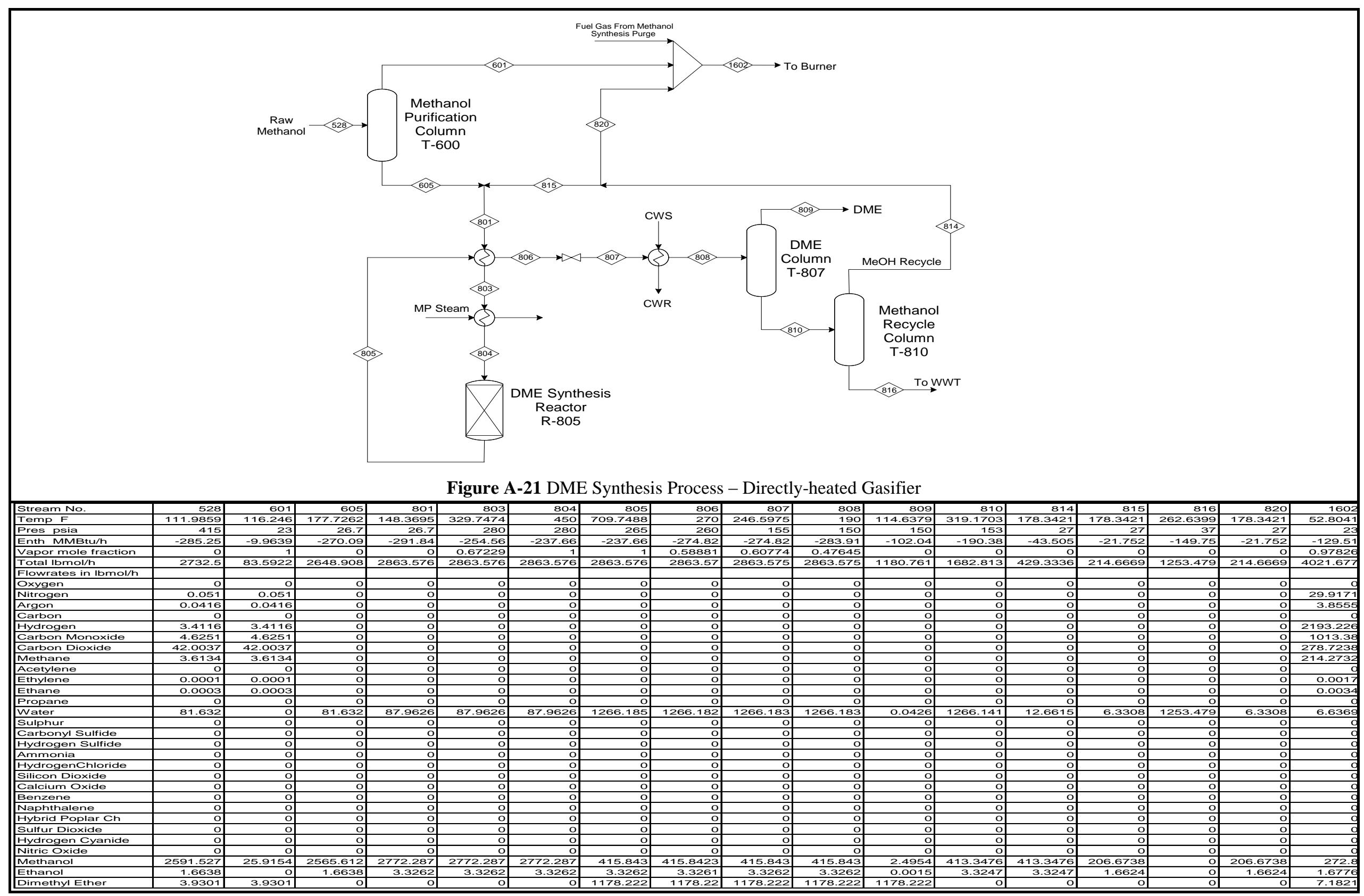




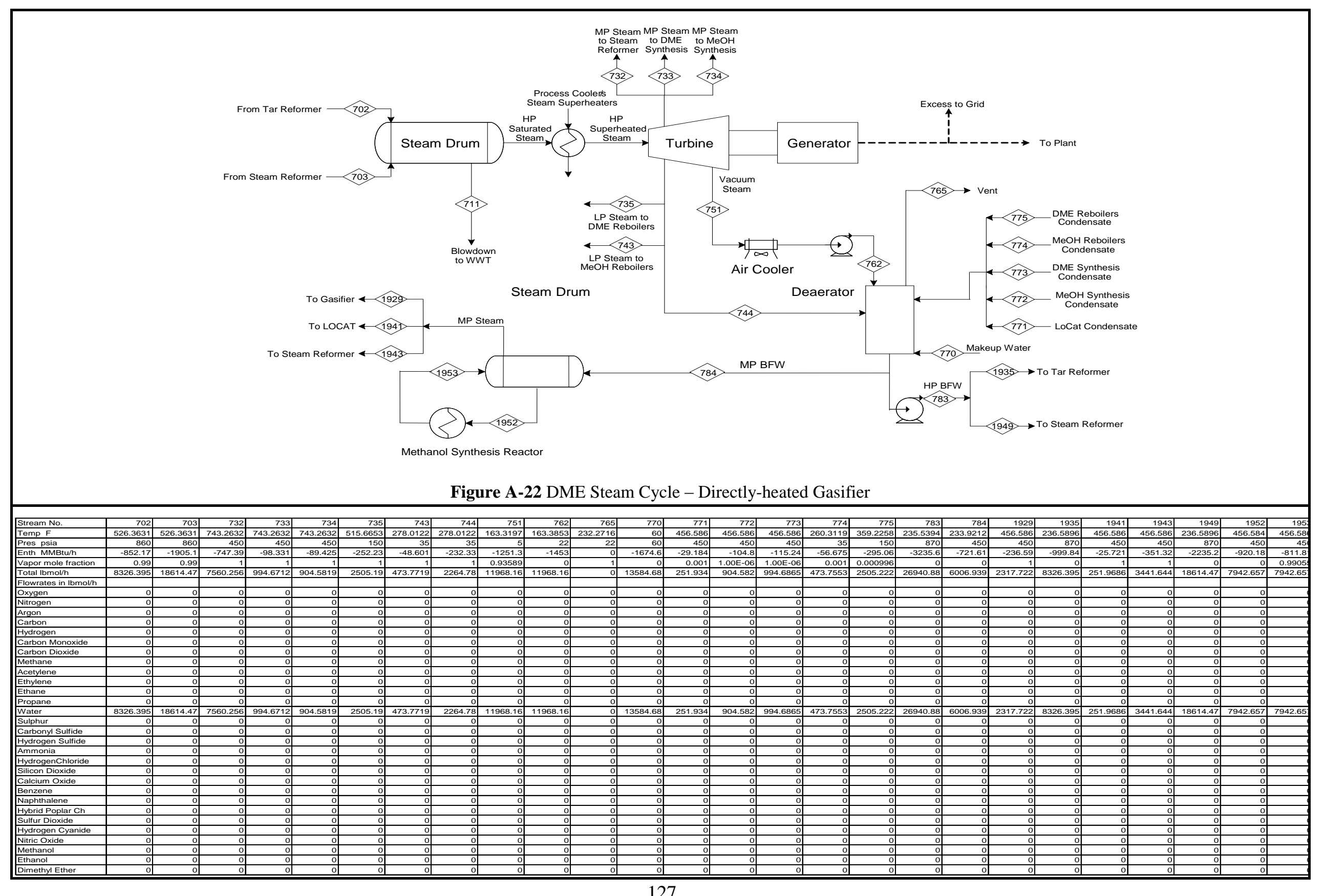




\section{A.6 Hydrothermal Liquefaction}




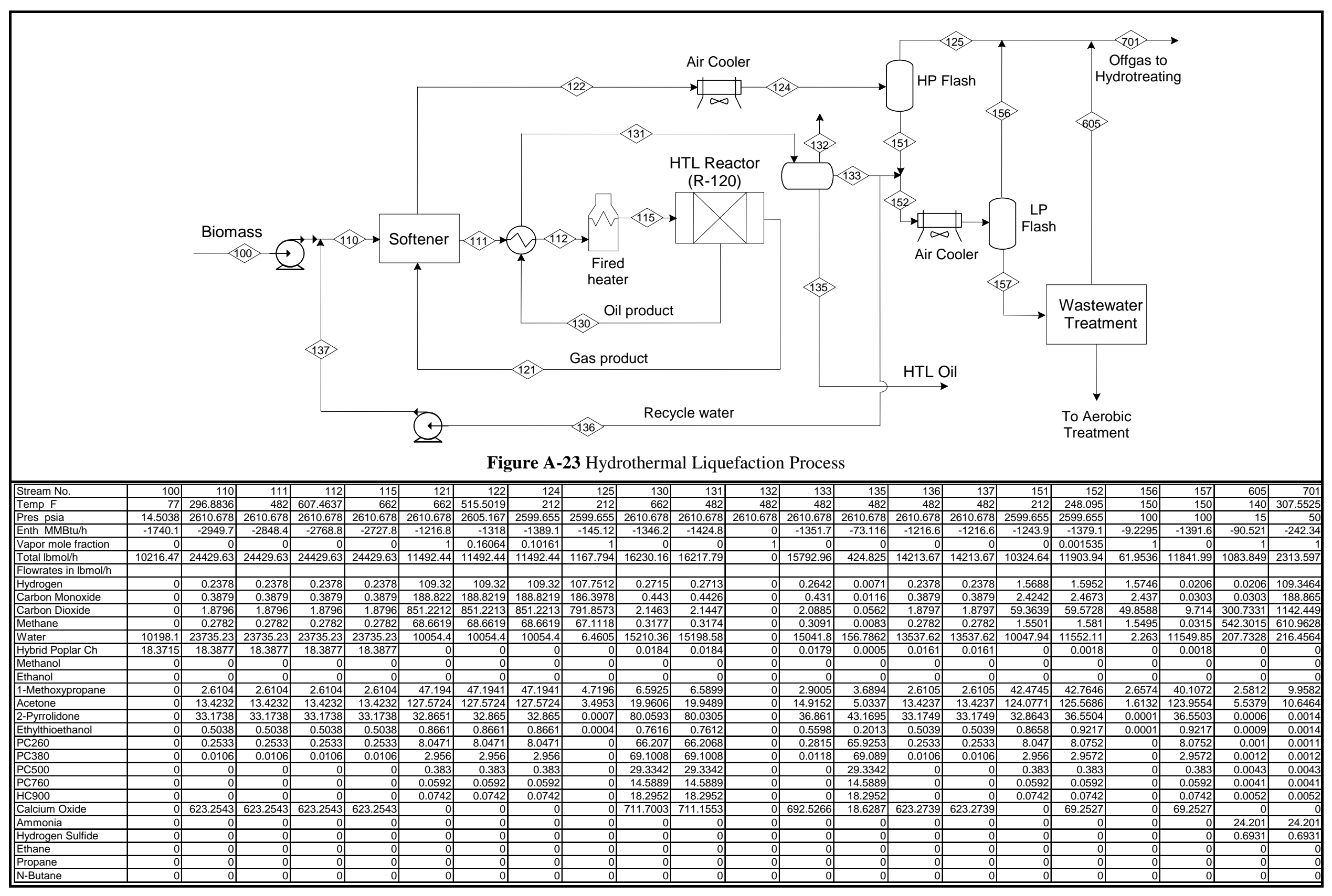




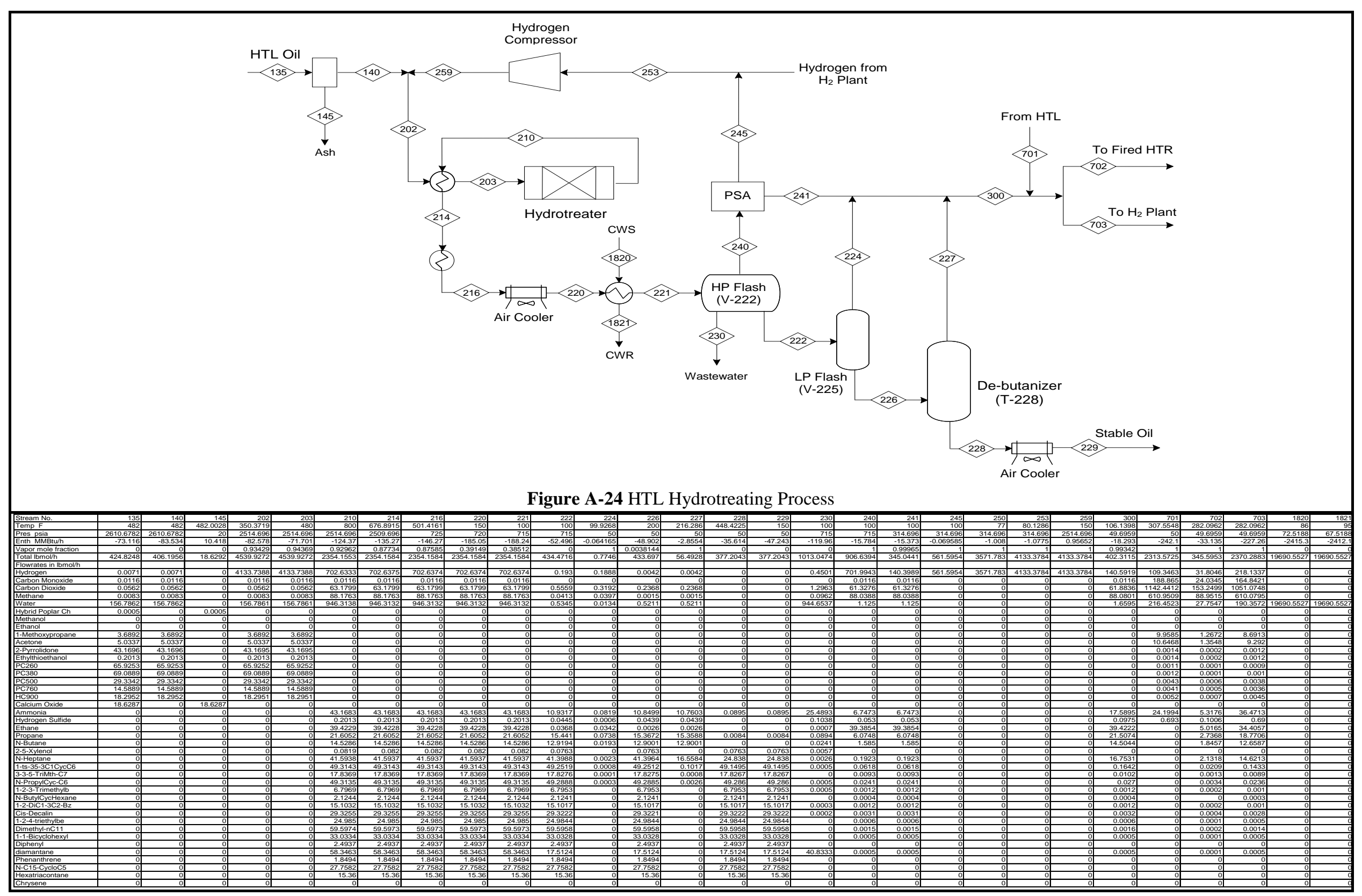




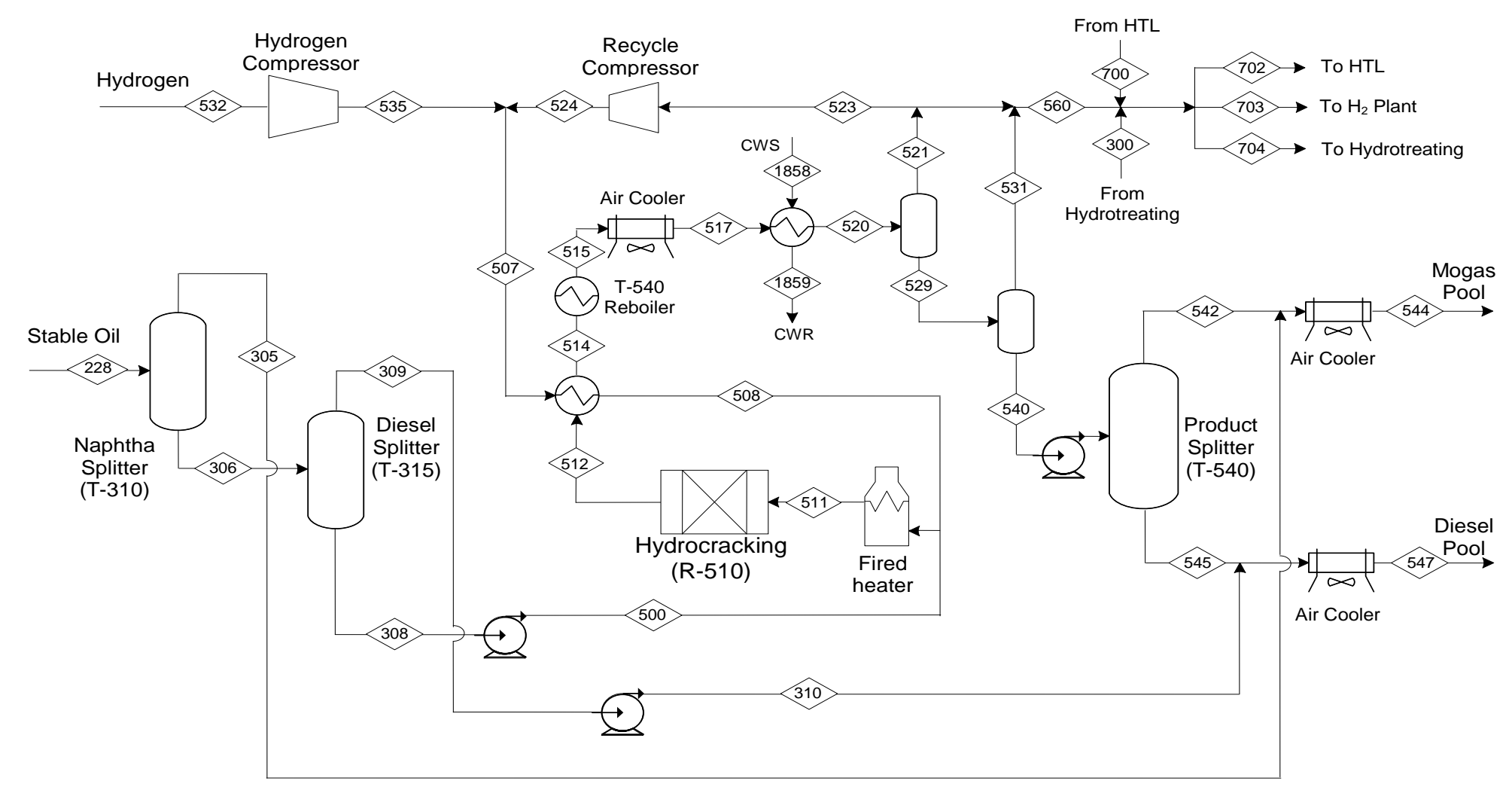

Figure A-25 HTL Hydrocracking Process 







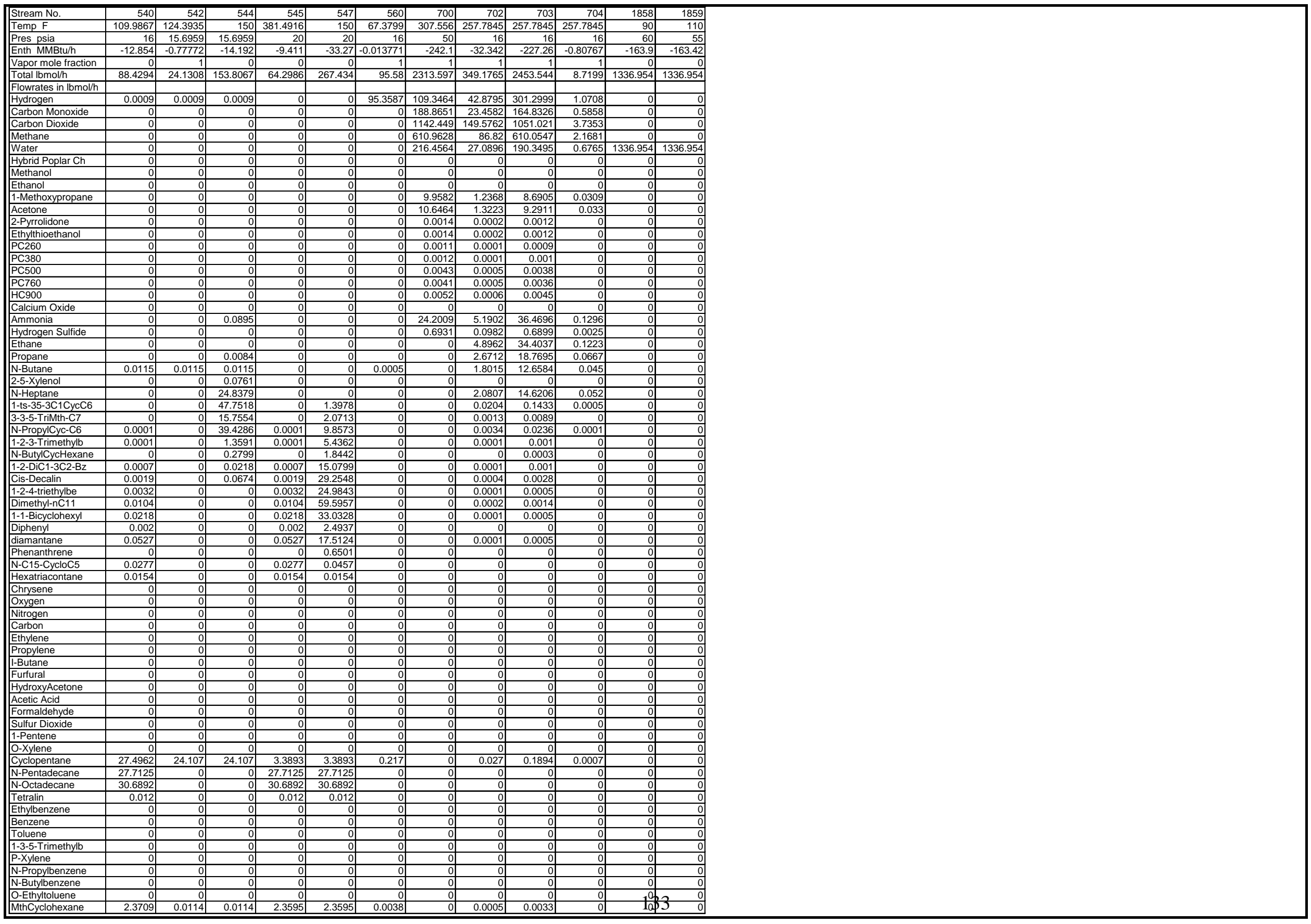




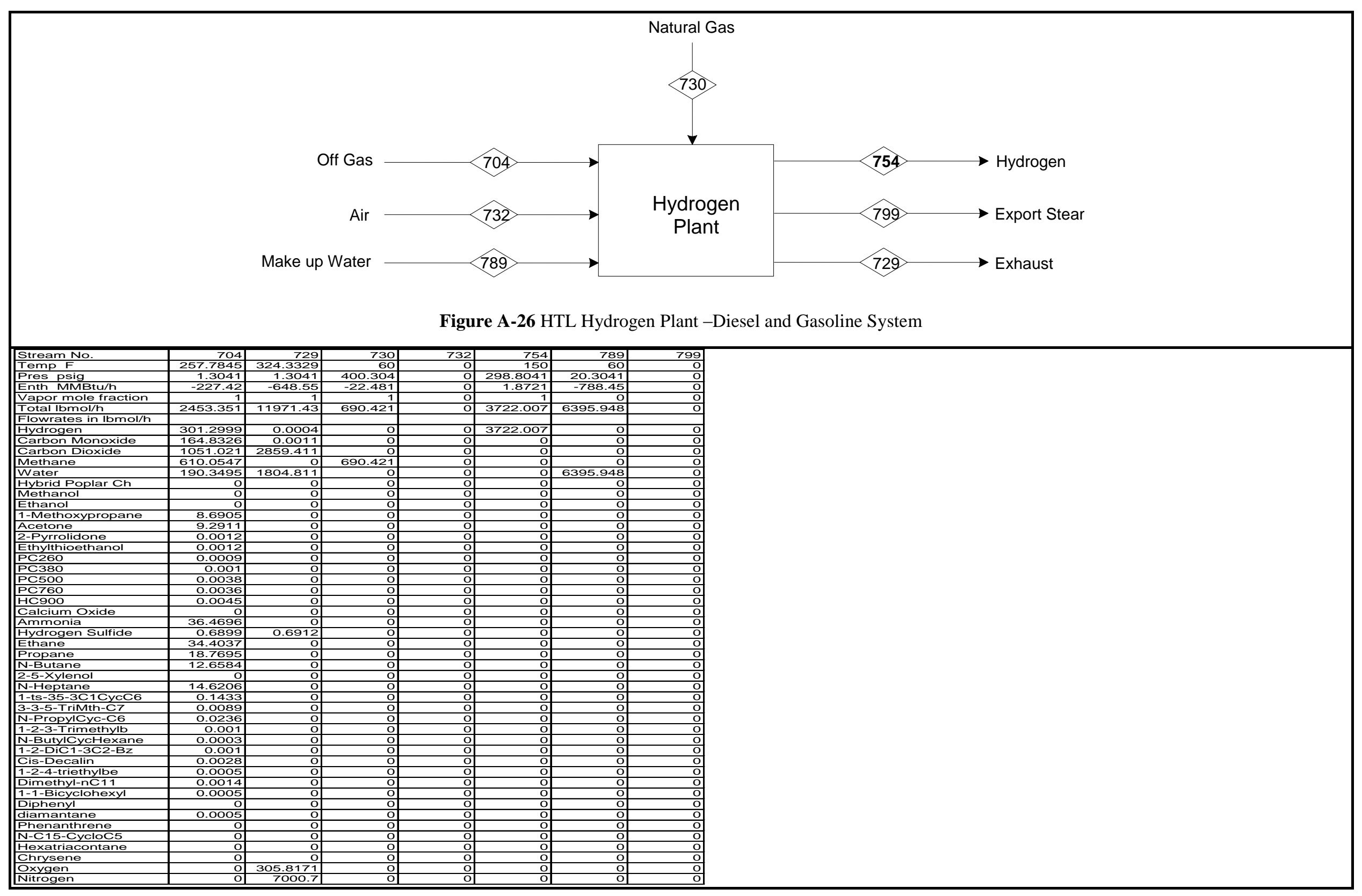





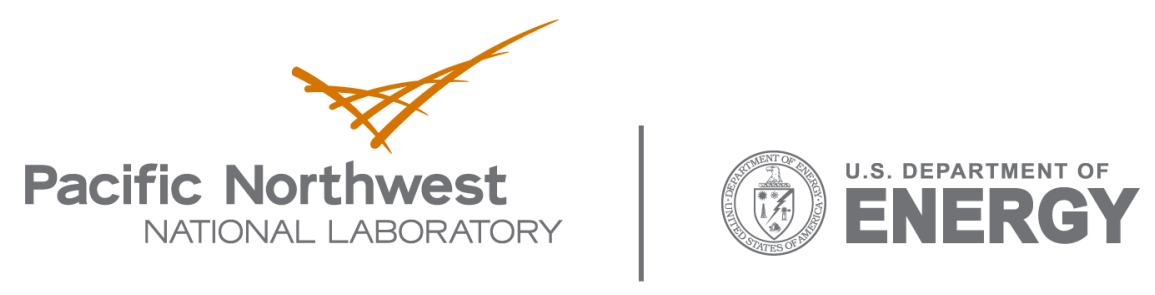

902 Battelle Boulevard

P.O. Box 999

Richland, WA 99352

1-888-375-PNNL (7665)

www.pnl.gov 